SUSTAINABILITY ANALYSIS AND ASSESSMENT IN THE SUPPLY CHAIN

by

PAYMAN AHI

Master of Engineering, Mechanical and Industrial Engineering, University of Toronto, 2000

Bachelor of Science, Industrial Engineering, Islamic Azad University, Karaj, Iran, 1990

\author{
A dissertation \\ presented to Ryerson University \\ in partial fulfillment of the requirements for the degree of \\ Doctor of Philosophy \\ in the Program of \\ Mechanical and Industrial Engineering (MIE)
}

Toronto, Ontario, Canada, 2014

(C) Payman Ahi 2014 


\section{AUTHOR'S DECLARATION FOR ELECTRONIC SUBMISSION OF A DISSERTATION}

I hereby declare that I am the sole author of this dissertation. This is a true copy of the dissertation, including any required final revisions, as accepted by my examiners.

I authorize Ryerson University to lend this dissertation to other institutions or individuals for the purpose of scholarly research.

I further authorize Ryerson University to reproduce this dissertation by photocopying or by other means, in total or in part, at the request of other institutions or individuals for the purpose of scholarly research.

I understand that my dissertation may be made electronically available to the public. 


\title{
ABSTRACT \\ Sustainability Analysis and Assessment in the Supply Chain
}

\author{
Payman Ahi \\ Doctor of Philosophy \\ Mechanical and Industrial Engineering \\ Ryerson University
}

2014

The purpose of this research is to investigate how sustainability is integrated into supply chain management (SCM). Emphasis is particularly devoted to determining how the sustainability of supply chains may be assessed. Four key objectives were developed to support this purpose: (1) define sustainable supply chain management (SSCM), (2) identify and analyze the published metrics for SSCM, (3) develop a comprehensive approach for assessing sustainability performance at the company level, and (4) develop an integrative sustainability performance framework for the broader context of supply chain.

The first two objectives were accomplished through two different sets of in-depth literature reviews. The reviews focused on analyzing the convergences and divergences in the literature on green supply chain management (GSCM), SSCM, and the metrics used in these areas. The reviews helped provide the basis for accomplishing the remaining research objectives. Accordingly, stochastic models for measuring sustainability performance at the company and supply chain levels were developed. 
This research addresses several important gaps in the literature. As research on the integration of sustainability into SCM continues to expand, it becomes increasingly important to highlight the inconsistencies in the various definitions and metrics used to measure GSCM and SSCM. The lack of reasonably consistent definitions and metrics may lead to confusion regarding the appropriate scope in theory and practice of SSCM initiatives. Exploring the implications of and potential resolutions to the many differences in the published definitions and metrics provide much needed reference points, and further provide the foundation necessary to support the development of scientifically-sound sustainability models.

By providing relatively simple and informative measurement, the model developed in Objective 3 presents a unique method of adopting the strong sustainability concept to assessing sustainability at the company level. Furthermore, by providing an original and straightforward analytical approach, the SSCM models developed in Objective 4 are one of the first to explicitly adopt probabilistic approaches for sustainability assessment in the supply chain context. Given their unique ability to accommodate any number of SSCM characteristics, the models can be employed as integrative, multi-dimensional tools for evaluating changes in the sustainability status of a supply chain over time. 


\section{ACKNOWLEDGEMENTS}

First and foremost, I would like to express my sincere appreciation to my academic supervisor, Professor Cory Searcy, for his invaluable and eternal guidance, advice and support in every step of the way in my PhD studies. Working with Professor Searcy was indeed a great, precious and unforgettable experience.

I would like to also express my gratitude to the members of my $\mathrm{PhD}$ dissertation examining committee, Professor Mohamad Jaber, Professor Mohamad Wahab Ismail, Professor Aziz Guergachi, Professor Marcos Santos, and Professor Alfred Guiffrida for their encouraging and constructive comments, suggestions and guidance. Moreover, I would like to extend my gratitude to Professor Ahmad Ghasempoor, the Mechanical and Industrial Engineering Graduate Program Director, for all his support along the way in my studies.

I am also deeply grateful to the great man and woman in my life, my dear late parents, who always fully supported me generously and unconditionally all the way to their last moments. Rest in Peace my Dearest Dad and Mom.

Last, but absolutely not least, I would like to particularly thank my beloved wife, Mojgan, who has never stopped supporting me with her perpetual presence, signifying her continuous and genuine love, patience and support that were always complemented by her beautiful and calming smile throughout this journey. 


\section{DEDICATION}

Along with loving memory of Bahman Ahi and Shaheen-Dokht Karimkhan Zand, my dearest

late father and mother, I affectionately dedicate this dissertation to Mojgan, my lovely, beautiful and calming wife. 


\section{TABLE OF CONTENTS}

Author's Declaration $\quad$ ii

Abstract $\quad$ iii

Acknowledgements $\quad$ v

Dedication vi vi

Table of Contents vii

List of Tables

List of Figures $\quad$ xiii

List of Acronyms $\quad$ xiv

CHAPTER 1: Introduction 1

1.1 Overview 1

1.2 Purpose 2

1.3 Organization of Dissertation 3

$\begin{array}{lr}\text { CHAPTER 2: Literature Review } & 7\end{array}$

$\begin{array}{ll}2.1 \text { Introduction } & 7\end{array}$

$\begin{array}{ll}2.2 \text { Views on Sustainability } & 7\end{array}$

2.2.1 Weak vs. Strong Sustainability Perspective 8

2.2.2 Triple Bottom Line Sustainability Perspective 10

2.3 Overview of Supply Chain Management 11

$\begin{array}{ll}2.4 \text { Sustainability Metrics } & 13\end{array}$

2.5 Analytical Modeling Approaches for Sustainability Assessment in the Supply Chain 15

$\begin{array}{ll}2.6 \text { Summary } & 18\end{array}$

CHAPTER 3: Research Motivations and Objectives 19

$\begin{array}{ll}3.1 \text { Introduction } & 19\end{array}$ 
$\begin{array}{ll}3.2 \text { Defining SSCM } & 20\end{array}$

3.3 Metrics for GSCM and SSCM 21

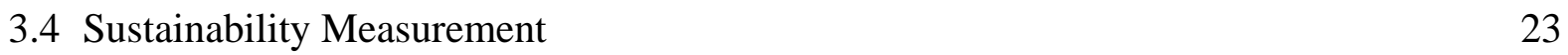

3.4.1 Assessing Sustainability Performance under the Strong Sustainability Perspective

3.4.2 Assessing Sustainability Performance in the Supply Chain

CHAPTER 4: Research Approach and Methodology

$\begin{array}{lll}4.1 & \text { Introduction } & 30\end{array}$

4.2 Objective 1: Define SSCM 31

4.3 Objective 2: Identify and Analyze the Published Metrics for SSCM 32

4.4 Objectives 3 and 4: Develop Mathematical Sustainability Models 34

CHAPTER 5: Defining Sustainable Supply Chain Management (SSCM) 40

$\begin{array}{ll}5.1 \text { Introduction } & 40\end{array}$

5.2 Key Characteristics of Business Sustainability 40

5.3 Key Characteristics of SCM 44

5.4 Results of Systematic Literature Search $\quad 47$

5.5 Analysis of the Published Definitions of GSCM and SSCM 51

5.5.1 Green Supply Chain Management Definitions 51

5.5.2 Sustainable Supply Chain Management Definitions 53

5.5.3 Business Sustainability Characteristics Addressed by the Definitions 55

5.5.3.1 Business Sustainability Characteristics Addressed by GSCM Definitions 56

5.5.3.2 Business Sustainability Characteristics Addressed by SSCM Definitions 57

$\begin{array}{ll}\text { 5.5.3.3 Summary } & 58\end{array}$

5.5.4 Supply Chain Management Characteristics Addressed by the Definitions 59

5.5.4.1 Supply Chain Management Characteristics Addressed by GSCM Definitions 61

5.5.4.2 Supply Chain Management Characteristics Addressed by SSCM Definitions 62

$\begin{array}{lll}5.5 .4 .3 & \text { Summary } & 63\end{array}$ 
5.5.5 Overall Summary 64

5.6 A New Definition of Sustainable Supply Chain Management 65

$\begin{array}{ll}5.7 \text { Conclusion } & 67\end{array}$

CHAPTER 6: Identification and Analyses of the Published Metrics for SSCM 68

$\begin{array}{ll}6.1 \text { Introduction } & 68\end{array}$

6.2 Background Information on the Sample 69

6.3 Frequency Analysis $\quad 72$

6.4 Analysis of Metrics by Key Characteristics of SSCM 77

6.4.1 Cross-Cutting Metrics 84

6.5 Analysis of Metrics by Theme 95

6.6 Conceptual Framework for Measuring Performance in GSCM and SSCM 99

$\begin{array}{ll}6.7 \text { Conclusion } & 103\end{array}$

CHAPTER 7: Develop a Mathematical Model for Assessing Sustainability Performance under the Green Economics Paradigm at the Company Level 105

$\begin{array}{ll}7.1 \text { Introduction } & 105\end{array}$

$\begin{array}{ll}7.2 \text { Model Structure } & 105\end{array}$

7.3 Illustrative Case Study on the Application of the Model 110

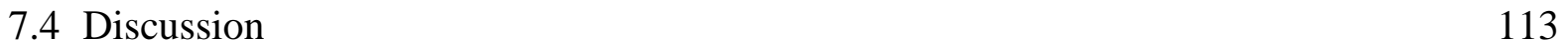

$\begin{array}{lll}\text { 7.4.1 Implications of the Model } & 116\end{array}$

$\begin{array}{ll}7.5 \text { Conclusion } & 117\end{array}$

CHAPTER 8: Develop Mathematical Models for Assessing Sustainability Performance in the Supply Chain

$\begin{array}{ll}8.1 \text { Introduction } & 119\end{array}$

8.2 Model Formulation 119

8.2.1 Generic SSCM Model 120

$\begin{array}{lll}\text { 8.2.2 Weighted SSCM Model } & 125\end{array}$ 
$\begin{array}{ll}\text { 8.3 Illustration and Discussion } & 129\end{array}$

8.3.1 Example Application of the SSCM Model 130

8.3.2 Implications of the SSCM Model 135

$\begin{array}{ll}8.4 \text { Conclusion } & 138\end{array}$

$\begin{array}{lr}\text { CHAPTER 9: Conclusion } & 140\end{array}$

$\begin{array}{ll}9.1 \text { Overall Summary } & 140\end{array}$

$\begin{array}{ll}9.2 \text { Research Contributions } & 140\end{array}$

$\begin{array}{ll}9.3 \text { Future Research Recommendations } & 145\end{array}$

$\begin{array}{lr}\text { APPENDICES } & 150\end{array}$

APPENDIX A: $\quad$ Analysis of Metrics Addressing Energy Issues 150

A.1 Inductive Analysis of Energy-Related Metrics 153

APPENDIX B: $\quad$ Analysis of Metrics Addressing Water Issues 156

APPENDIX C: $\quad$ Representative Sample Calculation for Sustainability Assessment of the Case Company 160

$\begin{array}{ll}\text { REFERENCES } & 161\end{array}$ 


\section{LIST OF TABLES}

\section{CHAPTER 5}

Table 5-1: Representative definitions of business sustainability 42

Table 5-2: Representative definitions of supply chain management 45

Table 5-3: Definitions of green supply chain management (GSCM) 51

Table 5-4: Definitions of sustainable supply chain management (SSCM) 53

Table 5-5: Key business sustainability characteristics addressed by the definitions 55

Table 5-6: Key SCM characteristics addressed by the definitions 60

\section{CHAPTER 6}

Table 6-1: Frequency rates of use of the identified metrics 72

Table 6-2: Identified metrics of green and sustainable supply chain management 73

Table 6-3: Distribution of SSCM key characteristics addressed by the identified metrics 79

Table 6-4: Summary of SSCM characteristics addressed by any one metric 85

Table 6-5: Number of metrics that addressed two characteristics of SSCM 86

Table 6-6: Examples of the metrics that addressed two SSCM characteristics 88

Table 6-7: Number of metrics, with examples, that addressed three characteristics of SSCM 90

Table 6-8: Number of metrics, with examples, that addressed four characteristics of SSCM 92

Table 6-9: Number of metrics, with examples, that addressed five characteristics of SSCM 93

Table 6-10: Representative examples of major themes addressed by the identified metrics of

$\begin{array}{ll}\text { GSCM and SSCM } & 96\end{array}$

\section{CHAPTER 7}

Table 7-1: Identified environmental performance indicators representing challenge factors

Table 7-2: Identified environmental performance indicators representing capacity factors 111

Table 7-3: Rationale for the selected challenge factors used in the case study 114

Table 7-4: Rationale for the selected capacity factors used in the case study 114 


\section{CHAPTER 8}

Table 8-1: Sustainability indicators representing capacity factors

Table 8-2: Sustainability indicators representing challenge factors

\section{APPENDICES}

Table A-1: Overview of metrics that addressed multiple SSCM characteristics for Energy-related issues

Table B-1: Overview of metrics that addressed multiple SSCM characteristics for Water-related issues

Table C-1: Challenge and Capacity Factors in Year 2011 


\section{LIST OF FIGURES}

\section{CHAPTER 4}

Figure 4-1: Structure of the conducted research 30

Figure 4-2: Framework for construction of the proposed sustainability models 37

\section{CHAPTER 5}

Figure 5-1: Distribution of the articles reviewed 48

Figure 5-2: Distribution of the articles analyzed for GSCM definitions 49

Figure 5-3: Distribution of the articles analyzed for SSCM definitions 50

Figure 5-4: Distribution of the key business sustainability characteristics addressed by the definitions $\quad 59$

Figure 5-5: Distribution of the key SCM characteristics addressed by the definitions 64

\section{CHAPTER 6}

Figure 6-1: Yearly distribution of the sources reviewed 69

Figure 6-2: Distribution of the articles analyzed for GSCM and SSCM metrics by journal 71

Figure 6-3: Number of metrics addressing each key characteristics of SSCM 94

Figure 6-4: Proposed conceptual framework for measuring performance in GSCM and SSCM

\section{CHAPTER 7}

Figure 7-1: Green economics paradigm 108

Figure 7-2: Sustainability of Hydro-Quebec Company in the period of 2009-2011 


\section{LIST OF ACRONYMS}

American Society for Engineering Management (ASEM)

Analytic Hierarchy Process (AHP)

Corporate Social Responsibility (CSR)

Cumulative Distribution Function (CDF)

Ecological Footprint (EF)

Global Reporting Initiative (GRI)

Greenhouse Gas (GHG)

Green Supply Chain Management (GSCM)

International Institute for Sustainable Development (IISD)

Input-Output Analysis (IOA)

Life Cycle Assessment (LCA)

Multi-Criteria Decision Making (MCDM)

Performance Management Association (PMA)

Probability Density Function (PDF)

Residual Hazardous Materials (RHMs)

Surplus Biocapacity (SB)

Supply Chain Management (SCM)

Sustainable Supply Chain Management (SSCM)

Triple Bottom Line (TBL)

World Commission on Environment and Development (WCED) 


\section{CHAPTER 1}

\section{INTRODUCTION}

\subsection{Overview}

There is an increasing recognition that organizations must address the issue of sustainability in their operations. Sustainability is commonly defined as utilizing resources to meet the needs of the present without compromising future generations' ability to meet their own needs (WCED, 1987). Considering the ambiguities and vagueness that surrounds this definition, complications frequently arise when attempting to apply the principles of sustainability in practice. The term “sustainability” has been interpreted in a variety of ways, ranging from an inter-generational philosophical position to a multi-dimensional term for business management. Early sustainability initiatives tended to focus on environmental issues. However, as time goes on, they are increasingly adopting a triple bottom line approach that emphasizes economic and social issues in addition to the traditional environmental focus of sustainability (Elkington, 1997). As this approach involves a higher number of interacting factors, a higher degree of complexity can be expected.

There are ongoing debates about the importance and application of sustainability in a business context. Business sustainability has been defined in a number of ways, with one possibility being "the creation of resilient organizations through integrated economic, social and environmental systems” (Bansal, 2010). By embracing the opportunities and controlling the risks that result from an organization's environmental, economic and social responsibilities, many argue that business sustainability can generate long term value for the involved stakeholders (Pojasek, 2007). As explained by Pojasek (2007, p. 81) "business sustainability must meet the needs of the organization and its stakeholders today while also protecting, sustaining, and enhancing the environmental, social, and economic resources needed for the future”. In a broader sense, business sustainability signifies the resiliency of organizations over time where they are closely connected to healthy environmental, economic and social systems so they are better positioned to respond to internal and external shocks. In light of the above, organizations are increasingly 
considering the life cycle implications of their decisions and hence, management of their supply chains is receiving increased prominence. A supply chain is a dynamic process that includes the continuous flow of materials, funds and information across multiple functional areas within and between chain members (Jain et al., 2009). Given that the supply chain contemplates the product from initial processing of raw materials to delivery to the end-user, a focus on supply chains is a step towards the wider adoption and development of sustainability (Linton et al., 2007). Considering the extensive nature of these two areas, there is a tangible requirement for developing a meaningful and more focused understanding of sustainability, particularly, when it is integrated with the supply chain management concept. Investigations of the ways sustainable supply chains are defined, interpreted and applied in practice are significant to such improved understanding and hence, are in strong demand (Ashby et al., 2012).

On the other hand, intense global competition has continued to escalate the need to improve the performance of organizations in managing their supply chains. This is further complicated by the fact that the range of factors considered in any improvement initiative are continually expanding. This is reflected in efforts to embed the principles of sustainability in goals, objectives, and targets at all levels of society. It is therefore becoming an essential requirement to measure the sustainability level of supply chains and also to monitor their performance towards sustainability. As reflected in the most-widely cited definition of sustainability, which emphasizes the need to meet the needs of the present generation without compromising the ability of future generations to meet their own needs (WCED, 1987), sustainability explicitly necessitates the long term capability of supply chains to meet certain functional requirements.

This research contributes to these needs by developing a comprehensive definition of sustainable supply chain management (SSCM), a database of metrics used to measure SSCM, and probabilistic models for assessing progress towards sustainability in the supply chain.

\subsection{Purpose}

The purpose of this research is to investigate how sustainability is integrated into supply chain management. Emphasis is particularly devoted to determining how the sustainability 
performance of organizations may be assessed at the company and supply chain levels. Four key objectives have been developed to support this purpose:

\section{Define SSCM.}

2. Identify and analyze the published metrics for SSCM.

3. Develop a mathematical model for assessing sustainability at the company level.

4. Develop mathematical models for assessing sustainability in the supply chain.

It is important to emphasize that the development of the proposed models in this research is guided by the need for ease of use, simplicity, and the ability to quickly provide feedback on the sustainability status.

\subsection{Organization of Dissertation}

This dissertation is organized around the remaining chapters as follows. The next chapter, Literature Review, is devoted to a tailored review of the literature most relevant to the topics of sustainability, supply chain management, metrics of sustainability, and analytical modeling approaches used to assess sustainability in the supply chain.

Chapter 3, Research Motivations and Objectives, addresses the research gaps and requirements highlighted in the literature, and defines the objectives of the research systematically. Chapter 4, Research Approach and Methodology, comprehensively discusses the methodology taken to achieve Objectives 1 and 2, and provides a detailed discussion of basic principles underlying the sustainability models proposed in Objectives 3 and 4.

Chapter 5, Defining Sustainable Supply Chain Management (SSCM), addresses Objective 1 of the research. The chapter is based on the paper:

Ahi, P., Searcy, C., 2013. A comparative literature analysis of definitions for green and sustainable supply chain management. Journal of Cleaner Production 52(1), 329-341, DOI: 10.1016/j.jclepro.2013.02.018. 
The final publication is available at:

http://www.sciencedirect.com/science/article/pii/S095965261300067X

Building systematically on the published definitions of GSCM and SSCM, this chapter focused on thoroughly examining the characteristics of business sustainability and supply chain management (SCM) that led to the identification of the key characteristics of SSCM, analyzing the identified definitions against the introduced key characteristics and highlighting their strengths and weaknesses alongside their convergences and divergences in the literature, and an original, comprehensive definition of SSCM was proposed. Accordingly, the manuscript addresses Objective 1, which provides the basis for further analysis carried out in the following chapters.

Chapter 6, Identification and Analyses of the Published Metrics for SSCM, addresses Objective 2 of the research. The chapter is based on the following papers:

Ahi, P., Searcy, C., 2014. An analysis of metrics used to measure performance in green and sustainable supply chains. Journal of Cleaner Production. (Accepted)

Ahi, P., Searcy, C., 2014. Measuring social issues in sustainable supply chains. In proceedings of the Performance Management Association (PMA) 2014 Conference on Performance Management: Designing the High-Performance Organization, Aarhus, Denmark, June 25-27.

Ahi, P., Searcy, C., 2014. Measuring energy issues in sustainable supply chains. In proceedings of the American Society for Engineering Management (ASEM) 2014 International Annual Conference on Entrepreneurship Engineering: Harnessing Innovation, Virginia Beach, USA, October 15-18. (Accepted)

The published metrics used in the GSCM and SSCM areas were systematically identified. The metrics were analyzed against the key characteristics of SSCM in order to determine the convergences and divergences of the published metrics and the core sustainability themes addressed by the identified metrics. Accordingly, the manuscripts address Objective 2 of the research. 
Chapter 7, Develop a Mathematical Model for Assessing Sustainability Performance under the Green Economics Paradigm at the Company Level, addresses Objective 3 of the research. The chapter is based on the following paper:

Ahi, P., Searcy, C., 2013. A stochastic approach for sustainability analysis under the green economics paradigm. Stochastic Environmental Research and Risk Assessment. Article in Press, DOI: 10.1007/s00477-013-0836-5.

The final publication is available at: http://link.springer.com/article/10.1007/s00477-013-0836-5

By providing an original and straightforward analytical approach, the developed model presents a unique method of adopting the strong sustainability concept to measuring and assessing sustainability at the company level. Additionally, by explicit recognition of context-dependent factors that either enable or inhibit progress towards company's sustainability, the model concisely illustrates progress towards sustainability of the company over time. The model also provides a basis for improved reporting and benchmarking in the field of sustainability performance measurement at the company level.

Chapter 8, Develop Mathematical Models for Assessing Sustainability in the Supply Chain, addresses Objective 4 of the research. The chapter is based on the following paper:

Ahi, P., Searcy, C., 2014. Assessing sustainability in the supply chain: A triple bottom line approach. Applied Mathematical Modelling, Under review (4 $4^{\text {th }}$ round of reviews).

By providing an original and straightforward analytical approach, the developed SSCM models are one of the first to explicitly adopt a probabilistic approach for sustainability measurement and assessment in the supply chain context. By highlighting the need to systematically identify the key sustainability challenges and opportunities in any particular supply chain, the developed models may provide a basis for improved reporting and standardization of data collection procedures across the entire supply chain. In this light, if data collection challenges can be overcome, the models provide practical and forthright ways to assess the sustainability performance of any supply chain. 
Chapter 9, Conclusion, closes the dissertation. This final chapter builds on the research objectives that are presented in Chapters 5, 6, 7 and 8. It presents a summary of the research contributions and provides recommendations for the future research directions.

In all cases, the primary author of the papers cited above was Mr. Payman Ahi. Mr. Ahi's involvement in the papers included aspects such as concept development, category identification for analysis, conducting the research, writing, and modifying the papers to the satisfaction of the journals' specific requirements for their publications. Dr. Cory Searcy was the second author in all cases. His involvement with the development of the papers included concept development, supervision of the research process, review of the papers, and corresponding with the journal with respect to their publications (for the Journal of Cleaner Production papers only). 


\section{CHAPTER 2}

\section{LITERATURE REVIEW}

\subsection{Introduction}

Sustainability and supply chain management (SCM) are two concepts that independently have created many debates over the last decade (Seuring et al., 2008; Chen and Paulraj, 2004). Recognizing that no review of the literature on these two subjects could be comprehensive, this chapter presents a review of the literature most relevant to the research areas proposed in this study. The review is therefore organized into the following four sections as views on sustainability, overview of supply chain management, sustainability metrics, and analytical modeling approaches for sustainability assessment in the supply chain.

\subsection{Views on Sustainability}

In the 1980's sustainable development was recognized as a global priority by major political leaders (WCED, 1987). Since then, an enormous amount of research has been conducted on this subject at all levels of society. Accordingly, sustainable development and sustainability were two of the most popular catchwords of the 1980s (Pearce, 1988). However, there has been a lack of consistency in interpretations discussed and employed in these areas. As previously noted, sustainability is commonly defined as utilizing resources to meet the needs of the present without compromising the ability of future generations to meet their own needs (WCED, 1987). Difficulties related to the definition of sustainability show that it is a complex and multidimensional issue, which merges efficiency and inter- and intra-generational equity on an environmental, economic, and social basis. The variety of methods used in an effort to address this concept reflects the challenges that exist in defining and measuring progress towards sustainability (Dzemydiene, 2008). These difficulties are reflected in a quote by Wilson et al. (2007, P. 300), who noted that "there is not a collective consensus of what sustainability means and of what constitutes sustainable development”. A terminology dilemma occurs due to the dual nature of the sustainable development concept, covering development as well as sustainability. Goodland and Ledec (1987) described sustainable development as the transformation 
(development) of economies, optimizing the economic and social benefits gained at present without putting the possibilities of reaching such benefits at risk in the future. Pearce (1988) argued that sustainability either means sustaining and supplementing natural environmental systems, or is a requirement for sustaining economic development. In 1992, the Rio de Janeiro Declaration on Environment and Development described sustainable development as long-term continuous development of society aimed at the satisfaction of humanity's needs during the present and in the future via rational usage and replenishment of natural resources (Rio Declaration on Environment and Development, 1992). Holdgate (1993) argued that development means understanding of the potential and capability of the available resources. Radermacher (1999) offered one of the broadest concepts of sustainability assessment, indicating that the definition of sustainability should include the elements of globalization, a long period of time (since environmental results are of long-term character), external effects and environmental policies.

Given the fact that the sustainability issues in developed countries have mostly been centered on environmental subjects, while in developing countries the issues of poverty and equity are being equally significant (Singh et al., 2012), one can argue that sustainable growth would refer to economic growth, which is backed and supported by the physical and social environment. Accordingly, sustainable development might be recognized as the process of economic development and structural changes assisting to extend human possibilities. In this light, sustainability can be viewed through sustainable and balanced development of human possibilities and the ability to assume social responsibility for oneself, the society, and future generations. Therefore, it can be argued that generally, sustainable development is concerned with processes while sustainability is a state. Nevertheless, the terms "sustainable development" and "sustainability" are frequently used interchangeably in the literature (Aras and Crowther, 2009). The same approach will be used in the current research.

\subsubsection{Weak vs. Strong Sustainability Perspective}

Sustainability has become closely associated with highlighting and understanding interactions between economic growth and the protection of the environment (Putzhuber and Hasenauer, 2010). As concisely summarized by Wilson et al. (2007) and Singh et al. (2009), sustainability 
can be viewed in terms of "weak sustainability" and "strong sustainability". The argument of weak and strong sustainability is often viewed as a debate between neoclassical and ecological economics (Ramos and Caeiro, 2010). Weak sustainability has been defined using the concept of economic capital that includes manpower (labor), machines and knowledge, and the concept of natural capital that covers the environment and natural resources. As Pearce (1988) stated, both economic capital and natural capital contribute to human wellbeing. Weak sustainability is considered to be the aggregation of economic and natural capital sources. According to the weak sustainability concept (Gutés, 1996), almost all kinds of natural capital can be replaced by economic capital. Some mainstream neoclassical economists such as Solow (1993) argued that economic capital can, in principle, substitute all natural capital except for unique places such as the Grand Canyon and Yosemite National Park. Accordingly, Solow $(1974,1986)$ and Hartwick (1977) argued that an economy would be economically sustainable if total wealth is not weakening. In this view, the Hartwick-Solow rule, often called weak sustainability (Gutés, 1996) implies that an economy is sustainable if the capital stock required for maintaining the economic output is non-declining (Gowdy, 2005).

The contrary position, i.e. the ecological economics perspective known as strong sustainability, believes that the services produced by humans or man-made systems cannot substitute many of the most fundamental services provided by nature (Ayres, 2008). The advocates for strong sustainability argue that natural capital is to a greater or lesser extent non-replaceable (Dietz and Neumayer, 2007). Generally, they argue that many natural ecological functions, as well as the natural resource stock of fossil fuels (signifying millions of years of accumulations of solar energy) are irreplaceable.

According to Ekins et al. (2003) the following four function categories are presented by natural capital. The raw materials required for production and direct consumption (i.e., food, wood and fossil fuels), absorption of the waste produced by the production and consumption, providing amenity services (i.e., the visual amenity of a landscape), and providing the basic life-support functions on which human life, as well as the first three categories of natural capital functions are dependent on. In other words, certain natural resources like life-support functions of nature and environment may be identified as supplying essential inputs to production, consumption or welfare for which no manufactured or human-made replacement is available. 
Based on the strong sustainability concept, it is necessary to keep and maintain each of the natural and economic capitals separately (Van den Bergh, 2010). In support of the strong sustainability position, Ayres (2007) emphasized that there are important real limitations to substitutability and resource replacement in nature. Moreover, Van den Bergh (2010) discussed bioethics in the context of environmental integrity and rights of nature. He expressed that the very strong sustainability position would imply that every component, physical stock or subsystem of the natural environment should be protected and carefully preserved. Based on Van den Bergh's remarks, a compromise version of strong sustainability focuses on maintaining ecosystems and environmental resources that are critical for life support or irreplaceable. Yet, as emphasized by Tatari et al. (2010) and Marvuglia et al. (2013), the direct and indirect role of renewable resources and ecosystem services (e.g., ecological resource consumption) that provide vital support to human activities are often excluded from the evaluation methods (e.g., life cycle assessment) employed to quantify the environmental impacts of products, processes and activities.

\subsubsection{Triple Bottom Line Sustainability Perspective}

Given the need for tackling issues like climate change, the loss of biodiversity, decreasing material availability, and meeting energy consumption requirements, sustainability is becoming an increasingly important concept for governance and policy dialogue. As addressed earlier, sustainability has different interpretations ranging from an inter-generational philosophical stand to a multi-dimensional expression for business management. Although it was originally conceived as a societal issue, sustainability is receiving increased attention among businesses. Among various comprehensions of sustainability, one central concept that helps to operationalize sustainability is the triple bottom line (TBL) approach, where a minimum performance is to be achieved in the environmental, economic and social dimensions (Elkington, 1997). Dyllick and Hockerts (2002) have also structured the sustainability dimensions as the business, natural and societal cases. Furthermore, this sustainability perspective is presented in literature by utilizing the planet, people and profit as the main features of sustainability (e.g., Shrivastava, 1995; Holliday, 2001; Salzmann et al., 2005; Asif et al., 2011). Advocates of this sustainability view argue that organizations that take the environmental (planet) and social (people) concerns along with the economic (profit) issues into consideration make more value over the long run and 
experience fewer risks, compared to organizations that focus only on the profit and financial issues.

\subsection{Overview of Supply Chain Management}

Many avenues of research have been pursued under the umbrella of SCM (Mentzer et al., 2001). Since its introduction as a concept in the early 1980s, the term SCM has been used to describe the planning and control of materials, information flows, and the logistics activities internally within a company and also externally between companies (Cooper et al., 1997; Fisher, 1997). Over time, research on SCM has continued to broaden in focus (Burgess et al., 2006).

Initially, SCM only involved materials flows. More recent research emphasizes additional aspects of SCM, such as risk (Tang, 2006; Colicchia and Strozzi, 2012), performance (Hassini et al., 2012), and integration (Fabbe-Costes and Jahre, 2007). There is also a growing emphasis on information flows, internal and external networks of relationships (Stock et al., 2010; Wong et al., 2012), and governance of supply networks (Pilbeam et al., 2012). These aspects are often reflected in the goal of SCM, which has been described as "effectively managing the flow of materials and information from supply sources to the final point of sale” (Zsidisin et al., 2000, p. 312) and "the management of the interface relationships among key stakeholders and enterprise functions” (Walters and Lancaster 2000, p. 160).

The approach to SCM is defined by the fact that there are dependencies between channels from the point of origin to the point of consumption (Lambert et al., 1998). Svensson (2002) argued that SCM is a business philosophy that simultaneously deals with the overall bi-directional dependencies of activities, actors, and resources on an operational, tactical, and strategic level, from the point of origin to the point of consumption in and between channels. Stock et al. (2010, p. 34) explained that SCM developed as “a means of improving an organization's competitive advantage and the competitiveness of its constituent members by creating mutually beneficial or symbiotic supply chain networks”. Integrating a variety of functions and processes within and between organizations is an essential element of SCM (Mentzer et al., 2008; Frankel et al., 2008). Accordingly, SCM concepts have been applied across organizations to improve operating performance, provide new sources of competitive advantage while offering better value(s) to 
consumers, and ultimately develop superior managed organizations and inter-organizational relationships (Trent, 2004).

Lambert et al. (1998, p. 1) defined SCM as "the integration of key business processes from enduser through original suppliers that provide products, services, and information that add value for customers and other stakeholders.” According to Handfield and Nichols (1999), SCM is the integration of all activities associated with the flow and transformation of goods from raw materials to the end users, through improved supply chain relationships to achieve a competitive advantage. Mentzer et al. (2001, p. 18) defined SCM as "the systemic, strategic coordination of the traditional business functions and the tactics across these business functions within a particular company and across businesses within the supply chain, for the purposes of improving the long-term performance of the individual companies and the supply chain as a whole”. Gibson et al. (2005, p. 22) developed a definition that describes SCM as "encompassing the planning and management of all activities involved in sourcing and procurement, conversion, demand creation and fulfillment, and all logistic management activities”. They also suggested that SCM involves coordination and collaboration activities with channel partners, which can be suppliers, intermediaries, third-party service providers, and end-users. Su and Yang (2010) stated that SCM is the integration of key business processes amongst a network of inter-reliant manufacturers, suppliers, distribution centers, and retailers to facilitate the improvement of the flow of goods, services, and information from original suppliers to end-users, with the purpose of reducing system-wide costs while keeping the required service levels. Fabbe-Costes et al. (2011, p. 229) framed SCM as “an integrative philosophy to manage total flows as cooperatively as possible, from the earliest raw materials suppliers to the ultimate customers, and beyond, namely the disposal and recycling processes, too”.

Considering all of the above, there are ongoing calls to strengthen the theoretical foundation of SCM (Carter, 2011) and hence, the depth of SCM continues to grow. Given the influence of SCM on the economic, environmental, and social impacts of an organization, it is vital to contemplate its relation to business sustainability initiatives. 


\subsection{Sustainability Metrics}

The terms "metrics" and "indicators" are frequently used interchangeably in sustainability measurement discussions (Tanzil and Beloff, 2006). Drawing on a dictionary definition, a "metric" may be defined as "a standard of measurement" (Merriam-Webster, 2014a) and an "indicator" may be defined as "a sign that shows the condition or existence of something" (Merriam-Webster, 2014b). More generally, sustainability metrics typically focus on quantitative measurement. Sustainability indicators typically have a broader focus. Indicators may be used to evaluate and motivate progress toward sustainability objectives (Veleva and Ellenbecker, 2001), covering both quantitative measures and narrative description of important sustainability issues (Tanzil and Beloff, 2006). However, it should be noted that these distinctions are not made in all cases. Sustainability metrics and indicators may be applied with different levels of complexity and are increasingly being recognized as practical tools for policy, decision making, and communication purposes in many contexts, including SSCM. They play a particularly critical role in measuring progress towards defined goals.

Corporate sustainability metrics are widely available and have been used by numerous organizations all over the world (Searcy, 2012). These metrics are frequently shared with the public in corporate sustainability reports. Previous research has shown that there is a great range in the types of metrics reported, though many metrics for all three areas of the triple bottom line are available (Roca and Searcy, 2012). The majority of metrics may be classified as either absolute or relative metrics. Absolute metrics “express operational performance in terms of what overall levels of performance are in specific areas of interest (e.g., water use) for an organization as a whole” (McElroy and van Engelen, 2012, p. 62), while relative metrics “express operational performance in terms of how performance in one area (e.g., water use) correlates to performance in another area (e.g., revenue or total production)” (McElroy and van Engelen, 2012, p. 63). Examples of absolute and relative metrics are widely available, including through the Global Reporting Initiative (GRI), which provides a list of over 90 indicators (GRI, 2013a). One of the key characteristics of metrics that focus on sustainability, however, is that they should be linked to the broader sustainability context in which an entity operates. 
Sustainability context is one of the GRI's key principles for defining the content of sustainability reports, along with stakeholder inclusiveness, materiality, and completeness (GRI, 2013a). The sustainability context principle states that organizations should present their "performance in the wider context of sustainability" (GRI, 2013a, p. 17). The implication is that reporting solely on absolute or relative metrics fails to address the underlying issue of sustainability context. As the GRI notes, this means that performance should be assessed "in the context of the limits and demands placed on environmental or social resources at the sector, local, regional, or global level” (GRI, 2013a, p. 17). Furthermore, the GRI implementation manual explicitly notes that supply chain topics should be considered in the consideration of sustainability context (GRI, 2013b).

Building on the GRI's sustainability context principle, McElroy and van Engelen (2012) argued that there is an urgent need to develop context-based metrics of sustainability. They defined context-based metrics as those that "express organizational performance in terms of impacts on vital capitals, relative to norms, standards or thresholds for what such impact ought to be (for specific periods of time) in order to be sustainable (e.g., total water consumed per employee per year compared with a fair or equitable allocation of available renewable supplies)" (McElroy and van Engelen, 2012, p. 65). As McElroy and van Engelen (2012) argued, the development of metrics that consider the broader sustainability context is frequently overlooked.

In view of the weak and strong sustainability perspectives, various sustainability metrics have been proposed. Drawing on research by Wilson et al. (2007) and Bohringer and Jochem (2007), there has been a range of metrics that adopt the weak sustainability position. Examples include the Index of Sustainable Economic Welfare (Daly and Cobb, 1989), Adjusted Net Savings - also known as the Genuine Savings index (Pearce and Atkinson, 1993), Genuine Progress Indicator (Cobb et al., 1995), Well-Being Index (Prescott-Allen, 2001), and Human Development Index (United Nations Development Programme, 2005). However, fewer published methods adopt the strong sustainability position, with the Ecological Footprint (EF) and the Surplus Biocapacity (SB) being the most prominent.

The Ecological Footprint (EF) was introduced by Wackernagel and Rees (1996) as the amount of land and water area that a human population would hypothetically need to provide the necessary 
resources for supporting itself and to absorb its wastes. The EF has been used as an environmental sustainability indicator with a wide variety of applications, such as to individual lifestyles, regions, cities, and nations throughout the world (e.g., Barrett and Scott, 2001a; Wackernagel, 1998). Its use at the company level has also been discussed in the literature (e.g., Barrett and Scott, 2001b; Herva et al., 2008; Holland, 2003; Wiedmann et al., 2009). This metric has been used to help determine the ability of an industrial system to adapt to the local natural limiting factors (Kratena, 2008). The EF is normally presented together with biocapacity, which measures the bioproductive supply (i.e., the biological production in a certain area). This might involve built or tarnished land. Biocapacity (or ecological supply) provides an indication of the capacity of a given biological production area to generate a continuous supply of renewable resources and to absorb its overflow wastes (Schaefer et al. 2006). The mathematical difference between EF and biocapacity is called Surplus Biocapacity (SB) (Giannetti et al., 2010). Like the EF metric, the SB evaluates the sustainability of consumption patterns. The SB stands for the difference between the ecological footprint of a country and its domestic production area of ecologically productive land and water (Giannetti et al., 2010).

\subsection{Analytical Modeling Approaches for Sustainability Assessment in the Supply Chain}

Measuring sustainability in a supply chain context is a growing area of interest among researchers and practitioners in the field (Glock et al., 2012; Brandenburg et al., 2014). However, the literature on this subject is still relatively limited. Drawing on the recent research by Hassini et al. (2012), Seuring (2013), and Brandenburg et al. (2014), quantitative models for assessing sustainability in a supply chain may be organized into the following distinct approaches:

- Life cycle assessment (LCA) based models

- Applications of the analytic hierarchy process (AHP)

- Equilibrium models

- Multi-criteria decision making (MCDM) models

- Input-output analysis (IOA) based models

- Composite metrics 
LCA is a systematic method for studying and evaluating the potential environmental impacts associated with a product, process, or activity, by identifying and quantifying materials used, energy consumed, and wastes discharged to the environment (Abdallah et al., 2012; Pishvaee and Razmi, 2012). Seuring (2013) found LCA to be the most commonly used technique for assessing sustainability issues in supply chains (Seuring, 2013). This finding is supported by earlier research (i.e., Pesonen, 2001) that had emphasized the use of LCA based criteria in a supply chain context. Evaluating environmental issues and attempting to minimize their impacts along a supply chain were the typical components addressed in this approach (e.g., Khoo et al., 2001; Sonesson and Berlin, 2003; Tan and Khoo, 2005; Ferretti et al., 2007; Cholette and Venkat, 2009; Edwards et al., 2010). AHP is the second most commonly used modeling approach for assessing sustainability issues in the supply chain context (Seuring 2013). AHP is a structured technique for organizing and analyzing complex and multi objective decisions (Saaty, 1990). This methodology does not usually contemplate a complete mathematical formulation of a specific problem, and hence is often employed as semi-quantitative decision making technique (e.g., Noci, 1997; Sarkis, 1998). However, it is widely used for simplifying and structuring complex decisions (Ho, 2008). Accordingly, considering the inclusion of sustainability requirements in the supply chain context, employing the AHP technique provided opportunities for assessing complex decision situations where environmental and economic goals were evaluated simultaneously (e.g., Sarkis, 1998, 2003; Hsu and Hu, 2008; Faisal, 2010). Equilibrium modeling is a standard and well established methodology on evaluating performance of an overall supply chain (Nagurney et al., 2002; Meixell and Gargeya, 2005) and is another commonly used approach for assessing sustainability concerns in supply chains (Seuring, 2013). The typical foundation of the equilibrium models in the literature were the balancing of environmental and economic issues, by offering a relevant equilibrium or optimum solution (e.g., Corbett and De Croix, 2001; Nagurney and Toyasaki, 2003; Kainuma and Tawara, 2006; Saint Jean, 2008). No probabilistic approach was emphasized in any of the published models. MCDM is another commonly utilized analytical modeling approach. MCDM is a discipline that explicitly considers multiple conflicting criteria, which need to be evaluated in decision-making processes. This approach is concerned with structuring and solving decisions and planning problems comprising multiple criteria. Optimizing environmental and economic criteria by balancing trade-offs or proposing optimal solutions are typically the main areas of emphasis in this 
approach (e.g., Fichtner et al., 2004; Hugo and Pistikopoulos, 2005; Geldermann et al., 2007; Georgiadis and Besiou, 2009). Seuring (2013) has explained that the identified MCDM and equilibrium models exhibit somewhat comparable initial points, in that they both intend to find a balance between various environmental and economic performance criteria. Input-output analysis (IOA) is another analytical modeling technique used for assessing sustainability related issues in supply chains (Brandenburg et al., 2014). In this modeling approach the relationships between outputs of some performance measures and the supply chain's input parameters and their related decision factors can be analyzed. Accordingly, the IOA technique provides opportunities to evaluate throughputs of environmental capital (e.g., renewable and nonrenewable ecological goods, material use, ecosystem services, and impact of emissions on human health) and economic goals (i.e., lowering costs and/or maximizing profits) along supply chain networks (e.g., Ukidwe and Bakshi, 2005; Bonney and Jaber, 2011; El Saadany et al., 2011; Jaber et al., 2011; Bonney and Jaber, 2013). The last analytical modeling approach that may be used to address sustainability issues in the supply chain context is developing and employing composite metrics (Hassini et al., 2012; Brandenburg et al., 2014). Composite metrics applied with varying levels of complexity (Turnhout et al., 2007) are gaining merit, and increasingly considered as efficient and practical tools for policy prioritization, decision-making, and communication with respect to different levels of system performance (Singh et al., 2012). Ample research has been conducted on this subject (e.g., Booysen, 2002; Saisana and Tarantola, 2002; Bohringer and Jochem, 2007; Mayer, 2008; Singh et al., 2009, 2012). Composite metrics are practical tools in focusing attention through their ability to summarize complex and multifaceted problems into one metric (Singh et al., 2012). While different methodologies have been proposed for the development and implementation of composite metrics in the sustainability context (e.g., Saisana and Tarantola, 2002; Nardo et al., 2005; Singh et al., 2007; Zhou et al., 2012; Ngai et al., 2013), it is often argued that composite metrics are too subjective, as their results undesirably are dependent on the specific weighting system employed alongside the aggregation method used for combining the various factors involved (Bohringer and Jochem, 2007; Singh et al., 2012). 


\subsection{Summary}

The literature reviewed in this chapter was exclusive to the research areas proposed in this study. Accordingly, by highlighting different sustainability perspectives, SCM views and requirements, definitions and types of sustainability measurement tools (i.e., metrics and indicators) in general, and analytical modeling approaches used exclusively to measure sustainability in the supply chain context, it provides the necessary foundations required for the analyses and discussions presented later in the research. 


\section{CHAPTER 3}

\section{RESEARCH MOTIVATIONS AND OBJECTIVES}

\subsection{Introduction}

As highlighted earlier, organizations are increasingly taking the life cycle implications of their decisions into consideration and thus, management of their supply chains is receiving increased attention. At the same time, there is also a considerable amount of activities and continuing developments in the field of sustainability, which makes it worthwhile for researchers and practitioners in different fields to take into account the impacts and implications of sustainability on traditional assumptions and practices in their fields of studies and operations (Linton et al., 2007; Gimenez and Tachizawa, 2012). Supply chain management is one of these research areas (Carter and Rogers, 2008).

Accordingly, the literature shows that there are ongoing debates around the importance and application of sustainability in a business context, and hence, businesses are increasingly integrating sustainability into their SCM practices (Morali and Searcy, 2013). Although the motivations of individual organizations may vary, key objectives generally include an interest in achieving sustainable streams of products, services, information and funds to provide maximum value to all involved stakeholders (Salzmann et al., 2005; Weber, 2008).

A major issue highlighted in the literature is that research on sustainable supply chains and its management is currently experiencing a dearth of established theories, models and frameworks (Abbasi and Nilsson, 2012). Another key issue highlighted is the lack of consensus on what characteristics can comprehensively portray business sustainability (Dahlsrud, 2008) and SCM (Stock and Boyer, 2009). Accordingly, to completely understand sustainable supply chains, it is necessary to closely analyze the relational features of SCM and investigate how they can be applied in practice to address all aspects of sustainability. This is further highlighted by Abbasi and Nilsson (2012) whom argued that environmental and social issues need to be taken into account in SCM in the same way as revenues and costs are considered today. 


\subsection{Defining SSCM}

Given the relatively new emphasis on the integration of sustainability and SCM, it is unsurprising that a number of different terms have been used to express this complex combination of concepts. Examples include green supply chain management (GSCM) (Srivastava, 2007), sustainable supply chain management (SSCM) (Carter and Rogers, 2008; Seuring and Muller, 2008), closed-loop supply chains (Quariguasi Frota Neto et al., 2009), green manufacturing and product recovery (Gungor and Gupta, 1999), and reverse logistics (Carter and Ellram, 1998; Fleischmann et al., 1997). It is recognized that these terms do not always completely overlap, but they are used interchangeably in many cases (Gurtu et al., 2012). Among these terms, Green Supply Chain Management (GSCM) and Sustainable Supply Chain Management (SSCM) are the two terms with the most rapidly growing usage that most obviously promote the strong linkages between the sustainability and SCM concepts (Ashby et al., 2012; Ahi and Searcy, 2013a).

One key issue underlined in the related recent literature reviews (i.e., Srivastava, 2007; Linton et al., 2007; Seuring and Muller, 2008; Carter and Rogers, 2008; Carter and Easton, 2011; Sarkis et al., 2011; Gimenez and Tachizawa, 2012; Abbasi and Nilsson, 2012; Ashby et al., 2012) is the profusion of definitions for both GSCM and SSCM. Given that research in both areas of GSCM and SSCM is still relatively new, a diversity of perspectives in terms of definitions is useful. However, as research on the integration of sustainability into SCM continues to expand, it will become increasingly important to address the inconsistencies in the various definitions of GSCM and SSCM. The lack of reasonably consistent definitions may lead to confusion regarding the appropriate scope in theory and practice of SSCM initiatives. Therefore, there is a tangible need for establishing a reference point on the great variety of definitions that have been published in these areas.

In order to respond to the highlighted needs discussed above, the current research aims to firstly define separate sets of characteristics that can comprehensively portray different themes of business sustainability and SCM. Then, the many published definitions of GSCM and SSCM will be systematically analyzed to identify the existing similarities and differences among them, and also to determine the extent to which they address the different characteristics of both 
business sustainability and SCM. This will be accomplished through a comparison of the identified GSCM and SSCM definitions against each other, and also against the defined characteristics of business sustainability and SCM. The analysis will help highlight the convergences and divergences in the literature as well as the strengths and weaknesses of the existing definitions. Ultimately, by taking the introduced key characteristics for business sustainability and SCM, a comprehensive description for GSCM and SSCM will be defined. This analysis will provide a basis for the next steps in the proposed research that will be discussed in the next sections. Based on the above, Objective 1 is therefore proposed as follows:

\section{Objective 1: Define SSCM}

\subsection{Metrics for GSCM and SSCM}

Drawing on a number of studies that have been focused on the broad issue of performance measurement in supply chains, different key issues explored in this area would include evaluating and monitoring progress, reporting of performance, identifying achievements, promoting improved process understanding, identifying critical issues, confirming priorities, and providing guidance for future actions, among other topics (e.g., Beamon, 1999a; Gunasekaran et al., 2004; Gunasekaran and Kobu, 2007; Cuthbertson and Piotrowicz, 2008, 2011; Akyuz and Erkan, 2010; Gopal and Thakkar, 2012). Suggested metrics for measuring supply chain performance are also widely available.

However, there is less research that focuses specifically on measuring performance in green or sustainable supply chains, but there is evidence of growing interest in this area. For example, Hervani et al. (2005) provided an overview of the issues related to environmental (green) supply chain performance measurement. They argued that the objective of a green supply chain is to eliminate or minimize negative environmental impacts (air, water, and land pollution) and waste of resources (energy, materials, products) from the extraction or acquisition of raw materials up to final use and disposal of products. Hervani et al. (2005) proposed the use of ISO 14031 as a basis for the performance management of GSCM. As a second example, Bai et al. (2012) suggested a seven-step methodology for joint environmental and business performance measurement. They highlighted a core set of essential business and environmental performance 
measures for sustainable supply chains. They also employed the supply chain operations reference model for developing both business and environmental measures for supply chain sourcing. As a third example, Bjorklund et al. (2012) conducted a review of literature on logistics management and performance measurement that were coupled with a discussion of environmental logistics theory. They highlighted that, although there are growing environmental demands and pressures from a number of different stakeholders (e.g., government, society, the market and industry), few attempts have been made to investigate how the outcomes from environmental measurement activities are externally communicated. They further underlined that there is a large concentration on measuring current effects of historical decisions rather than developing measures to support future management. Moreover, Bjorklund et al. (2012) argued that there is a requirement to incorporate measures across different managerial levels and to apply more process-oriented measures in the supply chain. However, few empirical examples are available to show how these can be accomplished. As a fourth example, Miemczyk et al. (2012) conducted a structured literature review on sustainability in purchasing and supply management. They focused on inter-organizational analysis at the three levels of dyad, supply chain, and network. They argued that research in these areas is more focused on internal or dyadic issues than on environmental considerations. They also highlighted that the social aspect of sustainability has received considerably less attention than the other dimensions. Their approach is limited to a purchasing perspective, and hence, some of the important supply chain issues (e.g., logistics and transportation) were excluded in their study. As a final illustrative example, it is interesting to note the recent special issue on performance measurement of sustainable supply chains in the International Journal of Productivity and Performance Measurement (e.g., Pazirandeh and Jafari, 2013; Reefke and Trocchi, 2013; Taticchi et al., 2013; Wang and Sarkis, 2013).

Despite the many published studies, including those noted above, no comprehensive inventory of metrics applied to GSCM and SSCM is yet available. This is a significant gap given the growing recognition that sustainability impacts extend beyond the boundary of any one firm (Seuring and Gold, 2013). There is a need to expand the definition of corporate sustainability performance to account for these broad impacts. Moreover, the lack of frameworks to develop reasonably practical sets of metrics may contribute to the confusion and uncertainty regarding the 
appropriate scope in theory and practice of GSCM and SSCM initiatives. Research on metrics for GSCM and SSCM can therefore help guide the application of these concepts while also reinforcing the need to reframe measurements of traditional business performance to incorporate the supply chain.

Building on the above, the identification and analysis of the published metrics for GSCM and SSCM provides a strong basis for future academic and practitioner work. This would emphasize the need to develop a common understanding of what GSCM and SSCM entail, to develop consolidated sets of metrics that provide a basis for comparison of performance between supply chains, and to link metrics to the broader sustainability context in which supply chains operate. Also, there is a need for an important starting point for managers interested in measuring sustainability performance in their supply chains. For academics, there is a need to find common ground regarding the key areas to be measured in GSCM and SSCM. Based on the above, Objective 2 is therefore proposed as follows:

\section{Objective 2: Identify and analyze the published metrics for SSCM}

\subsection{Sustainability Measurement}

Sustainability is an expansive, complex and heavily debated topic (Wilkinson et al, 2001). Considering the ambiguity and vagueness that surrounds the definition of sustainability (WCED, 1987), there are complications when attempting to apply the principles of sustainability in practice. This is further highlighted by Spangenberg (2005) whom argued that, from a scientific point of view, it is highly unlikely to provide one comprehensive metric or index of sustainability that could satisfy all the requirements posed by different philosophies. Moreover, the literature shows that there is a major and insistent gap between the diffusion of sustainability discussions and its feasible applications (Hamdouch and Zuindeau, 2010).

Sustainability is viewed as a holistic and interdisciplinary approach encompassing environmental, economic and social issues at different scales (e.g., individual system, company, corporation or supply chain). As addressed earlier, sustainability has different interpretations ranging from an inter-generational philosophical stand to a multi-dimensional expression for business management. The inter-generational philosophy position concentrates on making sure 
that future generations will not be negatively impacted by decisions that are made today. The multi-dimensional view concentrates on balancing the environmental, economic, and social dimensions of sustainability. In this view, sustainability is considered to be more than an aggregation of the important subjects, it is about their interconnections and the dynamics developed within an organization or a supply chain (Yakovleva et al., 2012; Singh et al., 2012). The multidimensionality of sustainability is a characteristic that makes the search for appropriate measures to monitor sustainability performance very difficult (Bodini, 2012).

While plenty of research has been conducted on sustainability metrics (e.g., Bohringer and Jochem, 2007; Mayer, 2008; Tanguay et al., 2010), the published metrics are focused primarily on the regional or national levels (e.g., Mirshojaeian Hosseini and Kaneko, 2011; Ronchi et al., 2002) and there have been relatively few attempts to design metrics at the level of the individual system (e.g., supply chain), organization or corporation (Searcy, 2012). In cases where metrics have been developed (e.g., Krajnc and Glavic, 2005a, 2005b; Lindholm et al., 2007; Searcy et al., 2007; Singh et al., 2007; Dantsis et al., 2010), uncertainty has rarely been considered (Searcy, 2012). Moreover, although some of the developed metrics are accepted among different stakeholders, policy makers are generally not using the majority of them due to measurement, weighting and indicator selection problems (Singh et al., 2009). Furthermore, drawing on research by Lenzen et al. (2004) and Searcy (2012), the published studies on sustainability assessment metrics have generally focused on short time horizons, and little has been done to highlight the cumulative impacts required for the explicit long-term focus of sustainability. All of these issues highlight the demand for additional research on the subject.

\subsubsection{Assessing Sustainability Performance under the Strong Sustainability Perspective}

As emphasized earlier, given the wide variety of interpretations of the concept, there are complications when aiming to operationalize sustainability (Ahi and Searcy, 2013a). Accordingly, providing one comprehensive sustainability metric that could satisfy all the needs of different philosophies (e.g., weak and strong sustainability perspectives), is scientifically unrealistic (Spangenberg, 2005). In this light, the development and use of tools that can appropriately quantify how sustainably human-industrial activities are dealing with flows of natural resources (e.g., energy and material) from and to the ecosystem, is still quite challenging 
(Eckelman, 2010; Schaubroeck et al., 2012). Accordingly, it is increasingly apparent that economic measures and standard sustainability measures fall short in their ability to deal with global ecological problems (Heuting and Reijnders, 2004).

Numerous activities are being undertaken that threaten environmental integrity, which often further pressure companies that are near or beyond their capacity to function sustainably (Wilson et al., 2007). As emphasized by the Rio de Janeiro Declaration on Environment and Development (1992), people's needs and aspirations must be balanced with healthy ecological systems. To address this challenge, models for measuring sustainability must more explicitly address the fundamental importance of environmental issues at all levels of society, including individual companies (Kuan et al., 2013). This is further supported by the green economics paradigm, which recognizes that the economy operates within social relationships that are embedded in nature (Cato, 2009). Societies cannot continue indefinitely with a deteriorating environment and natural resources. Signs of a deteriorating environment abound, with global warming, ozone layer depletion and ocean pollution among the prominent examples. Increasingly, decreases in natural capital are signifying possible economic impairments for all societies. As noted by Pearce (1988, P. 599), “constancy of natural capital or more specifically, the non-negativity of the rate of change in the natural capital relates probabilistically to sustainability”. Deteriorating natural resources may therefore be correlated with declines in sustainability at all levels of society, and hence, environmental sustainability is deemed to be a crucial subject of concern in the current century (Kuan et al., 2013). This would highlight the need for research on methods of measuring sustainability that adopt the strong sustainability concept at all levels of society, including individual companies.

While meaningful contributions have been made in an attempt to address strong sustainability, the existing metrics suffer from a number of weaknesses and limitations. A drawback for existing metrics is that the spatial information of the EF and biocapacity, as well as the spatial heterogeneity of natural capital and land use, are often excluded from the data reported in regional or national statistics (Erb, 2004). Also, the required data is often obtained through a variety of different sources with various quality standards. The regional and national figures are usually reported at a common resolution for political use and, hence, they might not be applicable for biocapacity evaluation at the precision level required for policy making at regional 
scales (Mayer, 2008). Moreover, the EF and SB concepts cannot signify the full range of environmental issues. Nature does not have significant absorptive capacity for many vital environmental problems (i.e., radioactive materials, pollution by heavy metals, persistent synthetic compounds) (Schaefer et al., 2006). Therefore, the substances without a considerable absorption or regenerative capacity are not fully accounted for the EF and biocapacity accounts. Similarly, those resources without a significant regenerative capacity are also not aligned with the concept of biologically productive area. For example, the biocapacity needed for sequestering $\mathrm{CO}_{2}$ emissions is considered in the SB related metrics, but the regeneration of the burnt fuel stocks are not often covered in the metrics (Nijkamp et al., 2004). Additionally, the EF and SB metrics are based on static analyses and hence they are lacking in predictive power (Rees, 2006). In light of the above, the EF and SB are generally viewed as being most useful when applied to the global level. However, there are challenges in applying them at other levels. Company level applications are particularly problematic since it is virtually impossible to assess the amount of land and water they have available for their use.

As mentioned earlier, a number of sustainability measurement tools (i.e., indicators, metrics, and indices) are available to assess sustainability performance at the company level. One of the challenges in measuring sustainability at this level is determining appropriate priorities (Searcy et al., 2008). The relevance and significance of corporate sustainability priorities can vary widely due to many factors, including variations in types of business, operational conditions, history, and other characteristics particular to a company. Generally, monetary benefits and expenditures, waste generation, resource usage (e.g., material, energy and water), emissions (e.g., toxic and pollutant), well-being of employees, and the interests of people in the communities affected by the company's operations are among the core sustainability aspects relevant to wide range of companies (Krajnc and Glavic, 2005b). However, although many lists of example metrics are available, there have been relatively few attempts to design sustainability metrics at the company level (Searcy, 2012).

Considering all of the above and building on discussions provided in Section 3.4, there remains a need for additional research on the measurement of sustainability at the company level (Azapagic, 2004). This is particularly needed given the prominent role focal firms play in the overall supply chain. There is a need for integrated assessment tools at the company level 
(Krajnc and Glavic, 2005b) that address the weaknesses noted above. This would emphasize the need for research on methods of measuring sustainability that adopt the strong sustainability concept at the level of individual companies. Based on the above, Objective 3 is therefore proposed as follows:

\section{Objective 3: Develop a mathematical model for assessing sustainability performance} under the green economics paradigm at the company level

\subsubsection{Assessing Sustainability Performance in the Supply Chain}

Over the past two decades, many organizations have taken steps to integrate the principles of sustainability into their long- and short-term decision-making. However, as highlighted earlier, sustainability is an issue that extends beyond the boundaries of any one firm (Seuring and Gold, 2013). To that end, there is a rapidly growing body of literature that focuses on the integration of sustainability with supply chain management (SCM). However, given the many players in a supply chain (e.g., suppliers, focal firm, distributors, retailers, customers, etc.), this is a more challenging issue than integrating sustainability into the operations of a single firm. Nevertheless, the increasing integration of sustainability into SCM demonstrates an evolving area where they exhibit explicit interactions. Accordingly, while the literature highlights a research bias toward practical measures as the means to address sustainability in supply chains, it does not offer a considerable number of tangible outputs (Ashby et al., 2012). Developing appropriate metrics and tools for the evolving field of SSCM is a challenging part of the research in this area. This was also emphasized by Hassini et al. (2012) who argued that there is a relative dearth of efforts on developing measures required for assessing sustainability in supply chains.

The essentially multidimensional nature of sustainability, embracing environmental, economic and social aspects as a minimum, requires simultaneous consideration of measures representing the various features of sustainability over time. Supply chains can simultaneously become more sustainable in some dimensions and less sustainable in others. It is also possible that supply chains may become volatile even if most related indicators are exhibiting improvements. Accordingly, it may be argued that focusing on sustainability will provide a basis for resolving the conflicts between the three areas of the triple bottom line and, in doing so, drive improved 
relationships and overall supply chain performance (Ozkul and Barut, 2009). Therefore, more research on the exchanges between conflicting sustainability objectives is required (Hahn et al., 2010). The fact that the sustainability objectives underlined in the TBL approach are not always mutually supportive is seldom recognized in the development of sustainability measures (Glock et al., 2012). An integrative sustainability framework is required to analyze the trade-offs among such objectives (e.g., reduction of emissions and material use, lessening income differentiation and unemployment, increase in life expectancy, educational achievement and life satisfaction) across all the involved channels in the supply chain(s) (Brandenburg et al., 2014).

The literature shows that there is a very strong dominance on addressing the environmental dimension of sustainability in a supply chain (e.g., Tan and Khoo, 2005; Hervani et al., 2005; Pishvaee and Razmi, 2012; Jaber et al., 2013). While the environmental aspect of sustainability forms the main foundation in the majority of the modeling approaches identified (Seuring, 2013; Brandenburg et al., 2014), it is important to acknowledge that there are a number of publications that address both the environmental and economic dimensions of sustainable supply chain performance (e.g., Khoo et al., 2001; Ukidwe and Bakshi, 2005; Ferretti et al., 2007; El Saadany et al., 2011; Wee et al., 2011; Abdallah et al., 2012; Zhang and Liu, 2013). However, very few approaches explicitly address the social dimension of sustainability (e.g., Sonesson and Berlin, 2003; Clift, 2003; Brent, 2005; H'Mida and Lakhal, 2007). Overall, although assessing sustainability in the supply chain has become an interesting research area in the academic literature (Shuaib et al., 2011; Brandenburg et al., 2014), the existing approaches rarely offer an integrated approach that takes the many different aspects of sustainability into consideration simultaneously (De Brito and Van der Laan, 2010; Hassini et al., 2012). Again, the concentration has been first on environmental issues and then on the combination of environmental and economic aspects, while the focus on the social features of sustainability (e.g., Hutchins and Sutherland, 2008) has been relatively limited (Seuring and Muller, 2008; Glock et al., 2012). This is further emphasized by Seuring (2013) and Brandenburg et al. (2014) who argued that the social aspect is almost completely missing or sometimes grasped in a far too simplified manner in the sustainability measurement studies. This argument is also supported by the wider literature reviews available (e.g., Srivastava, 2007; Seuring and Muller, 2008; Gold et al., 2010; Tang and Zhou, 2012), which also highlighted a lack of research on social features. 
Considering all of the discussions provided above, there is a clear requirement for developing integrative frameworks that take all sustainability features into account for assessing the sustainability level of supply chains. This is also supported by Seuring (2013) who emphasized that there is a clear research gap concerning the overall integration of the three sustainability dimensions of TBL. Furthermore, as emphasized by Brandenburg et al. (2014), there is a tangible need for stochastic modeling approaches to measuring sustainability in supply chains in order to take into account the complex and uncertain decision environments in which they operate. In this light, the current study aims to respond to these needs by developing integrative probabilistic models that adopt the TBL sustainability perspective as a minimum, and can be used as a practical tool for sustainability assessment of supply chains. Based on the above, Objective 4 is therefore proposed as follows:

Objective 4: Develop mathematical models for assessing sustainability performance in the supply chain 


\section{CHAPTER 4}

\section{RESEARCH APPROACH AND METHODOLOGY}

\subsection{Introduction}

To achieve the research objectives discussed in Chapter 3, a systematic approach was conducted. This approach is illustrated in Figure 4-1.

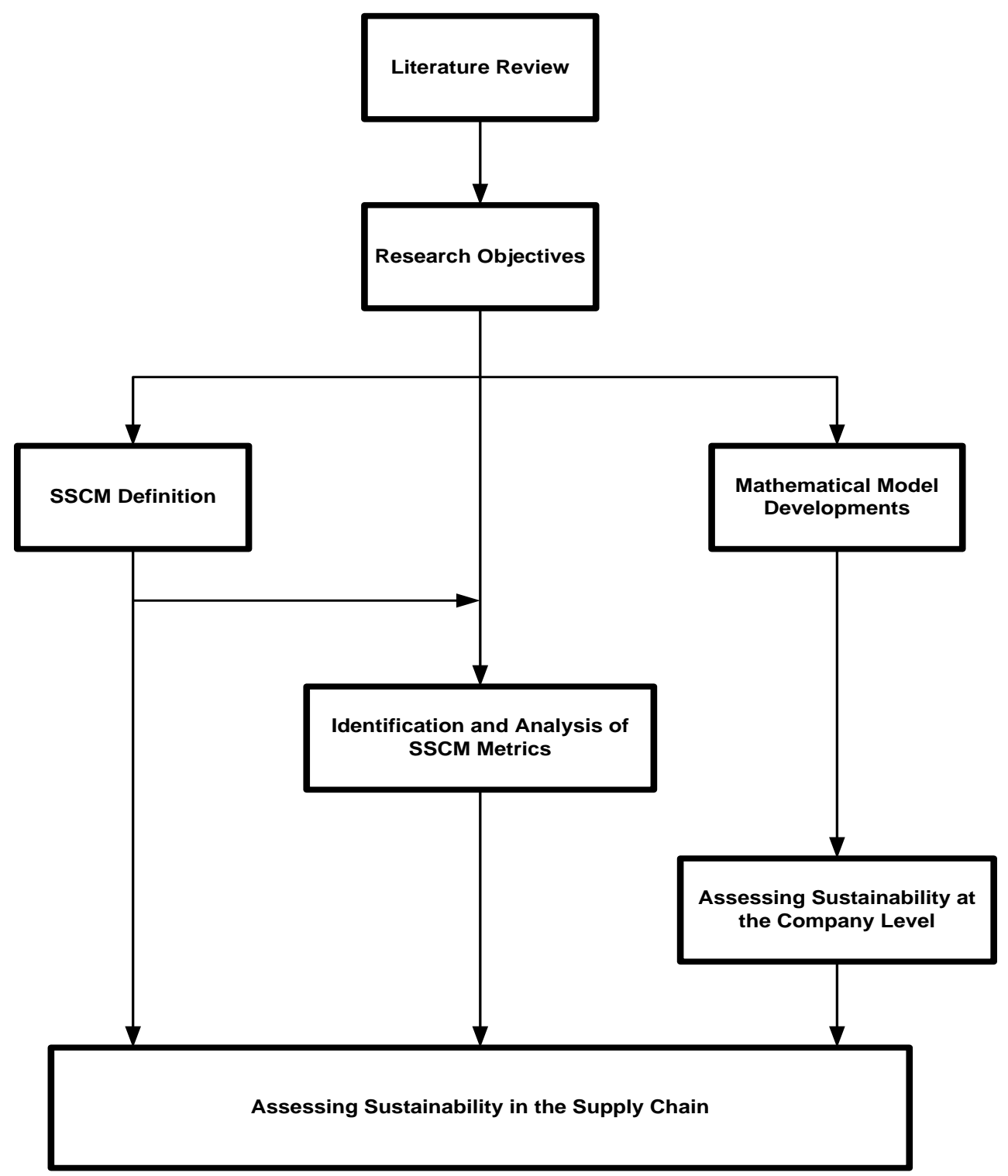

Figure 4-1: Structure of the conducted research 
Drawing on the information displayed in Figure 4-1, two different sets of systematic research literature reviews were conducted to achieve Objectives 1 and 2. Accordingly, details of each review will be discussed in Sections 4.2 and 4.3, respectively. Basic principles underlying the mathematical models developed in Objectives 3 and 4 will be discussed in detail in Section 4.4.

\subsection{Objective 1: Define SSCM}

The purpose of Objective 1 was to identify and analyze the definitions of GSCM and SSCM published in the peer-reviewed literature. This would provide a basis for the development of a new, comprehensive definition of SSCM. To achieve this purpose, a structured research literature review conducted. Tranfield et al. (2003) explained that literature reviews have dual purposes. First, the intellectual structure of an identified field needs to be mapped, consolidated and evaluated. Building on that work, the key knowledge gaps and opportunities to address them can be identified. The underlying rationale is to develop and expand the body of knowledge in the field. In this light, systematic literature reviews have been developed substantially over the last few decades and are currently playing a major role in evidence based practices (Tranfield et al., 2003). By adopting a scientific, imitable, and transparent process, systematic literature reviews can provide an appropriate audit track for decisions, procedures, and conclusions made by the reviewers (Cook et al., 1997).

Following the logics discussed above, the conducted literature review focused on a search of all articles published in the Scopus database. Scopus was selected due to its broad coverage of sustainability, supply chain, management, and engineering journals. The search was limited to articles published in English in peer-reviewed journals. Conference papers were excluded from the search. To identify the relevant articles, a structured keyword search was conducted. The method of a structured keyword search in databases and/or library services is the most common way to conduct a literature search on a particular subject (i.e., in this case GSCM and SSCM) and is used across several disciplines (Seuring and Gold, 2012). Accordingly, the terms "green supply chain management" and "sustainable supply chain management" were separately searched. The search for each of the keywords was conducted along with the terms "define”, “defining” and "definition” by utilizing the "All Fields" category. The data range was set for the papers published from “All years” to "Present” (i.e., January 31, 2012), and all of the "Subject 
Areas” available in Scopus were chosen for each of the conducted searches. References cited in the papers identified through the Scopus search were also used as secondary sources to identify additional relevant publications.

Each of the identified papers was searched to identify any explicit definitions of GSCM and SSCM. Statements were considered as definitions if they explicitly expressed the essential nature of GSCM or SSCM (adapted from Merriam-Webster, 2012). In cases where a definition was reproduced from another source, the original paper was considered the basis of the definition. Each unique definition was recorded in a spreadsheet along with the reference information of the article. Once the database of definitions was developed, each group of definitions (i.e., GSCM and SSCM) was carefully examined. Each definition was analyzed using a word-for-word content analysis (Krippendorf, 2004). Content analysis is a useful and efficient tool for performing systematic and transparent literature reviews (Seuring and Gold, 2012). The approach of conducting a keyword analysis and systematically reviewing the literature through a structured content analysis has been employed in a number of recent literature reviews on SCM topics (e.g.; Burgess et al., 2006; Seuring and Muller, 2008; Gold et al., 2010; Carter and Easton, 2011; Gold and Seuring, 2011; Delbufalo, 2012; Abbasi and Nilsson, 2012). Building on that approach, in this study, the key sustainability and SCM characteristics reflected in each published definition of GSCM and SSCM were identified and recorded. Once the analysis was completed, the results were examined in detail. The analysis provided the basis for the development of a new definition of SSCM. The database developed as a result of this process provided the basis for the analysis and discussion presented later in the research.

\subsection{Objective 2: Identify and Analyze the Published Metrics for SSCM}

To achieve this objective, a systematic research literature review was conducted to identify peerreviewed articles that focus on GSCM and SSCM. As emphasized earlier, systematic literature reviews are transparent, evidence-based activities (Tranfield et al., 2003) that clearly delineate the decisions, procedures, and conclusions made by those conducting the reviews (Cook et al., 1997). Literature reviews have been widely used for data collection and evaluation purposes in GSCM and SSCM research (e.g., Burgess et al., 2006; Seuring and Muller, 2008; Gold et al., 2010; Carter and Easton, 2011; Abbasi and Nilsson, 2012). 
Given the broad nature of the GSCM and SSCM concepts, the systematic literature review in this study applied several screening criteria to identify relevant articles. The systematic literature review focused on all peer-reviewed articles published in the English language in the Scopus database. As noted earlier, Scopus was selected because it provides a broad coverage of sustainability, supply chain, management, and engineering journals. Conference papers were excluded from the search. The screening of articles within Scopus was then based on a two-stage keyword search. The first sets of keywords were "green supply chain management" and "sustainable supply chain management". To identify articles within that sample that focused on performance measurement, the second set of keywords focused on a search for the terms of "metrics", "indicators", and "performance measures". The data range was set for the articles published from "All years" to "2012", inclusive. Additionally, the "All Fields" category as well as all of the "Subject Areas" available in Scopus were chosen for the search. References cited in the articles identified through the Scopus search were also used as secondary sources to identify additional relevant publications.

Using the procedures discussed above, a total of 354 articles were originally identified through the Scopus search. It was not possible to access 10 articles in the identified sample through either an online search or an interlibrary loan. Therefore, the total number of articles identified through the Scopus search was 344. All of the articles in this sample were carefully analyzed to identify the published metrics on GSCM and SSCM. Metrics were identified based on an application of the definitions provided in Section 2.4 (i.e., Sustainability Metrics). In most cases, the authors of the articles analyzed explicitly identified them through the use of the terms "metric", "indicator", or "measure". All metrics that were highlighted in charts, tables, figures, boxes, bulleted lists, numbered lists, bold characters, or italics characters were also recorded. In all cases, the exact wording of the metric, as it appears in the paper, was recorded. The source of each metric was also recorded. If the metric cited in the paper was drawn from another source, the original article was also examined and considered as the basis of the metric. This process led to identification and analysis of 101 additional publications (over and above those identified in the original Scopus search). The total number of sources examined in this study was therefore 445 (i.e., 344 $+101=445$ ). Accordingly, all citations to the original source of an identified metric were recorded to provide an accurate accounting for the frequency a metric appeared in the literature. 
This will yield a greater understanding of the popularity of the metrics cited. It is important to acknowledge that many of the identified metrics were similar. For example, two otherwise identical metrics may include the words "data base" and "database" or "use" and "usage" or "emissions" and "emissions of". To address these issues, each metric was analyzed using a wordfor-word content analysis (Krippendorf, 2004; Seuring and Gold, 2012). In cases where the metrics were essentially found the same, they were combined. All of the same metrics were then added to determine the frequency count.

In addition to computing the frequency counts, detailed analyses were conducted to determine the key features of the identified metrics. The rationale is that these analyses would provide a reasonable basis for determining the extent to which core sustainability and SCM issues were addressed by the metrics.

Finally, it should be noted that the metrics were also classified as to whether they were (1) quantitative or qualitative and (2) absolute, relative, or context-based metrics. Building on discussions provided in Section 2.4, for the purposes of this study, a quantitative metric is expressed as "the quantified and verifiable information used for quantitative assessment of measuring, comparing, or tracking performance of sustainability issues and objectives", while a qualitative metric is expressed as "the information used to evaluate perceptions, attitudes, and strategies that motivate progress toward sustainability objectives covering narrative description of important sustainability issues".

The conducted analysis provided the basis for the development of an original conceptual framework for measuring sustainability in supply chains.

\subsection{Objectives 3 and 4: Develop Mathematical Sustainability Models}

The core assumption of the models developed in this study is that there are several factors that either enable or hinder progress towards sustainability. A number of organization specific and operating environment specific factors can be drawn from the literature. For example, prominent organization specific factors could include the desire to reduce costs (Green et al., 1996; Handfield et al., 1997; Carter and Dresner, 2001; Walker et al., 2008), the management of risk (Green et al., 1996; Walker et al., 2008), the drive to improve quality (Handfield et al., 1997; Pil 
and Rothenberg, 2003), the desire to obtain ISO 14000 certification (Montabon et al., 2000), the level of employee involvement (Hanna et al., 2000; Carter and Dresner, 2001), the values of the organizational founder (Handfield et al., 1997;Wycherley, 1999; Walker et al., 2008), and investor pressure (Green et al., 1996; Trowbridge, 2001). Clearly, customer demands (Carter and Dresner, 2001), collaboration with suppliers (Klassen and Vachon, 2003), and the integration of the supply network (Vachon and Klassen, 2006; Walker et al., 2008) will also play important roles. Monitoring performance has also been widely identified as a key factor in this regard (Porter and Van de Linde, 1995; Carter et al., 2000; Melnyk et al., 2003; Gonzalez-Benito and Gonzalez-Benito, 2005; Chen, 2005; Rao and Holt, 2005; Walker et al., 2008). Key factors in the broader operating environment that may either enable or inhibit progress towards sustainability in the supply chain may include regulations (Green et al., 1996; Walton et al., 1998; Beamon, 1999b; Hall, 2001; Min and Galle, 2001; Zhu and Sarkis, 2006; Walker et al., 2008) and proactive action to prevent further regulation (Carter and Dresner, 2001; Bowen et al., 2001a, 2001b). Public pressure (Beamon, 1999b), competitive challenges (Lamming and Hampson, 1996; Sharma and Vredenburg, 1998; New et al., 2000; Sarkis, 2003; Noori and Chen, 2003; Ferguson and Toktay, 2006; Zhu and Sarkis, 2006; Walker et al., 2008), and the limits of the local and global environment (Rockstrom et al., 2009) are other representative examples. Many of these organization specific and operating environment specific factors could serve as either an enabler or an inhibitor of sustainability depending on how they are handled by the focal organization individually or as part of a supply chain.

Given the fact that not all relations identified in sustainability analysis will have similar relevance, weight and meaning, the involved supportive and hindering factors are all considered fundamentally context dependent. Furthermore, since it is difficult to determine the precise transition between states of sustainability and unsustainability in general, it is only possible to assess progress (or decline) towards sustainability, rather than struggle to describe the firm status of sustainability for organizations (Azapagic and Perdan, 2000). Additionally, decision makers require timely information, which reveals whether a company, organization, or a supply chain is generally becoming more or less sustainable (Foran et al., 2005). In light of the above and considering the fact that all potential supportive and hindering factors for sustainability are fundamentally context dependent, it can be argued that the prediction of being successful (or 
unsuccessful) in sustainability is essentially a probabilistic problem (Ahi and Searcy, 2013b). Accordingly, as utilization of probabilistic methods has been previously deemed to be a feasible and practical approach in sustainability analysis (Putzhuber and Hasenauer, 2010), this study argues that, the nondeterministic, variable characterization of sustainability functions can provide a realistic analytical model for sustainability assessments, and hence, probabilistic sustainability models are proposed. This line of argument is also in line with the findings of Brandenburg et al. (2014) who highlighted that there is a clear requirement for stochastic modeling approaches to measuring sustainability, particularly, in a supply chain context.

As emphasized earlier, the underlying assumption in the current study is that there are factors that enable and inhibit progress towards sustainability. Accordingly, it is conceptualized that any organization will have certain challenge-resisting capacity. In this view, the enabler factors support the organization's competence by strengthening the capability of the organization to move towards sustainability. The barrier factors cause challenges to the organization, and/or reduce the strength of the organization to withstand such challenges. If the organization's capacity (strength) exceeds the challenges (stresses) that are induced by the presented barriers, the organization under consideration will exhibit sustainability. Otherwise, it will regress from sustainability. Figure 4-2 illustrates the framework underlying the development of the proposed models. 


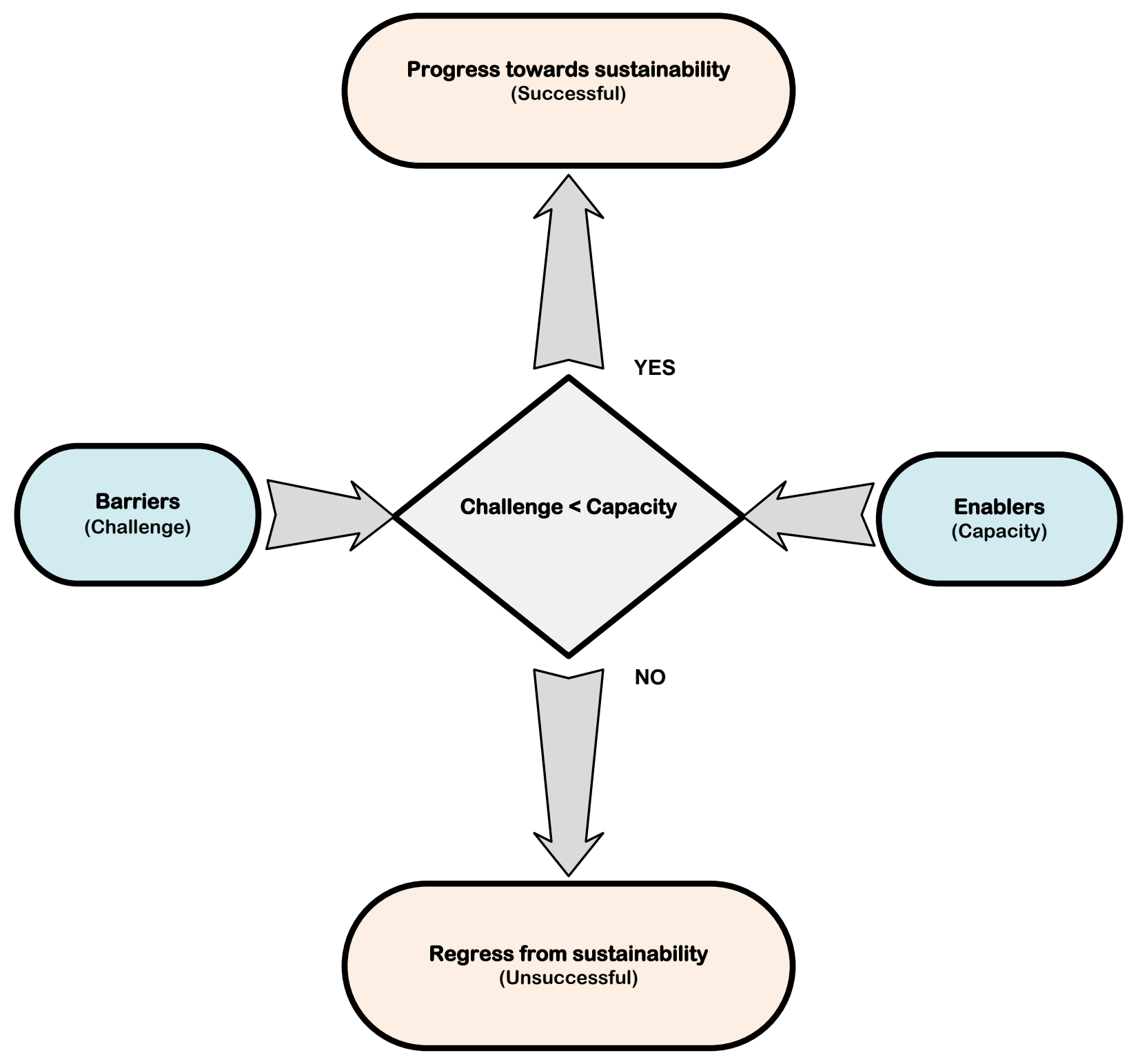

Figure 4-2: Framework for construction of the proposed sustainability models

Building on discussions provided above, identifying and understanding the potential enabler and barrier factors are important for the development of the proposed sustainability models. These enablers and barriers will vary from organization to organization, but it is possible to offer several representative examples. Using renewable energy, recycling chemicals, reusing process water (e.g., for cooling), increasing return on average capital employed, customer satisfaction, and contributions to local and national employment are some examples of the enabling factors that may support an organization's capacity. On the other hand, emissions of $\mathrm{CO}_{2}$, ozone 
depleting substances, acid gases, toxic materials, waste yield, fines and penalties paid for noncompliances with all the involved legal requirements, customer complaints, and work interruptions due to lost-time injuries as result of work related accidents, are some examples of potential barriers to sustainability and therefore impose challenges on the organization.

According to the framework illustrated in Figure 4-2, an organization will be considered successful when its capacity surpasses the imposed challenges. In other words, the sustainability of an organization will be an estimation of the ability of the organization under consideration to withstand challenges imposed by the presented barriers. Therefore, in the proposed models, the organization is considered sustainable (or successful to be sustainable) if and only if the challenge(s) imposed on it do not exceed the organization's capacity. The challenge represents an aggregate of the obstacles and barriers, which can be analyzed probabilistically by treating challenges as random variables. Rate of non-renewable energy used relative to the total energy consumption, total waste yield as a proportion of the amount of non-saleable products relative to the total amount of materials used, disposal rate of hazardous solid wastes, and rate of waste chemicals not used by (both) internal and external sources highlight potential environmental challenges to the organization. Potential economic challenges could be represented by the ratio of faulty orders and/or orders received with damage or defected products over the total orders issued, and rate of non-compliance-related penalties paid relative to the total obtained revenue, while the percentage of work interruptions due to lack of the required trainings and/or work related accidents and the rate of customer complaints and/or dissatisfaction could represent potential social challenges to the organization. Capacity is also treated as a random variable and represents effects of all states and conditions affecting the organization's competence. Again, many possibilities for example indicators exist and the indicators selected for any particular organization must address the unique requirements of that organization. The level of recycled or re-used packaging relative to the total amount of packaging, rate of water recycled and reused (e.g., cooling, waste and rain water) relative to the total water withdrawn from the source, percentage of residual hazardous materials (RHMs) diverted from landfill (i.e., all highlighting environmental issues), total costs of employment as a proportion of net sales, ratio of green purchases (i.e., environmental-friendly material and/or products) over the total purchases made, proportion decrease in total cycle time (i.e., all highlighting economic issues), community 
donations as percentage of domestic pre-tax profits, rate of employment sourced from local communities, rate of customer satisfaction, and percentage increase in environmental, health and safety, and skill related trainings (i.e., all highlighting social issues) can be some representations for the supporting factors towards an organization's sustainability. Many of these example sustainability indicators for both capacity and challenge factors are typically reported in publicly available corporate sustainability reports, though some further work may be necessary in order to translate them into numbers that can be used in a probabilistic model.

Building on principles and assumptions discussed above, Objective 3 aims to develop a comprehensive approach for the measurement of a company's sustainability performance by adopting the strong sustainability concept. Accordingly, a range of indicators rooted explicitly in the strong sustainability concept will be utilized. To demonstrate the application of the developed sustainability model, a case study that is based on publicly available data for several key relevant indicators will be presented.

By expanding the model developed and applied in Objective 3, an integrative sustainability performance framework for a broader context of supply chain will be developed in Objective 4. Accordingly, by taking as many characteristics as may be involved in SSCM, the sustainability models developed in Objective 4 can be employed as practical tools for sustainability assessment of supply chains.

Furthermore, it is necessary to emphasize that in the current study, simplicity, ease of use and the ability to quickly provide feedback on sustainability status, are the basic principles considered as prerequisites for the development of the proposed sustainability models. 


\section{CHAPTER 5}

\section{DEFINING SUSTAINABLE SUPPLY CHAIN MANAGEMENT (SSCM)}

\subsection{Introduction}

The purpose of this chapter is to first investigate and highlight the key characteristics of business sustainability and SCM, and then to identify and analyze the published definitions of GSCM and SSCM. This is accomplished through a structured keyword search for the relevant articles published in the Scopus database. The details of the systematic research literature review conducted on identifying definitions for GSCM and SSCM were provided in Chapter 4 (i.e., Research Approach and Methodology). Following the identification of the published GSCM and SSCM definitions, an analysis of the results will be carried out through a comparison of the identified definitions against each other and against the key characteristics of both business sustainability and SCM. The analysis will help highlight the convergences and divergences in the literature as well as the strengths and weaknesses of the existing definitions. The analysis also

provides the basis for the development of a new definition for SSCM. This will provide a reference point for future research in the GSCM and SSCM areas.

The structure of this chapter is organized as follows. The discussions of the key characteristics of business sustainability and SCM are provided in the next two sections, respectively. The results of systematic literature search on the published definitions for GSCM and SSCM are presented in Section 5.4. A detailed analysis of the published definitions of GSCM and SSCM are discussed in Section 5.5. Building on the provided analysis, a new comprehensive definition for SSCM is presented and discussed in Section 5.6. The chapter closes with a conclusion in Section 5.7 .

\subsection{Key Characteristics of Business Sustainability}

As mentioned earlier, sustainability issues are receiving increased attention among businesses. Business sustainability initiatives are often conducted under a variety of titles, with "corporate sustainability” (Steurer et al., 2005) being among the most prominent. Business sustainability 
initiatives are often closely associated with "corporate social responsibility (CSR)” initiatives. In fact, although there are those who would argue against the practice, sustainability and CSR are often used as synonyms in a corporate context (Van Marrewijk, 2003). An analysis of definitions of corporate sustainability, business sustainability, and CSR shows that they share a number of key features.

Table 5-1 presents a representative summary of definitions for these terms. The definitions were identified based on a scan of the literature and the list should be viewed as illustrative rather than comprehensive. Although analyses of definitions for CSR have been published (e.g., Dahlsrud, 2008), no compilations of definitions for these terms were found. The definitions in Table 5-1 show that sustainability issues in a corporate context should focus on an integrated perspective of the triple bottom line, focus on addressing the needs of key stakeholders, and adopt a long-term perspective. The need to build resilient organizations is also highlighted, as is the voluntary nature of many business sustainability initiatives. Building on the analysis in Table 5-1, the key characteristics of business sustainability may therefore be expressed as: (1) economic focus, (2) environmental focus, (3) social focus, (4) stakeholder focus, (5) volunteer focus, (6) resilience focus, and (7) long-term focus. These characteristics are consistent with a previous analysis of 37 definitions of CSR, which identified the five key CSR dimensions as stakeholder, social, economic, voluntariness, and environmental (Dahlsrud, 2008). Also, Table 5-1 includes a set of notes explaining how each characteristic was interpreted in the analysis. 
Table 5-1: Representative definitions of business sustainability

\begin{tabular}{|c|c|c|c|c|c|c|c|c|}
\hline \multirow[b]{2}{*}{ Definition Source } & \multirow[b]{2}{*}{ Definition } & \multicolumn{7}{|c|}{ Characteristics Exhibited* } \\
\hline & & 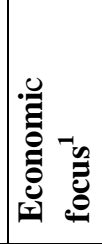 & 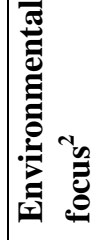 & | & 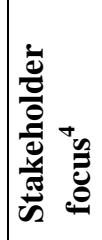 & 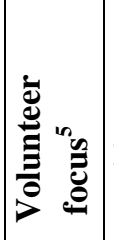 & 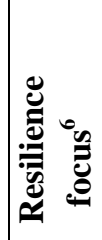 & 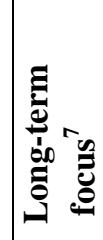 \\
\hline IISD, 1992, p. 11 & $\begin{array}{l}\text { For the business enterprise, sustainable development means adopting business strategies and } \\
\text { activities that meet the needs of the enterprise and its stakeholders today while protecting, } \\
\text { sustaining, and enhancing the human and natural resources that will be needed in the future. }\end{array}$ & 口 & 口 & 口 & - & & & 口 \\
\hline $\begin{array}{l}\text { Dyllick and Hockerts, 2002, } \\
\text { p. } 131\end{array}$ & $\begin{array}{l}\text { Corporate sustainability can accordingly be defined as meeting the needs of a firm's direct and } \\
\text { indirect stakeholders (such as shareholders, employees, clients, pressure groups, communities } \\
\text { etc), without compromising its ability to meet the needs of future stakeholders as well. }\end{array}$ & & & & 口 & & & $\square$ \\
\hline $\begin{array}{l}\text { Van Marrewijk, 2003, p. } \\
102\end{array}$ & $\begin{array}{l}\text { In general, corporate sustainability and, CSR [corporate social responsibility] refer to company } \\
\text { activities - voluntary by definition - demonstrating the inclusion of social and environmental } \\
\text { concerns in business operations and in interactions with stakeholders. This is the broad - some } \\
\text { would say "vague" - definition of corporate sustainability and CSR. }\end{array}$ & $\boldsymbol{\square}$ & $\boldsymbol{\square}$ & $\boldsymbol{\square}$ & 口 & - & & \\
\hline $\begin{array}{l}\text { Caldelli and Parmigiani, } \\
\text { 2004, p. } 159\end{array}$ & $\begin{array}{l}\text { The approach to CS [corporate sustainability] implies integration of criteria of economic, social } \\
\text { and environmental performance (referring to the triple bottom line: people, planet, profit) in } \\
\text { company's decision-making processes. To the above aspects we add a fourth dimension, that of } \\
\text { principles: every firm is by definition guided by a system of values, which determines its } \\
\text { context and orientation. }\end{array}$ & 口 & $\square$ & 口 & - & & & \\
\hline Steurer et al., 2005, p. 274 & $\begin{array}{l}\text { While SD [sustainable development] is commonly perceived as societal guiding model, which } \\
\text { addresses a broad range of quality of life issues in the long term, CS [corporate sustainability] is } \\
\text { a corporate guiding model, addressing the short- and long-term economic, social and } \\
\text { environmental performance of corporations. }\end{array}$ & 口 & 口 & 口 & & & & 口 \\
\hline Bansal, 2010, p. 1 & $\begin{array}{l}\text { Business sustainability } n \text {. the creation of resilient organizations through integrated economic, } \\
\text { social and environmental systems. }\end{array}$ & घ & घ & घ & & & $\mathbf{\square}$ & \\
\hline $\begin{array}{l}\text { Slawinski and Bansal, 2010, } \\
\text { p. } 1\end{array}$ & $\begin{array}{l}\text { We define business sustainability as the ability of firms to respond to short-term financial, } \\
\text { social and environmental demands, without compromising their long-term financial, social and } \\
\text { environmental performance. }\end{array}$ & $\mathbf{\square}$ & E & 口 & & & & \\
\hline
\end{tabular}




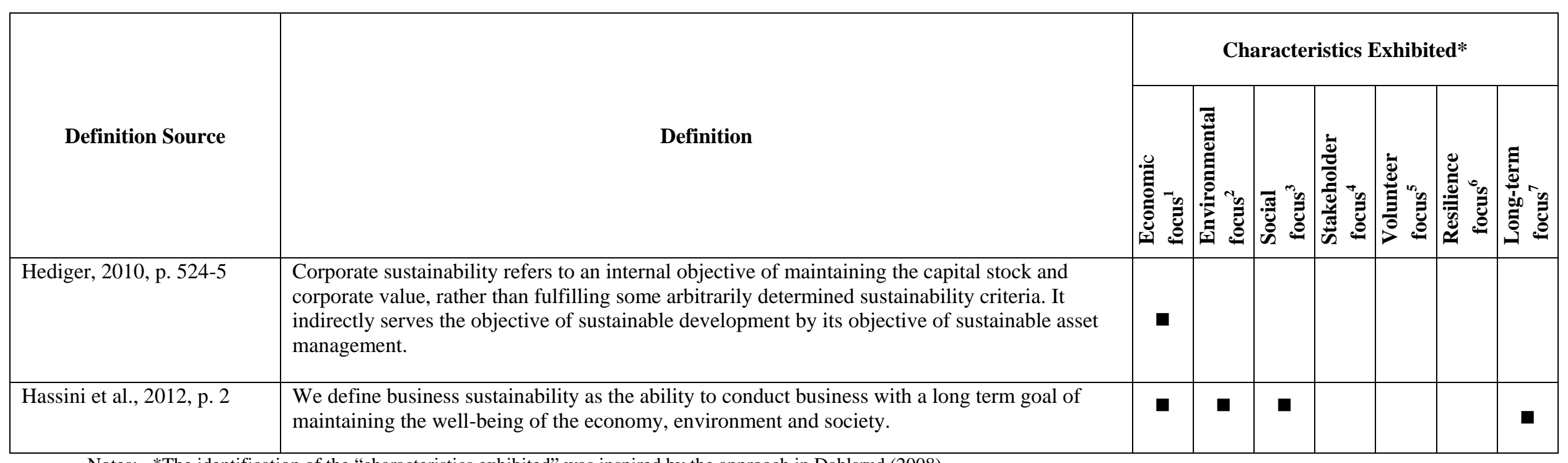

Notes: *The identification of the "characteristics exhibited" was inspired by the approach in Dahlsrud (2008).

${ }^{1}$ Economic focus: The definition includes language related to the economic dimension of sustainability.

${ }^{2}$ Environmental focus: The definition includes language related to the environmental dimension of sustainability.

${ }^{3}$ Social focus: The definition includes language related to the social dimension of sustainability.

${ }^{4}$ Stakeholder focus: The definition includes explicit reference to stakeholders, including (but not limited to) customers, consumers, and suppliers.

${ }^{5}$ Volunteer focus: The definition includes reference to the voluntary nature of business sustainability.

${ }^{6}$ Resilience focus: The definition includes reference to resilience, defined as "an ability to recover from or adjust easily to misfortune or change" (Merriam-Webster, 2012).

${ }^{7}$ Long-term focus: The definition includes reference to the long-term nature of sustainability. Reference to the future or the long-term was taken as indications of a longterm focus. 


\subsection{Key Characteristics of SCM}

The growing interest in SCM over the years, has led to the development of numerous definitions to describe SCM in several disciplines (Charvet et al., 2008). Building on discussions provided in Section 2.3 (i.e., Overview of Supply Chain Management), a summary of representative definitions for SCM is presented in Table 5-2. These definitions have been collected through a scan of literature and are presented chronologically. As with the definitions for business sustainability, the list should be viewed as illustrative rather than comprehensive. An analysis of the definitions in Table 5-2 shows that there are a number of themes associated with the concept of SCM. The definitions highlight that SCM is focused on managing flows of materials, services, and information within and between firms. The scope of SCM is thus widely recognized to be very broad. In order to manage these activities, there is a clear emphasis on the need to coordinate an extensive series of activities within and between firms. This is supported by the fact that "more and more organizations are coordinating multiple flows with other organizations in their supply chain because coordination tremendously increases the overall efficiency of the supply chain” (Singhal and Singhal, 2012, p. 240). Additionally, an emphasis on meeting stakeholder needs, particularly those of customers, feature prominently in the definitions. The management of internal and external relationships also features prominently. Accordingly, Chen and Paulraj (2004, p. 121) suggested that "the business world is composed of a network of interdependent relationships developed and fostered through strategic collaboration with the goal of deriving mutual benefits”. The key outcomes of these activities are to create value, improve efficiency, and improve overall performance in the supply chain. Based on an analysis of the SCM definitions summarized in Table 5-2, the key characteristics of SCM may thus be expressed as: (1) flow focus, (2) coordination focus, (3) stakeholder focus, (4) relationship focus, (5) value focus, (6) efficiency focus, and (7) performance focus. There is also a set of notes in Table 2-2 that explain how each characteristic was interpreted in the analysis. 
Table 5-2: Representative definitions of supply chain management

\begin{tabular}{|c|c|c|c|c|c|c|c|c|}
\hline \multirow[b]{2}{*}{ Definition Source } & \multirow[b]{2}{*}{ Definition } & \multicolumn{7}{|c|}{ Characteristics Exhibited* } \\
\hline & & 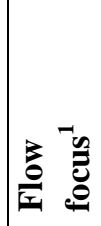 & 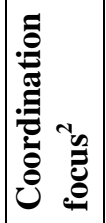 & 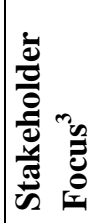 & 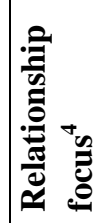 & 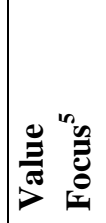 & 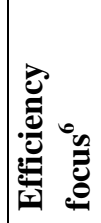 & 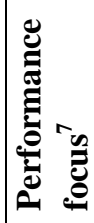 \\
\hline Lambert et al., 1998, p. 1 & $\begin{array}{l}\text { The integration of key business processes from end-user through original suppliers that provide } \\
\text { products, services, and information that add value for customers and other stakeholders. }\end{array}$ & a & $\boldsymbol{\square}$ & $\boldsymbol{\square}$ & & $\mathbf{\square}$ & & \\
\hline $\begin{array}{l}\text { Larson and Rogers, 1998, p. } \\
2\end{array}$ & $\begin{array}{l}\text { The coordination of activities, within and between vertically linked firms, for the purpose of } \\
\text { serving end customers at a profit. }\end{array}$ & & $\mathbf{\square}$ & 口 & & $\mathbf{\square}$ & & \\
\hline $\begin{array}{l}\text { Walters and Lancaster, } \\
\text { 2000, p. } 160\end{array}$ & $\begin{array}{l}\text { The management of the interface relationships among key stakeholders and enterprise functions } \\
\text { that occur in the maximization of value creation which is driven by customer needs satisfaction } \\
\text { and facilitated by efficient logistics management. }\end{array}$ & & & $\boldsymbol{\square}$ & & $\mathbf{\square}$ & $\mathbf{\square}$ & \\
\hline Mentzer et al., 2001, p. 18 & $\begin{array}{l}\text { The systemic, strategic coordination of the traditional business functions and the tactics across } \\
\text { these business functions within a particular company and across businesses within the supply } \\
\text { chain, for the purposes of improving the long-term performance of the individual companies } \\
\text { and the supply chain as a whole. }\end{array}$ & & $\mathbf{\square}$ & $\boldsymbol{\square}$ & & & & \\
\hline Lummus et al., 2001, p. 428 & $\begin{array}{l}\text { All the activities involved in delivering a product from raw material through to the customer, } \\
\text { including sourcing raw materials and parts, manufacturing and assembly, warehousing and } \\
\text { inventory tracking, order entry and order management, distribution across all channels, delivery } \\
\text { to the customer, and the information systems necessary to monitor all of these activities. }\end{array}$ & $\mathbf{\square}$ & $\mathbf{\square}$ & $\mathbf{\square}$ & & & & \\
\hline Elmuti, 2002, p. 49 & $\begin{array}{l}\text { The manufacturers, suppliers, transporters, warehouses, retailers, and customers are involved in } \\
\text { a dynamic but constant flow of information, products, and funds. The suppliers and distributors } \\
\text { that were once adversaries are now becoming partners for the betterment of both corporations. } \\
\text { Managing the chain of events in this process is called SCM. }\end{array}$ & $\mathbf{\square}$ & $\mathbf{\square}$ & $\mathbf{\square}$ & & & & \\
\hline Heikkila, 2002, p. 749 & $\begin{array}{l}\text { A set of practices aimed at managing and coordinating the supply chain from raw material } \\
\text { suppliers to ultimate customers. }\end{array}$ & - & $\mathbf{\square}$ & $\mathbf{\square}$ & & & & \\
\hline Gibson et al., 2005, p. 22 & $\begin{array}{l}\text { Encompassing the planning and management of all activities involved in sourcing and } \\
\text { procurement, conversion, demand creation and fulfilment, and all logistic management } \\
\text { activities. }\end{array}$ & & $\square$ & & & & & \\
\hline
\end{tabular}




\begin{tabular}{|c|c|c|c|c|c|c|c|c|}
\hline \multirow[b]{2}{*}{ Definition Source } & \multirow[b]{2}{*}{ Definition } & \multicolumn{7}{|c|}{ Characteristics Exhibited* } \\
\hline & & $\frac{\sqrt{1}}{3} \underbrace{0}_{0}$ & $\begin{array}{ll}0 \\
0\end{array}$ & 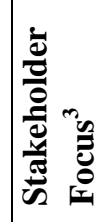 & 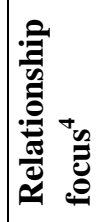 & مإِ & 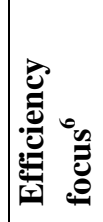 & 总 \\
\hline Eng, 2005, p. 4 & $\begin{array}{l}\text { Managing the inputs of goods or services including a range of activities not only within a single } \\
\text { department in an organization but also from different departments and outside the organization, } \\
\text { for final users from procurement of raw materials through to the end of the products' useful life. }\end{array}$ & $\mathbf{\square}$ & $\mathbf{\square}$ & $\mathbf{\square}$ & $\mathbf{\square}$ & & & \\
\hline $\begin{array}{l}\text { Stock and Boyer, 2009, } \\
\text { p.706 }\end{array}$ & $\begin{array}{l}\text { The management of a network of relationships within a firm and between interdependent } \\
\text { organizations and business units consisting of material suppliers, purchasing, production } \\
\text { facilities, logistics, marketing, and related systems that facilitate the forward and reverse flow } \\
\text { of materials, services, finances and information from the original producer to final customer } \\
\text { with the benefits of adding value, maximizing profitability through efficiencies, and achieving } \\
\text { customer satisfaction. }\end{array}$ & $\mathbf{\square}$ & घ & घ & घ & घ & घ & \\
\hline Xu, 2011, p. 183 & $\begin{array}{l}\text { A set of synchronised activities for integrating suppliers, manufacturers, transporters, and } \\
\text { customers efficiently so that the right product or service is delivered at the right quantities, at } \\
\text { the right time, to the right places. }\end{array}$ & & 口 & घ & & & घ & $\mathbf{\square}$ \\
\hline Ashby et al., 2012, p. 502 & $\begin{array}{l}\text { Fundamentally a practical discipline which focuses on products and processes and the } \\
\text { links/relationships that facilitate these. }\end{array}$ & $\boldsymbol{\square}$ & & & $\square$ & & & \\
\hline
\end{tabular}

Notes: *The identification of the "characteristics exhibited" was inspired by the approach in Stock and Boyer (2009).

${ }^{1}$ Flow focus: The definition includes language related to the flows of materials, services, or information. Reference to the supply chain was considered to implicitly refer to this focus area.

${ }^{2}$ Coordination focus: The definition includes reference to coordination within the organization or between organizations. Reference to the supply chain or the product life cycle was considered to implicitly refer to this focus area.

${ }^{3}$ Stakeholder focus: The definition includes explicit reference to stakeholders, including (but not limited to) customers, consumers, and suppliers.

${ }^{4}$ Relationship focus: The definition includes reference to the networks of internal and external relationships. This includes mentioning the coordination of interorganizational business processes.

${ }^{5}$ Value focus: The definition includes reference to value creation, including increasing profit or market share and converting resources into usable products.

${ }^{6}$ Efficiency focus: The definition includes reference to efficiency, including a reduction in inputs.

${ }^{7}$ Performance focus: The definition includes reference to performance, including applying performance measures, improving performance, improving competitive capacity, monitoring, and achieving goals. 
The characteristics summarized in Table 5-2 are broadly consistent with a previous analysis of 173 definitions of SCM, which identified the three major SCM themes as activities, benefits, and constituents/components, as well as six associated sub-themes: material/physical, finances, services and information flows; networks of relationships (internal and external); value creation; creates efficiencies; customer satisfaction; and constituents or components (Stock and Boyer, 2009, p. 698). Furthermore, the key SCM characteristics suggested above are also broadly in line with the findings in Burgess et al. (2006). Based on a systematic analysis of 100 randomly selected refereed journal articles in the SCM field, Burgess et al. (2006) identified the key themes in SCM as leadership, intra-and inter-organizational relationships, logistics, process improvement orientation, information system, and business results and outcomes.

SCM shares the stakeholder focus with the concept of business sustainability. There is also a growing effort to incorporate the other characteristics of sustainability into SCM. This is reflected in ongoing research on GSCM and SSCM. However, the many published definitions of GSCM and SSCM have yet to be systematically analyzed to determine the extent to which they address the characteristics of both business sustainability and SCM. The remainder of this study focuses on this issue.

\subsection{Results of Systematic Literature Search}

As of January 31, 2012, a total of 124 papers for "green supply chain management" and 56 papers for "sustainable supply chain management" were identified in the Scopus search. Figure 5-1 shows a distribution of the published articles by year over a range of 10 years between 2002 and 2012. Figures 5-2 and 5-3 show the distribution of reviewed articles by journal for GSCM and SSCM, respectively. The figures highlight the multidisciplinary approach required in a systematic literature review (Tranfield et al., 2003; Burgess et al., 2006). As shown in the figures, the journals cover a wide range of core topic areas, with an emphasis on sustainability, production, operations, strategy, business, and supply chain management. The wide variety of journals found to be addressing definitions of GSCM and SSCM, illustrates the diversity of approaches that can be taken in order to research the same subjects (Tranfield et al., 2003; Burgess et al., 2006). 


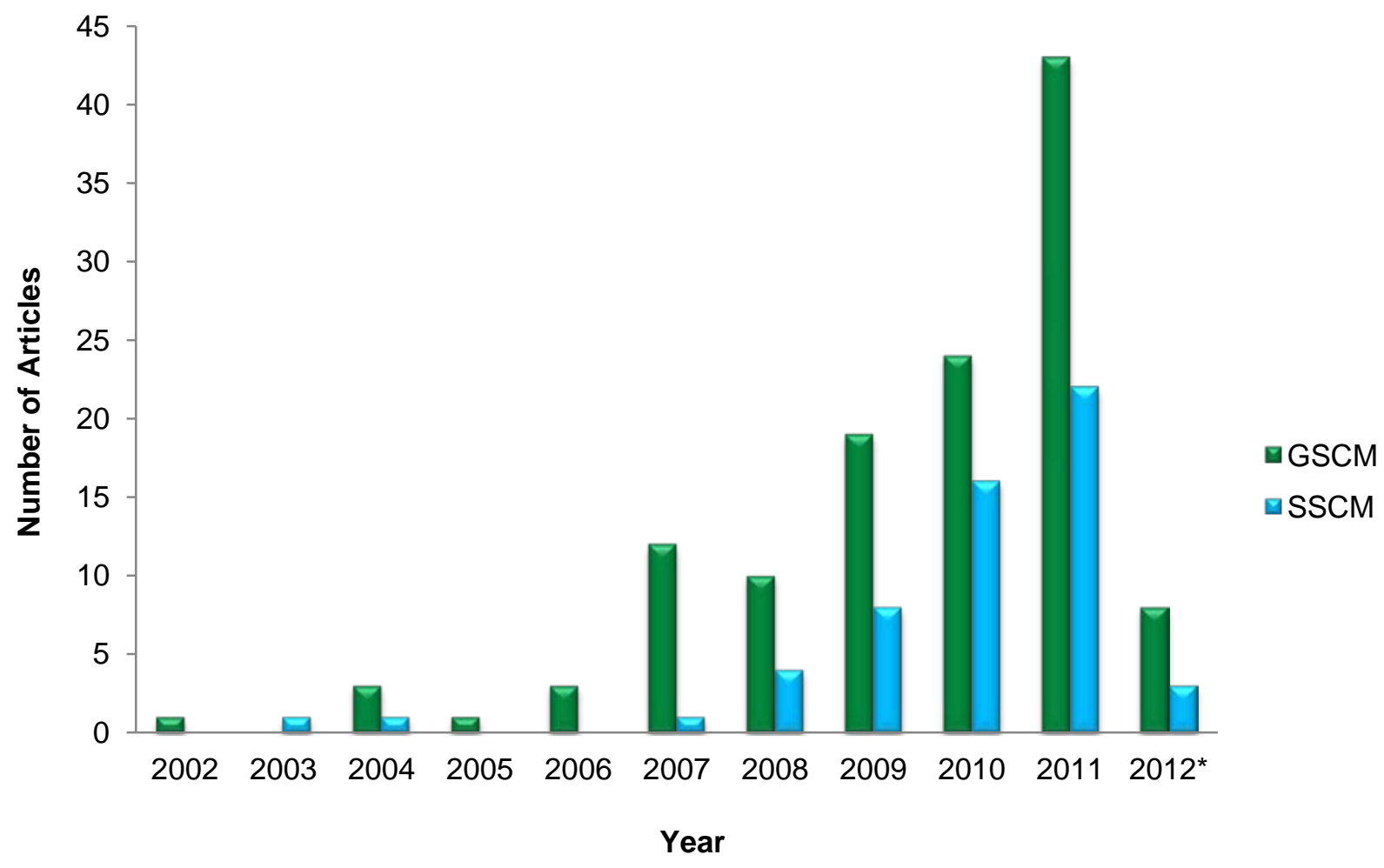

Note: *Data for the year 2012 includes articles published up to January 31th

Figure 5-1: Distribution of the articles reviewed 


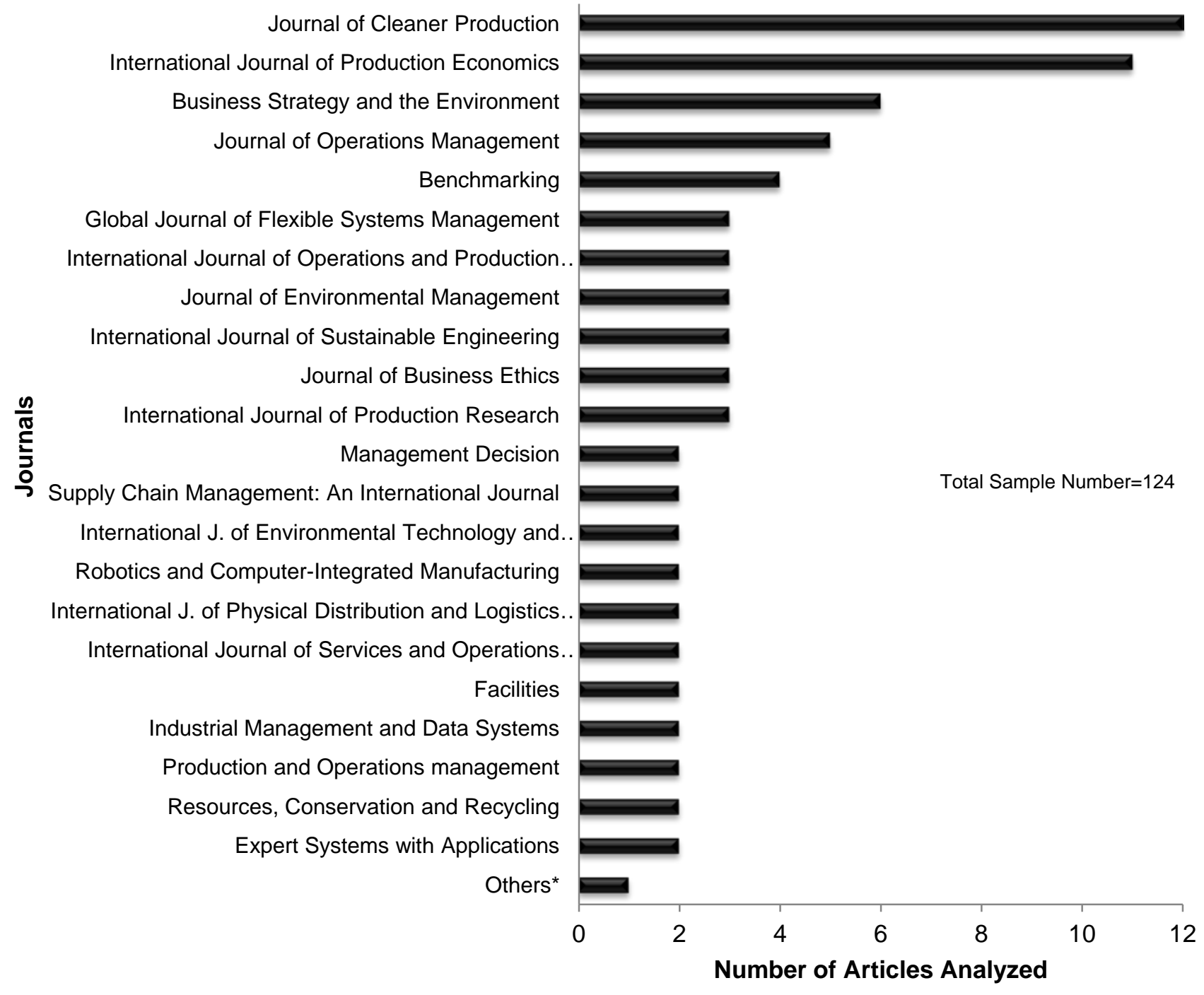

Note: *The remaining journals published only one relevant paper

Figure 5-2: Distribution of the articles analyzed for GSCM definitions 


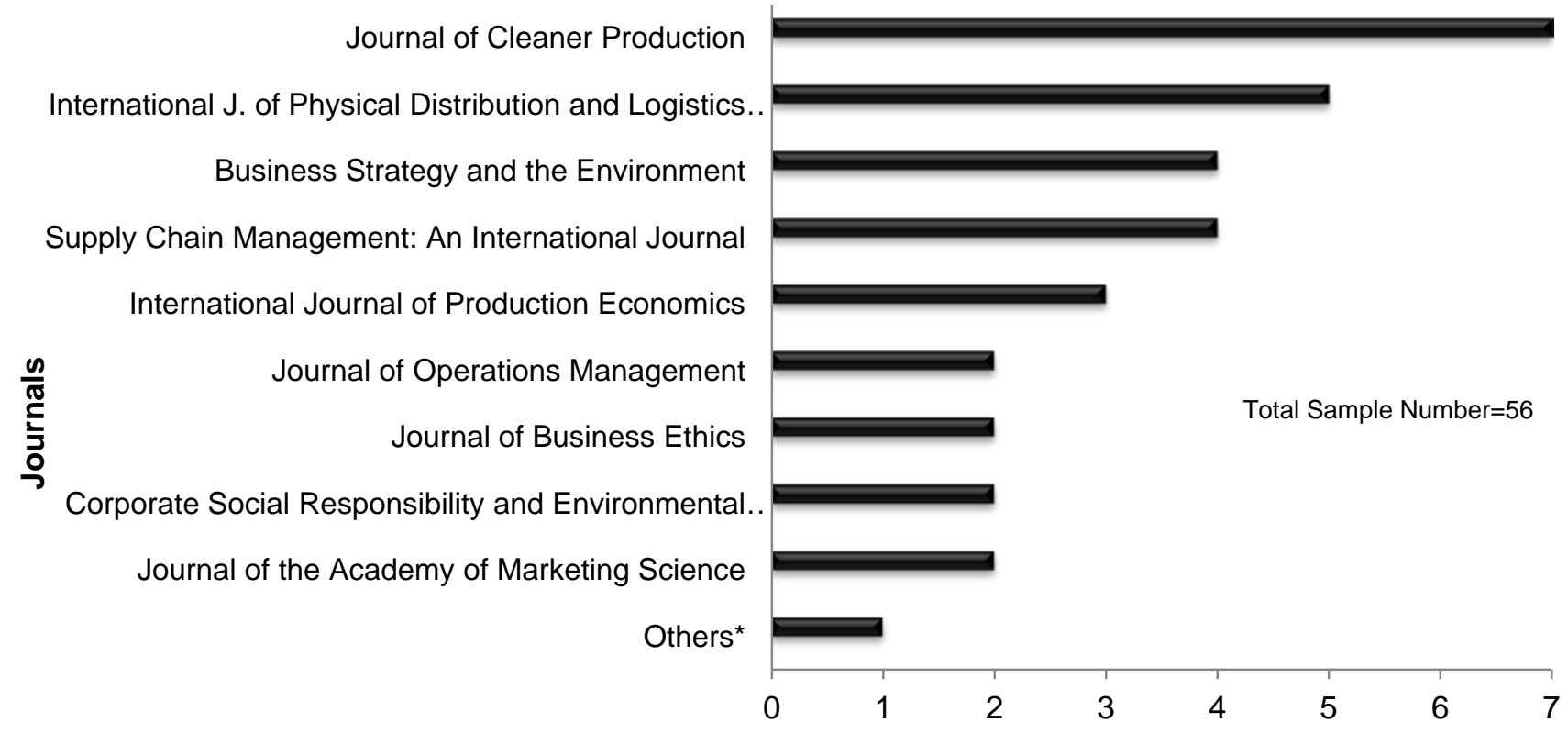

Number of Articles Analyzed

Note: *The remaining journals published only one relevant paper

Figure 5-3: Distribution of the articles analyzed for SSCM definitions

It should be noted that the literature review conducted in this study was extensive, but not exhaustive. While Scopus provides broad coverage of the academic literature, it does not cover every peer-reviewed publication and, hence, it is possible that relevant papers on GSCM or SSCM were missed. As an illustration of this point, this study considered 180 papers. However, a recent literature survey conducted by Seuring and Muller (2008) identified 191 papers on the subject of SSCM. The difference in numbers may be explained by the use of different databases and search terms. In particular, the use of the terms "define", "defining" and "definition" in the search conducted as part of this study may have led to the smaller paper count. Nonetheless, the papers included in this study provided a reasonable representation of the research on GSCM and SSCM. 


\subsection{Analysis of the Published Definitions of GSCM and SSCM}

In this section, results for the published definitions of GSCM will be provided followed by the results for the published definitions of SSCM. In both cases, the results will be presented chronologically in tables. The results are analyzed and discussed in the remaining sub-sections.

\subsubsection{Green Supply Chain Management Definitions}

A total of 22 unique definitions for GSCM were identified in the search. A summary of the definitions is provided in Table 5-3. The last two columns in Table 5-3 contain a summary of the Scopus citations for the paper containing the definition, and a list of other papers that cited and used a pre-existing definition listed (both as of January 31, 2012). These columns provide some insights into the uptake of the definition.

Table 5-3: Definitions of green supply chain management (GSCM)

\begin{tabular}{|c|c|c|c|}
\hline $\begin{array}{l}\text { Definition } \\
\text { Source }\end{array}$ & Definition & $\begin{array}{l}\text { Scopus } \\
\text { Citations }\end{array}$ & Used by \\
\hline $\begin{array}{l}\text { Handfield et } \\
\text { al. (1997) }\end{array}$ & $\begin{array}{l}\text { Application of environmental management principles to the } \\
\text { entire set of activities across the whole customer order cycle, } \\
\text { including design, procurement, manufacturing and } \\
\text { assembly, packaging, logistics, and distribution. }\end{array}$ & 132 & \\
\hline $\begin{array}{l}\text { Zhu et al. } \\
\text { (2005, p. 450) }\end{array}$ & $\begin{array}{l}\text { An important new archetype for enterprises to achieve profit } \\
\text { and market share objectives by lowering their environmental } \\
\text { risks and impacts while raising their ecological efficiency. }\end{array}$ & 91 & \\
\hline $\begin{array}{l}\text { Hervani et al. } \\
\text { (2005, p. 334) }\end{array}$ & $\begin{array}{l}\text { Green Purchasing + Green Manufacturing/Materials } \\
\text { Management + Green Distribution/Marketing + Reverse } \\
\text { Logistics }\end{array}$ & 81 & \\
\hline $\begin{array}{l}\text { Sheu et al. } \\
\text { (2005) }\end{array}$ & $\begin{array}{l}\text { Combination of both the product manufacturing supply } \\
\text { chain and used-product reverse logistics chain. }\end{array}$ & 85 & \\
\hline $\begin{array}{l}\text { Srivastava } \\
\text { (2007, p. 54-5) }\end{array}$ & $\begin{array}{l}\text { Integrating environmental thinking into supply-chain } \\
\text { management, including product design, material sourcing } \\
\text { and selection, manufacturing processes, delivery of the final } \\
\text { product to the consumers as well as end-of-life management } \\
\text { of the product after its useful life. }\end{array}$ & 170 & $\begin{array}{l}\text { Shang et al. (2010); } \\
\text { Caniato et al. (2012); } \\
\text { DeGiovanni and } \\
\text { EspositoVinzi } \\
\text { (2012) }\end{array}$ \\
\hline $\begin{array}{l}\text { H’Mida and } \\
\text { Lakhal (2007, } \\
\text { p. 6) }\end{array}$ & $\begin{array}{l}\text { The practice of monitoring and improving environmental } \\
\text { performance in the supply chain during a product's life } \\
\text { cycle. }\end{array}$ & 0 & \\
\hline
\end{tabular}




\begin{tabular}{|c|c|c|c|}
\hline $\begin{array}{l}\text { Definition } \\
\text { Source }\end{array}$ & Definition & $\begin{array}{l}\text { Scopus } \\
\text { Citations }\end{array}$ & Used by \\
\hline $\begin{array}{l}\text { Lakhal et al. } \\
(2007)\end{array}$ & $\begin{array}{l}\text { Olympic green supply chain characterized by five-circled } \\
\text { flag of the Olympics as zero emissions, zero waste in } \\
\text { activities, zero waste of resources, zero use of toxic } \\
\text { substances, zero waste in product life-cycle, in addition to } \\
\text { green inputs and green outputs. }\end{array}$ & 2 & \\
\hline $\begin{array}{l}\text { Srivastava } \\
(2008, \text { p. 535) }\end{array}$ & $\begin{array}{l}\text { Integration of sound environmental management choices } \\
\text { with the decision making process for the conversion of } \\
\text { resources into usable products. }\end{array}$ & 70 & \\
\hline $\begin{array}{l}\text { Lee and } \\
\text { Klassen }(2008 \text {, } \\
\text { p. } 575)\end{array}$ & $\begin{array}{l}\text { A buying organization's plans and activities that integrate } \\
\text { environmental issues into supply chain management in order } \\
\text { to improve the environmental performance of suppliers and } \\
\text { customers. }\end{array}$ & 11 & \\
\hline $\begin{array}{l}\text { Albino et al. } \\
\text { (2009, p. 88) }\end{array}$ & $\begin{array}{l}\text { A strategic approach addressed to extend environmental } \\
\text { measures to the whole supply chain. }\end{array}$ & 17 & \\
\hline $\begin{array}{l}\text { Wee et al. } \\
\text { (2011, p. 603) }\end{array}$ & $\begin{array}{l}\text { Integration of environment considerations into supply chain } \\
\text { management, including product design, material sourcing } \\
\text { and selection, manufacturing processes, delivery of the final } \\
\text { product to the consumers, and end-of-life management of } \\
\text { the greening products. }\end{array}$ & 0 & \\
\hline $\begin{array}{l}\text { Gavronski et } \\
\text { al. (2011, p. } \\
\text { 875) }\end{array}$ & $\begin{array}{l}\text { The complex of mechanisms implemented at the corporate } \\
\text { and plant level to assess or improve the environmental } \\
\text { performance of a supplier base. }\end{array}$ & 0 & \\
\hline $\begin{array}{l}\text { Lau (2011, p. } \\
\text { 874) }\end{array}$ & $\begin{array}{l}\text { Integrating environmental thinking into closed-loop supply } \\
\text { chain management. }\end{array}$ & 0 & \\
\hline $\begin{array}{l}\text { El Saadany et } \\
\text { al. (2011, p. } \\
1203)\end{array}$ & $\begin{array}{l}\text { Reducing energy and virgin raw material usage and waste } \\
\text { generation, and increasing product recovery options. } \\
\text { Greening usually refers to the forward supply chain } \\
\text { functions such as production, purchasing, materials } \\
\text { management, warehousing and inventory control, } \\
\text { distribution, shipping, and transport logistics. }\end{array}$ & 0 & \\
\hline $\begin{array}{l}\text { Wu and Pagel, } \\
\text { 2011, p.578 }\end{array}$ & $\begin{array}{l}\text { The environmental dimension of sustainability in a supply } \\
\text { chain context. }\end{array}$ & 2 & \\
\hline $\begin{array}{l}\text { Gnoni et al. } \\
\text { (2011, p. 129) }\end{array}$ & $\begin{array}{l}\text { An approach that aims to integrate environmental issues into } \\
\text { SC management procedure starting from product design, and } \\
\text { continuing through material sourcing and selection, } \\
\text { manufacturing processes, the final product delivery and end- } \\
\text { of-life management. }\end{array}$ & 0 & \\
\hline $\begin{array}{l}\text { Yeh and } \\
\text { Chuang (2011, } \\
\text { p. 4244) }\end{array}$ & $\begin{array}{l}\text { Management between suppliers, their products and } \\
\text { environment, that is to say, the environment protection } \\
\text { principle is brought into suppliers' management system. Its } \\
\text { purpose is to add environment protection consciousness into } \\
\text { original products and to improve competitive capacity in } \\
\text { markets. }\end{array}$ & 1 & \\
\hline $\begin{array}{l}\text { Sarkis et al. } \\
(2011, \text { p. 3) }\end{array}$ & $\begin{array}{l}\text { Integrating environmental concerns into the inter- } \\
\text { organizational practices of SCM including reverse logistics. }\end{array}$ & 9 & \\
\hline
\end{tabular}




\begin{tabular}{|c|c|c|c|}
\hline $\begin{array}{l}\text { Definition } \\
\text { Source }\end{array}$ & Definition & $\begin{array}{l}\text { Scopus } \\
\text { Citations }\end{array}$ & Used by \\
\hline $\begin{array}{l}\text { Kim et al. } \\
(2011)\end{array}$ & $\begin{array}{l}\text { A set of practices intended to effect, control and support } \\
\text { environmental performance by allocating possible human } \\
\text { material resources and redefining organizational } \\
\text { responsibilities and procedures. }\end{array}$ & 0 & \\
\hline $\begin{array}{l}\text { Parmigiani et } \\
\text { al. (2011) }\end{array}$ & The impact of supply chains on environmental performance. & 0 & \\
\hline $\begin{array}{l}\text { Buyukozkan } \\
\text { and Cidci } \\
\text { (2012) }\end{array}$ & $\begin{array}{l}\text { A way for firms to achieve profit and market share } \\
\text { objectives by lowering environmental impacts and } \\
\text { increasing ecological efficiency. }\end{array}$ & 0 & \\
\hline $\begin{array}{l}\text { Andic et al. } \\
\text { (2012) }\end{array}$ & $\begin{array}{l}\text { Minimizing and preferably eliminating the negative effects } \\
\text { of the supply chain on the environment. }\end{array}$ & 0 & \\
\hline
\end{tabular}

Note: These 22 unique definitions of GSCM are from a total of 124 identified articles analyzed.

\subsubsection{Sustainable Supply Chain Management Definitions}

A total of 12 unique definitions for SSCM were identified in the search. A summary of the definitions is provided in Table 5-4. As in Table 5-3, the last two columns in Table 5-4 contain a summary of the Scopus citations for the paper containing the definition and a list of other papers that cited and used a pre-existing definition listed (both as of January 31, 2012). These columns also provide some insights into the uptake of the definition.

Table 5-4: Definitions of sustainable supply chain management (SSCM)

\begin{tabular}{|l|l|c|l|}
\hline \multicolumn{1}{|c|}{$\begin{array}{c}\text { Definition } \\
\text { Source }\end{array}$} & \multicolumn{1}{|c|}{ Definition } & $\begin{array}{c}\text { Scopus } \\
\text { Citations }\end{array}$ & \multicolumn{1}{|c|}{ Used by } \\
\hline $\begin{array}{l}\text { Jorgensen and } \\
\text { Knudsen } \\
\text { (2006, p. 450) }\end{array}$ & $\begin{array}{l}\text { The means by which companies manage their social } \\
\text { responsibilities across dislocated production processes } \\
\text { spanning organizational and geographical boundaries. }\end{array}$ & 8 & \\
\hline $\begin{array}{l}\text { Carter and } \\
\text { Rogers (2008, } \\
\text { p. 368) }\end{array}$ & $\begin{array}{l}\text { The strategic, transparent integration and achievement of an } \\
\text { organization's social, environmental, and economic goals in } \\
\text { the systemic coordination of key inter-organizational } \\
\text { business processes for improving the long-term economic } \\
\text { performance of the individual company and its supply } \\
\text { chains. }\end{array}$ & 68 & $\begin{array}{l}\text { Preuss (2009); } \\
\text { Subramoniam et al. } \\
\text { Liu et al. (2011); } \\
\text { Carter and Easton } \\
\text { (2011) }\end{array}$ \\
\hline $\begin{array}{l}\text { Seuring and } \\
\text { Muller (2008, } \\
\text { p. 1700) }\end{array}$ & $\begin{array}{l}\text { The management of material, information and capital flows } \\
\text { as well as cooperation among companies along the supply } \\
\text { chain while taking goals from all three dimensions of } \\
\text { sustainable development, i.e., economic, environmental and } \\
\text { social, into account which are derived from customer and } \\
\text { stakeholder requirements. }\end{array}$ & 117 & $\begin{array}{l}\text { Preuss (2009) } \\
\text { Ramani et al. } \\
\text { (2010); } \\
\text { Gold et al. (2010); } \\
\text { Wolf and Seuring } \\
\text { (2010); } \\
\text { Seuring (2011) }\end{array}$ \\
\hline
\end{tabular}




\begin{tabular}{|c|c|c|c|}
\hline $\begin{array}{l}\text { Definition } \\
\text { Source }\end{array}$ & Definition & $\begin{array}{l}\text { Scopus } \\
\text { Citations }\end{array}$ & Used by \\
\hline $\begin{array}{l}\text { Seuring (2008, } \\
\text { p. 132) }\end{array}$ & $\begin{array}{l}\text { The integration of sustainable development and supply chain } \\
\text { management [in which] by merging these two concepts, } \\
\text { environmental and social aspects along the supply chain } \\
\text { have to be taken into account, thereby avoiding related } \\
\text { problems, but also looking at more sustainable products and } \\
\text { processes. }\end{array}$ & 25 & \\
\hline $\begin{array}{l}\text { Ciliberti et al. } \\
\text { (2008, p. } \\
\text { 1580) }\end{array}$ & $\begin{array}{l}\text { The management of supply chains where all the three } \\
\text { dimensions of sustainability, namely the economic, } \\
\text { environmental, and social ones, are taken into account. }\end{array}$ & 14 & $\begin{array}{l}\text { Moore and Manring } \\
\text { (2009) }\end{array}$ \\
\hline $\begin{array}{l}\text { Font et al. } \\
\text { (2008, p. 260) }\end{array}$ & $\begin{array}{l}\text { Adding sustainability to existing supply chain management } \\
\text { processes, to consider environmental, social and economic } \\
\text { impacts of business activities. }\end{array}$ & 5 & \\
\hline $\begin{array}{l}\text { Pagell and Wu } \\
\text { (2009, p. 38) }\end{array}$ & $\begin{array}{l}\text { The specific managerial actions that are taken to make the } \\
\text { supply chain more sustainable with an end goal of creating a } \\
\text { truly sustainable chain. }\end{array}$ & 22 & \\
\hline $\begin{array}{l}\text { Badurdeen et } \\
\text { al. (2009, p. } \\
\text { 57) }\end{array}$ & $\begin{array}{l}\text { Involvement of the planning and management of sourcing, } \\
\text { procurement, conversion and logistics activities involved } \\
\text { during pre-manufacturing, manufacturing, use and post-use } \\
\text { stages in the life cycle in closed-loop through multiple life- } \\
\text { cycles with seamless information sharing about all product } \\
\text { life-cycle stages between companies by explicitly } \\
\text { considering the social and environmental implications to } \\
\text { achieve a shared vision. }\end{array}$ & 6 & \\
\hline $\begin{array}{l}\text { Haake and } \\
\text { Seuring (2009, } \\
\text { p. 285) }\end{array}$ & $\begin{array}{l}\text { The set of supply chain management policies held, actions } \\
\text { taken, and relationships formed in response to concerns } \\
\text { related to the natural environment and social issues with } \\
\text { regard to the design, acquisition, production, distribution, } \\
\text { use, reuse, and disposal of the firm's goods and services. }\end{array}$ & 7 & \\
\hline $\begin{array}{l}\text { Wolf (2011, p. } \\
\text { 223) }\end{array}$ & $\begin{array}{l}\text { The degree to which a manufacturer strategically } \\
\text { collaborates with its supply chain partners and } \\
\text { collaboratively manages intra- and inter-organization } \\
\text { processes for sustainability. }\end{array}$ & 1 & \\
\hline $\begin{array}{l}\text { Closs et al. } \\
\text { (2011, p. 102) }\end{array}$ & $\begin{array}{l}\text { Reflection of the firm's ability to plan for, mitigate, detect, } \\
\text { respond to, and recover from potential global risks. Risks } \\
\text { involving substantial marketing and supply chain } \\
\text { considerations include product development, channel } \\
\text { selection, market decisions, sourcing, manufacturing } \\
\text { complexity, transportation, government and industry } \\
\text { regulation, resource availability, talent management, } \\
\text { alternative energy platforms, and security. }\end{array}$ & 1 & \\
\hline $\begin{array}{l}\text { Wittstruck and } \\
\text { Teuteberg } \\
\text { (2011, p. 142) }\end{array}$ & $\begin{array}{l}\text { An extension to the traditional concept of Supply Chain } \\
\text { Management by adding environmental and social/ethical } \\
\text { aspects. }\end{array}$ & 0 & \\
\hline
\end{tabular}

Note: These 12 unique definitions of SSCM are from a total of 56 identified articles analyzed. 


\subsubsection{Business Sustainability Characteristics Addressed by the Definitions}

A summary of the key sustainability characteristics addressed by the published definitions of GSCM and SSCM is provided in Table 5-5. The table includes a set of notes explaining how each characteristic was interpreted in the analysis.

Table 5-5: Key business sustainability characteristics addressed by the definitions

\begin{tabular}{|c|c|c|c|c|c|c|c|c|}
\hline \multirow[b]{2}{*}{ Category } & \multirow[b]{2}{*}{ Definition } & \multicolumn{7}{|c|}{ Sustainability Characteristics } \\
\hline & & 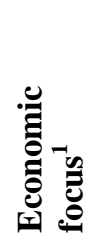 & 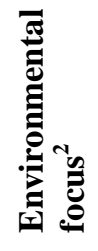 & 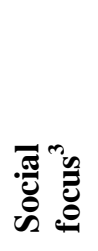 & 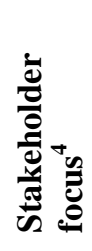 & 递 & 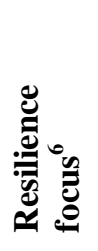 & 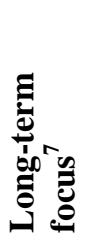 \\
\hline \multirow{22}{*}{ GSCM } & Handfield et al. (1997) & & - & & - & & & \\
\hline & Zhu et al. (2005) & घ & घ & & & & & \\
\hline & Hervani et al. (2005) & & घ & & & & & घ \\
\hline & Sheu et al. (2005) & & & & & & & [ \\
\hline & Srivastava, (2007) & & - & & $\mathbf{\square}$ & & & - \\
\hline & H’Mida and Lakhal (2007) & & $\mathbf{\square}$ & & & & & - \\
\hline & Lakhal et al. (2007) & & $\mathbf{\square}$ & & & & & घ \\
\hline & Srivastava, (2008) & & $\mathbf{\square}$ & & & & & \\
\hline & Lee and Klassen (2008) & & घ & & घ & & & \\
\hline & Albino et al. (2009) & & घ & & & & & \\
\hline & Wee et al. (2011) & & $\mathbf{\square}$ & & - & & & - \\
\hline & Gavronski et al. (2011) & & $\mathbf{\square}$ & & - & & & \\
\hline & Lau (2011) & & $\boldsymbol{\square}$ & & & & & - \\
\hline & El Saadany et al. (2011) & & घ & & & & & घ \\
\hline & Wu and Pagel (2011) & & - & & & & & \\
\hline & Gnoni et al. (2011) & & - & & & & & - \\
\hline & Yeh and Chuang (2011) & - & $\boldsymbol{\square}$ & & - & & & \\
\hline & Sarkis et al. (2011) & & - & & & & & - \\
\hline & Kim et al. (2011) & & $\mathbf{\square}$ & & - & & & \\
\hline & Parmigiani et al. (2011) & & - & & & & & \\
\hline & Buyukozkan and Cidci (2012) & - & - & & & & & \\
\hline & Andic et al. (2012) & & 匹 & & & & & \\
\hline SSCM & Jorgensen and Knudsen (2006) & & & घ & & & & \\
\hline
\end{tabular}




\begin{tabular}{|l|l|c|c|c|c|c|}
\hline \multirow{2}{*}{ Definition } & \multicolumn{5}{|c|}{ Sustainability Characteristics } \\
\cline { 3 - 7 } & & &
\end{tabular}

\subsubsection{Business Sustainability Characteristics Addressed by GSCM Definitions}

In the published definitions for GSCM, only 3 (14\%) explicitly addressed multiple dimensions of the triple bottom line. In these papers (i.e., Zhu et al., 2005; Yeh and Chuang, 2011; Buyukozkan and Cidci, 2012), both environmental and economic considerations were explicitly addressed. The remaining definitions, with one exception (i.e., Sheu et al., 2005), focused exclusively on the environmental dimension of sustainability. Social issues were not explicitly mentioned in any of the published definitions of GSCM. The focus on environmental issues was to be expected given the nature of the term "GSCM", which clearly emphasizes this dimension of sustainability. 
Again, Sheu et al. (2005) were the only authors that did not explicitly address environmental issues in their definition.

Among the other sustainability characteristics examined, only the stakeholder focus and longterm focus categories were addressed by some of the definitions. Table 2-5 shows that 7 (32\%) of the definitions demonstrated some focus on stakeholders. The stakeholders that were specifically mentioned included customers (Handfield et al., 1997; Lee and Klassen, 2008), consumers (Srivastava, 2007; Wee et al., 2011), employees (Kim et al., 2011), and suppliers (Lee and Klassen, 2008; Gavronski et al., 2011; Yeh and Chuang, 2011). It is important to note, however, that these definitions generally provided only a passing reference to these stakeholders. Table 2-5 also shows that 10 (46\%) of the definitions demonstrated a long-term focus. This was generally indicated through reference to end-of-life product management, product reuse, product recovery, reverse logistics, and closed-loop supply chains. None of the definitions explicitly mentioned future generations or the management of the supply chain over the long-term.

The volunteer focus and resilience focus categories were not addressed by any of the definitions studied. The voluntary nature of sustainability is rarely made explicit in definitions of business sustainability, though previous research has shown that several definitions of CSR do make the point (Dahlsrud, 2008). Resilience is also rarely addressed in definitions of business sustainability. This may help explain why these characteristics were not incorporated into the published definitions of GSCM.

\subsubsection{Business Sustainability Characteristics Addressed by SSCM Definitions}

An analysis of the definitions suggested for SSCM found that although all three dimensions of the triple bottom line were explicitly addressed, they were not present in all suggested definitions. Jorgensen and Knudsen (2006) were the only authors that limited their focus to the social dimension. Five (42\%) definitions addressed two dimensions of sustainability. Seuring (2008), Badurdeen et al. (2009), and Haak and Seuring (2009) focused on combinations of the environmental and social aspects of sustainability. Wittstruck and Teuteberg (2011) highlighted ethics as part of the social feature of sustainability, and suggested a definition for SSCM that emphasizes the environmental and ethical aspects of sustainability in the supply chain. Closs et 
al. (2011) focused on a combination of the economic and environmental features of sustainability by highlighting the importance of substantial marketing and consideration of alternative energy platforms in the supply chain. The remaining definitions (50\%) addressed all three aspects of the triple bottom line. These included definitions by Carter and Rogers (2008), Seuring and Muller (2008), Ciliberti et al. (2008), Font et al. (2008), Pagell and Wu (2009), and Wolf (2011). A review of the Scopus citations shows that the papers by Carter and Rogers (2008) and Seuring and Muller (2008) are the most cited among those reviewed on SSCM.

Beyond the triple bottom line dimensions, Table 5-5 shows that the other sustainability characteristics considered were addressed by one definition or another, with the exception of the volunteer focus. Five (42\%) definitions addressed the stakeholder focus characteristic. Stakeholders were broadly referred to in one definition, while the others mentioned resources, suppliers or customers. One-third of the definitions studied addressed the long-term focus characteristic. Carter and Rogers (2008) explicitly mentioned the importance of improving the company's long-term economic performance. The other three definitions addressing the longterm focus characteristic did so more indirectly, as was seen in the definitions of GSCM. Only 1 (8\%) of the definitions emphasized the resilience focus characteristic (Closs et al., 2011). This directed clear focus to the many risks involved in SCM and the importance of the company's ability to recover from and adapt to these risks. Overall, the most comprehensive definitions from a sustainability perspective were provided by Carter and Rogers (2008) who addressed 5 of the 7 characteristics, and by Seuring and Muller (2008), Pagell and Wu (2009), Badurdeen et al. (2009), Wolf (2011), and Closs et al. (2011) who each addressed 4.

\subsubsection{Summary}

Overall, the results show that the definitions for GSCM were generally more narrowly focused than those for SSCM and had an overwhelming emphasis on environmental issues. Though some definitions of SSCM show considerable overlap with definitions of GSCM, it is clear that SSCM is essentially an extension of GSCM. While the integration of environmental thinking into SCM practices is found to be the central point of concern in all of the definitions of GSCM, the definitions of SSCM adopt a broader triple bottom line perspective. Both GSCM and SSCM had several definitions that addressed the stakeholder focus and long-term focus of sustainability. 
Resilience was addressed by only one of the definitions in both categories, while the voluntary focus of business sustainability was not captured by any of the published definitions. This may reflect the fact that actions do not necessarily need to be voluntary to qualify as GSCM or SSCM. The distribution of the key business sustainability characteristics highlighted in the analysis is shown in Figure 5-4.

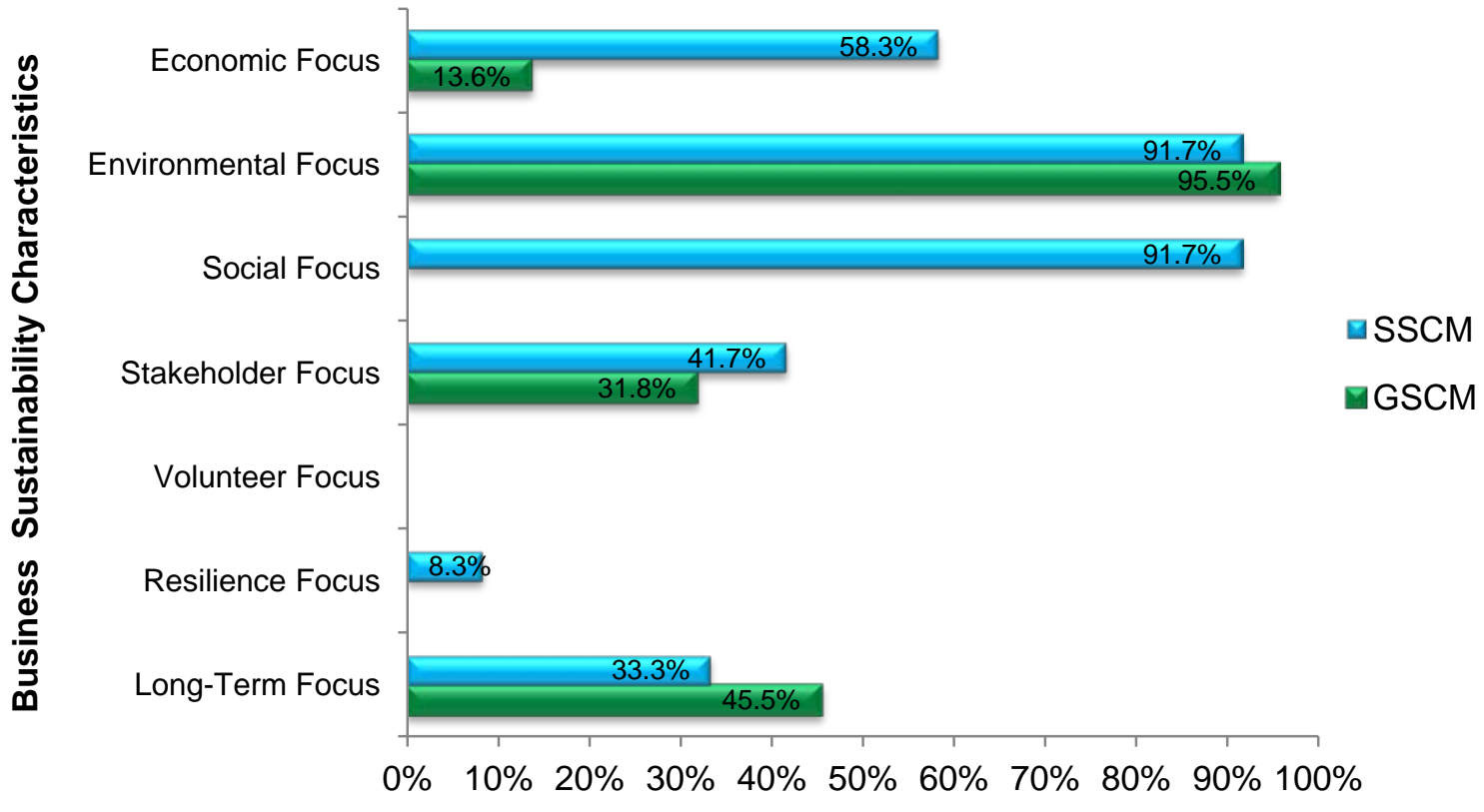

Percentage of Definitions

Figure 5-4: Distribution of the key business sustainability characteristics addressed by the definitions

\subsubsection{Supply Chain Management Characteristics Addressed by the Definitions}

A summary of the key SCM characteristics addressed by the published definitions of GSCM and SSCM is provided in Table 5-6. The table includes a set of notes explaining how each characteristic was interpreted in the analysis. 
Table 5-6: Key SCM characteristics addressed by the definitions

\begin{tabular}{|c|c|c|c|c|c|c|c|c|}
\hline \multirow[b]{2}{*}{ Category } & \multirow[b]{2}{*}{ Definition } & \multicolumn{7}{|c|}{ SCM Characteristics } \\
\hline & & $\frac{z_{0}^{-}}{e^{-}}$ & 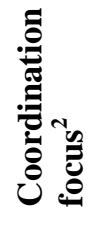 & 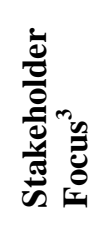 & 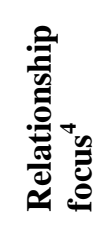 & 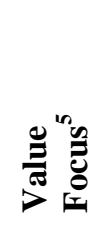 & 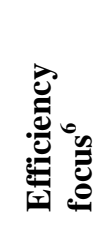 & 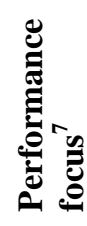 \\
\hline \multirow{22}{*}{ GSCM } & Handfield et al. (1997) & - & - & - & & & & \\
\hline & Zhu et al. (2005) & & & & & घ & - & \\
\hline & Hervani et al. (2005) & - & 匹 & & & & & \\
\hline & Sheu et al. (2005) & - & घ & & & & & \\
\hline & Srivastava (2007) & घ & - & - & & & & \\
\hline & H'Mida and Lakhal (2007) & - & 匹 & & & & & - \\
\hline & Lakhal et al. (2007) & - & - & & & & - & \\
\hline & Srivastava (2008) & - & - & & & - & & \\
\hline & Lee and Klassen (2008) & $\square$ & - & - & & & & - \\
\hline & Albino et al. (2009) & घ & 匹 & & & & & घ \\
\hline & Wee et al. (2011) & - & - & - & & & & \\
\hline & Gavronski et al. (2011) & & $\square$ & $\square$ & & & & - \\
\hline & Lau (2011) & - & - & & & & & \\
\hline & El Saadany et al. (2011) & - & ш & & & & - & \\
\hline & Wu and Pagel (2011) & - & - & & & & & \\
\hline & Gnoni et al. (2011) & ! & 匹 & & & & & \\
\hline & Yeh and Chuang (2011) & - & 匹 & - & घ & & & - \\
\hline & Sarkis et al. (2011) & - & - & & - & & & \\
\hline & Kim et al. (2011) & - & - & - & & & & - \\
\hline & Parmigiani et al. (2011) & - & - & & & & & - \\
\hline & Buyukozkan and Cidci (2012) & & & & & - & - & \\
\hline & Andic et al. (2012) & घ & घ & & & & & घ \\
\hline \multirow{6}{*}{ SSCM } & Jorgensen and Knudsen (2006) & & - & & & & & \\
\hline & Carter and Rogers (2008) & & - & - & - & & & - \\
\hline & Seuring and Muller (2008) & - & - & - & 口 & & & \\
\hline & Seuring (2008) & - & $\square$ & & & & & \\
\hline & Ciliberti et al. (2008) & - & - & & & & & \\
\hline & Font et al. (2008) & - & - & & & & & \\
\hline
\end{tabular}




\begin{tabular}{|c|c|c|c|c|c|c|c|c|}
\hline \multirow{8}{*}{ Category } & \multirow[b]{2}{*}{ Definition } & \multicolumn{7}{|c|}{ SCM Characteristics } \\
\hline & & $\frac{3}{2}$ & 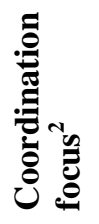 & 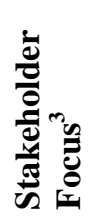 & 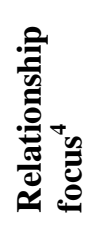 & 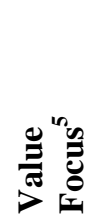 & 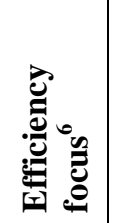 & 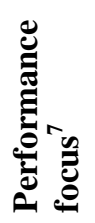 \\
\hline & Pagell and Wu (2009) & - & - & & & & & \\
\hline & Badurdeen et al. (2009) & - & - & - & $\mathbf{\square}$ & & & - \\
\hline & Haake and Seuring (2009) & $\mathbf{\square}$ & - & & $\mathbf{\square}$ & & & \\
\hline & Wolf (2011) & - & - & - & $\mathbf{\square}$ & & & \\
\hline & Closs et al. (2011) & $\mathbf{\square}$ & - & - & & & & \\
\hline & Wittstruck and Teuteberg (2011) & - & - & & & & & \\
\hline \multicolumn{9}{|c|}{$\begin{array}{l}{ }^{2} \text { Coordination focus: The definitio } \\
\text { organizations. Reference to the su } \\
\text { considered to implicitly refer to th } \\
{ }^{3} \text { Stakeholder focus: The definition } \\
\text { customers, consumers, and supplie } \\
{ }^{4} \text { Relationship focus: The definition } \\
\text { This includes mentioning the coor } \\
{ }^{5} \text { Value focus: The definition includ } \\
\text { and converting resources into usab } \\
{ }^{6} \text { Efficiency focus: The definition in } \\
{ }^{7} \text { Performance focus: The definition }\end{array}$} \\
\hline
\end{tabular}

\subsubsection{Supply Chain Management Characteristics Addressed by GSCM Definitions}

The analysis showed that the coordination focus and the flow focus were overwhelmingly the most frequently addressed SCM characteristics in the GSCM definitions. The coordination focus was addressed in 20 of the 22 (91\%) definitions while the flow focus was addressed in 19 (86\%) of the definitions. In many cases, these characteristics were addressed implicitly through reference in the definition to supply chains or supply chain management. The heavy emphasis on these two characteristics reflects their importance in SCM overall and the need to reflect them in any extensions of the concept, as in GSCM.

Each of the other SCM characteristics were also addressed in the definitions of GSCM. The stakeholder focus was addressed in 7 (32\%) of the definitions. As previously mentioned, the stakeholder focus characteristic was the only one that directly overlapped with the characteristics 
of business sustainability. The performance focus characteristic, which was addressed in 8 (36\%) of the definitions, was reflected in a number of ways, including reference to environmental performance (H'Mida and Lakhal, 2007; Lee and Klassen, 2008; Kim et al., 2011; Parmigiani et al., 2011; Gavronski et al., 2011; Andic et al., 2012), environmental measures (Albino et al., 2009), and improving competitive capacity (Yeh and Chuang, 2011). The efficiency focus of SCM was reflected in 4 (18\%) definitions, including in direct references to efficiency (Zhu et al., 2005), zero waste (Lakhal et al., 2007; Buyukozkan and Cidci, 2012), and reducing resource usage (El Saadany et al., 2011). The value focus was addressed by 3 (14\%) of the definitions. This was accomplished through reference to profit and market share (Zhu et al., 2005; Buyukozkan and Cidci, 2012) and conversion of resources into usable products (Srivastava, 2008). Finally, the relationship focus characteristic was addressed by only 2 (9\%) of the definitions. Yeh and Chuang (2011) addressed this characteristic through reference to management between suppliers and supplier management systems while Sarkis et al. (2011) did so through reference to inter-organizational practices.

Overall, the results show that there was good coverage of the characteristics of SCM in the definitions suggested for GSCM, though different authors certainly emphasized different aspects. The most comprehensive definitions were provided by Yeh and Chuang (2011) who addressed 5 of the 7 SCM characteristics and by Kim et al. (2011) and Lee and Klassen (2008) who each addressed 4.

\subsubsection{Supply Chain Management Characteristics Addressed by SSCM Definitions}

In the definitions for SSCM, the analysis showed that the most commonly addressed SCM characteristics are the coordination focus and the flow focus. The coordination focus was addressed in all 12 of the published definitions, while the flow focus appeared in 10 (83\%) of the definitions. As with the GSCM definitions, these characteristics were in many cases addressed implicitly through the use of the terms "supply chain" or "supply chain management" in the definitions.

Of the remaining SCM characteristics, only three (i.e. relationship focus, stakeholder focus and performance focus) were addressed in the SSCM definitions. Five (42\%) of the definitions 
addressed the relationship focus. Haak and Seuring (2009) explicitly mentioned the forming of relationships. The coordination of inter-organizational business processes (Carter and Rogers, 2008; Wolf, 2011), cooperation among companies (Seuring and Muller, 2008), and seamless information sharing between companies (Badurdeen et al., 2009) were also interpreted as a demonstration of the relationship focus. The stakeholder focus was also addressed by 5 (42\%) definitions. Seuring and Muller (2008) referred to customer and stakeholder requirements, Carter and Rogers (2008) and Wolf (2011) mentioned the individual company and the supply chain partners, Closs et al. (2011) highlighted resource availability and talent management, and Badurdeen et al. (2009) implied a focus on suppliers based on the need to achieve a shared vision. The performance focus was addressed only by $2(17 \%)$ of the SSCM definitions. Carter and Rogers (2008) explicitly referred to the long-term economic performance of the company. Badurdeen et al. (2009) indirectly referenced performance through their emphasis of the need to achieve a shared vision.

The value focus and efficiency focus characteristics were not explicitly addressed by any of the published SSCM definitions. It is important to note that this may be a matter of interpretation. In cases where the economic dimension of sustainability was mentioned, this may be considered an indication of the value focus by some analysts. However, in this study, a more explicit reference to value focus was sought.

Overall, the most comprehensive definitions from the perspective of the SCM characteristics were offered by Badurdeen et al. (2009) who addressed 5 of the 7 characteristics and by Seuring and Muller (2008), Carter and Rogers (2008), and Wolf (2011) who each addressed 4.

\subsubsection{Summary}

The results show that the majority of both the GSCM and SSCM definitions addressed the flow focus and coordination focus characteristics of SCM. In both cases, this was largely done through the insertion of words referring to the supply chain or supply chain management in the definitions. The SSCM definitions showed more definitions placing an emphasis on the stakeholder focus and/or the relationship focus despite the much greater number of definitions of GSCM. Unlike the GSCM definitions that addressed the performance focus in more than a third 
of the definitions, the SSCM definitions rarely referred to this SCM characteristic. None of the SSCM definitions addressed the value focus or efficiency focus, though these were not widely addressed in the GSCM definitions either. The distribution of the key SCM characteristics highlighted in the analysis is shown in Figure 5-5.

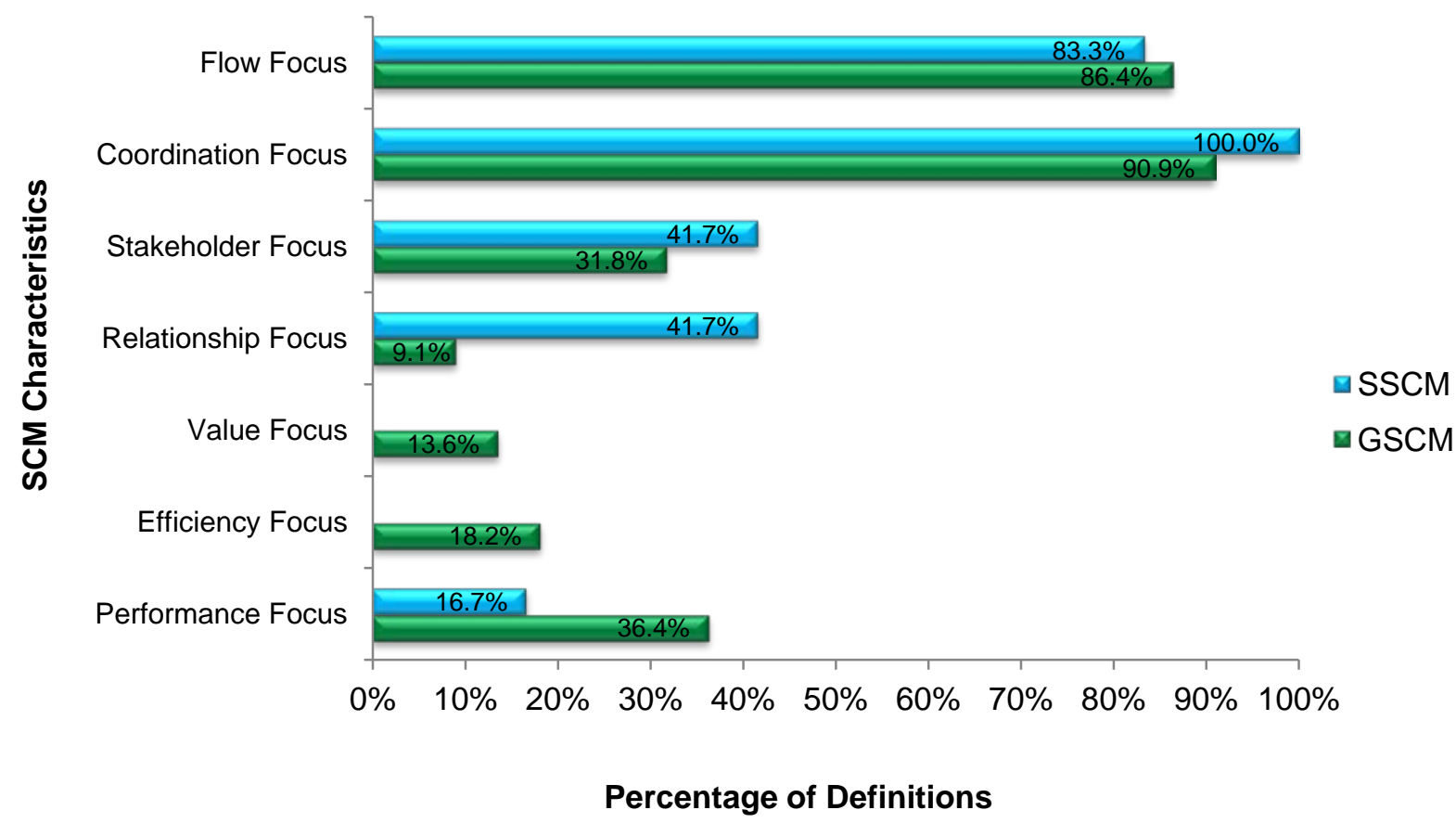

Figure 5-5: Distribution of the key SCM characteristics addressed by the definitions

\subsubsection{Overall Summary}

Analysis of the results shows that integration of sustainability into SCM began by focusing on merging “green” considerations with SCM practices. The number of published papers addressing GSCM has continued to grow considerably over time (Figure 5-1). The need to embed environmental considerations in SCM is thus well established in the literature, a point highlighted by Ashby et al. (2012) and Gimenez and Tachizawa (2012). In parallel to the continued growth of research on GSCM, a more holistic view of sustainability and its integration with SCM has emerged. Figure 5-1 also shows growing momentum for research in the area of SSCM. 
The results also show that there are a variety of ways in which both GSCM and SSCM have been defined. Considering all of the business sustainability and SCM characteristics examined (i.e., 13 characteristics in total since the stakeholder focus applied to both), the definitions provided by Carter and Rogers (2008) and Badurdeen et al. (2009) addressed the largest number of individual characteristics with a total of 9. The definitions provided by Seuring and Muller (2008), Wolf (2011), and Yeh and Chuang (2011) all addressed 8 characteristics each. Four of these most comprehensive definitions are from the SSCM definition list. This reflects the fact that the SSCM definitions generally did a better job of addressing the sustainability and SCM characteristics. These results also show, however, that none of the studied definitions address all of the identified characteristics of business sustainability and SCM. This is likely a result of the many different definitions of both sustainability and SCM themselves and the desire on the part of the authors to develop a relatively concise definition.

\subsection{A New Definition of Sustainable Supply Chain Management}

The characteristics of business sustainability and SCM identified in this study provide the basis for proposing new definitions for GSCM and SSCM. Building on the discussions earlier in this study, SSCM may be defined as:

"The creation of coordinated supply chains through the voluntary integration of economic, environmental, and social considerations with key inter-organizational business systems designed to efficiently and effectively manage the material, information, and capital flows associated with the procurement, production, and distribution of products or services in order to meet stakeholder requirements and improve the profitability, competitiveness, and resilience of the organization over the short- and long-term."

A separate definition of GSCM is not explicitly offered here. Given that SSCM is viewed in this study as an extension of GSCM, a definition of GSCM would be similar to the suggested definition of SSCM, but would exclude the integration of economic and social considerations. In any case, the definition suggested above for SSCM meets all 13 of the key characteristics of business sustainability and SCM identified in this study. 
From the perspective of the sustainability characteristics, the need to address the triple bottom line of economic, environmental, and social considerations is clearly highlighted in the definition. As previously explained, the need to address these considerations has been widely recognized in earlier definitions of SSCM. However, many of the other business sustainability characteristics identified in this study have not previously been widely addressed. The new suggested definition explicitly reflects the need for SSCM to adopt a long-term focus, a characteristic that was addressed in only 4 (33\%) of the earlier definitions of SSCM (Carter and Rogers, 2008; Haak and Seuring, 2009; Pagell and Wu, 2009; Badurdeen et al., 2009). Resilience focus was previously highlighted by only one published definition (Closs et al., 2011), while the volunteer focus was not addressed by any of them. Both of these business sustainability characteristics are clearly emphasized in the new suggested definition. The final business sustainability characteristic (i.e. the stakeholder focus) was also shared with the characteristics of SCM. Among the existing definitions of SSCM, this characteristic was most explicitly addressed by Seuring and Muller (2008). Carter and Rogers (2008), Badurdeen et al. (2009), Wolf (2011) and Closs et al. (2011) also addressed the need to focus on stakeholders to varying degrees. The new suggested definition unambiguously addresses this characteristic.

The new suggested definition also addresses the remaining SCM characteristics. As the earlier analysis demonstrated, the flow focus and coordination focus are addressed in the majority of the existing SSCM definitions. They are also explicitly highlighted in the new suggested definition. The relationship focus is addressed through the emphasis on inter-organizational business systems. This focus was captured in only 5 (42\%) of the previously published definitions of SSCM (Carter and Rogers, 2008; Seuring and Muller, 2008; Haak and Seuring, 2009; Badurdeen et al., 2009; Wolf, 2011). The value and efficiency characteristics were not captured by any of the existing definitions. However, both are presented in the new suggested definition. The former is captured by highlighting the importance of the organization's profitability, while the latter is stressed by addressing the requirement for efficiency in managing flows throughout the life cycle of the products or services. Finally, the performance characteristic is addressed by stressing the need to efficiently and effectively manage the supply chain and through its emphasis on improving competitiveness. The performance characteristic had previously been addressed by only two definitions (Carter and Rogers, 2008 and Badurdeen et al., 2009). 
The new definition suggested in this study represents a needed improvement over existing definitions of SSCM. None of the previously published definitions addressed more than 9 of the 13 identified characteristics of business sustainability and SCM. As a result, it is argued they do not fully capture the meaning of SSCM. The new suggested definition can therefore provide a reference point for future research in the GSCM and SSCM areas.

\subsection{Conclusion}

Sustainability is increasingly integrated into SCM practices and hence, terms and expressions in the field of SSCM are becoming important. Accordingly, different definitions for green supply chain management (GSCM) and sustainable supply chain management (SSCM) have been proposed by different researchers. In this chapter a systematic research literature review was conducted to identify the published definitions of GSCM and SSCM. Accordingly, the study conducted in this chapter provides a needed reference point on the great variety of definitions published in these areas. The results showed that 22 and 12 distinct definitions have been published to describe GSCM and SSCM, respectively. The analysis showed that there were many differences, both large and small, among the published definitions. The definitions varied in their coverage of 7 business sustainability characteristics (i.e., economic, environmental, social, stakeholder, volunteer, resilience, and long-term focuses) and 7 SCM characteristics (i.e., flow, coordination, stakeholder, relationship, value, efficiency, and performance focuses). No comprehensive definition of GSCM or SSCM was identified, but there were several definitions that addressed at least half of the identified characteristics. To provide a reference point for future research in these areas, a new comprehensive definition of SSCM was suggested in this chapter. The suggested definition captures all the key characteristics of both business sustainability and SCM. It is important to acknowledge that different researchers may classify the characteristics associated with each definition differently, but the results discussed in this chapter nonetheless provide an illustration of broad trends. 


\section{CHAPTER 6}

\section{IDENTIFICATION AND ANALYSES OF THE PUBLISHED METRICS FOR SSCM}

\subsection{Introduction}

The review and analysis of 22 published definitions of GSCM and 12 definitions of SSCM discussed in Chapter 5 highlighted that there is a great range in the content and scope of these definitions. As a result, questions remain on how these concepts may be applied in practice. In particular, there are ongoing questions with respect to how progress towards environmental or sustainability goals in a supply chain context may be measured.

The purpose of this chapter is to identify and analyze the metrics that have been published in the peer-reviewed academic literature on GSCM and SSCM. This is accomplished through a content analysis of all articles on GSCM and SSCM published in the Scopus database up to the end of 2012. Building on discussions provided in Section 2.4, this study specifically focuses on the identification and analysis of both quantitative and qualitative metrics, in addition to absolute, relative and context-based metrics published in the peer-reviewed literature on GSCM and SSCM.

The structure of this chapter is organized as follows. The results of systematic literature search on metrics for GSCM and SSCM are provided in the next section by highlighting the background information on the sample of papers analyzed. A frequency analysis of all metrics for GSCM and SSCM appearing in the literature is provided in Section 6.3. The detailed analyses of the reported metrics by the key characteristics of SSCM followed by the themes (explicit core issues) they address are presented in Sections 6.4 and 6.5, respectively. An original conceptual framework for measuring performance in GSCM and SSCM is provided in Section 6.6. The chapter concludes with a summary of the implications of the research in Section 6.7. 


\subsection{Background Information on the Sample}

Building on discussions provided in Section 4.3, a total of 2555 unique metrics were identified through the review of 445 published sources examined. The yearly distribution of the 445 articles reviewed in this study is shown in Figure 6-1. The figure shows that the number of articles published with relevance to GSCM and SSCM metrics has rapidly increased over time, with a particular acceleration in these publications occurring since 2007. Many of the early publications provided metrics that would be referenced in later research.

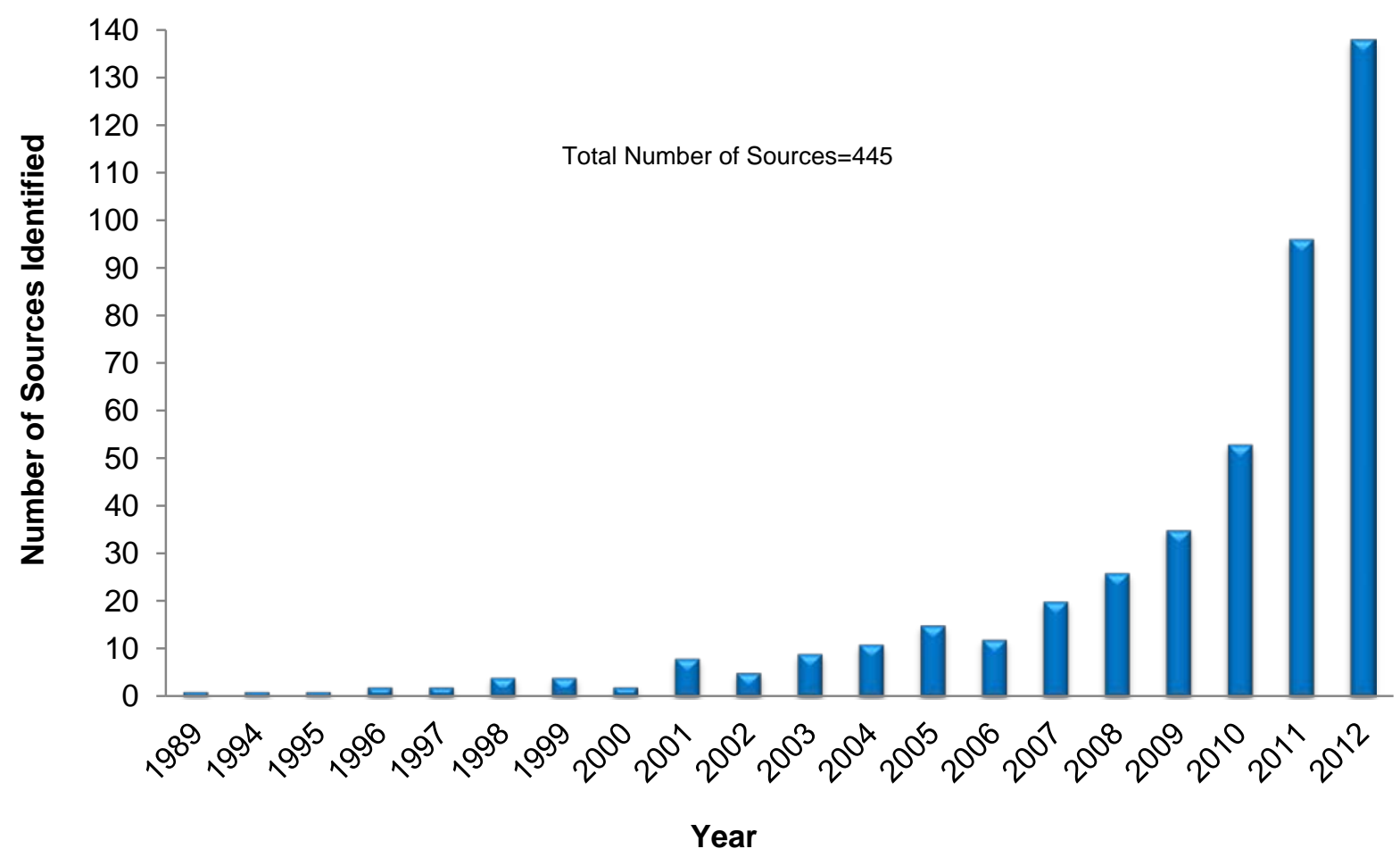

Figure 6-1: Yearly distribution of the sources reviewed

As illustrated in Figure 6-1, the first publication dealing with relevant metrics was published in 1989. In that article, Lockyer and Wynne (1989) presented two key metrics: “environmental costs" and "inventory cost”. Although these metrics were not specifically focused on GSCM and SSCM, they were later used in numerous publications in these areas (e.g., Azevedo et al., 2012; Hervani et al., 2005). After a gap of several years, relevant publications again began appearing in the mid-1990s. In 1994, Graham et al. (1994) presented a metric focused on “quality”. As will be seen in the next section, this metric was relatively widely-used in subsequent research on GSCM 
and SSCM (e.g., Buyukozkan and Cifci, 2011; Gold et al., 2010; Kuo et al., 2010; Zhu et al., 2010). Metrics focused on quality underline the attention that buyers pay to the incoming quality of products provided by suppliers. Other metrics appearing early on in the literature included “information processing cost” (Stewart, 1995) and “air emissions” (Hart and Ahuja, 1996; Klassen and McLaughlin, 1996). These metrics were later widely used in articles specifically focused on GSCM and SSCM. In their article focused on the impact of environmental management on firm performance, Klassen and McLaughlin (1996) introduced many other metrics that would later be referenced in publications on GSCM and SSCM (e.g., Azevedo et al., 2012; El Saadany et al., 2011; Zhu et al., 2008), including “solid wastes”, “energy used”, “buying environmental friendly materials”, “process innovation”, “environmental policies and audits”, and "recovery cost (+/-)”, among others. Noci’s 1997 article on assessing supplier performance introduced many other metrics that would later be referenced (e.g., Kuo et al., 2010), including “green competencies”, “current environment efficiency”, “supplier’s green image", and "net life cycle cost”. These early publications provided a basis for the relatively steady growth in relevant publications beginning in 1998, and rapidly accelerating after 2007.

Figure 6-2 provides a summary of the journals that have published at least 3 articles on GSCM or SSCM performance measurement. As highlighted earlier, the Scopus search engine covers a wide range of peer-reviewed journals in the scientific, technical, and social sciences. Given the research methodology conducted (i.e., employing Scopus as the primary means of identifying relevant articles), many engineering-, business-, ethics-, supply chain-, and sustainabilityoriented journals were examined. Accordingly, Figure 6-2 highlights the multidisciplinary nature of the systematic literature review carried out in this study (Burgess et al., 2006; Tranfield et al., 2003). The majority of the papers were published in either specialty sustainability or supply chain journals, though it is important to note that they appeared in publications covering broader interests as well. 


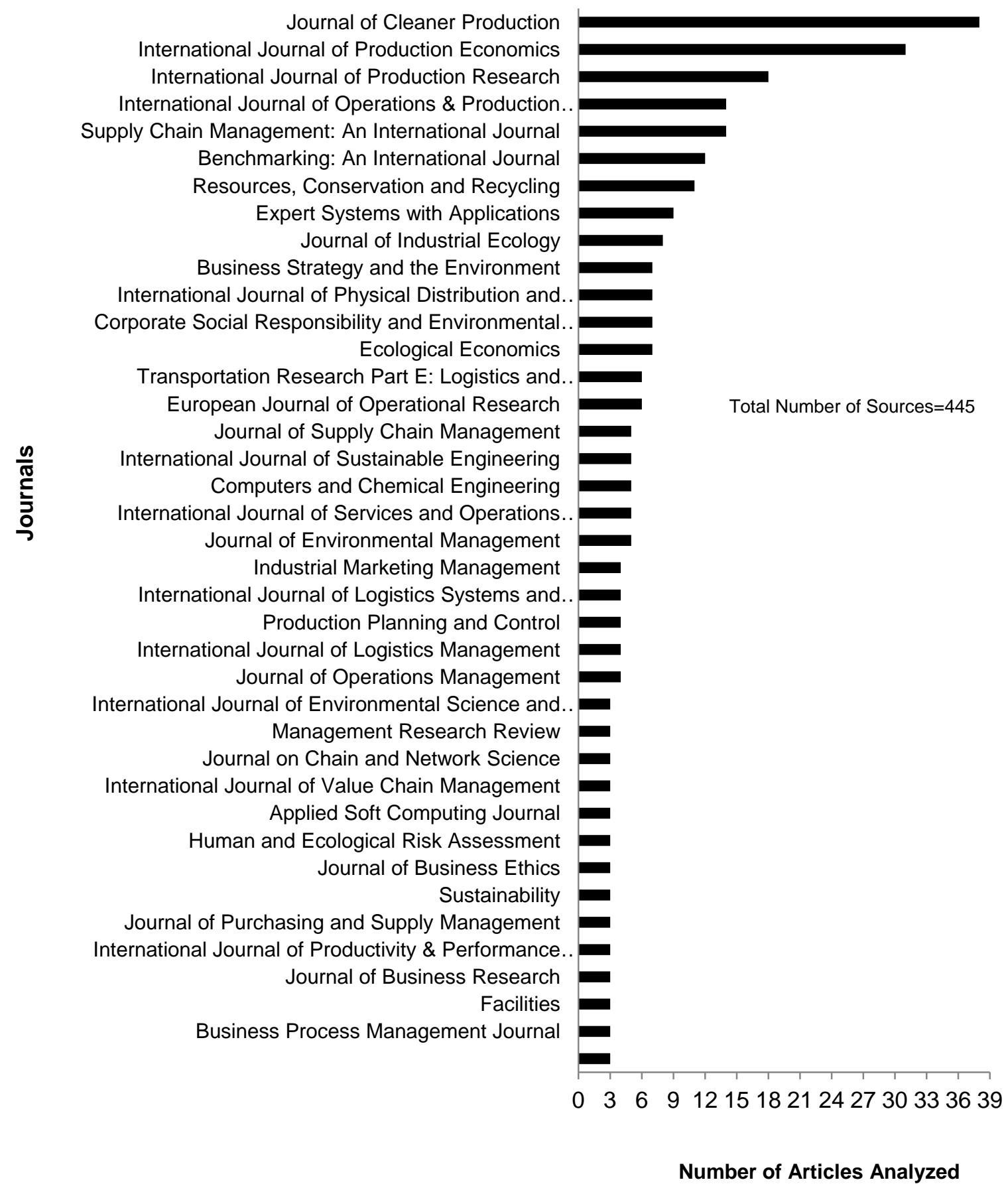

Note: 103 and 30 journals published 1 and 2 relevant articles, respectively.

Figure 6-2: Distribution of the articles analyzed for GSCM and SSCM metrics by journal 


\subsection{Frequency Analysis}

A total of 2555 unique metrics were identified in the review. The frequency of use of the metrics is summarized in Table 6-1. As highlighted in that table, approximately two-thirds of the metrics (1683) appeared in the literature only once. Considering the number of metrics that appeared two (611) or three (87) times, respectively, it is observed that approximately 93\% of the metrics appeared fewer than four times. Table 6-1 also highlights that just five (0.2\%) metrics were used more than twenty times.

Table 6-1: Frequency rates of use of the identified metrics

\begin{tabular}{|c|c|}
\hline Frequency of use & No. of unique Metrics \\
\hline 1 & 1683 \\
\hline 2 & 611 \\
\hline 3 & 87 \\
\hline $\mathbf{4}$ & $\mathbf{7 5}$ \\
\hline 5 & 28 \\
\hline 6 & 20 \\
\hline 7 & 10 \\
\hline 8 & 9 \\
\hline 9 & 5 \\
\hline 10 & 3 \\
\hline 11 & 9 \\
\hline 12 & 4 \\
\hline 13 & 1 \\
\hline 14 & 1 \\
\hline 15 & 1 \\
\hline 18 & 1 \\
\hline 19 & 2 \\
\hline 21 & 1 \\
\hline 24 & 2 \\
\hline 28 & 1 \\
\hline 31 & $\mathbf{2 5 5 5}$ \\
\hline Total & \\
\hline$* e . g ., 75$ unique metrics were addressed in 4 different sources \\
\hline Note:
\end{tabular}


Table 6-2 presents the complete list of metrics that appeared five or more times. Table 6-2 underlines the great variety of metrics that appeared in the literature. The metrics are varied in their coverage of quantitative and qualitative measurements. The analysis shows that over twothirds of the identified metrics (i.e., 1801 metrics or $70.5 \%$ of the total) were found to have a primarily quantitative nature. Less than one-third of the metrics (29.5\%) were classified as qualitative. Examples of both quantitative and qualitative metrics are available in Table 6-2. Table 6-2 also provides examples of metrics classified as absolute, relative, and context-based metrics. Overall, 2126 metrics (83.2\% of the total) were classified as absolute metrics, 429 (16.8\%) were classified as relative metrics, and no metric was classified as a context-based metric.

Table 6-2: Identified metrics of green and sustainable supply chain management

\begin{tabular}{|c|c|c|c|c|c|c|}
\hline \multirow[b]{2}{*}{ Metrics* } & \multirow[b]{2}{*}{$\begin{array}{c}\text { Frequency } \\
\text { Rate }\end{array}$} & \multicolumn{5}{|c|}{ Types } \\
\hline & & 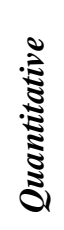 & 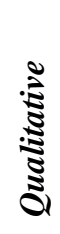 & 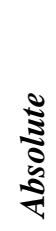 & $\frac{\stackrel{\Xi}{\Xi}}{\tilde{\Xi}}$ & 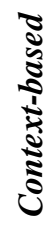 \\
\hline Quality & 31 & $\checkmark$ & & & J & \\
\hline Air emissions & 28 & 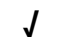 & & $\checkmark$ & & \\
\hline Energy use & 24 & $\sqrt{ }$ & & $\sqrt{ }$ & & \\
\hline Greenhouse gas emissions & 24 & $\sqrt{ }$ & & $\sqrt{ }$ & & \\
\hline Energy consumption & 21 & $\checkmark$ & & $\sqrt{ }$ & & \\
\hline Recycling & 19 & $\mathrm{~J}$ & & J & & \\
\hline Solid waste(s) & 19 & $\sqrt{ }$ & & $\sqrt{ }$ & & \\
\hline Flexibility & 18 & & $\checkmark$ & $\checkmark$ & & \\
\hline Environmental management system & 15 & & J & $\sqrt{ }$ & & \\
\hline Customers' satisfaction & 14 & $\sqrt{ }$ & & $\sqrt{ }$ & & \\
\hline Carbon footprint & 13 & $\checkmark$ & & J & & \\
\hline Life cycle assessment (LCA) & 12 & $\sqrt{ }$ & & $\sqrt{ }$ & & \\
\hline Profit & 12 & $\sqrt{ }$ & & J & & \\
\hline Cost & 12 & $J$ & & J & & \\
\hline Water consumption & 12 & $\checkmark$ & & $\checkmark$ & & \\
\hline
\end{tabular}




\begin{tabular}{|c|c|c|c|c|c|c|}
\hline \multirow[b]{2}{*}{ Metrics* } & \multirow[b]{2}{*}{$\begin{array}{l}\text { Frequency } \\
\text { Rate }\end{array}$} & \multicolumn{5}{|c|}{ Types } \\
\hline & & 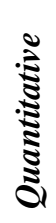 & 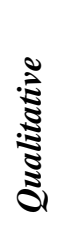 & $\frac{\mathfrak{\Xi}}{8}$ & 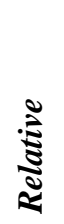 & 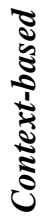 \\
\hline Product characteristics & 11 & $\checkmark$ & & $\sqrt{ }$ & & \\
\hline Energy efficiency & 11 & $\checkmark$ & & & J & \\
\hline Environmental costs & 11 & $\checkmark$ & & $\sqrt{ }$ & & \\
\hline Market share & 11 & $\checkmark$ & & $\sqrt{ }$ & & \\
\hline Reduction of air emission(s) & 11 & $\checkmark$ & & $\sqrt{ }$ & & \\
\hline Reduction of solid wastes & 11 & $\checkmark$ & & $\checkmark$ & & \\
\hline Return on investment & 11 & $\mathrm{~J}$ & & & $J$ & \\
\hline Operational cost (Operating cost) & 11 & $\checkmark$ & & $\sqrt{ }$ & & \\
\hline ISO 14001 certification & 11 & & $\checkmark$ & $\sqrt{ }$ & & \\
\hline Level of process management & 10 & $\mathrm{~J}$ & & 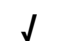 & & \\
\hline $\mathrm{CO}_{2}$ emissions & 10 & $\checkmark$ & & $\sqrt{ }$ & & \\
\hline Water waste & 10 & $\checkmark$ & & $\sqrt{ }$ & & \\
\hline Product features & 9 & & $\checkmark$ & $\sqrt{ }$ & & \\
\hline Management initiatives & 9 & & $J$ & $\sqrt{ }$ & & \\
\hline Responsiveness & 9 & & $J$ & $\sqrt{ }$ & & \\
\hline Decrease of frequency for environmental accidents & 9 & $\sqrt{ }$ & & $\sqrt{ }$ & & \\
\hline Water use & 9 & $\checkmark$ & & $\sqrt{ }$ & & \\
\hline Management commitment & 8 & $J$ & & $\sqrt{ }$ & & \\
\hline Product quality & 8 & $\checkmark$ & & $\sqrt{ }$ & & \\
\hline Process optimization for waste reduction & 8 & $\checkmark$ & & & $\sqrt{ }$ & \\
\hline Cost savings & 8 & $\checkmark$ & & $\sqrt{ }$ & & \\
\hline $\begin{array}{l}\text { Decrease of consumption for Hazardous/Harmful/Toxic } \\
\text { materials }\end{array}$ & 8 & $\checkmark$ & & $\sqrt{ }$ & & \\
\hline Emissions & 8 & $\checkmark$ & & $\sqrt{ }$ & & \\
\hline Environmental competencies & 8 & $\sqrt{ }$ & & $\sqrt{ }$ & & \\
\hline Delivery & 8 & $\checkmark$ & & $\sqrt{ }$ & & \\
\hline Reduction of waste water & 8 & $\sqrt{ }$ & & $\sqrt{ }$ & & \\
\hline Supplier commitment & 7 & & $J$ & $\checkmark$ & & \\
\hline Buying env. friendly materials & 7 & $\mathrm{~J}$ & & 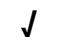 & & \\
\hline
\end{tabular}




\begin{tabular}{|c|c|c|c|c|c|c|}
\hline \multirow[b]{2}{*}{ Metrics* } & \multirow[b]{2}{*}{$\begin{array}{c}\text { Frequency } \\
\text { Rate }\end{array}$} & \multicolumn{5}{|c|}{ Types } \\
\hline & & 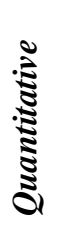 & 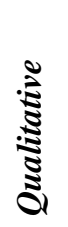 & 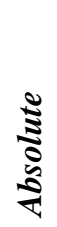 & $\frac{\stackrel{\Xi}{\Xi}}{\tilde{\Xi}}$ & 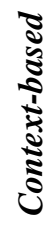 \\
\hline Recycling revenues & 7 & 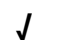 & & $\sqrt{ }$ & & \\
\hline Pollution control & 7 & $\checkmark$ & & $\sqrt{ }$ & & \\
\hline Buying env. friendly technology & 7 & $\checkmark$ & & $\sqrt{ }$ & & \\
\hline Energy used & 7 & $J$ & & $\sqrt{ }$ & & \\
\hline Chemical waste (e.g. lead) & 7 & $\sqrt{ }$ & & $\sqrt{ }$ & & \\
\hline Total Cost & 7 & $J$ & & $\sqrt{ }$ & & \\
\hline Traditional supply chain cost & 7 & $J$ & & $\sqrt{ }$ & & \\
\hline Cost/price & 7 & $\sqrt{ }$ & & & $\sqrt{ }$ & \\
\hline Customer returns & 6 & $\sqrt{ }$ & & $\sqrt{ }$ & & \\
\hline Decrease of cost for energy consumption & 6 & $\checkmark$ & & $\sqrt{ }$ & & \\
\hline Decrease of fee for waste treatment & 6 & $J$ & & $\sqrt{ }$ & & \\
\hline Process innovation & 6 & & $\checkmark$ & $\sqrt{ }$ & & \\
\hline Product design for remanufacturing & 6 & & $J$ & $\sqrt{ }$ & & \\
\hline Green design & 6 & & $\checkmark$ & $\sqrt{ }$ & & \\
\hline Decrease of fine for environmental accidents & 6 & $J$ & & $\sqrt{ }$ & & \\
\hline Energy & 6 & 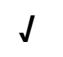 & & $\sqrt{ }$ & & \\
\hline Decrease of cost for materials purchasing & 6 & $\sqrt{ }$ & & $\sqrt{ }$ & & \\
\hline Discrimination & 6 & & 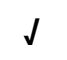 & $\sqrt{ }$ & & \\
\hline Research and Development & 6 & & $\sqrt{ }$ & $\sqrt{ }$ & & \\
\hline Emissions to air & 6 & $\sqrt{ }$ & & $\sqrt{ }$ & & \\
\hline Carbon emission & 6 & $J$ & & $\sqrt{ }$ & & \\
\hline Disposal costs & 6 & $\checkmark$ & & $\sqrt{ }$ & & \\
\hline Green image & 6 & & $J$ & $\sqrt{ }$ & & \\
\hline Total supply chain cost & 6 & $J$ & & $\sqrt{ }$ & & \\
\hline Total inventory cost & 6 & $\checkmark$ & & $\sqrt{ }$ & & \\
\hline Production costs & 6 & $J$ & & $\sqrt{ }$ & & \\
\hline Env. policies and audits & 6 & & $J$ & $\sqrt{ }$ & & \\
\hline Quality system (e.g. ISO 14000) & 6 & & $J$ & $J$ & & \\
\hline
\end{tabular}




\begin{tabular}{|c|c|c|c|c|c|c|}
\hline \multirow[b]{2}{*}{ Metrics* } & \multirow[b]{2}{*}{$\begin{array}{l}\text { Frequency } \\
\text { Rate }\end{array}$} & \multicolumn{5}{|c|}{ Types } \\
\hline & & 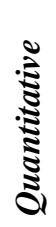 & 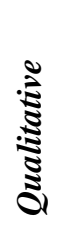 & 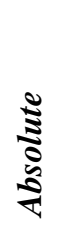 & 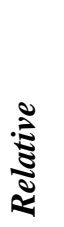 & 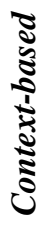 \\
\hline Marketing and green image & 5 & & 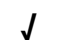 & $\sqrt{ }$ & & \\
\hline $\begin{array}{l}\text { Cumulative energy demand (primary energy used over the life } \\
\text { cycle of a product or a process) }\end{array}$ & 5 & $\sqrt{ }$ & & $\sqrt{ }$ & & \\
\hline Labour productivity & 5 & $\checkmark$ & & & $\checkmark$ & \\
\hline Human capital & 5 & $\sqrt{ }$ & & $\sqrt{ }$ & & \\
\hline Revenues from "green” products & 5 & $\checkmark$ & & $\sqrt{ }$ & & \\
\hline Cost avoidance from environmental actions & 5 & $\mathrm{~J}$ & & J & & \\
\hline Supplier initiatives & 5 & & $\checkmark$ & $\sqrt{ }$ & & \\
\hline Recovery cost (+/-) & 5 & $\checkmark$ & & $\sqrt{ }$ & & \\
\hline Capacity utilization & 5 & $\mathrm{~J}$ & & & J & \\
\hline Raw material costs & 5 & $\sqrt{ }$ & & $\sqrt{ }$ & & \\
\hline Raw material consumption & 5 & $\checkmark$ & & $\sqrt{ }$ & & \\
\hline Health and Safety Incidents & 5 & & $\mathrm{~J}$ & J & & \\
\hline Security & 5 & & $J$ & $\sqrt{ }$ & & \\
\hline Health & 5 & & $\checkmark$ & $\sqrt{ }$ & & \\
\hline Education & 5 & & $\checkmark$ & $\sqrt{ }$ & & \\
\hline Decrease of fee for waste discharge & 5 & $\checkmark$ & & $\sqrt{ }$ & & \\
\hline Waste reduction & 5 & $\checkmark$ & & $\sqrt{ }$ & & \\
\hline Pollution prevention & 5 & & $\checkmark$ & $\sqrt{ }$ & & \\
\hline Disposal method & 5 & & $\checkmark$ & $\sqrt{ }$ & & \\
\hline Business wastage & 5 & $\checkmark$ & & $\sqrt{ }$ & & \\
\hline Sustainability cost & 5 & $\checkmark$ & & $\sqrt{ }$ & & \\
\hline Delivery lead time & 5 & $\checkmark$ & & $\sqrt{ }$ & & \\
\hline Manufacturing cost & 5 & $\checkmark$ & & $\sqrt{ }$ & & \\
\hline Technology capability & 5 & & $\checkmark$ & $\sqrt{ }$ & & \\
\hline Financial capability & 5 & $\sqrt{ }$ & & $\sqrt{ }$ & & \\
\hline Capital investment & 5 & $\checkmark$ & & $\sqrt{ }$ & & \\
\hline Improve enterprises environmental situation & 5 & & $\sqrt{ }$ & $\sqrt{ }$ & & \\
\hline Water emissions & 5 & $\mathrm{~J}$ & & J & & \\
\hline
\end{tabular}

Note: $\quad$ * Only metrics with the frequency rate of 5 or more are presented. 
The results highlight the great variety of approaches for measuring GSCM and SSCM. It is clear that no general agreement on what should be measured in these areas exists. This may be due to lack of agreement on the definitions of GSCM and SSCM. There is still considerable debate about what should even be included in GSCM or SSCM (Ashby et al., 2012; Ahi and Searcy, 2013a), much less how they should be measured. Given that GSCM and SSCM are still in their relatively early stages of development, the great variety of metrics is healthy as they present a multitude of approaches for measuring aspects of these concepts. However, it is likely that there will need to be some convergence on how GSCM and SSCM should be measured over time if they are to continue their advance into mainstream organizational management. Although there will always be a need for metrics that address the unique circumstances of any particular supply chain, a lack of reasonably consistent metrics will greatly impede efforts to compare performance between different supply chains. The results also highlight that the overwhelming majority of the metrics are not tied to the broader sustainability context in which supply chains operate. Although there are a multitude of metrics focused on the measurement of absolute or relative performance, there are few metrics that make any effort to link to the broader environmental (e.g., Rockstrom et al., 2009) or social (e.g., McElroy et al., 2008) context and none that meet the definition of context-based metrics provided earlier. Building on arguments by McElroy and van Engelen (2012), this is a significant gap in sustainability measurement that must be addressed to get a sense of whether supply chains are truly sustainable or not in the short- and long-term. Organizations must undoubtedly pay attention to their absolute and relative performance metrics. These are essential in monitoring their own performances over time. However, they must also link their performances to the broader sustainability context in which they, and their supply chains, operate. Comprehensive measurement of GCSM or SSCM requires the use of absolute, relative, and context-based sustainability metrics.

\subsection{Analysis of Metrics by Key Characteristics of SSCM}

A number of sustainability frameworks were considered to guide the analyses of the metrics, including the GRI, ISO 14031, and ISO 26000. However, it was soon recognized that the application of these frameworks would be problematic since they were not designed primarily to address the measurement of sustainability in a supply chain context. The definition of SSCM suggested in Chapter 5 (i.e., published in Ahi and Searcy, 2013a) was therefore used as a basis 
for an analysis of the extent to which the metrics addressed the key characteristics of SSCM. It is important to emphasize that different interpretations have been provided to describe SSCM in the literature (Ahi and Searcy, 2013a). The decision to use the definition of SSCM offered in Chapter 5 was made for several reasons. First, that definition was derived following an in-depth analysis of 22 published definitions of GSCM and 12 published definitions of SSCM. The definition was based on a review of the recent literature and captures the current state-of-the art in SSCM. Second, the definition was further based on an analysis of the underlying characteristics of business sustainability and SCM. Using a definition of SSCM based on these primary principles provided insight into key aspects of business sustainability and SCM that were not adequately captured in the definitions published earlier. The definition provided in Chapter 5 is arguably the most comprehensive definition of SSCM offered to date. The definition therefore provides a strong starting point for determining what issues should be measured when assessing SSCM performance.

Following the logic developed in Chapter 5, each metric identified in the literature search was evaluated to determine whether it addressed the 7 key characteristics of business sustainability (i.e., "economic, environmental, social, stakeholder, volunteer, resilience, and long-term focuses") and 7 key characteristics of SCM (i.e., "flow, coordination, stakeholder, relationship, value, efficiency, and performance focuses") identified in the chapter. Since the stakeholder focus appeared in both lists of characteristics, each metric was thus analyzed against a total of 13 key characteristics of SSCM. Cases where metrics addressed multiple characteristics were also noted. A summary of the results of this analysis is provided in Table 6-3. Definitions of each characteristic are also provided in the table. 
Table 6-3: Distribution of SSCM key characteristics addressed by the identified metrics

\begin{tabular}{|c|c|c|c|c|c|c|c|c|c|c|c|c|c|}
\hline \multirow[b]{2}{*}{ Metrics } & \multicolumn{13}{|c|}{ SSCM Characteristics* } \\
\hline & 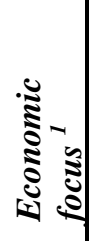 & 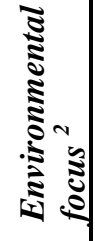 & 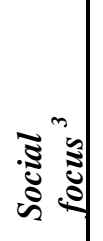 & 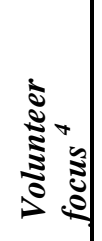 & 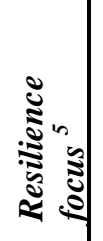 & 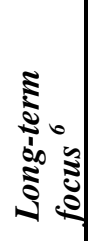 & 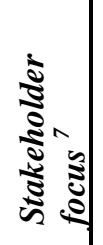 & 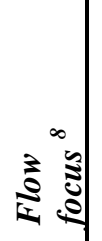 & 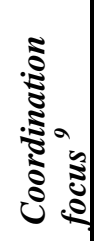 & 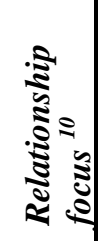 & 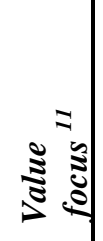 & 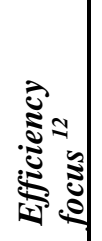 & 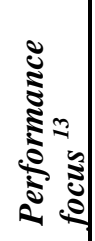 \\
\hline Quality & $\mathrm{J}$ & J & 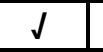 & & & & & & & & & & \\
\hline Air emissions & & $\sqrt{ }$ & & & & & & & & & & & \\
\hline Energy use & & $\sqrt{2}$ & & & & & & & & & & & \\
\hline Greenhouse gas emissions & & J & & & & & & & & & & & \\
\hline Energy consumption & & $\sqrt{ }$ & & & & & & & & & & & \\
\hline Recycling & & $\mathrm{J}$ & & & & & & & & & & & \\
\hline Solid waste(s) & & $\sqrt{ }$ & & & & & & & & & & & \\
\hline Flexibility & $\mathrm{J}$ & & & & & & & & & & & & \\
\hline Environmental management system & & $\sqrt{ }$ & & & & & & & & & & & \\
\hline Customers' satisfaction & $\mathrm{J}$ & & J & & & & $\mathrm{J}$ & & & & & & \\
\hline Carbon footprint & & 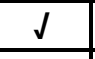 & & & & & & & & & & & \\
\hline Life cycle assessment (LCA) & & $\sqrt{2}$ & & & & $\sqrt{2}$ & & & & & & & \\
\hline Cost & $\mathrm{J}$ & & & & & & & & & & & & \\
\hline Profit & $J$ & & & & & & & & & & $\sqrt{ }$ & & \\
\hline Water consumption & & $\sqrt{ }$ & & & & & & & & & & & \\
\hline Energy efficiency & & $\begin{array}{l} \\
\end{array}$ & & & & & & & & & & $\mathrm{J}$ & \\
\hline Reduction of air emission(s) & & J & & & & & & & & & & & \\
\hline Reduction of solid wastes & & $\sqrt{ }$ & & & & & & & & & & & \\
\hline Product characteristics & $\mathrm{d}$ & $\mathrm{J}$ & $\mathrm{J}$ & & & & & & & & & & \\
\hline Return on investment & $\mathrm{J}$ & & & & & & & & & & & & \\
\hline Environmental costs & $\sqrt{3}$ & $\begin{array}{l} \\
\end{array}$ & & & & & & & & & & & \\
\hline Market share & 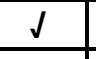 & & & & & & & & & & $J$ & & \\
\hline Operational cost (Operating cost) & $\mathrm{J}$ & & & & & & & & & & & & \\
\hline
\end{tabular}




\begin{tabular}{|c|c|c|c|c|c|c|c|c|c|c|c|c|c|}
\hline \multirow[b]{2}{*}{ Metrics } & \multicolumn{13}{|c|}{ SSCM Characteristics* } \\
\hline & 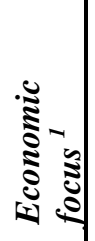 & 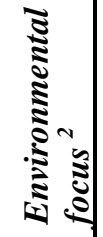 & 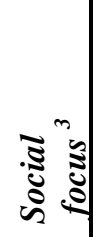 & 竎 & 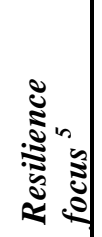 & 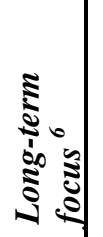 & 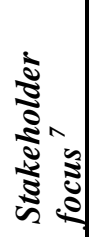 & $\frac{3}{1} \overbrace{}^{\infty}$ & 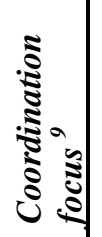 & 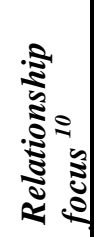 & 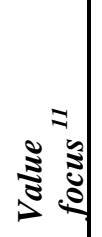 & 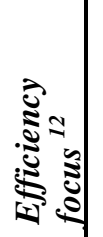 & 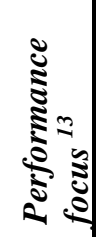 \\
\hline ISO 14001 certification & & $\mathrm{J}$ & & & & & & & & & & & \\
\hline $\mathrm{CO}_{2}$ emissions & & $\bar{J}$ & & & & & & & & & & & \\
\hline Level of process management & 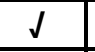 & 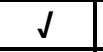 & & & & & & & & & & & \\
\hline Water waste & & $\sqrt{2}$ & & & & & & & & & & & \\
\hline Product features & $\mathrm{J}$ & J & $\mathrm{J}$ & & & & & & & & & & \\
\hline Management initiatives & $\mathrm{J}$ & & $\mathrm{J}$ & & & & & & & & & & \\
\hline Responsiveness & $\mathrm{J}$ & & $\mathrm{J}$ & & & & & & & & & & \\
\hline Decrease of frequency for environmental accidents & & $\mathrm{J}$ & & & & & & & & & & & \\
\hline Water use & & $\sqrt{2}$ & & & & & & & & & & & \\
\hline Decrease of consumption for Hazardous/Harmful/Toxic materials & & $\mathrm{J}$ & & & & & & & & & & & \\
\hline Emissions & & $\mathrm{J}$ & & & & & & & & & & & \\
\hline Process optimization for waste reduction & & $\mathrm{J}$ & & & & & & & & & & & $\mathrm{J}$ \\
\hline Environmental competencies & & $\sqrt{2}$ & & & & & & & & & & & \\
\hline Delivery & J & & & & & & & & & & & & \\
\hline Management commitment & 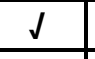 & $\mathrm{J}$ & $\mathrm{J}$ & & & & & & & & & & \\
\hline Product quality & 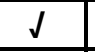 & 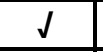 & J & & & & & & & & & & \\
\hline Cost savings & $\sqrt{ }$ & & & & & & & & & & & & J \\
\hline Reduction of waste water & & $\mathrm{J}$ & & & & & & & & & & & \\
\hline Energy used & & $\sqrt{J}$ & & & & & & & & & & & \\
\hline Buying env. friendly materials & $J$ & J & & & & & & & & & & & \\
\hline Recycling revenues & $\mathrm{J}$ & $\mathrm{J}$ & & & & & & & & & & & \\
\hline Chemical waste (e.g. lead) & & 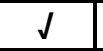 & & & & & & & & & & & \\
\hline Pollution control & & $\bar{J}$ & & & & & & & & & & & $\mathrm{~J}$ \\
\hline Total cost & J & & & & & & & & & & & & \\
\hline
\end{tabular}




\begin{tabular}{|c|c|c|c|c|c|c|c|c|c|c|c|c|c|}
\hline \multirow[b]{2}{*}{ Metrics } & \multicolumn{13}{|c|}{ SSCM Characteristics* } \\
\hline & 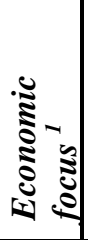 & 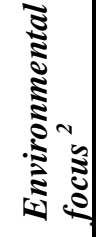 & : & 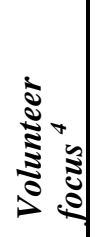 & 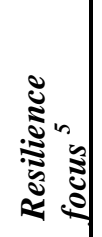 & 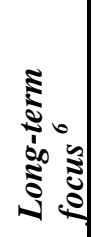 & 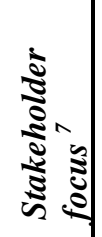 & $\frac{3}{2}$ & 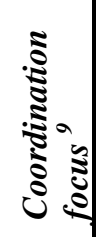 & 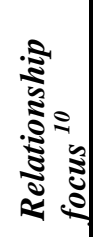 & 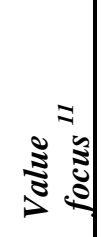 & 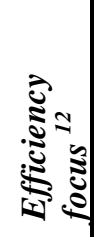 & 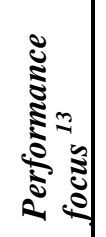 \\
\hline Supplier commitment & $\mathrm{J}$ & & $\mathrm{J}$ & & & & $\mathrm{J}$ & & & & & & \\
\hline Traditional supply chain cost & J & & & & & & & & & & & & \\
\hline Buying env. friendly technology & $J$ & $\sqrt{2}$ & & & & & & & & & & & \\
\hline Cost/price & $\mathrm{J}$ & & & & & & & & & & & & \\
\hline Decrease of cost for energy consumption & $\mathrm{J}$ & $\mathrm{J}$ & & & & & & & & & & & \\
\hline Energy & & $\mathrm{J}$ & & & & & & & & & & & \\
\hline Decrease of cost for materials purchasing & J & & & & & & & & & & & & \\
\hline Discrimination & & & J & & & & & & & & & & \\
\hline Research and Development & & & 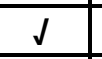 & & & & & & & & & & \\
\hline Emissions to air & & $\mathrm{J}$ & & & & & & & & & & & \\
\hline Carbon emission & & 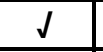 & & & & & & & & & & & \\
\hline Decrease of fee for waste treatment & J & $\mathrm{J}$ & & & & & & & & & & & \\
\hline Disposal costs & J & & & & & & & & & & & & \\
\hline Customer returns & J & & $\sqrt{2}$ & & & & $\mathrm{~J}$ & & & & & & \\
\hline Green image & & $\sqrt{2}$ & & & & & & & & & & & \\
\hline Total supply chain cost & J & & & & & & & & & & & & \\
\hline Process innovation & J & $\mathrm{J}$ & & & & & & & & & & & \\
\hline Product design for remanufacturing & J & $\mathrm{J}$ & & & & & & & & & & & \\
\hline Total inventory cost & 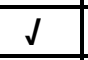 & & & & & & & & & & & & \\
\hline Green design & 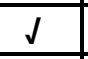 & J & & & & & & & & & & & \\
\hline Production costs & $\mathrm{J}$ & & & & & & & & & & & & \\
\hline Decrease of fine for environmental accidents & $\sqrt{2}$ & $\mathrm{~J}$ & & & & & & & & & & & \\
\hline Env. policies and audits & & 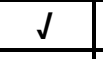 & & & & & & & & & & & \\
\hline Quality system (e.g. ISO 14000) & & J & & & & & & & & & & & \\
\hline
\end{tabular}




\begin{tabular}{|c|c|c|c|c|c|c|c|c|c|c|c|c|c|}
\hline \multirow[b]{2}{*}{ Metrics } & \multicolumn{13}{|c|}{ SSCM Characteristics* } \\
\hline & 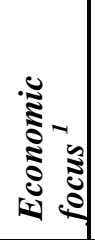 & 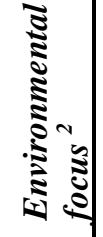 & : & 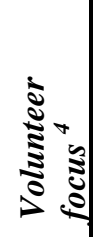 & 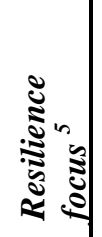 & 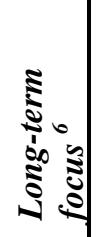 & 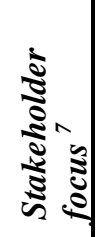 & 空 & 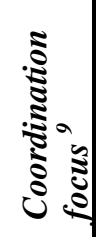 & 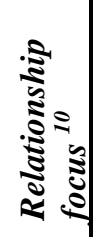 & 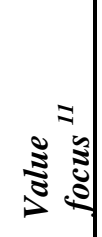 & 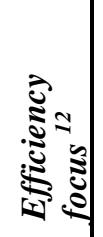 & 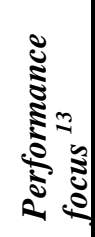 \\
\hline $\begin{array}{l}\text { Cumulative energy demand (primary energy used over the life cycle of a product } \\
\text { or a process) }\end{array}$ & & $\sqrt{ }$ & & & & $\sqrt{ }$ & & & & & & & \\
\hline Raw material costs & $\mathrm{J}$ & & & & & & & & & & & & \\
\hline Raw material consumption & & $\mathrm{J}$ & & & & & & & & & & & \\
\hline Health and Safety Incidents & & & $\mathrm{J}$ & & & & & & & & & & \\
\hline Security & & & $\mathrm{J}$ & & & & & & & & & & \\
\hline Labour productivity & J & & $\mathrm{J}$ & & & & & & & & & & \\
\hline Human capital & J & & $\sqrt{ }$ & & & & & & & & & & \\
\hline Health & & & $\bar{J}$ & & & & & & & & & & \\
\hline Education & & & $\mathrm{J}$ & & & & & & & & & & \\
\hline Decrease of fee for waste discharge & $\mathrm{J}$ & & & & & & & & & & & & \\
\hline Waste reduction & & J & & & & & & & & & & & \\
\hline Pollution prevention & & $\sqrt{ }$ & & & & & & & & & & & \\
\hline Disposal method & & $\sqrt{2}$ & & & & & & & & & & & \\
\hline Business wastage & & J & & & & & & & & & & & \\
\hline Revenues from "green” products & J & $\mathrm{J}$ & & & & & & & & & & & \\
\hline Cost avoidance from environmental actions & J & J & & & & & & & & & & & \\
\hline Sustainability cost & $\sqrt{2}$ & & & & & & & & & & & & \\
\hline Supplier initiatives & & & $\mathrm{J}$ & & & & $\mathrm{J}$ & & & & & & \\
\hline Delivery lead time & J & & & & & & & & & & & & \\
\hline Marketing and green image & J & J & & & & & & & & & $\mathrm{J}$ & & \\
\hline Recovery cost (+/-) & J & $\sqrt{2}$ & & & & & & & & & & & \\
\hline Manufacturing cost & J & & & & & & & & & & & & \\
\hline Capacity utilization & $\sqrt{J}$ & & & & & & & & & & & & $\sqrt{J}$ \\
\hline Technology capability & J & & & & & & & & & & & & \\
\hline
\end{tabular}




\begin{tabular}{|c|c|c|c|c|c|c|c|c|c|c|c|c|c|}
\hline \multirow[b]{2}{*}{ Metrics } & \multicolumn{13}{|c|}{ SSCM Characteristics* } \\
\hline & 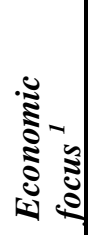 & 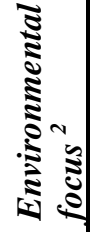 & 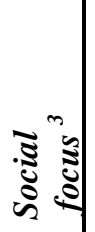 & 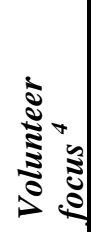 & 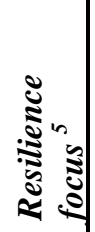 & 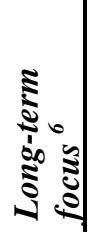 & 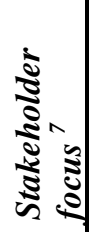 & $\frac{3}{1} \stackrel{0}{3}$ & 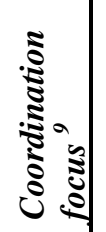 & 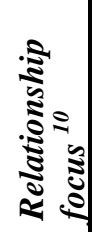 & 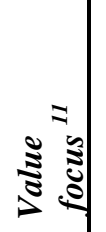 & 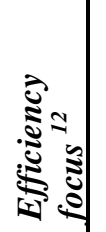 & 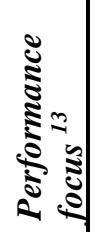 \\
\hline Financial capability & $\checkmark$ & & & & & & & & & & & & \\
\hline Capital investment & $\sqrt{2}$ & & & & & & & & & & & & \\
\hline Improve enterprises environmental situation & & $J$ & & & & & & & & & & & \\
\hline Water emissions & & 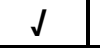 & & & & & & & & & & & \\
\hline
\end{tabular}

Notes: $\quad *$ All the definitions are adopted from Ahi and Searcy (2013a):

${ }^{1}$ Economic focus: "The definition includes language related to the economic dimension of sustainability."

${ }^{2}$ Environmental focus: "The definition includes language related to the environmental dimension of sustainability."

${ }^{3}$ Social focus: "The definition includes language related to the social dimension of sustainability."

${ }^{4}$ Volunteer focus: "The definition includes reference to the voluntary nature of business sustainability."

${ }^{5}$ Resilience focus: "The definition includes reference to resilience, defined as "an ability to recover from or adjust easily to misfortune or change” (Merriam-Webster,

2012)”. Note that metrics specifically addressing risk were considered to address this focus as well.

${ }^{6}$ Long-term focus: “The definition includes reference to the long-term nature of sustainability. Reference to end-of-life management, reuse, product recovery, reverse logistics, the closed-loop supply chain, and the product life cycle were taken as indications of a long-term focus.”

${ }^{7}$ Stakeholder focus: "The definition includes explicit reference to stakeholders, including (but not limited to) customers, consumers, and suppliers."

${ }^{8}$ Flow focus: "The definition includes language related to the flows of materials, services, or information. Reference to the supply chain was considered to implicitly refer to this focus area."

${ }^{9}$ Coordination focus: "The definition includes reference to coordination within the organization or between organizations. Reference to the supply chain, the product life cycle, or activities across channels was considered to implicitly refer to this focus area."

${ }^{10}$ Relationship focus: "The definition includes reference to the networks of internal and external relationships. This includes mentioning the coordination of interorganizational business processes."

${ }^{11}$ Value focus: "The definition includes reference to value creation, including increasing profit or market share and converting resources into usable products."

${ }^{12}$ Efficiency focus: "The definition includes reference to efficiency, including a reduction in inputs."

${ }^{13}$ Performance focus: "The definition includes reference to performance, including applying performance measures, improving performance, improving competitive capacity, monitoring, and achieving goals.” 
Analysis of the results shows that approximately $60 \%$ of the metrics focused on a single key characteristic of SSCM. The emphasis on metrics that address one characteristic is not necessarily surprising as metrics are often created to measure progress and guide decisionmaking on a specific issue. Over one-third of the metrics (i.e., 782 metrics or $30.6 \%$ of the total) were found to focus exclusively on environmental issues, 435 (17\%) were found to focus on economic issues, and 310 (12.1\%) were found to focus on social issues. “Air emissions” (28 times), “Energy use” (24), and "Greenhouse gas emissions" (24) were some of the high frequency environmental metrics utilized. “Cost” (12 times), "Return on investment” (11), and “Operational cost” (11) were among the highest frequency economic metrics utilized. Examples of high frequency social metrics include "Discrimination” (6 times), "Health and safety incidents" (5), and "Regulatory and public services" (4). Additional examples are provided in Table 6-3.

\subsubsection{Cross-Cutting Metrics}

Over $40 \%$ of the metrics addressed more than one key characteristic of SSCM. This is of note given that a sustainability perspective is intended to promote an examination of the interrelationships between issues. A summary of the SSCM characteristics that were addressed by any one metric is provided in Table 6-4. As summarized in Table 6-4, 1527 metrics addressed just one characteristic, 744 addressed two characteristics, 247 addressed 3 characteristics, 29 addressed 4 characteristics, and 8 addressed 5 characteristics. No one metric addressed 6 or more characteristics of SSCM. 
Table 6-4: Summary of SSCM characteristics addressed by any one metric

\begin{tabular}{|c|c|c|c|c|c|c|c|c|c|c|c|c|c|c|}
\hline \multicolumn{2}{|l|}{ Categories } & \multicolumn{13}{|c|}{ Number of SSCM Characteristics Addressed in each Category } \\
\hline $\begin{array}{l}\text { No. of Characteristics } \\
\text { Addressed by Any One Metric }\end{array}$ & $\begin{array}{l}\text { No. of } \\
\text { Metrics }\end{array}$ & 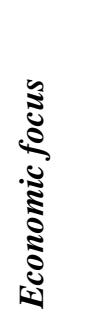 & 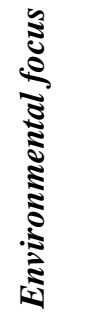 & 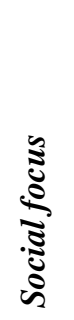 & 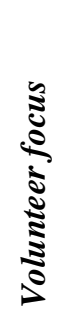 & 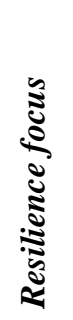 & 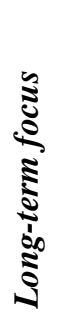 & 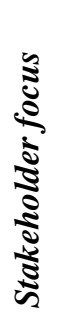 & $\frac{\frac{5}{0}}{\frac{3}{3}}$ & 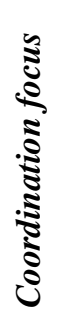 & 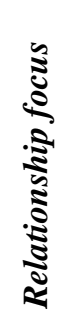 & $\frac{\frac{v}{0}}{\frac{v}{0}}$ & 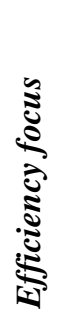 & 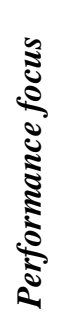 \\
\hline 1 & 1527 & 435 & 782 & 310 & 0 & 0 & 0 & 0 & 0 & 0 & 0 & 0 & 0 & 0 \\
\hline 2 & 744 & 369 & 410 & 281 & 4 & 9 & 64 & 160 & 3 & 4 & 4 & 64 & 20 & 96 \\
\hline 3 & 247 & 165 & 205 & 149 & 0 & 1 & 25 & 95 & 2 & 13 & 5 & 24 & 9 & 48 \\
\hline 4 & 29 & 23 & 27 & 16 & 0 & 6 & 8 & 16 & 0 & 4 & 1 & 6 & 1 & 8 \\
\hline 5 & 8 & 7 & 7 & 4 & 0 & 0 & 5 & 5 & 3 & 2 & 0 & 1 & 1 & 5 \\
\hline Total & 2555 & 999 & 1431 & 760 & 4 & 16 & 102 & 276 & 8 & 23 & 10 & 95 & 31 & 157 \\
\hline
\end{tabular}


The analysis shows that in any combination of addressing various SSCM characteristics, at least one of the economic, environmental, and social focuses was involved. With that in mind, 744 metrics (29.1\% of the total) addressed just two of the characteristics. A summary of the metrics that addressed two characteristics is provided in Table 6-5.

Table 6-5: Number of metrics that addressed two characteristics of SSCM

\begin{tabular}{|c|c|c|c|}
\hline SSCM Characteristics & Economic focus & Environmental focus & Social focus \\
\hline Economic focus & & & \\
\hline Environmental focus & 168 & & \\
\hline Social focus & 70 & 78 & \\
\hline Volunteer focus & 0 & 0 & 4 \\
\hline Resilience focus & 1 & 5 & 3 \\
\hline Long-term focus & 7 & 57 & 0 \\
\hline Stakeholder focus & 12 & 41 & 107 \\
\hline Flow focus & 2 & 1 & 0 \\
\hline Coordination focus & 1 & 3 & 0 \\
\hline Relationship focus & 1 & 1 & 2 \\
\hline Value focus & 59 & 3 & 2 \\
\hline Efficiency focus & 5 & 14 & 1 \\
\hline Performance focus & 43 & 39 & 14 \\
\hline
\end{tabular}


Analysis of Table 6-5 shows that the economic and environmental focuses of SSCM were the most frequently addressed among those metrics that covered two characteristics (i.e., 168 metrics or $6.6 \%$ of the total). The social and stakeholder focuses (107 metrics or $4.2 \%$ ), environmental and social focuses (78 metrics or 3.1\%), and economic and social focuses (70 metrics or 2.7\%) were next. It is also interesting to note that several combinations of characteristics were not covered by any metric. For example, the social focus did not have any explicit overlap with the long-term, flow, or coordination focuses. Examples of the specific metrics that addressed two SSCM characteristics are provided in Table 6-6.

A number of cross-cutting metrics addressed more than two different characteristics of SSCM. In cases where 3 characteristics were simultaneously addressed by a single metric (i.e., 247 metrics or $9.7 \%$ of the total), the most common combination was for metrics that addressed the economic, environmental, and social focuses of SSCM (i.e., 65 metrics or $2.5 \%$ of the total). The next most frequently addressed combinations of characteristics in this category were environmental, social, and stakeholder focuses (41 metrics or 1.6\%), followed by economic, environmental, and performance focuses (26 metrics or $1 \%$ of the total). A complete summary of the cases where three characteristics were addressed by any one metrics is provided in Table 6-7. Examples of each combination are also provided in the table.

A number of other metrics addressed either 4 (i.e., 29 metrics or $1.1 \%$ of the total) or 5 (8 metrics or $0.3 \%$ of the total) of the key SSCM characteristics. Among those metrics that simultaneously addressed 4 characteristics of SSCM, the combination of economic, environmental, social, and stakeholder focuses was most common (i.e., 6 metrics or $0.2 \%$ of the total). Finally, in cases where 5 characteristics were simultaneously addressed, the economic, environmental, long-term, flow, and performance focuses were the most frequently addressed characteristics (i.e., 2 metrics or $0.08 \%$ of the total). All the combinations identified for the various characteristics addressed by the metrics of these categories are provided in Tables 6-8 and 6-9, respectively. These two tables also present example metrics for the relevant combination of characteristics. It is important to note that no metric addressed 6 or more characteristics of SSCM. 
Table 6-6: Examples of the metrics that addressed two SSCM characteristics

\begin{tabular}{|c|c|c|c|}
\hline $\begin{array}{c}\text { SSCM } \\
\text { Characteristics }\end{array}$ & Economic focus & Environmental focus & Social focus \\
\hline \multicolumn{4}{|l|}{ Economic focus } \\
\hline Environmental focus & $\begin{array}{l}\text { Environmental costs (11), Buying } \\
\text { environmentally friendly materials (7), } \\
\text { Decrease of cost for energy consumption (6) }\end{array}$ & & \\
\hline Social focus & $\begin{array}{l}\text { Customer's satisfaction (14), Customer } \\
\text { returns (6), Human capital (5) }\end{array}$ & $\begin{array}{l}\text { Environmental social concerns (4), Number of } \\
\text { employees with incentives related to environmental } \\
\text { goals (3), Cooperation with customers for green } \\
\text { packaging (2) }\end{array}$ & \\
\hline Volunteer focus & --- & --- & $\begin{array}{l}\text { Participation in voluntary programs (2), } \\
\text { Volunteer hours spent at local schools (1), } \\
\text { Number of individual volunteering (1) }\end{array}$ \\
\hline Resilience focus & Risks and recoverability (\%; \%) (1) & $\begin{array}{l}\text { Risk of severe accidents (2), Environmental risks } \\
\text { (1), Risks of environmental accidents (1) }\end{array}$ & $\begin{array}{l}\text { Corruption risk (2), Health status and risks } \\
\text { (1), Risk information sharing (1) }\end{array}$ \\
\hline Long-term focus & $\begin{array}{l}\text { Net life cycle cost (2), Long-term debt, } \\
\text { including current portion (1), Revenues of } \\
\text { reused parts (1) }\end{array}$ & $\begin{array}{l}\text { Life cycle assessment (LCA) (12), Cumulative } \\
\text { energy demand (primary energy used over the life } \\
\text { cycle of a product or a process) (5), Product life } \\
\text { cycle stage (2) }\end{array}$ & --- \\
\hline Stakeholder focus & $\begin{array}{l}\text { Supplier lead time (2), Returning customers } \\
\text { ratio (2), Level of supplier preprocessing of } \\
\text { raw materials (1) }\end{array}$ & $\begin{array}{l}\text { Environmental partnership with suppliers (2), } \\
\text { Energy used per customer (2), Choosing suppliers } \\
\text { according to environmental criteria (2) }\end{array}$ & $\begin{array}{l}\text { Stakeholder engagement (4), Stakeholder } \\
\text { empowerment (4), The rights of } \\
\text { stakeholders (2) }\end{array}$ \\
\hline Flow focus & $\begin{array}{l}\text { Cash flow (1), Cash flow provided by } \\
\text { operating activities (1) }\end{array}$ & $\begin{array}{l}\text { Annual mass-flow of different materials used } \\
\text { (excluding energy carriers and water) (in tons) (1) }\end{array}$ & --- \\
\hline
\end{tabular}




\begin{tabular}{|c|c|c|c|}
\hline $\begin{array}{c}\text { SSCM } \\
\text { Characteristics }\end{array}$ & Economic focus & Environmental focus & Social focus \\
\hline Coordination focus & Cooperation degree (1) & $\begin{array}{l}\text { Collaborating with other companies and } \\
\text { organisations for environmental initiatives (1), } \\
\text { Improving opportunities for reducing waste through } \\
\text { cooperation with other actors (1), Cross-functional } \\
\text { cooperation between departments for environmental } \\
\text { improvements (1) }\end{array}$ & --- \\
\hline Relationship focus & Networks (2) & $\begin{array}{l}\text { Interaction and harmony co-exist with natural } \\
\text { systems on production and consumption systems (1) }\end{array}$ & Relationship (3), After sales service (2) \\
\hline Value focus & Profit (12), Market share (11), Sales (4) & $\begin{array}{l}\text { Energy requirement per unit of net value added (1), } \\
\text { Dependency on ozone-depleting substances per unit } \\
\text { of net value added (1), Global warming contribution } \\
\text { per unit of net value added (1) }\end{array}$ & $\begin{array}{l}\text { Publicly available missions and values } \\
\text { statement(s) (2), Value added and } \\
\text { community benefits (1) }\end{array}$ \\
\hline Efficiency focus & $\begin{array}{l}\text { Existing efficiency vs. cost of upgrading (2), } \\
\text { Increased cost efficiency (1), } \\
\text { Productivity/efficiency (1) }\end{array}$ & $\begin{array}{l}\text { Energy efficiency (11), Water efficiency (4), } \\
\text { Recycling efficiency (3) }\end{array}$ & Institutional efficiency (1) \\
\hline Performance focus & $\begin{array}{l}\text { Cost savings (8), Capacity utilization (5), } \\
\text { Operational performance (4) }\end{array}$ & $\begin{array}{l}\text { Process optimization for waste reduction (8), } \\
\text { Pollution control (7), Optimization of process to } \\
\text { reduce air emissions (4) }\end{array}$ & $\begin{array}{l}\text { Optimization of process to reduce noise } \\
\text { (4), Effectiveness of staff training } \\
\text { programs (2), Health and safety } \\
\text { performance measurement systems (1) }\end{array}$ \\
\hline
\end{tabular}


Table 6-7: Number of metrics, with examples, that addressed three characteristics of SSCM

\begin{tabular}{|c|c|c|}
\hline SSCM Characteristics & $\begin{array}{l}\text { No. of } \\
\text { Metrics }\end{array}$ & Examples of Cross-cutting Metrics (Frequency rates) \\
\hline Economic, Environmental and Social focuses & 65 & $\begin{array}{l}\text { Quality (31), Product features (9), Major environmental, social, and economic impacts associated } \\
\text { with the life cycle of products and services (2) }\end{array}$ \\
\hline Environmental, Social and Stakeholder focuses & 41 & \# of Certified suppliers (3), Supplier’s green image (2), Green consumer perception (2) \\
\hline Economic, Environmental and Performance focuses & 26 & $\begin{array}{l}\text { Facility material use and performance (2), Environmental technology investment cost savings (1), } \\
\text { Performance in using resources (1) }\end{array}$ \\
\hline Economic, Social and Stakeholder focuses & 21 & $\begin{array}{l}\text { Customers' satisfaction (14), Customer returns (6), Flexibility of production systems to meet } \\
\text { particular customer needs (3) }\end{array}$ \\
\hline Economic, Environmental and Value focuses & 15 & $\begin{array}{l}\text { Marketing and green image (5), Sale of scrap and used materials (2), Energy consumption per } \\
\text { added industrial value (1) }\end{array}$ \\
\hline Economic, Environmental and Long-term focuses & 14 & $\begin{array}{l}\text { Reuse and remanufacturing (2), Longer operational life of production equipment and products (2), } \\
\text { Recovery of the company’s end-of-life products (1) }\end{array}$ \\
\hline Economic, Environmental and Efficiency focuses & 8 & $\begin{array}{l}\text { Transportation network efficiency (2), Significant improvement in terms of resources } \\
\text { management efficiency (2), Development of energy-efficient products (1) }\end{array}$ \\
\hline Environmental, Stakeholder and Performance focuses & 7 & $\begin{array}{l}\text { Supplier performance (2), Effectiveness of supplier training in environmental issues (1), } \\
\text { Effectiveness of supplier monitoring (1) }\end{array}$ \\
\hline Environmental, Stakeholder and Coordination focuses & 5 & $\begin{array}{l}\text { Cooperation with suppliers for environmental objectives (2), Environmental collaboration with } \\
\text { customers (1), Cooperation with our suppliers for eco-design (1) }\end{array}$ \\
\hline Economic, Social and Long-term focuses & 5 & $\begin{array}{l}\text { Procedures to assist product and service designers to create products or services with reduced } \\
\text { adverse life cycle impact (2), Active participation of wholesalers in products collection, recovery } \\
\text { and reuse (1), Active participation of retailers in products collection, recovery and reuse (1) }\end{array}$ \\
\hline Economic, Stakeholder and Value focuses & 4 & $\begin{array}{l}\text { Virgin-component supplier's profits (1), Increased market share as a result of enhanced reputation } \\
\text { attracting new customers (1), Profitability of the supplier (1) }\end{array}$ \\
\hline Social, Stakeholder and Performance focuses & 4 & $\begin{array}{l}\text { Percentage of significant suppliers and contractors that have undergone screening on human rights } \\
\text { and actions taken (1), Customer service performance (1), Suppliers' human rights performance (1) }\end{array}$ \\
\hline Economic, Environmental and Stakeholder focuses & 3 & $\begin{array}{l}\text { Supplier management (1), Supplier innovativeness (1), Transporting products to the consumers } \\
\text { (1) }\end{array}$ \\
\hline Environmental, Long-term and Stakeholder focuses & 3 & $\begin{array}{l}\text { Percentage of suppliers offering component recovery and reuse (1), Raw material recycled from } \\
\text { consumer (1), Packaging reuse, refurbish, recycle, salvage, donate, etc. via retailers, wholesalers, } \\
\text { manufacturers and suppliers (1), }\end{array}$ \\
\hline Environmental, Social and Coordination focuses & 3 & $\begin{array}{l}\text { Cross-functional cooperation for environmental improvements (2), The firm sponsors } \\
\text { environmental events and/or establishes collaboration with ecologist organizations (1), Close } \\
\text { environmental manufacturer-client cooperation (1) }\end{array}$ \\
\hline Social, Stakeholder and Relationships focuses & 3 & Supplier relationships (3), Interaction with suppliers (3), Relationship to the supplier (1) \\
\hline
\end{tabular}




\begin{tabular}{|c|c|c|}
\hline SSCM Characteristics & $\begin{array}{l}\text { No. of } \\
\text { Metrics }\end{array}$ & Examples of Cross-cutting Metrics (Frequency rates) \\
\hline Economic, Value and Performance focuses & 2 & Price performance value (1), Profits/savings (1) \\
\hline Environmental, Social and Performance focuses & 2 & $\begin{array}{l}\text { Management systems pertaining to social and environmental performance (2), Developing a } \\
\text { mutual understanding of responsibilities regarding environmental performance (2) }\end{array}$ \\
\hline Economic, Stakeholder and Coordination focuses & 2 & Cooperation with suppliers (1), Strengthening cooperation with partners (1) \\
\hline Economic, Stakeholder and Performance focuses & 1 & $\begin{array}{l}\text { Rethinking and restructuring supply strategy and the organization and management of supplier } \\
\text { portfolio through, e.g. tiered networks, bundled outsourcing, and supply base reduction (1) }\end{array}$ \\
\hline Economic, Environmental and Flow focuses & 1 & Total flow quantity of scrap (4) \\
\hline Economic, Social and Performance focuses & 1 & Expenditure saved on illness and accident prevention (1) \\
\hline Economic, Long-term and Value focuses & 1 & Short-term and long-term profits (2) \\
\hline Economic, Flow and Performance focuses & 1 & Optimized workflow (1) \\
\hline Environmental, Efficiency and Performance focuses & 1 & Optimisation of efficiency through the use of energy efficient vehicles (1) \\
\hline Environmental, Coordination and Performance focuses & 1 & $\begin{array}{l}\text { When there is a wish to improve in some environmental aspect, the firm establishes collaboration } \\
\text { with other firms so that they can help to achieve the improvement (1) }\end{array}$ \\
\hline Environmental, Social and Relationship focuses & 1 & $\begin{array}{l}\text { The firm adapts or modifies organizational structures (the organizational chart and the description } \\
\text { of roles within the organization) if necessary in order to facilitate environmental management (1) }\end{array}$ \\
\hline Environmental, Social and Value focuses & 1 & $\begin{array}{l}\text { Cleaner production activities are recognized by society, as a result of which the value of corporate } \\
\text { brand is increased (1) }\end{array}$ \\
\hline Environmental, Resilience and Performance focuses & 1 & Effective management of environmental risks affecting our business (1) \\
\hline Environmental, Long-term and Value focuses & 1 & Quantity of non-product output returned to market by recycling or reuse (3) \\
\hline Environmental, Long-term and Performance focuses & 1 & Effectiveness of reverse logistics system (1) \\
\hline Social, Stakeholder and Coordination focuses & 1 & Customer cooperation (2) \\
\hline Social, Coordination and Relationship focuses & 1 & Collaborative relationships (1) \\
\hline
\end{tabular}


Table 6-8: Number of metrics, with examples, that addressed four characteristics of SSCM

\begin{tabular}{|c|c|c|}
\hline SSCM Characteristics & $\begin{array}{l}\text { No. of } \\
\text { Metrics }\end{array}$ & Examples of Cross-cutting Metrics (Frequency rates) \\
\hline Economic, Environmental, Social and Stakeholder focuses & 6 & $\begin{array}{l}\text { Arranging for funds to help suppliers to purchase equipment for pollution prevention, } \\
\text { waste water recycling, etc. (1), Consumer concern towards sustainable practices (1), } \\
\text { Level of management effort to enlighten consumers on sustainability (1) }\end{array}$ \\
\hline Environmental, Social, Stakeholder and Coordination focuses & 4 & $\begin{array}{l}\text { Cooperation with customers for green packaging (2), Cooperation with customers for } \\
\text { cleaner production ( } 2 \text { ), Cooperation with customers for using less energy during } \\
\text { product transportation (2) }\end{array}$ \\
\hline Economic, Environmental, Social and Resilience focuses & 4 & Risk (2), Risk reduction (1), Total perceived risks (1) \\
\hline Economic, Environmental, Long-term and Performance focuses & 3 & $\begin{array}{l}\text { Savings from recycled materials (2), Material recovery cost savings (1), } \\
\text { Competitiveness of the forward and reverse supply chain (1) }\end{array}$ \\
\hline Economic, Environmental, Value and Performance focuses & 3 & $\begin{array}{l}\text { Level of market share controlled by green products (1), Sales revenue attributable to a } \\
\text { new product or a by-product designed to meet environmental performance objectives } \\
\text { (1), Output value of products utilisation of waste gas, water \& solid wastes (1) }\end{array}$ \\
\hline Economic, Environmental, Social and Long-term focuses & 1 & $\begin{array}{l}\text { Major environmental, social, and economic impacts associated with the life cycle of } \\
\text { products and services (2) }\end{array}$ \\
\hline Economic, Environmental, Resilience and Performance focuses & 1 & Environmental risk/ penalties cost savings (1) \\
\hline Economic, Environmental, Resilience and Stakeholder focuses & 1 & $\begin{array}{l}\text { Reduced risk of business interruption as a result of regulatory violation, boycott, } \\
\text { supplier interruption, spills, toxic release, etc. (1) }\end{array}$ \\
\hline Economic, Environmental, Long-term and Value focuses & 1 & $\begin{array}{l}\text { Material recyclables in \% (i.e., Annual value of components recycled at the end of } \\
\text { product life cycle in \$ / Annual production aggregated in \$) (1) }\end{array}$ \\
\hline Economic, Environmental, Stakeholder and Value focuses & 1 & Value of supplier environmental initiatives (per month) (1) \\
\hline Economic, Stakeholder, Relationship and Efficiency focuses & 1 & $\begin{array}{l}\text { After-sales service efficiency = number of customers served/the number of customers } \\
\text { seeking service (2) }\end{array}$ \\
\hline Economic, Long-term, Stakeholder and Value focuses & 1 & Recycled-component supplier’s profits (1) \\
\hline Environmental, Long-term, Stakeholder and Performance focuses & 1 & $\begin{array}{l}\text { Percentage of suppliers having environmental management, auditing systems and life- } \\
\text { cycle environmental accounting (1) }\end{array}$ \\
\hline Environmental, Social, Long-term and Stakeholder focuses & 1 & Encourage customers to reuse/recycling of products/packaging (1) \\
\hline
\end{tabular}


Table 6-9: Number of metrics, with examples, that addressed five characteristics of SSCM

\begin{tabular}{|c|c|c|}
\hline SSCM Characteristics & $\begin{array}{l}\text { No. of } \\
\text { Metrics }\end{array}$ & Examples of Cross-cutting Metrics (Frequency rates) \\
\hline $\begin{array}{l}\text { Economic, Environmental, Long-term, Flow and Performance } \\
\text { focuses }\end{array}$ & 2 & $\begin{array}{l}\text { Capacity to manage reverse flows (2), Managing reverse material flows to reduce } \\
\text { transportation (1) }\end{array}$ \\
\hline $\begin{array}{l}\text { Economic, Environmental, Social, Stakeholder and Performance } \\
\text { focuses }\end{array}$ & 1 & Level of supplier performance on sustainability (1) \\
\hline $\begin{array}{l}\text { Economic, Environmental, Social, Efficiency and Performance } \\
\text { focuses }\end{array}$ & 1 & Overall efficiency achieved by means of sustainable production practices (1) \\
\hline $\begin{array}{l}\text { Economic, Environmental, Social, Long-term, and Stakeholder } \\
\text { focuses }\end{array}$ & 1 & End of life (post-consumer) (1) \\
\hline $\begin{array}{l}\text { Economic, Environmental, Long-term, Stakeholder and Value } \\
\text { focuses }\end{array}$ & 1 & $\begin{array}{l}\text { Product use, return to retailers, resell to other consumers, salvage, recondition, } \\
\text { refurbish, recycle, donate (1) }\end{array}$ \\
\hline $\begin{array}{l}\text { Environmental, Stakeholder, Flow, Coordination and Performance } \\
\text { focuses }\end{array}$ & 1 & $\begin{array}{l}\text { Increasing the level of coordination of planning decisions and flow of goods with } \\
\text { suppliers including dedicated investments (e.g. information systems, dedicated } \\
\text { capacity/tools/equipment, dedicated workforce) (1) }\end{array}$ \\
\hline $\begin{array}{l}\text { Environmental, Social, Long-term, Stakeholder and Coordination } \\
\text { focuses }\end{array}$ & 1 & Level of customer cooperation in returning of ELVs [end-of-life vehicles] (1) \\
\hline
\end{tabular}


A summary of the number of times each characteristic was addressed is illustrated in Figure 6-3. Note that the figure includes cross-cutting metrics, which is why the total is greater than 2555.

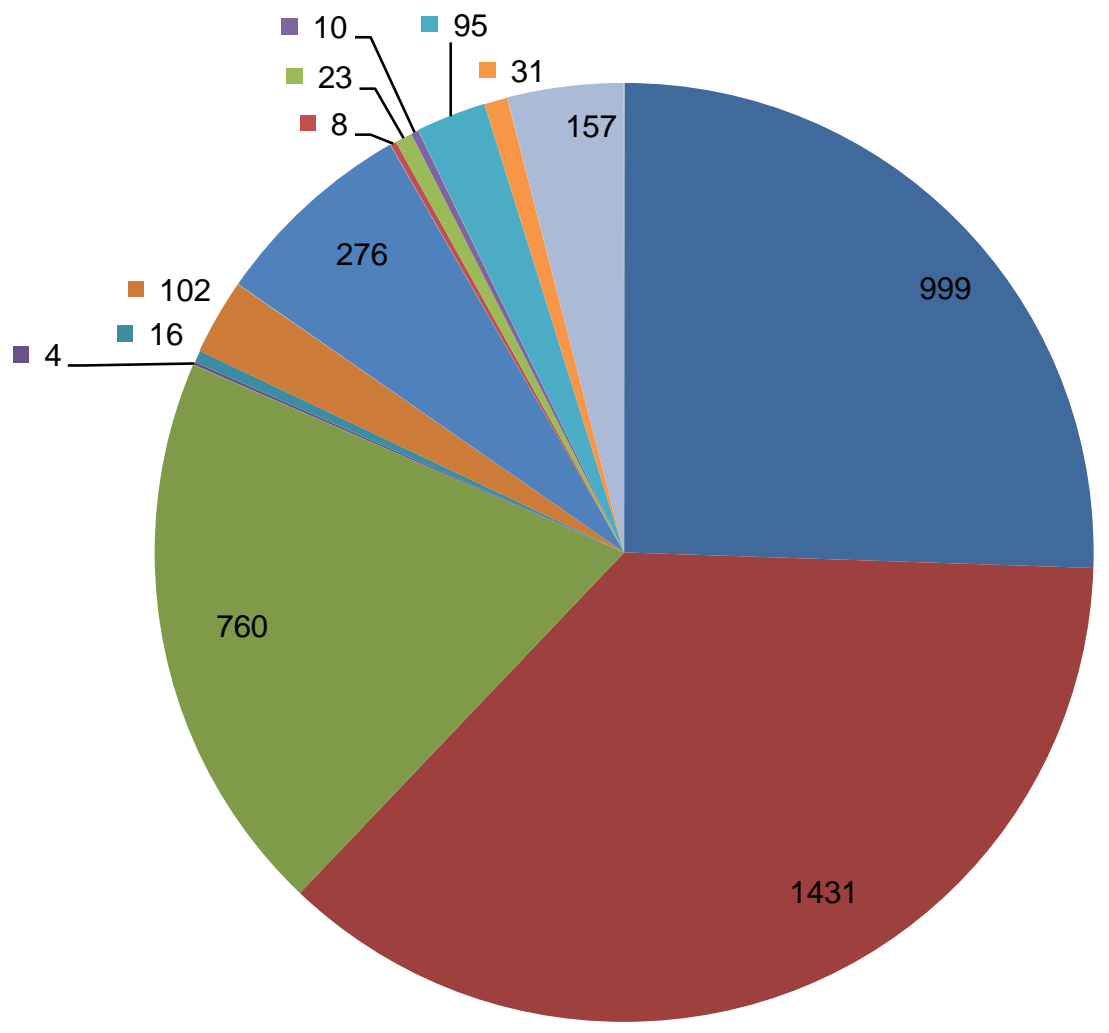

\author{
Economic \\ Environmental \\ - Social \\ - Volunteer \\ Resilience \\ - Long-term \\ - Stakeholder \\ alow \\ Coordination \\ nelationship \\ Value \\ Efficiency \\ - Performance
}

Figure 6-3: Number of metrics addressing each key characteristics of SSCM

Overall, the environmental characteristic was by far the most addressed by the published metrics. Given the fact that SSCM can be arguably considered as an extension of GSCM (Ahi and Searcy, 2013a), it is unsurprising that the environmental characteristic of SSCM would represent the greatest portion of metrics identified. This is further supported by the fact that GSCM has a longer history of research than SSCM (Ahi and Searcy, 2013a). Moreover, the fact that many countries require that organizations meeting certain thresholds publicly report on aspects of their environmental impacts (e.g., through the Toxic Release Inventory Program in the United States) may have encouraged the relatively high level of focus on this characteristic. Several researchers (e.g., Glock et al., 2012; Hasle and Jensen, 2012; Miemczyk et al., 2012; Sarkis et al., 2010; Seuring, 2013) have noted that social issues are generally underrepresented in the study of 
GSCM and SSCM. The findings presented above lend some credence to that argument, in that social issues are represented less than environmental and economic issues, though it is important to note that social issues have certainly not been completely neglected. In fact, when compared to the other characteristics of SSCM, social issues are relatively well represented. Other characteristics of SSCM that had a sizeable number of representative metrics included the stakeholder, performance, long-term, and value focuses.

A number of characteristics, however, were not broadly addressed by the metrics. These lessrepresented characteristics of SSCM included the efficiency, coordination, resilience, relationship, flow, and volunteer focuses. While there were few explicit measures of these characteristics, it is important to acknowledge that some of them may be implicitly represented. For example, though there are few metrics that specifically focus on voluntary initiatives, it is not mandatory to report on the overwhelming majority of the metrics identified in most jurisdictions around the world. Many of the metrics would, therefore, be measured on a voluntary basis if they were applied in practice. It is also important to recognize that individual metrics do not necessarily need to address all characteristics of SSCM. Metrics are often created to specifically focus on a particular goal and are therefore explicitly not intended to simultaneously address multiple issues. Although it is desirable to have some cross-cutting metrics in order to promote an integrated view of sustainability measurement in supply chains, creating individual metrics that simultaneously address 13 characteristics is not particularly realistic. Composite metrics would likely be needed to achieve such a goal. In any case, the important point is that the metric systems applying to a particular supply chain should strive to capture all the 13 key characteristics of SSCM. While an individual metric is unlikely to capture all of those characteristics, a metric system should be capable of collectively addressing them.

\subsection{Analysis of Metrics by Theme}

A review of Table 6-2 indicates that a number of key themes (explicit core issues) were addressed by the metrics. For example, although a number of different metrics were used, it is clear that many metrics were used to highlight issues related to quality. To determine the key themes that were addressed by the metrics, a keyword analysis was conducted. A detailed analysis of the metrics showed that they collectively addressed over 50 different major themes. A 
summary of the major themes addressed by 10 or more metrics is provided in Table 6-10. Examples of metrics that address each major theme are also provided in the table. It is recognized that the classification of the metrics by theme is open to some interpretation.

Table 6-10: Representative examples of major themes addressed by the identified metrics of

GSCM and SSCM

\begin{tabular}{|c|c|c|}
\hline Major Themes * & $\begin{array}{l}\text { No. of } \\
\text { Metrics }\end{array}$ & Examples of Metrics (Frequency rates) \\
\hline Product(s) & 261 & $\begin{array}{l}\text { Product characteristics (11), Product features (9), Product design for } \\
\text { remanufacturing (6) }\end{array}$ \\
\hline Cost(s) & 176 & Cost (12), Environmental costs (11), Operational cost (11) \\
\hline Waste(s) & 148 & $\begin{array}{l}\text { Solid waste(s) (19), Reduction of solid wastes (11), Process } \\
\text { optimization for waste reduction (8) }\end{array}$ \\
\hline Recycle / Reuse & 140 & Recycling (19), Recycling revenues (7), Recycling efficiency (3) \\
\hline Material(s) & 131 & $\begin{array}{l}\text { Decrease of consumption for Hazardous/Harmful/Toxic materials (8), } \\
\text { Buying env. friendly materials (7), Raw material consumption (5) }\end{array}$ \\
\hline Labour / Employment / Workforce & 130 & $\begin{array}{l}\text { Labour productivity (5), Employment compensation (4), Employee } \\
\text { satisfaction (3) }\end{array}$ \\
\hline Energy & 113 & Energy use (24), Energy consumption (21), Energy efficiency (11) \\
\hline Emission(s) & 91 & Air emissions (28), Greenhouse gas emissions (24), $\mathrm{CO}_{2}$ emissions (10) \\
\hline Transportation & 84 & $\begin{array}{l}\text { Reducing transportation costs (3), Transportation network efficiency (2), } \\
\text { Transportation modes (2) }\end{array}$ \\
\hline Water & 76 & Water consumption (12), Water use (9), Water efficiency (4) \\
\hline Process & 72 & $\begin{array}{l}\text { Level of process management (10), Process optimization for waste } \\
\text { reduction (8), Process innovation (6) }\end{array}$ \\
\hline Customer(s) & 69 & $\begin{array}{l}\text { Customers' satisfaction (14), Customer returns (6), Customer complaint } \\
\text { level (3) }\end{array}$ \\
\hline Policy(ies) / Regulation(s) & 55 & $\begin{array}{l}\text { Env. policies and audits (6), Number of regulatory violations by type } \\
\text { (2), Lack of support and guidance from regulatory authorities (1) }\end{array}$ \\
\hline Quality & 45 & $\begin{array}{l}\text { Quality (31), Quality improvement (4), Capability of quality } \\
\text { management (1) }\end{array}$ \\
\hline Training / Education & 38 & $\begin{array}{l}\text { Percentage of employees trained (4), Supporting educational institutions } \\
\text { (4), Environmental training (2) }\end{array}$ \\
\hline Pollution & 36 & $\begin{array}{l}\text { Pollution control (7), Pollution prevention (5), Capacity to reduce } \\
\text { pollution (2) }\end{array}$ \\
\hline Service(s) & 36 & $\begin{array}{l}\text { Service infrastructure (4), After sales service (4), Increase in service } \\
\text { intensity (1) }\end{array}$ \\
\hline Investment(s) & 34 & $\begin{array}{l}\text { Return on investment (11), Capital investment (5), Environment } \\
\text { investment (3) }\end{array}$ \\
\hline Technology & 34 & $\begin{array}{l}\text { Buying env. friendly technology (7), Technology capability (5), } \\
\text { Competence for environmental technologies (2) }\end{array}$ \\
\hline Health and Safety & 31 & Health (5), Health and safety practices (4), Human health (3) \\
\hline Supply & 30 & Supply redundancy (3), Supply chain finance (2), Supply capacity (1) \\
\hline Order & 30 & $\begin{array}{l}\text { Economic order quantity (2), Number of back orders (2), Order fulfill } \\
\text { rate (1) }\end{array}$ \\
\hline
\end{tabular}




\begin{tabular}{|c|c|c|}
\hline Major Themes * & $\begin{array}{l}\text { No. of } \\
\text { Metrics }\end{array}$ & Examples of Metrics (Frequency rates) \\
\hline Disposal & 27 & $\begin{array}{l}\text { Disposal method (5), Potential liability for disposal of hazardous } \\
\text { materials (2), Technology disposal program (1) }\end{array}$ \\
\hline Market & 27 & $\begin{array}{l}\text { Market share (11), New market opportunities (4), Market concentration } \\
\text { (2) }\end{array}$ \\
\hline Time (Cycle Time / Lead Time) & 27 & $\begin{array}{l}\text { Delivery lead time (5), Percentage decrease in manufacturing lead time } \\
\text { (3), Total supply chain cycle time (3) }\end{array}$ \\
\hline Sale(s) & 24 & $\begin{array}{l}\text { Sales (4), Sale of excess capital equipment (2), ROS (Return On Sales) } \\
\text { (1) }\end{array}$ \\
\hline Profit & 24 & Profit (12), Profitability (2), Chain-based profits (1) \\
\hline Life Cycle / End of life & 24 & $\begin{array}{l}\text { Life cycle assessment (LCA) (12), Life-cycle accounting (2), Formal, } \\
\text { written commitments requiring an evaluation of life cycle impacts (2) }\end{array}$ \\
\hline Compliance & 23 & $\begin{array}{l}\text { Magnitude and nature of penalties for non-compliance (2), } \\
\text { Environmental compliance and auditing programs (2), Compliance with } \\
\text { sectoral price behavior (1) }\end{array}$ \\
\hline Community & 23 & $\begin{array}{l}\text { Supporting Community Projects (4), \# Community complaints (3), } \\
\text { Community initiatives (3) }\end{array}$ \\
\hline Saving(s) & 23 & $\begin{array}{l}\text { Saving resources (1), Savings rate (1), Savings achieved through } \\
\text { reductions in resource use (1) }\end{array}$ \\
\hline Price & 21 & $\begin{array}{l}\text { Price of final products (2), Price performance value (1), Purchase price } \\
\text { (1) }\end{array}$ \\
\hline Income /Wage /Salary & 20 & $\begin{array}{l}\text { Net income (3), Ratio of lowest wage to provincial minimum (2), } \\
\text { Internal and external salary ratios (2) }\end{array}$ \\
\hline Accident(s) & 20 & $\begin{array}{l}\text { Decrease of frequency for environmental accidents (9), Accidents or } \\
\text { spills (4), Risk of severe accidents (2) }\end{array}$ \\
\hline Public & 19 & $\begin{array}{l}\text { Number of public consultation opportunities (2), Adequacy of reporting } \\
\text { and information provided to the public (2), Significant improvement in } \\
\text { terms of public relation (1) }\end{array}$ \\
\hline Demand & 18 & $\begin{array}{l}\text { Demand rate (1), Maximum demand (units) (1), Percentage increase in } \\
\text { demand flexibility (1) }\end{array}$ \\
\hline Image & 18 & $\begin{array}{l}\text { Green image (6), Marketing and green image (5), Supplier’s green } \\
\text { image (2) }\end{array}$ \\
\hline Risk(s) & 17 & Risk (2), Corruption risk (2), Total perceived risks (1) \\
\hline Revenue(s) & 15 & $\begin{array}{l}\text { Recycling revenues (7), Revenues from "green” products (5), Sales } \\
\text { revenue attributable to a new product or a by-product designed to meet } \\
\text { environmental performance objectives (1) }\end{array}$ \\
\hline Biodiversity & 14 & $\begin{array}{l}\text { Existence of an up-to-date biodiversity policy (2), Effects on } \\
\text { biodiversity (2), Preserve biodiversity (1) }\end{array}$ \\
\hline Consumer(s) & 14 & $\begin{array}{l}\text { Retention of green consumers (2), Green consumer perception (2), } \\
\text { Providing information to encourage green choices by consumers ( } 2 \text { ) }\end{array}$ \\
\hline Competition & 14 & $\begin{array}{l}\text { Increasing competitiveness (2), Durable competitive advantage (2), } \\
\text { Competitive intensity (1) }\end{array}$ \\
\hline Opportunity(ies) & 14 & $\begin{array}{l}\text { Job opportunities (4), Trading opportunities (2), Perceived opportunity } \\
\text { for advancement (2) }\end{array}$ \\
\hline Expense / Expenditure & 13 & $\begin{array}{l}\text { Percentage of proactive vs reactive expenditures (4), \$ Operating } \\
\text { expenditures (3), Benefits as percentage of payroll expense (1) }\end{array}$ \\
\hline Taxing / Custom & 10 & Taxes (4), Tax breaks (2), Tax and custom duties (1) \\
\hline
\end{tabular}

Note: * Only the major themes addressed by 10 or more metrics are provided. 
Table 6-10 highlights that different major themes were addressed to differing degrees. This is not surprising given the large numbers of identified metrics and sources from which they were drawn. It is clear, however, that the metrics tended to measure a relatively small number of core themes from a variety of perspectives. For example, of the 113 metrics that specifically focused on energy, the majority focused on issues related to energy consumption and energy efficiency. Overall, the examples in Table 6-10 serve to further reinforce the general lack of agreement on how the key GSCM and SSCM issues should be measured. Although metrics focused on the same theme appear repeatedly in the literature, they approach the measurement of that theme from a wide range of different perspectives.

To provide illustrations of the point that a number of different metrics may be used to measure similar underlying issues, detailed analyses of all metrics explicitly addressing energy- and water-related issues are provided in Appendices A and B, respectively.

The examples provided and discussed above and in the Appendices demonstrate the many ways that issues pertaining to one core SSCM issue (e.g., energy or water) may be addressed in performance measurement. This focus on a relatively small number of core themes per issue in the illustrations based on energy- and water-related metrics may be seen in other instances, such as metrics pertaining to emissions, waste, or biodiversity. Therefore, although the data presented in this chapter shows that there is little agreement on the specific metrics that should be utilized to measure performance in GSCM and SSCM, it is clear that there is some agreement on the core issues that should be measured. This may provide a basis for consolidation of the number of metrics used going forward.

Moreover, the analysis shows that there is a broad coverage of key sustainability issues in the metrics for GSCM and SSCM. The key gap is not that any sustainability issues have obviously been missed, but rather that the connection to the broader sustainability context has not been made. The need for this connection is further highlighted in the conceptual framework presented in the next section. 


\subsection{Conceptual Framework for Measuring Performance in GSCM and SSCM}

The analysis presented above highlighted several fundamental points. First, there is clear need for metrics that address the broader sustainability context in which a supply chain operates. None of the identified metrics addressed the definition of context-based metrics provided earlier in Section 2.4, particularly the aspect focused on "what such impact ought to be (for specific periods of time) in order to be sustainable” (McElroy and van Engelen, 2012). Second, there is a need for metrics that address the entire spectrum of SSCM. The analysis showed that there are metrics available that cover all the 13 key characteristics of SSCM identified in Chapter 5. However, several of these characteristics have received relatively little attention. This underscores that core aspects of SSCM may be overlooked in current measurement efforts. Third, many of the published metrics do not explicitly address all of the key players in the supply chain. While the focal firm is implicitly considered in virtually all of the metrics, other key players (such as suppliers, distributors, and retailers) have received considerably less attention. The analysis therefore supports the need to develop a conceptual framework for measuring sustainability performance in supply chains that addresses these fundamental issues.

With the above in mind, a conceptual framework for measuring performance in green and sustainable supply chains is proposed in Figure 6-4. The purpose of the framework is to provide a starting point for academics and practitioners seeking to develop metrics for GSCM and SSCM. The framework is based on three fundamental propositions:

P1: Metrics for GSCM and SSCM must address the key players in the supply chain.

P2: Metrics for GSCM and SSCM must address the broader sustainability context of the supply chain.

P3: Metrics for GSCM and SSCM must address the key characteristics of GSCM and SSCM. 


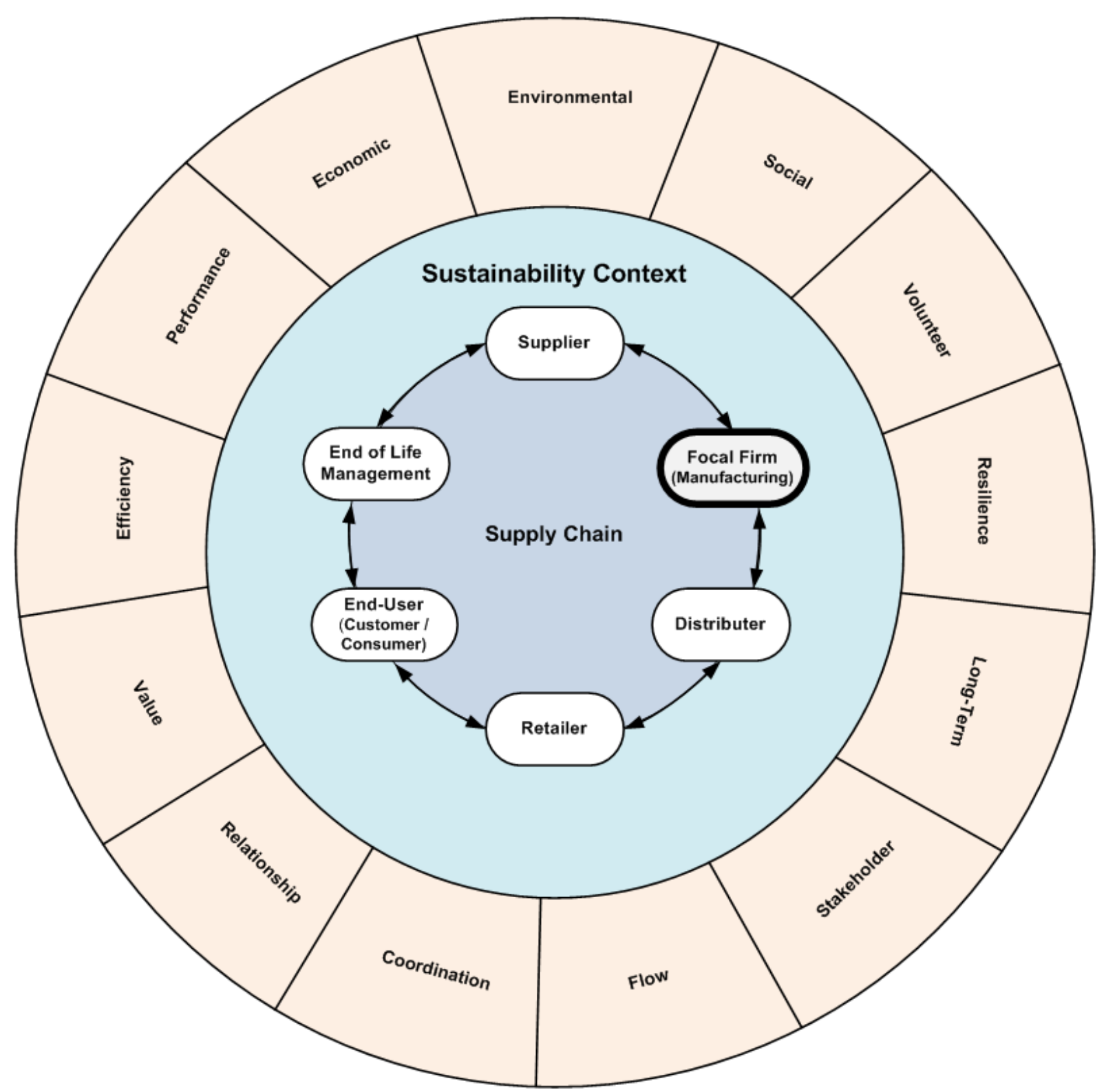

Figure 6-4: Proposed conceptual framework for measuring performance in GSCM and SSCM

Building on Proposition 1, the framework highlights six key players in a sustainable supply chain, namely the supplier, focal firm, distributor, retailer, end-user (i.e., customer), and end-oflife management (i.e., recyclers, reusers, and disposers). These six players roughly mirror the findings in Hassini et al. (2012), who structured a sustainable supply chain as a wheel encompassing six spokes of a supply chain: sourcing, transformation, delivery, value proposition, customers, and recycling. The key differences is that the framework in this study explicitly highlights the centrality of the focal firm to the chain and it adopts a broader view of 
the final player in the chain (i.e., through an emphasis on end-of-life management rather than recycling alone). In Figure 6-4, the focal firm is shaded and highlighted in bold to indicate that any metrics for GSCM or SSCM must be designed with its needs in mind. Although the metrics may have other uses, one key purpose of any metric will be to inform decision-making within the focal firm. Double-headed arrows between the players highlight the need to accommodate both forward and reverse flows throughout the supply chain, which signifies the importance of both forward and reverse logistic behaviours.

Building on Proposition 2, the framework highlights that all of the players in the supply chain are explicitly embedded in a broader sustainability context. This highlights that any supply chain must be designed to take into account the economic, environmental, and social impacts of the chain on the local, regional, and global environments in which it operates. Moreover, it explicitly emphasizes that any effort to measure performance in green and sustainable supply chains must take sustainability context into account. As indicated in the analysis in the previous section, the broader sustainability context has been overlooked in the existing metrics for GSCM and SSCM.

Building on Proposition 3, Figure 6-4 shows that the key characteristics of SSCM encircle the entire framework. As noted in the earlier discussions, measuring GSCM would require addressing the same characteristics of SSCM, with the exception of the economic and social characteristics. Although it is recognized that no one metric may simultaneously address all of the key characteristics of GSCM or SSCM, it is important that any system of metrics collectively addresses them if the intent is to measure performance in those realms. Embedding the framework in these characteristics underlines that any metrics used to measure GSCM or SSCM must be explicitly based on a definition of those concepts.

The framework is intended to be broadly applicable. However, it is important to emphasize that different metrics may be used for different supply chains. Any effort to measure SSCM performance must address the specific circumstances of the particular chain being assessed. It is therefore recognized that priorities will vary from chain to chain and these will change over time. Ultimately, it will be up to the decision-makers in the focal firm to determine how those choices will be made, though consultation with key internal and external stakeholders (with particular emphasis on those stakeholders representing other players in the supply chain) should serve as an 
input to the prioritization process. As Figure 6-4 illustrates, it is important that each player in the chain, the broader sustainability context, and the key characteristics of SSCM are considered in the development of metrics. Overlooking any of these elements could mean that important issues of SSCM are missed. It is unlikely that any one metric will simultaneously address all elements of the framework. However, the framework underscores that it is necessary for all elements to be addressed by the collective set of metrics.

The framework can be used as a basis for developing new metrics for measuring performance in green and sustainable supply chains or for evaluating existing metrics. For example, although the literature provides a sound starting point for the development of metrics, the framework highlights several areas where those metrics could be improved. Among the 2555 metrics identified in the literature, it is clear that there are metrics available that address all six of the main players in the supply chain. Table 6-10 also showed earlier that there is a broad coverage of the key themes relevant to GSCM and SSCM. There are also metrics that address all 13 of the key characteristics of SSCM identified in Chapter 5, though it is important to stress once again that the characteristics are addressed to widely varying degrees. However, the review of published metrics also showed that there are no metrics that address the broader sustainability context of GSCM and SSCM. This is further highlighted by the framework, which underscores that this is a key oversight.

The key strength of the framework is its ability to structure thinking and discussion regarding the measurement of performance in green and sustainable supply chains. The framework certainly does not invalidate other frameworks in GSCM and SSCM, but it is the first to explicitly incorporate the key characteristics of SSCM and the notion of sustainability context with respect to performance measurement. The framework explicitly builds on the analysis in this chapter, which itself was rooted in the previously published literature. The key characteristics of SSCM, the concept of sustainability context, and the key players in the supply chain have all been discussed in the academic literature. The uniqueness of the framework is rooted in the fact that it has explicitly brought these concepts together in an integrated way in order to address the issue of measuring performance in SSCM. In doing so, the framework provides a needed starting point for the development of metrics that comprehensively address GSCM and SSCM. 


\subsection{Conclusion}

The study carried out in this chapter presents the most comprehensive analysis of metrics published in the literature on GSCM and SSCM. A systematic research literature review was conducted to provide a needed reference point on the great variety of metrics highlighted in these areas. The results showed that a total of 2555 unique metrics have been addressed in the literature published up to the end of 2012. The metrics were analyzed in depth from a number of different perspectives. The analysis provided a basis for the development of an original conceptual framework for measuring performance in green and sustainable supply chains. It is recognized that there are some limitations to the study. First, although Scopus covers a wide range of peer-reviewed journals in the scientific, technical, and social sciences, it does not include all reputable peer-reviewed journals. Therefore, using different search terms and additional databases beyond Scopus may have resulted in the identification of additional metrics. Second, although the conceptual framework flows logically from the analysis, it has not been tested in practice. However, despite these limitations, the analysis yielded several important insights with respect to the measurement of GSCM and SSCM. The key implications of the study are discussed below.

It is argued that the study carried out in this chapter presents an important starting point for both academics and managers interested in measuring the sustainability performance of supply chains. Accordingly, the study provides a number of important academic and practical implications. One of the key points to emerge from the analysis is that there was a great range in the frequency of use of the metrics. The majority of the metrics were used only once, while the most frequently utilized metric was highlighted just 31 times in the papers analyzed. The great range of metrics utilized indicates that a general lack of agreement on what should be measured in GSCM and SSCM remains. Although an extensive array of metrics in these areas is available, this presents challenges in determining the metrics most appropriate to measuring green or sustainable performance in a particular supply chain. The wide range in the published metrics provides challenges for both academics and practitioners. From an academic perspective, there is a need to develop clearly defined metrics that use relatively standard language when measuring the same core issue. As the analysis indicated, in many cases, a number of different metrics were used to measure essentially the same thing. From a practical perspective, the need to use clearly defined 
metrics with relatively standardized terminology is needed in order to promote greater comparability in assessing the sustainability performance of different supply chains. While different supply chains will undoubtedly require metrics unique to their particular circumstances, there are also likely some metrics (e.g., emissions) that could be compared across chains if they were defined and measured in the same way. Overall, the analysis underlines the need to find common ground regarding the key areas to be measured in GSCM and SSCM.

Although there was a tremendous number of metrics available in the literature, this study also highlights the need for new metrics that comprehensively address SSCM. This need was explicitly highlighted by the proposed conceptual framework.

As shown in the analysis, all 13 key characteristics of SSCM suggested in Chapter 5 (i.e., economic, environmental, social, volunteer, resilience, long-term, stakeholder, flow, coordination, relationship, value, efficiency and performance focuses) were addressed to some extent by the metrics. Environmental issues were by far the best represented. A number of crosscutting metrics that address multiple characteristics of SSCM were also identified and analyzed. However, a number of characteristics received relatively little attention. In particular, few metrics were developed for the resilience, relationship, coordination, and flow characteristics. One of the key points of this study is that definitions of GSCM and SSCM provide a critical reference point for application-based initiatives. Greater emphasis on these relatively overlooked characteristics is therefore needed to ensure that the full scope of GSCM and SSCM are addressed in practice. Both academics and practitioners should therefore pay greater attention to these characteristics going forward. 


\section{CHAPTER 7}

\section{DEVELOP A MATHEMATICAL MODEL FOR ASSESSING SUSTAINABILITY PERFORMANCE UNDER THE GREEN ECONOMICS PARADIGM AT THE COMPANY LEVEL}

\subsection{Introduction}

The purpose of this chapter is to propose a stochastic model that explicitly addresses the potential barriers and enablers to sustainability in order to measure and assess the sustainability level of a company. Given that the potential barriers and enablers to sustainability are context dependent, the stochastic model developed in this chapter assumes that a variable characterization of sustainability functions can describe a realistic analytical model for a company's sustainability behavior. By adopting the strong sustainability perspective, a case scenario is used to demonstrate the application of the proposed model in a major Canadian electric utility. By providing relatively simple and informative measurement, the proposed sustainability model can be used as a practical and effective tool to assess the sustainability level of any company under consideration and to evaluate sustainability fluctuation of the company over time.

The reminder of the chapter is organized as follows. A detailed discussion on the model structure will be presented in the next section. To illustrate the application of the proposed sustainability model, a numerical case study will be provided in Section 7.3. The related discussion and the implications of the proposed model will be presented in Section 7.4. The conclusion will be provided in Section 7.5.

\subsection{Model Structure}

As previously implied, not all interactions involved in sustainability analysis will have comparable relevance, and hence, the potential barriers and enablers to sustainability are essentially context dependent. In this light, different barrier and enabler related factors will be important for different companies. Furthermore, the priority that is given to the relevant factors 
may also change over time. This is complicated by the fact that different factors may be measured in different units or even in qualitative terms, while the relationship between the factors may also be unclear (Marchini et al., 2009). Accordingly, the model presented in this study builds on the premise that prediction of success, or lack thereof, in progressing towards sustainability is inherently a stochastic problem. Hence, nondeterministic, variable characterizations of sustainability functions can provide a reasonable basis for analytical description of a company's progress towards sustainability. As emphasized earlier, one of the reasons the model developed in this study focuses on progress towards sustainability is that it is difficult to discern the transition between states of sustainability and unsustainability. This is further supported by Azapagic and Perdan (2000) who argued that it is relatively impossible to measure sustainability status in absolute terms. However, corporate decision-makers, public policy makers, and the general public require timely, digestible information on whether a company is generally becoming more or less sustainable. To respond to this need, a stochastic model that evaluates a company's ability to progress towards sustainability is developed in this section.

Building on discussions provided in Section 4.4, in the proposed model, the company is deemed to be making progress towards sustainability if and only if the challenge(s) placed on the company do not surpass the company's capacity. Drawing on the same discussions, the challenge represents an aggregate of the hurdles, barriers and external conditions, which can be analyzed probabilistically by considering challenges as random variables. Capacity is also treated as a random variable and signifies effects of all states and conditions affecting the capability, or lack of knowledge about the company's capability. Again, the challenge and capacity factors will vary somewhat from company to company. However, a number of general examples for the challenge and capacity factors were discussed in Section 4.4.

For any company under consideration, the first step is to determine factors that affect the existing challenge and capacity. It is important to recognize that different factors may have different effects on different companies. Once the factors have been identified, the probability distributions of the influencing factors are required to compute the sustainability of the company, which has been defined in the model presented in this study to be the probability that the imposed challenges are not greater than the capacity of the company. On this note, the 
probability that the company is sustainable (or positioned to be sustainable) is equal to the probability that the enforced challenges are less than the company's capacity. Therefore:

$$
\operatorname{Sus}_{k}=P_{r}\left(H_{k}<C_{k}\right)
$$

Where:

$$
\begin{aligned}
& S u s_{k}=\text { Sustainability of the company } \\
& H_{k}=\text { Challenge imposed to the company } \\
& C_{k}=\text { Capacity of the company }
\end{aligned}
$$

If the Probability Density Function (PDF) for the challenge $H_{k}$ can be denoted by $f(h)$, then the corresponding Cumulative Distribution Function (CDF) for the challenge could be defined as:

$$
F(\hat{h})=\int_{0}^{\widehat{h}} f(h) d_{h}
$$

Similarly, if the PDF for the capacity $C_{k}$ can be denoted by $f(c)$, then the corresponding CDF for the capacity could be defined as:

$$
F(\hat{c})=\int_{0}^{\hat{c}} f(c) d_{c}
$$

Based on the proposed model, the sustainability of a company is the probability that the imposed challenges are not exceeding the company's capacity. Therefore, Eq. (7.1) can be written as:

$$
\operatorname{Sus}_{k}=P_{r}\left(H_{k}<C_{k}\right)=\int_{0}^{\infty} f(c)\left[\int_{0}^{c} f(h) d_{h}\right] d_{c}
$$

Where:

$$
\begin{aligned}
& h=\text { Random variable representing factors acting as challenge to the company } \\
& c=\text { Random variable representing factors supporting capacity of the company }
\end{aligned}
$$


The model adopts a strong sustainability perspective. As described in the green economics paradigm (Cato, 2009), the economy operates within social relationships, which are embedded within nature. Moreover, according to the concept of strong sustainability (Ayres, 2007; Van den Bergh, 2010), human activity is enclosed within the confines of the limits of the environmental carrying capacity. Therefore, focusing on the sustainability objectives, economic growth as well as quality of life improvements are constrained by the boundary of ecological limits (Barrett and Scott, 2001b). As illustrated in Figure 7-1, the economy is a part of society, which is nestled inside of the environment. In this view, both economy and society are dependent on the environment and thus are constrained by the environmental limits.

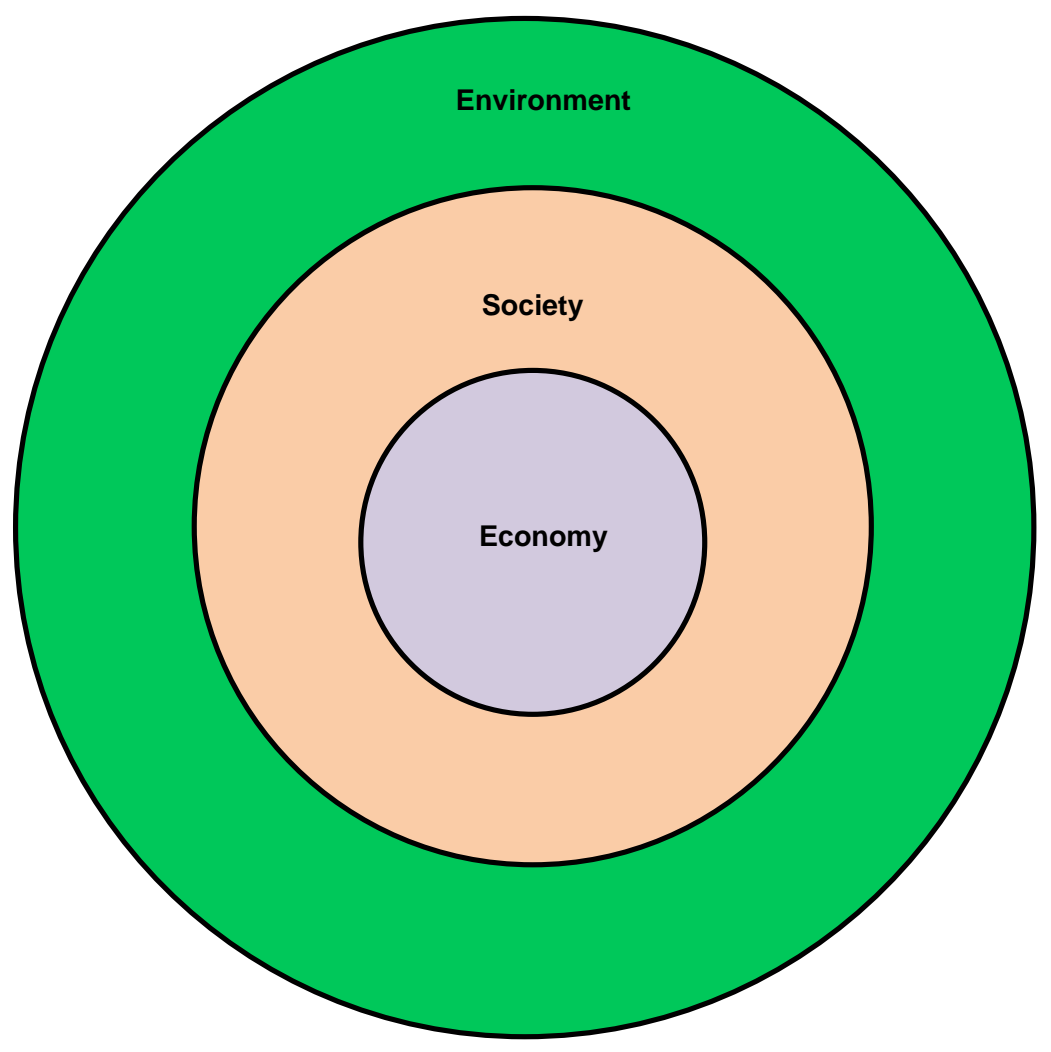

Figure 7-1: Green economics paradigm

Considering all of the above, by taking the strong sustainability perspective, the proposed model is based on the assumption that evaluating sustainability performance based on environmentally related factors as the main affecting players can provide a suitable representation for sustainability. This assumption builds on a point that has also been highlighted by Kuan et al. 
(2013). Therefore, in order to evaluate the sustainability performance of a company under the green economics paradigm, the environmentally related factors can be assumed to be the primary factors affecting the challenge and capacity of the company independently. Another assumption in this study is that sustainability computations will be carried out while assuming normal distributions for both challenge and capacity factors. Normal distribution is an analytical tool that is commonly used in practice as a simple model for complex events, where a large number of results can be obtained in a precise structure. Normal distribution is pertinent when variability in challenge, capacity, or both factors is caused by the sum of many effects, no one of which is domineering. Therefore by considering the normal distribution for all the involved variables in Eq. (7.4), sustainability of the company may be defined as:

$$
\operatorname{Sus}_{k}=\int_{0}^{\infty} \frac{1}{\sigma_{c} \sqrt{2 \pi}} e^{-\frac{\left(c-\mu_{c}\right)^{2}}{2 \sigma_{c}^{2}}}\left[\int_{0}^{c} \frac{1}{\sigma_{h} \sqrt{2 \pi}} e^{-\frac{\left(h-\mu_{h}\right)^{2}}{2 \sigma_{h}^{2}}} d_{h}\right] d_{c}
$$

Where:

$$
\begin{aligned}
& \mu_{h}=\text { Mean value of the variable } h \\
& \mu_{c}=\text { Mean value of the variable } c \\
& \sigma_{h}=\text { Standard deviation of the variable } h \\
& \sigma_{c}=\text { Standard deviation of the variable } c
\end{aligned}
$$

As defined in Eq. (7.5), the sustainability of the company under consideration is the probability that the company can thrive in overcoming the imposed challenges on the company. To simplify the proposed model, Eq. (7.5) may be written as: (Kapur and Lamberson, 1977)

$$
\operatorname{Sus}_{k}=1-\varphi\left(-\frac{\mu_{c}-\mu_{h}}{\left(\sigma_{c}^{2}+\sigma_{h}^{2}\right)^{1 / 2}}\right)
$$

Therefore by applying Eq. (7.6) and using the standard normal table, the sustainability of the company can be estimated.

As mentioned earlier, simplicity, ease of use and the ability to promptly provide feedback on a company's sustainability status were the basic principles considered as prerequisites in the 
development of the proposed sustainability model. The model was also fundamentally based on the strong sustainability perspective. In the following section, a case study is presented to demonstrate the application of the proposed model. The case study is based on publicly available data for several key environmental indicators.

\subsection{Illustrative Case Study on the Application of the Model}

In order to demonstrate the application of the proposed sustainability model, Hydro-Quebec was selected as a case company. Hydro-Quebec is a government-owned corporation that generates, transmits and distributes electricity in Quebec, Canada, and is one of the biggest electric utilities in North America (Hydro-Quebec, 2012). With sixty hydroelectric and one nuclear generation stations, Hydro-Quebec is the largest electricity generator in Canada and the largest hydroelectric producer in the world (Hydro-Quebec, 2011a).

The challenge and capacity factors were determined based on an extensive review of the environmental indicators published in Hydro-Quebec's publicly available sustainability reports (Hydro-Quebec, 2011b). Due to the stochastic nature of the proposed model, and also drawing on research by Ebert and Welsch (2004) highlighting the significance of using ratio scale in sustainability analysis, the utilized indicators have been expressed as percentages. The identified indicators representing the challenge and capacity factors are summarized in Tables 7-1 and 7-2, respectively. By using the data summarized in Tables 7-1 and 7-2 and applying Eq. (7.6), the sustainability of Hydro-Quebec in generating, transmitting and distributing electricity can be calculated for each year separately. 
Table 7-1: Identified environmental performance indicators representing challenge factors

\begin{tabular}{|c|c|c|c|}
\hline \multirow{2}{*}{ Challenge Factors } & \multicolumn{3}{|c|}{ Year } \\
\hline & 2009 & 2010 & 2011 \\
\hline Area of transmission-line rights-of-way treated with herbicides (\%) & 27.37 & 29.36 & 22.05 \\
\hline Area of dikes and dams treated with herbicides (\%) & 49.28 & 26.69 & 38.48 \\
\hline $\begin{array}{l}\text { GHG emissions from thermal electricity generation relative to total GHG } \\
\text { emissions from all reported sources }{ }^{a}(\%)\end{array}$ & 86.82 & 79.03 & 79.35 \\
\hline $\begin{array}{l}\text { Indirect emissions associated with power transmission and distribution relative to } \\
\text { emissions avoided by net exports of electricity }{ }^{a}(\%)\end{array}$ & $2.17^{b}$ & 2.49 & 0.81 \\
\hline Spills due to equipment breakage (\%) & 45.00 & 56.00 & 51.50 \\
\hline
\end{tabular}

Table 7-2: Identified environmental performance indicators representing capacity factors

\begin{tabular}{|l|c|c|c|}
\hline \multicolumn{2}{|c|}{ Capacity Factors } & \multicolumn{2}{c|}{ Year } \\
\cline { 2 - 5 } & 2009 & $\mathbf{2 0 1 0}$ & 2011 \\
\hline Renewable energy generated relative to total energy generated (\%) & 97.58 & 97.81 & 97.91 \\
\hline Energy saved through conservation and/or efficiency improvement plans (\%) & 0.00 & 19.71 & 40.26 \\
\hline Underground hookups on the distribution system (\%) & 32.00 & 36.00 & 40.00 \\
\hline Residual hazardous materials (RHMs) diverted from landfill (\%) & 95.00 & 95.00 & 94.00 \\
\hline Insulating oil recovered and reused internally (\%) & 88.40 & 91.00 & 88.80 \\
\hline
\end{tabular}


Focusing on the strong sustainability perspective, the results of these calculations are shown in Figure 7-2. These results portray the sustainability of Hydro-Quebec in the period of 3 years between 2009 and 2011. Accordingly, through the consideration of the involved challenge and capacity factors, the calculated value for sustainability explains that with the probability of 79.10\%, Hydro-Quebec was successful in prevailing over the imposed challenges, and thus progressed towards sustainability in 2011. A detailed sample calculation for the year 2011 is provided in Appendix C.

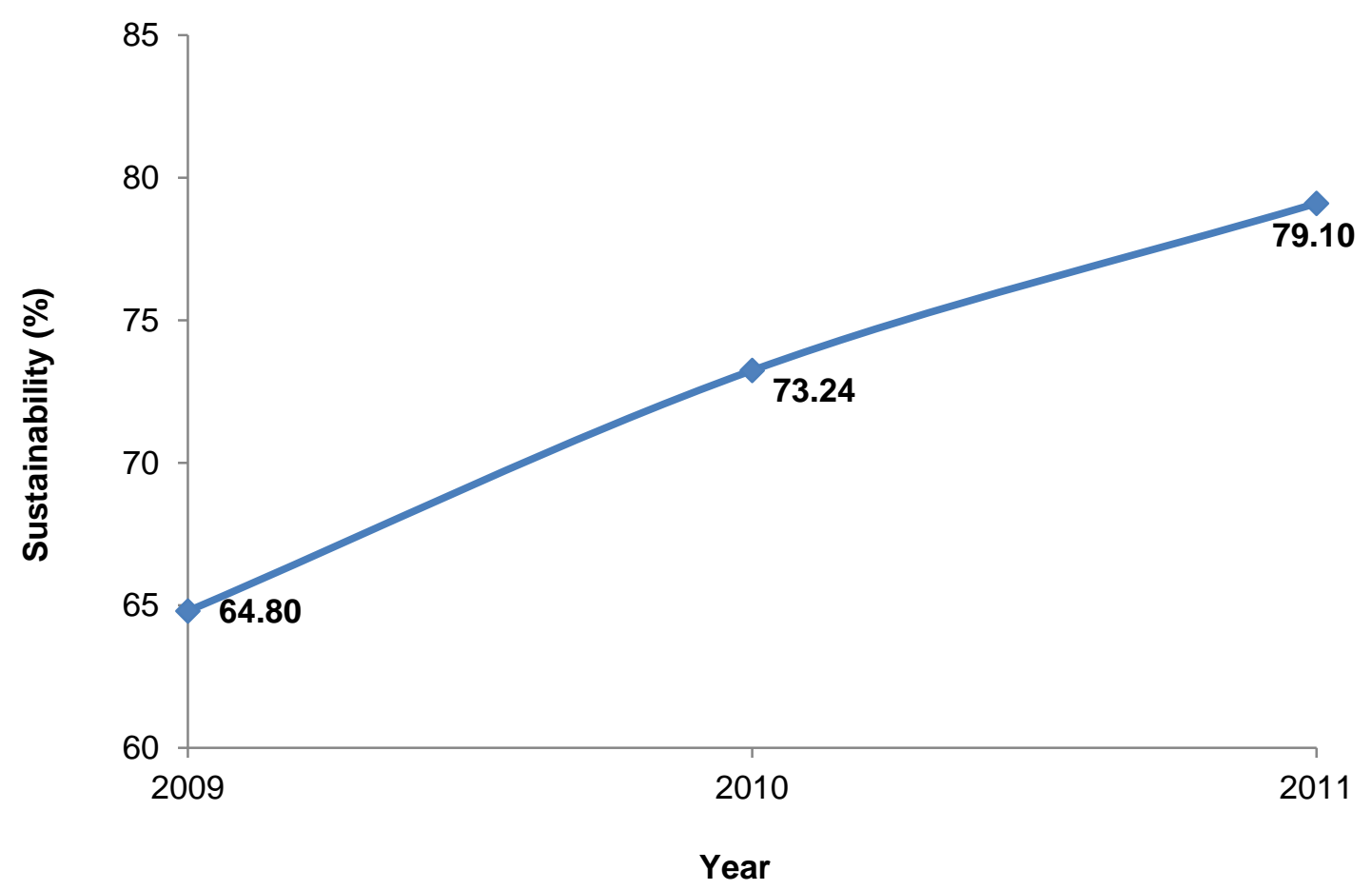

Figure 7-2: Sustainability of Hydro-Quebec Company in the period of 2009-2011

Taking Eq. (7.6), if the challenge and capacity factors are simultaneously intensifying there might not be much progress perceived towards sustainability. If, on the other hand, the factors are moving in opposite directions, we would expect to see a move towards, or away from, sustainability. In this view, strengthening the capacity of company to comprehensively overcome the imposed challenges will result in a higher sustainability value. Accordingly, a closer sustainability value to 1 or $100 \%$ signifies a better expansion of the company's capability in prevailing over the imposed challenges. 
Nevertheless, information collected in Tables 7-1 and 7-2 shows fluctuations in the involved challenge and capacity factors for the designated period of operation (i.e., 2009 to 2011). The effects of such fluctuations on Hydro-Quebec's sustainability over time can be clearly observed in Figure 7-2.

\subsection{Discussion}

Hydro-Quebec's sustainability reports are based on the guidelines provided by the Global Reporting Initiative (GRI, 2013c). There are different categories required by the GRI in which environmental performance indicators should be reported accordingly. These categories are energy, water, biodiversity, atmospheric emissions (i.e., greenhouse gases (GHGs) and acid gases), effluents and waste (including 4R-D program criteria that are reduction at the source, reuse, recycling, reclamation, then disposal), products and services, compliance and transport (Hydro-Quebec, 2011c).

As discussed earlier in Section 4.4, there are some factors that cause challenges to the company, and/or reduce the capacity of the company to withstand such challenges and ultimately hinder progress towards sustainability. The reported indicators summarized in Table 7-1 represent such conduct and hence are used as the challenge factors required for the proposed sustainability evaluations. On the contrary, the capacity factors are supporting the company's capability by strengthening the capacity of the company to move towards sustainability. In this context, the reported indicators summarized in Table 7-2 provide such behavior and hence represent the capacity factors required for the proposed sustainability measurement.

The rationale for the selected challenge and capacity factors used in the case study are summarized in Tables 7-3 and 7-4, respectively. It should also be emphasized that different challenge and capacity factors would have different effects on sustainability outcomes. However, since data availability was an essential point in selecting the indicators used, the impacts of different challenge and capacity factors are evenly distributed, as they are considered equally weighted factors at this stage. 
Table 7-3: Rationale for the selected challenge factors used in the case study

\begin{tabular}{|l|l|}
\hline \multicolumn{1}{|c|}{ Representative Indicator } & \multicolumn{1}{c|}{ Rationale } \\
\hline $\begin{array}{l}\text { Area of transmission-line rights-of-way treated with } \\
\text { herbicides }\end{array}$ & $\begin{array}{l}\text { Herbicides have adverse impacts on the environment and } \\
\text { biodiversity. }\end{array}$ \\
\hline Area of dikes and dams treated with herbicides & $\begin{array}{l}\text { Minimizing emissions caused by greenhouse gases is a } \\
\text { key policy objective in many companies due to their } \\
\text { influence in global climate change. }\end{array}$ \\
\hline $\begin{array}{l}\text { GHG emissions from thermal electricity generation relative } \\
\text { to total GHG emissions from all reported sources }\end{array}$ & $\begin{array}{l}\text { Indirect emissions associated with power transmission and } \\
\text { distribution relative to emissions avoided by net exports of } \\
\text { electricity }\end{array}$ \\
\hline Spills due to equipment breakage & $\begin{array}{l}\text { Contaminant spills can cause severe environmental } \\
\text { damage. }\end{array}$ \\
\hline
\end{tabular}

Table 7-4: Rationale for the selected capacity factors used in the case study

\begin{tabular}{|l|l|}
\hline \multicolumn{1}{|c|}{ Representative Indicator } & \multicolumn{1}{c|}{ Rationale } \\
\hline $\begin{array}{l}\text { Renewable energy generated relative to total energy } \\
\text { generated }\end{array}$ & $\begin{array}{l}\text { Generating renewable energy will conserve non-renewable } \\
\text { energy sources and ultimately helps strengthen the capacity } \\
\text { of the company to move towards sustainability. }\end{array}$ \\
\hline $\begin{array}{l}\text { Energy saved through conservation and/or efficiency } \\
\text { improvement plans }\end{array}$ & $\begin{array}{l}\text { Saving energy of any kind will help lower consumption of } \\
\text { energy sources, which aligns with sustainability principles. }\end{array}$ \\
\hline Underground hookups on the distribution system & $\begin{array}{l}\text { Using underground hookups on the distribution system will } \\
\text { allow municipalities to obtain aesthetic and environmental } \\
\text { benefits. This will help lower environmental impacts in } \\
\text { heritage, cultural and tourist sites. }\end{array}$ \\
\hline $\begin{array}{l}\text { Residual hazardous materials (RHMs) diverted from } \\
\text { landfill }\end{array}$ & $\begin{array}{l}\text { Diverting RHMs from landfills lessens environmental } \\
\text { impacts and associated health issues. }\end{array}$ \\
\hline Insulating oil recovered and reused internally & $\begin{array}{l}\text { Considering 4R-D program criteria (i.e. reduction at the } \\
\text { source, reuse, recycling, reclamation, then disposal), the } \\
\text { more materials are recycled and reused less waste will be } \\
\text { produced. This will help lower consumption of natural } \\
\text { resources. }\end{array}$ \\
\hline
\end{tabular}


Drawing on the above, it is necessary to highlight that for the presented case study, energy, biodiversity, atmospheric emissions and waste were the only categories in which the collected data was available and reported consistently. Indicators for other categories required by the GRI (e.g., water) were either not available or applicable to Hydro-Quebec. On the other hand, data might have been available but not reported due to the confidentiality purposes (Hydro-Quebec, 2011c). Nevertheless, the presented data in the Tables (7-1) and (7-2) (i.e., possibly originated by the aggregation of some other relevant inputs) were the only proper data, which could be extracted from the extensive review of information publically published in the sustainability reports of the case company. Accordingly, it is important to emphasize that if more indicators had been reported in the published reports, more challenge and capacity factors could have been included in the calculations, and hence, the entailed sustainability evaluations would have been more conclusive. Ideally, more indicators could be used for the sustainability evaluations of a typical electric utility. Percentage of non-renewable energy used relative to the total energy consumed, percentage of direct and/or indirect energy consumption by primary energy source relative to the total (direct and indirect) energy used, number of permitted sites causing downstream and/or underground water quality problems relative to the total number of permitted operation sites, number of water sources significantly affected by withdrawal or use of water relative to total number of involved water sources, number of permitted operation sites that have a problem of land contamination relative to the total number of permitted sites, and overall average of opacity around the plant or operation area are some examples for such indicators representing challenge factors. Also, percentage of renewable energy consumption relative to total energy used, number of initiatives to reduce direct and/or indirect energy consumption relative to the total number of initiatives for energy efficiency, total energy loss through power transmission and distribution relative to total energy generated, percentage of $\mathrm{CO}_{2}$ emissions potentially sequestered by planting trees to the total $\mathrm{CO}_{2}$ emissions produced, total water recycled and reused (e.g., cooling, waste and rain water) relative to the total water used from all sources, and percentage of water saved through conservation and/or efficiency improvement plans are some examples for potential indicators representing capacity factors involved in the operation of a typical electric utility. 
Furthermore, it should also be noted that while the employment of normal distributions is generally a common approach in practice, in the developed model the negative values for the involved capacity and challenge variables were considered inadmissible. Accordingly, when the coefficients of variations of the involved factors (i.e., challenge and capacity variables) will be less than 0.3 , the probability of negative values for the respective data will be negligible. Therefore, the probability of negative variable(s) for the involved challenge and capacity factors under the normal density were deemed as zero in the developed model. Limiting the probability of a negative random variable under the normal distribution to zero has also been used in the relevant literature (i.e., Guiffrida and Jaber, 2008).

\subsubsection{Implications of the Model}

The results presented in Figure 7-2 show the progress of Hydro-Quebec towards sustainability in each year of its operation between 2009 and 2011. These results also show the actual sustainability trend for Hydro-Quebec in which the same challenge and capacity factors have been utilized in those three years. By applying the same approach, fluctuations in the company's sustainability can easily be evaluated over time. This is one of the key strengths of the model. However, it is important to recognize that, since there are few mandatory systems for sustainability reporting currently in place, the model must largely rely on data that has been voluntarily reported. The effectiveness of tools, like the sustainability model developed in this study, is very much dependant on the information being made available by the company under evaluation. There may also be opportunities to use the proposed sustainability model for making comparisons between companies operating within the same sector. This, however, requires that two or more companies use the same indicators that are measured in the same way. Standards and guidelines, such as the GRI, may help facilitate such comparisons as they become more widely applied and as reporting processes are standardized.

Furthermore, to respond to a requirement highlighted in the literature (Kuan et al., 2013), the strong sustainability concept has been a focal point in the development and use of the proposed model. Also, given its probabilistic nature, the proposed sustainability model can address uncertainty behaviors, which have usually been treated with probability techniques in ecological studies (Chavas, 2000), but have rarely been addressed in the approaches that adopt the strong 
sustainability concept (Baumgartner and Quaas, 2009). Moreover, by using the cumulative distribution functions for the involved factors, the proposed model can also embrace the cumulativeness of the involved impacts required for the long-term focus of sustainability.

The proposed sustainability model is easy to use and also can provide necessary support for policy and decision makers in establishing priorities for development as well as evaluation of progress towards sustainability. Accordingly, the proposed sustainability model can be used as an environmental performance measurement tool required for the environmental management programs that involve continuous improvement and generate synergistic effects on the company’s competitiveness (Yang et al., 2010). Furthermore, the proposed sustainability model can provide an important foundation and input for research in the broader area of sustainability performance measurement systems.

\subsection{Conclusion}

The concept of sustainability is widely recognized as being difficult to implement in practice. One of the key difficulties is the need to measure the sustainability level of companies, and to monitor their progress towards or away from sustainability. Given that sustainability is a complex issue with context dependent barriers and enablers, with a difficult to discern transition between states of sustainability and unsustainability, a stochastic representation of sustainability can provide a reasonable basis for analytical modeling of a company's sustainability performance. Accordingly, to quantitatively measure the sustainability of a company, a stochastic model was proposed in this study. Furthermore, to illustrate the application of the proposed sustainability model, it was applied in a numerical case study by utilizing the actual related data for a Canadian electric utility. Fluctuations in the company’s sustainability over time were evaluated and discussed thoroughly. Furthermore, classification of the reported indicators as challenge and capacity factors required for the application of the proposed sustainability model may not be immediately apparent. Therefore, some underlying principles were provided in this study to alleviate the issue of subjectivity that may be involved in such a classification process. 
The developed model makes several contributions to the literature. The model is one of the first to explicitly adopt a probabilistic approach to sustainability measurement and assessment. It also provides an original, straightforward method of measuring and assessing the sustainability of a company from the strong sustainability perspective. The explicit recognition of contextdependent factors that either enable or inhibit progress towards sustainability is another unique feature of the model. Finally, the model concisely illustrates progress towards sustainability over time. This may provide a basis for improved reporting and benchmarking in the field of sustainability performance measurement at the company level. 


\section{CHAPTER 8}

\section{DEVELOP MATHEMATICAL MODELS FOR ASSESSING SUSTAINABILITY PERFORMANCE IN THE SUPPLY CHAIN}

\subsection{Introduction}

This chapter proposes two mathematical models for assessing sustainability in the supply chain. The models are based on the notion that a probabilistic representation of sustainability can realistically account for its challenges. This approach is in line, particularly, with the findings of Brandenburg et al. (2014) who emphasized that there is a clear requirement for stochastic modeling approaches to measuring sustainability in a supply chain context.

Nevertheless, the development of the proposed models was guided by the need for ease of use, simplicity, and the ability to quickly provide feedback on the sustainability status of supply chains over time. With that in mind, the remainder of the chapter is structured as follows. A detailed discussion on formulation of the models will be presented in the next section. An application of the model is illustrated in Section 8.3. The implications of the models are also discussed in detail in this section. The chapter closes with a conclusion in Section 8.4.

\subsection{Model Formulation}

Building on discussions provided in Section 4.4, the first step in assessing the sustainability of any supply chain is to determine the parameters that affect the supply chain's capacity and challenge. Since different supply chains operate in different contexts, these parameters will vary from one supply chain to another. Given that the primary users of the sustainability assessment will be decision-makers in the supply chain's focal firm, ultimate responsibility for the selection of these parameters rests with the focal firm. Consultation with other players in the supply chain (e.g., suppliers, distributors, etc.) and other key external stakeholders (e.g., communities, nongovernmental organizations, etc.) will be important inputs into the selection of the key capacity and challenge factors. Furthermore, it is important to recognize that different decision-makers may wish to assign different weights to different capacity and challenge factors. Therefore, a 
process of incorporating different weights (priorities) for the indicators incorporated into the model is also required. This will provide opportunity to evaluate sustainability of the supply chain(s) more comprehensively. Considering all of the above, a detailed construction of the proposed SSCM model will be presented in the following two sub-sections. First, the structure of a generic form of the SSCM model will be discussed. Then, by incorporating a priority scheme into the proposed generic model, a weighted SSCM model will be developed.

\subsubsection{Generic SSCM Model}

Drawing on discussions provided in Section 4.4, sustainability in this study is conceptualized as the probability that the supply chain's capacity is greater than the challenge imposed on the supply chain. Accordingly, the probability that the supply chain is sustainable (or positioned to progress towards sustainability) is equal to the probability that the supply chain's capacity is more than the imposed challenge. This is consistent with the modeling approach outlined in Chapter 7. Therefore:

$$
\operatorname{Sus}_{S C}=P_{r}\left(S_{S C}>G_{S C}\right)=P_{r}\left(S_{S C}-G_{S C}>0\right)
$$

Where:

$$
\begin{aligned}
& S u s_{S C}=\text { Sustainability of the supply chain } \\
& S_{S C}=\text { Capacity (strength) of the supply chain } \\
& G_{S C}=\text { Challenge imposed to the supply chain }
\end{aligned}
$$

If the Probability Density Functions (PDF) for the capacity $S_{S C}$ and challenge $G_{S C}$ can be denoted by $f(s)$ and $f(g)$, respectively, then the corresponding Cumulative Distribution Functions (CDF) for the capacity and challenge may be defined as:

$$
\begin{aligned}
& F(\hat{s})=\int_{0}^{\hat{s}} f(s) d_{s} \\
& F(\hat{g})=\int_{0}^{\hat{g}} f(g) d_{g}
\end{aligned}
$$


Based on the discussion above, the sustainability of a supply chain is the probability that the capacity exceeds the challenge. Under these conditions, the assumption is that progress towards SSCM is being made. Therefore:

$$
\operatorname{Sus}_{S C}=P_{r}\left(S_{S C}>G_{S C}\right)=\int_{0}^{+\infty} f(s)\left[\int_{0}^{s} f(g) d_{g}\right] d_{s}
$$

Where:

$$
\begin{aligned}
& s=\text { Random variable representing capacity (strength) of the supply chain } \\
& g=\text { Random variable representing challenge to the supply chain }
\end{aligned}
$$

For the purposes of this study, sustainability computations are carried out while assuming normal distributions for both capacity and challenge parameters. As emphasized in Chapter 7, the normal distribution is appropriate in this context since the variability in capacity, challenge, or both parameters is caused by the sum of many effects, no one of which is dominant. Therefore, applying the normal distribution for the involved variables in Eq. (8.4), the PDFs for capacity and challenge can be denoted as follows:

$$
\begin{aligned}
& f(s)=\frac{1}{\sigma_{s} \sqrt{2 \pi}} e^{-\frac{\left(s-\mu_{s}\right)^{2}}{2 \sigma_{s}^{2}}} \\
& f(g)=\frac{1}{\sigma_{g} \sqrt{2 \pi}} e^{-\frac{\left(g-\mu_{g}\right)^{2}}{2 \sigma_{g}^{2}}}
\end{aligned}
$$

Where:

$$
\begin{aligned}
& \mu_{s}=\text { Mean value of the variable } s \\
& \mu_{g}=\text { Mean value of the variable } g \\
& \sigma_{s}=\text { Standard deviation of the variable } s \\
& \sigma_{g}=\text { Standard deviation of the variable } g
\end{aligned}
$$

By applying Eqs (8.5) and (8.6) in Eq. (8.4), the sustainability of the supply chain can be defined as: 


$$
\operatorname{Sus}_{S C}=\int_{0}^{\infty} \frac{1}{\sigma_{s} \sqrt{2 \pi}} e^{-\frac{\left(s-\mu_{s}\right)^{2}}{2 \sigma_{s}^{2}}}\left[\int_{0}^{s} \frac{1}{\sigma_{g} \sqrt{2 \pi}} e^{-\frac{\left(g-\mu_{g}\right)^{2}}{2 \sigma_{g}^{2}}} d_{g}\right] d_{s}
$$

Eq. (8.7) therefore explicitly recognizes that the sustainability of the supply chain under consideration is the probability that the supply chain can succeed in overcoming the challenges imposed on it. Eq. (8.7) may be simplified as follows:

$$
\operatorname{Sus}_{S C}=1-\varphi\left(-\frac{\mu_{s}-\mu_{g}}{\left(\sigma_{S}^{2}+\sigma_{g}^{2}\right)^{1 / 2}}\right)
$$

The sustainability of the supply chain can therefore be estimated by applying Eq. (8.8) and using the standard normal table. It should be noted that, since both modeling approaches underlined in Chapters 7 and 8 assume normal distributions for the involved factors, Eq. (8.7) and (8.8) were also used in Chapter 7.

Since the main purpose of the current study is to evaluate a supply chain's progress towards sustainability over time, the proposed model has been designed to accommodate " $p$ " number of designated periods (e.g., year), over which the sustainability analysis will be carried out. The model also recognizes that any supply chain will have multiple capacity and challenge factors. Each of these components can be comprised of " $n$ " different types of variables (e.g., environmental, economic, social, and potentially other factors). These variables will jointly form the capacity and challenge components in every designated period. In a key departure from sustainability model developed in Chapter 7, which focused on a single dimension, the generic SSCM model proposed in here adopts a multi-dimensional approach to assessing sustainability performance.

Building on the discussion above, if $X_{1}, X_{2_{t}}, X_{3_{t}}, \ldots, X_{n_{t}}$ represent the factors affecting the capacity of the supply chain during period " $t$ ", then the PDF for these factors may be denoted as $f\left(x_{1_{t}}\right), f\left(x_{2_{t}}\right), f\left(x_{3_{t}}\right), \ldots, f\left(x_{n_{t}}\right)$, and the corresponding CDF for the capacity of the supply chain in period " $t$ ” can be defined as:

$$
F\left(s_{t}\right)=\int_{0}^{\hat{x}_{1}} \int_{0}^{\hat{x}_{2} t} \int_{0}^{\hat{x}_{3} t} \ldots \int_{0}^{\hat{x}_{n_{t}}} f\left(x_{1_{t}}, x_{2_{t}}, x_{3_{t}}, \ldots, x_{n_{t}}\right) d_{x_{1}} d_{x_{2 t}} d_{x_{3}} \ldots d_{x_{n_{t}}}
$$


As shown in Eq. (8.9), $f\left(x_{1}, x_{2_{t}}, x_{3_{t}}, \ldots, x_{n_{t}}\right)$ is a joint PDF constructed from random variables (i.e., environmental, economic, social, and potentially other factors) that affect the capacity and jointly form the variable " $s_{t}$ ", which represents the capacity of the supply chain in period " $t$ ".

Similarly, if $Y_{1_{t}}, Y_{2_{t}}, Y_{3_{t}}, \ldots, Y_{n_{t}}$ represent the challenge factors imposed on the supply chain in period " $t$ ", then the PDF for these factors may be denoted as $f\left(y_{1_{t}}\right), f\left(y_{2_{t}}\right), f\left(y_{3_{t}}\right), \ldots, f\left(y_{n_{t}}\right)$, and the corresponding CDF for the challenge to the supply chain in period " $t$ " can be defined as:

$$
F\left(g_{t}\right)=\int_{0}^{\hat{y}_{1 t}} \int_{0}^{\hat{y}_{2 t}} \int_{0}^{\hat{y}_{3 t}} \ldots \int_{0}^{\hat{y}_{n t}} f\left(y_{1_{t}}, y_{2_{t}}, y_{3_{t}}, \ldots, y_{n_{t}}\right) d_{y_{1}} d_{y_{2_{t}}} d_{y_{3_{t}}} \ldots d_{y_{n_{t}}}
$$

Taking Eq. (8.10), $f\left(y_{1_{t}}, y_{2_{t}}, y_{3_{t}}, \ldots, y_{n_{t}}\right)$ is a joint PDF constructed from random variables that jointly form the variable " $g_{t}$ ", which represents the challenge to the supply chain in period " $t$ ".

Based on assumptions that all of the factors comprising the supply chain's capacity and challenge are normally distributed, the CDF for the respective capacity and challenge of a supply chain in period " $t$ " can be defined as:

$$
\begin{aligned}
& F\left(s_{t}\right)=\int_{0}^{\hat{x}_{1 t}} \int_{0}^{\hat{x}_{2 t}} \cdots \int_{0}^{\hat{x}_{n_{t}}}\left(\frac{1}{2 \pi}\right)^{\frac{n}{2}}\left|V_{s_{t}}\right|^{-\frac{1}{2}} \exp \left\{-\frac{1}{2} A_{s_{t}}{ }^{T} V_{s_{t}}{ }^{-1} A_{s_{t}}\right\} d_{x_{1_{t}}} d_{x_{2_{t}}} \ldots d_{x_{n_{t}}} \\
& F\left(g_{t}\right)=\int_{0}^{\hat{y}_{1}} \int_{0}^{\hat{y}_{2 t}} \ldots \int_{0}^{\hat{y}_{n_{t}}}\left(\frac{1}{2 \pi}\right)^{\frac{n}{2}}\left|V_{g_{t}}\right|^{-\frac{1}{2}} \exp \left\{-\frac{1}{2} A_{g_{t}}{ }^{T} V_{g_{t}}{ }^{-1} A_{g_{t}}\right\} d_{y_{1_{t}}} d_{y_{2_{t}}} \ldots d_{y_{n_{t}}}
\end{aligned}
$$

Where:

$$
\begin{aligned}
& V_{s_{t}}=\text { Variance covariance matrix for } x_{i_{t}} \\
& V_{s_{t}}{ }^{-1}=\text { Matrix inverse of } V_{s_{t}} \\
& A_{s_{t}}=\text { Vector of means for } x_{i_{t}} \\
& A_{s_{t}}{ }^{T}=\text { Transpose of matrix } A_{s_{t}} \\
& V_{g_{t}}=\text { Variance covariance matrix for } y_{i_{t}}
\end{aligned}
$$




$$
\begin{aligned}
& V_{g_{t}}{ }^{-1}=\text { Matrix inverse of } V_{g_{t}} \\
& A_{g_{t}}=\text { Vector of means for } y_{i_{t}} \\
& A_{g_{t}}{ }^{T}=\text { Transpose of matrix } A_{g_{t}} \\
& \hat{x}_{i_{t}}=\text { Maximum value for } x_{i_{t}} \\
& \hat{y}_{i_{t}}=\text { Maximum value for } y_{i_{t}} \\
& i=\text { Index of respective sustainability indicators representing capacity and challenge factors } \\
& i=1,2,3, \ldots, n \\
& t=\text { Index of designated periods: } 1,2,3, \ldots, p
\end{aligned}
$$

By applying Eq. (8.11) and Eq. (8.12), the capacity and challenge of the supply chain in period " $t$ " can be calculated.

Considering the fact that the main goal in this study is to evaluate progress towards sustainability of a supply chain over time, Eqs (8.7) and (8.8) can now be written as:

$$
\begin{aligned}
\operatorname{Sus}_{S C_{t}} & =\int_{0}^{\infty} \frac{1}{\sigma_{s_{t}} \sqrt{2 \pi}} e^{-\frac{\left(s_{t}-\mu_{s_{t}}\right)^{2}}{2 \sigma_{s_{t}}^{2}}}\left[\int_{0}^{s_{t}} \frac{1}{\sigma_{g_{t}} \sqrt{2 \pi}} e^{-\frac{\left(g_{t}-\mu_{g_{t}}\right)^{2}}{2 \sigma_{g_{t}}^{2}}} d_{g_{t}}\right] d_{s_{t}} \\
\operatorname{Sus}_{S C_{t}} & =1-\varphi\left(-\frac{\mu_{s_{t}}-\mu_{g_{t}}}{\left(\sigma_{s_{t}}^{2}+\sigma_{g_{t}}^{2}\right)^{1 / 2}}\right)
\end{aligned}
$$

Where:

$$
\begin{aligned}
& S u s_{S C}=\text { Sustainability of the supply chain in the period " } t \text { " } \\
& \mu_{s_{t}}=\text { Mean value of the variable } s_{t} \\
& \mu_{g_{t}}=\text { Mean value of the variable } g_{t} \\
& \sigma_{s_{t}}=\text { Standard deviation of the variable } s_{t} \\
& \sigma_{g_{t}}=\text { Standard deviation of the variable } g_{t}
\end{aligned}
$$


By calculating the related capacity and challenge components for different periods of " $t$ " and applying the results in Eq. (8.14) in conjunction with use of the standard normal table, the sustainability of the supply chain under consideration can be estimated for each period of interest, separately.

\subsubsection{Weighted SSCM Model}

As emphasized earlier, considering the companies' unique local circumstances in any particular supply chain, different decision-makers may wish to assign different weights to different involved capacity and challenge factors. Accordingly, these weights should be signifying the importance of the involved factors. With that in mind, if $X_{1_{t}}, X_{2_{t}}, X_{3_{t}}, \ldots, X_{n_{t}}$ represent the factors affecting the capacity of the supply chain during period " $t$ ", and moreover, $w_{x_{1}}, w_{x_{2_{t}}}, w_{x_{3_{t}}}, \ldots, w_{x_{n_{t}}}$ represent the respective importance coefficients (i.e., weights) for these supporting factors, then the PDF for these factors may be denoted as $f\left(w_{x_{1}} \cdot x_{1_{t}}\right), f\left(w_{x_{2} t} \cdot x_{2_{t}}\right)$, $f\left(w_{x_{3} t} \cdot x_{3_{t}}\right), \ldots, f\left(w_{x_{n}} \cdot x_{n_{t}}\right)$, respectively. The incorporation of a weighting scheme further distinguishes this model from that presented in Chapter 7, which assumed that all factors were equally weighted. Therefore, the corresponding CDF for the capacity of the supply chain in period " $t$ " can be defined as:

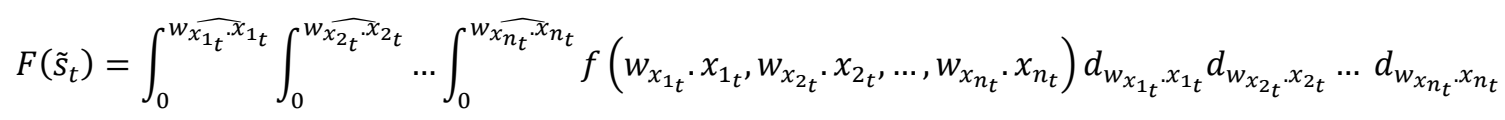

Taking Eq. (8.15), $f\left(w_{x_{1}} \cdot x_{1_{t}}, w_{x_{2} t} \cdot x_{2_{t}}, w_{x_{3}} \cdot x_{3 t}, \ldots, w_{x_{n_{t}}} \cdot x_{n_{t}}\right)$ is a joint PDF constructed from random variables representing the weighted supporting factors (i.e., environmental, economic, social, and potentially other factors) that affect the capacity and jointly form the variable " $\tilde{s}_{t}$ ", which represents the capacity of the supply chain in period " $t$ ".

Similarly, if $Y_{1_{t}}, Y_{2_{t}}, Y_{3_{t}}, \ldots, Y_{n_{t}}$ represent the challenge factors imposed to the supply chain in period " $t$ ", and moreover, $w_{y_{1} t}, w_{y_{2}}, w_{y_{3} t}, \ldots, w_{y_{n_{t}}}$ represent the respective importance coefficients (i.e., weights) signifying the prominence of these challenge factors, then the PDF for these factors may be denoted as $f\left(w_{y_{1}} \cdot y_{1_{t}}\right), f\left(w_{y_{2 t}} \cdot y_{2_{t}}\right), f\left(w_{y_{3 t}} \cdot y_{3_{t}}\right), \ldots, f\left(w_{y_{n_{t}}} \cdot y_{n_{t}}\right)$, 
respectively. Therefore, the corresponding CDF for the challenge to the supply chain in period " $t$ ” can be defined as:

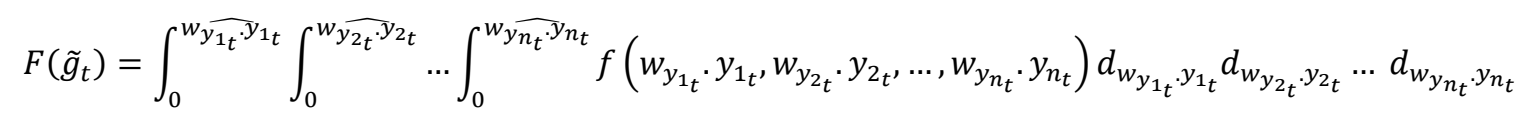

Taking Eq. (8.16), $f\left(w_{y_{1}}, y_{1_{t}}, w_{y_{2}} \cdot y_{2_{t}}, w_{y_{3_{t}}} \cdot y_{3_{t}}, \ldots, w_{y_{n_{t}}} \cdot y_{n_{t}}\right)$ is a joint PDF constructed from random variables representing the weighted challenging factors that jointly form the variable " $\tilde{g}_{t}$ ", which represents the challenge to the supply chain in period " $t$ ".

Based on assumptions that all of the factors affecting the supply chain's capacity and challenge exhibiting normal distributions, the CDF for the respective capacity and challenge of a supply chain in period " $t$ ” can be defined as:

$$
\begin{aligned}
& F\left(\tilde{s}_{t}\right)
\end{aligned}
$$

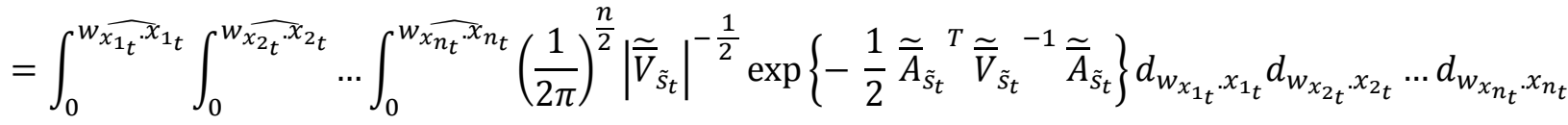

$$
\begin{aligned}
& F\left(\tilde{g}_{t}\right)
\end{aligned}
$$

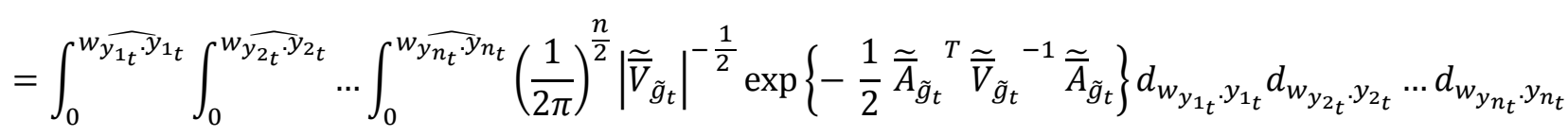

Where:

$$
\begin{aligned}
& \widetilde{\bar{V}}_{\tilde{s}_{t}}=\text { Variance covariance matrix for } w_{x_{i_{t}}} \cdot x_{i_{t}} \\
& \widetilde{\bar{V}}_{\tilde{s}_{t}}{ }^{-1}=\text { Matrix inverse of } \widetilde{\bar{V}}_{\tilde{s}_{t}} \\
& \widetilde{\bar{A}}_{\tilde{s}_{t}}=\text { Vector of means for } w_{x_{i_{t}}} \cdot x_{i_{t}} \\
& \widetilde{\bar{A}}_{\tilde{s}_{t}}{ }^{T}=\text { Transpose of matrix } \widetilde{\bar{A}}_{\tilde{s}_{t}} \\
& \widetilde{\bar{V}}_{\tilde{g}_{t}}=\text { Variance covariance matrix for } w_{y_{i_{t}}} \cdot y_{i_{t}} \\
& \widetilde{\bar{V}}_{\tilde{g}_{t}}{ }^{-1}=\text { Matrix inverse of } \widetilde{\bar{V}}_{\tilde{g}_{t}}
\end{aligned}
$$




$$
\begin{aligned}
& \widetilde{\bar{A}}_{\tilde{g}_{t}}=\text { Vector of means for } w_{y_{i_{t}}} \cdot y_{i_{t}} \\
& \widetilde{\bar{A}}_{\tilde{g}_{t}}{ }^{T}=\text { Transpose of matrix } \widetilde{\bar{A}}_{\tilde{g}_{t}} \\
& w_{x_{l_{t}} \cdot x_{l_{t}}}=\text { Maximum value for } w_{x_{i_{t}}} \cdot x_{i_{t}} \\
& w_{y_{l_{t}} \cdot y_{l_{t}}}=\text { Maximum value for } w_{y_{i_{t}}} \cdot y_{i_{t}} \\
& i=\text { Index of respective sustainability indicators representing capacity and challenge factors } \\
& i=1,2,3, \ldots, n \\
& t=\text { Index of designated periods: } 1,2,3, \ldots, p
\end{aligned}
$$

Applying Eq. (8.13), the sustainability of the supply chain under consideration can thus be defined as:

$$
\widetilde{\operatorname{Sus}_{S C}} C_{t}=\int_{0}^{\infty} \frac{1}{\sigma_{\tilde{s}_{t}} \sqrt{2 \pi}} e^{-\frac{\left(\tilde{s}_{t}-\mu_{\tilde{s}_{t}}\right)^{2}}{2 \sigma_{\tilde{s}_{t}}^{2}}}\left[\int_{0}^{\tilde{s}_{t}} \frac{1}{\sigma_{\tilde{g}_{t}} \sqrt{2 \pi}} e^{-\frac{\left(\tilde{g}_{t}-\mu_{\tilde{g}_{t}}\right)^{2}}{2 \sigma_{\tilde{g}_{t}}^{2}}} d_{\tilde{g}_{t}}\right] d_{\tilde{s}_{t}}
$$

Eq. (8.19) may be further simplified as follows:

$$
\widetilde{S u s_{S C}}=1-\varphi\left(-\frac{\mu_{\tilde{s}_{t}}-\mu_{\tilde{g}_{t}}}{\left(\sigma_{\tilde{S}_{t}}^{2}+\sigma_{\tilde{g}_{t}}^{2}\right)^{1 / 2}}\right)
$$

Where:

$$
\begin{aligned}
& \widetilde{S u S_{S C}}=\text { Sustainability of the supply chain in the period " } t \text { " with incorporated weighting scheme } \\
& \mu_{\tilde{s}_{t}}=\text { Mean value of the variable } \tilde{s}_{t} \\
& \mu_{\tilde{g}_{t}}=\text { Mean value of the variable } \tilde{g}_{t} \\
& \sigma_{\tilde{s}_{t}}=\text { Standard deviation of the variable } \tilde{s}_{t} \\
& \sigma_{\tilde{g}_{t}}=\text { Standard deviation of the variable } \tilde{g}_{t}
\end{aligned}
$$

By calculating the related capacity and challenge components for different periods of " $t$ ” and applying the results in Eq. (8.20) in conjunction with use of the standard normal table, the 
sustainability of the supply chain under consideration can be estimated for each period of interest, separately.

In the weighted SSCM model proposed, all the factors affecting capacity and challenge of the supply chain can be assigned their respective prominence weights signifying their relative importance (as determined by decision-makers in the focal firm within the supply chain) in the sustainability performance of supply chains. As highlighted earlier, considering the unique local situations of companies within any particular supply chain, different decision-makers may wish to assign different importance coefficients to different involved capacity and challenge factors. Accordingly, there are a number of weighting options that are available. Techniques like factor analysis and data envelopment analysis (i.e., derived from statistical techniques), or analytic hierarchy process, budget allocation process, and Delphi models (i.e., participatory methods) can all provide a method of assigning the respective importance coefficients as weights (Nardo et al., 2005).

As noted earlier, the approach used in this chapter shares two key features with the approach employed in Chapter 7. First, the notion of potential barriers and enablers of sustainability articulated in Section 4.4 is one of the foundations of the models developed in this chapter. The studies in both chapters further recognize that these factors are context-dependent. Assuming a normal distribution for all the involved variables in the models developed in both chapters is the second shared key feature. This is a common assumption in research employing probabilistic models that are applicable outside of the sustainability realm. However, there are also a number of important differences between the models developed in each chapter. The model developed in Chapter 7 focused on a one-dimensional approach to measuring the environmental performance of a company at the level of a single firm. As outlined above, this chapter provides a multidimensional perspective to measuring the sustainability performance of a supply chain. The generic SSCM model developed in this chapter is therefore capable of accommodating scenarios not envisioned in Chapter 7. It specifically addresses the key SSCM characteristics (i.e., the economic, social, and potentially other performance characteristics of SSCM) that were not explicitly incorporated into the model developed in the previous chapter. Moreover, it underlines the need to consider players in the supply chain beyond the focal firm. Given the growing recognition that sustainability extends beyond the boundaries of any one firm (Seuring and Gold, 
2013), this represents a significant extension of the model developed in the earlier chapter. Furthermore, the weighted SSCM model described above incorporates a mechanism for weighting of the various factors included in the model. This is in recognition of the fact that different factors may have different priorities in different supply chains. The model developed in Chapter 7 assumed that the weights for each factor were equal in all cases. In practice, all sustainability factors are rarely of equal importance in different supply chains. The weighted SSCM model presented in this chapter, therefore, provides greater flexibility for decisionmakers. The model provides a clear method of tailoring efforts to measure sustainability in supply chains to the unique circumstances faced by those decision-makers. Moreover, the model presented in Chapter 7 is discrete in measuring sustainability of the company under consideration at each of the calculation periods involved. However, both of the generic and weighted SSCM models presented in this chapter provide unique opportunities for evaluating sustainability of the supply chain at any designated period of interest whilst the cumulative effects of all the involved factors in all the previous periods are being considered. With the above in mind, the SSCM models developed in the current chapter represent significant extensions of the model presented in the previous chapter. Overall, it is important to stress that the studies presented in Chapters 7 and 8 , therefore, each represents unique contributions.

\subsection{Illustration and Discussion}

As mentioned earlier, the proposed models recognize that any supply chain will have multiple capacity and challenge factors. These factors may be represented by sustainability indicators. Several representative example indicators were provided in Section 4.4. Other representative examples are widely available in corporate sustainability reports, particularly those produced in accordance with the reporting guidelines provided by the Global Reporting Initiative (GRI) (GRI, 2013a). Although these representative indicators provide a useful reference point, it is important to stress that the specific capacity and challenge factors must be tailored to suit the unique circumstances of the supply chain under evaluation. In other words, they must address the specific context within which that supply chain operates. That said, one of the key features of the

probabilistic model provided here is that the indicators must be expressed as a percentage. This builds on the research of Ebert and Welsch (2004), who underscored the importance of using ratio scale indicators in sustainability analysis. To demonstrate how indicators may be selected 
and employed, this section presents an illustrative application of the proposed SSCM model. This example will demonstrate how the model may be used in practice. A detailed discussion of the implications of the model is also provided.

\subsubsection{Example Application of the SSCM Model}

Measuring the sustainability of any supply chain necessitates that data is available at the supply chain level. However, virtually all corporate sustainability indicators are based on data that addresses a single organization. Indicators that address suppliers are typically limited. For example, the world's most widely-used sustainability reporting guidelines, the Global Reporting Initiative (GRI) (GRI, 2103a), have relatively little to say on supply chains. Of the 91 performance indicators suggested by the GRI, only 15 address supply chain issues (GRI, 2013a, p. 86). "Percentage of new suppliers that were screened using environmental criteria", "Significant actual and potential negative environmental impacts in the supply chain and actions taken”, "Percentage of new suppliers that were screened using labor practices criteria”, "Significant actual and potential negative impacts for labor practices in the supply chain and actions taken”, "Percentage of new suppliers that were screened using human rights criteria”, "Percentage of new suppliers that were screened using criteria for impacts on society", and "Significant actual and potential negative impacts on society in the supply chain and actions taken” are some representative examples of such indicators suggested by the GRI (GRI, 2013a). The GRI thus underlines the need to address supply chain issues in sustainability performance measurement. These indicators provide additional insight into the types of metrics that can be incorporated into the SSCM models proposed in this study, but it is important to stress that different focal firms will choose to include different indicators into their measurement schemes. However, it is also important to note that indicators suggested by the GRI do not provide much, if any, guidance on how to aggregate data at the supply chain level. Additionally, indicators that address core sustainability issues, such as emissions and economic value added, tend to be restricted to a single entity in the supply chain. It has been widely noted in the literature that data collection has overwhelmingly focused on single firms rather than the supply chain as a whole (e.g., Pagell and Wu, 2009; Bjorklund et al., 2012; Miemczyk et al., 2012; Hassini et al., 2012; Seuring and Gold, 2013; Seuring, 2013). 
This makes the testing of models with real-world data difficult. Corporations are not widely publicly reporting on the impacts of their supply chains and data is generally not presented at the supply chain level. This may be due to the difficulties of aligning data collection and reporting procedures across the many players in a supply chain. Finally, it is important to emphasize that the probabilistic approach employed by the models in this study necessitates that the indicators be translated into probability numbers. Although some publicly reported indicators may already appear in this format, many do not. Some examples of how publicly available data could be used to develop probability numbers for a company have been provided in Chapter 7. However, it is important to underline that data availability is a fundamental issue for any model focused on measuring sustainability performance in supply chains. There is a relatively small amount of data available that is reported at the level of a supply chain. This is true of both the academic and practitioner literature. In the rare cases where such data is available, it is generally not reported in a probabilistic fashion. Therefore, few examples of probabilistic indicators for supply chains currently exist. For illustrative purposes, examples for potential capacity and challenge factors that can be used at the supply chain level were given in Section 4.4. These examples provide insight into how sustainability factors can be translated into probability numbers. As previously noted, the specific sustainability factors that are relevant to any particular supply chain will vary, but the principles of translating the factors into probability numbers are broadly the same as shown in the examples. However, given the fact that publicly available data on such factors is rarely available, a key challenge in applying the model in practice is therefore not just in conceiving potential sustainability factors to include in the model, but also in the availability of the data needed to support those factors.

Nonetheless, the challenges described above necessitate the use of a theoretical example to demonstrate the application of the models presented in the previous section of the chapter. Further discussions of the challenges associated with data collection at the supply chain level are provided in the discussion on the implications of the model. It is therefore necessary to make several assumptions to demonstrate the application of the model. Assume that by adopting the TBL sustainability approach, the model recognizes that different environmental, economic, and social variables are involved in the supply chain. Accordingly, presume that 5 sustainability indicators considered for each variable type are presented in Tables 8-1 and 8-2, where $j$ (i.e., 1 , 
$2, \ldots, 5$ ) is the index of such indicators and $t$ (i.e., $1,2, \ldots, 5$ ) is the index of designated periods (i.e., years). It should be noted that for the sake of simplicity, all of the respective importance coefficients (weights) for the sustainability indicators involved in this example were set to be equal. Also, it must be stressed that these indicators must be selected to suit the unique circumstances of any particular supply chain, but the indicators listed above and in Section 4.4 provide some insight into the options available.

Table 8-1: Sustainability indicators representing capacity factors*

\begin{tabular}{|c|c|c|c|c|c|}
\hline \multirow{2}{*}{$v_{s j_{t}}, c_{s j_{t}}, o_{s j_{t}}$} & \multicolumn{5}{|c|}{$t$} \\
\hline & 1 & 2 & 3 & 4 & 5 \\
\hline$v_{s 1_{t}}$ & $\hat{v}_{s_{1_{1}}}$ & $\hat{v}_{s_{1_{2}}}$ & $\hat{v}_{s_{1_{3}}}$ & $\hat{v}_{s_{1_{4}}}$ & $\hat{v}_{s_{15}}$ \\
\hline$v_{s 2_{t}}$ & $\hat{v}_{s_{2_{1}}}$ & $\hat{v}_{s_{2_{2}}}$ & $\hat{v}_{s_{2_{3}}}$ & $\hat{v}_{s_{2_{4}}}$ & $\hat{v}_{s_{25}}$ \\
\hline$v_{s 3 t}$ & $\hat{v}_{s_{3_{1}}}$ & $\hat{v}_{s_{3_{2}}}$ & $\hat{v}_{s_{3_{3}}}$ & $\hat{v}_{s_{3_{4}}}$ & $\hat{v}_{s_{5}}$ \\
\hline$v_{s 4_{t}}$ & $\hat{v}_{s_{4_{1}}}$ & $\hat{v}_{s_{4_{2}}}$ & $\hat{v}_{S_{4_{3}}}$ & $\hat{v}_{s_{4_{4}}}$ & $\hat{v}_{S_{4_{5}}}$ \\
\hline$v_{s 5_{t}}$ & $\hat{v}_{s_{5_{1}}}$ & $\hat{v}_{s_{5_{2}}}$ & $\hat{v}_{s_{5_{3}}}$ & $\hat{v}_{5_{5_{4}}}$ & $\hat{v}_{S_{5_{5}}}$ \\
\hline$c_{s 1_{t}}$ & $\hat{c}_{s_{1_{1}}}$ & $\hat{c}_{s_{1_{2}}}$ & $\hat{c}_{s_{1_{3}}}$ & $\hat{c}_{s_{1_{1}}}$ & $\hat{c}_{s_{15}}$ \\
\hline$c_{s 2_{t}}$ & $\hat{c}_{s_{2_{1}}}$ & $\hat{c}_{s_{2_{2}}}$ & $\hat{c}_{s_{2_{3}}}$ & $\hat{c}_{s_{2_{4}}}$ & $\hat{c}_{s_{2_{5}}}$ \\
\hline$c_{s{ }^{\prime} t}$ & $\hat{c}_{s_{3_{1}}}$ & $\hat{c}_{s_{3_{2}}}$ & $\hat{c}_{S_{3_{3}}}$ & $\hat{c}_{S_{3_{4}}}$ & $\hat{c}_{s_{3_{5}}}$ \\
\hline$c_{s 4_{t}}$ & $\hat{c}_{s_{4_{1}}}$ & $\hat{c}_{s_{4_{2}}}$ & $\hat{c}_{s_{4_{3}}}$ & $\hat{c}_{s_{4_{4}}}$ & $\hat{c}_{s_{4_{5}}}$ \\
\hline$c_{s 5_{t}}$ & $\hat{c}_{s_{5_{1}}}$ & $\hat{c}_{S_{5_{2}}}$ & $\hat{c}_{S_{5_{3}}}$ & $\hat{c}_{S_{5_{4}}}$ & $\hat{c}_{S_{5_{5}}}$ \\
\hline$o_{s 1_{t}}$ & $\hat{o}_{s_{1_{1}}}$ & $\hat{o}_{s_{1_{2}}}$ & $\hat{o}_{s_{1_{3}}}$ & $\hat{o}_{s_{1_{4}}}$ & $\hat{o}_{s_{1_{5}}}$ \\
\hline$o_{s 2_{t}}$ & $\hat{o}_{s_{2_{1}}}$ & $\hat{o}_{s_{2}}$ & $\hat{o}_{s_{2_{3}}}$ & $\hat{o}_{s_{2_{4}}}$ & $\hat{o}_{s_{25}}$ \\
\hline$o_{s 3_{t}}$ & $\hat{o}_{s_{3_{1}}}$ & $\hat{o}_{s_{3_{2}}}$ & $\hat{o}_{s_{3_{3}}}$ & $\hat{o}_{s_{3_{4}}}$ & $\hat{o}_{s_{3}}$ \\
\hline$o_{s 4_{t}}$ & $\hat{o}_{s_{4_{1}}}$ & $\hat{o}_{s_{4_{2}}}$ & $\hat{o}_{s_{4_{3}}}$ & $\hat{o}_{S_{4_{4}}}$ & $\hat{o}_{s_{4_{5}}}$ \\
\hline$o_{s 5_{t}}$ & $\hat{o}_{s_{5_{1}}}$ & $\hat{o}_{s_{5_{2}}}$ & $\hat{o}_{S_{5_{3}}}$ & $\hat{o}_{S_{5_{4}}}$ & $\hat{o}_{S_{5_{5}}}$ \\
\hline
\end{tabular}


Table 8-2: Sustainability indicators representing challenge factors*

\begin{tabular}{|c|c|c|c|c|c|}
\hline \multirow{2}{*}{$v_{g j_{t}}, c_{g j_{t}}, o_{g j_{t}}$} & \multicolumn{5}{|c|}{$t$} \\
\hline & 1 & 2 & 3 & 4 & 5 \\
\hline$v_{g 1_{t}}$ & $\hat{v}_{g_{1_{1}}}$ & $\hat{v}_{g_{12}}$ & $\hat{v}_{g_{13}}$ & $\hat{v}_{g_{1_{4}}}$ & $\hat{v}_{g_{1}}$ \\
\hline$v_{g 2_{t}}$ & $\hat{v}_{g_{21}}$ & $\hat{v}_{g_{2_{2}}}$ & $\hat{v}_{g_{2_{3}}}$ & $\hat{v}_{g_{2_{4}}}$ & $\hat{v}_{g_{2 s}}$ \\
\hline$v_{g 3_{t}}$ & $\hat{v}_{g_{3_{1}}}$ & $\hat{v}_{g_{3_{2}}}$ & $\hat{v}_{g_{3_{3}}}$ & $\hat{v}_{g_{3_{4}}}$ & $\hat{v}_{g_{3 s}}$ \\
\hline$v_{g 4_{t}}$ & $\hat{v}_{g_{4_{1}}}$ & $\hat{v}_{g_{4_{2}}}$ & $\hat{v}_{g_{4_{3}}}$ & $\hat{v}_{g_{4_{4}}}$ & $\hat{v}_{g_{4_{s}}}$ \\
\hline$v_{g 5_{t}}$ & $\hat{v}_{g_{5_{1}}}$ & $\hat{v}_{g_{5_{2}}}$ & $\hat{v}_{g_{5_{3}}}$ & $\hat{v}_{g_{5_{4}}}$ & $\hat{v}_{g_{5 s}}$ \\
\hline$c_{g 1_{t}}$ & $\hat{c}_{g_{1_{1}}}$ & $\hat{c}_{g_{1_{2}}}$ & $\hat{c}_{g_{1_{3}}}$ & $\hat{c}_{g_{1_{4}}}$ & $\hat{c}_{g_{15}}$ \\
\hline$c_{g 2_{t}}$ & $\hat{c}_{g_{2_{1}}}$ & $\hat{c}_{g_{2_{2}}}$ & $\hat{c}_{g_{2_{3}}}$ & $\hat{c}_{g_{2_{4}}}$ & $\hat{c}_{g_{2 s}}$ \\
\hline$c_{g 3_{t}}$ & $\hat{c}_{g_{3_{1}}}$ & $\hat{c}_{g_{3_{2}}}$ & $\hat{c}_{g_{3_{3}}}$ & $\hat{c}_{g_{3_{4}}}$ & $\hat{c}_{g_{3 s}}$ \\
\hline$c_{g 4_{t}}$ & $\hat{c}_{g_{4_{1}}}$ & $\hat{c}_{g_{4_{2}}}$ & $\hat{c}_{g_{43}}$ & $\hat{c}_{g_{4_{4}}}$ & $\hat{c}_{g_{4 !}}$ \\
\hline$c_{g 5_{t}}$ & $\hat{c}_{g_{5_{1}}}$ & $\hat{c}_{g_{5_{2}}}$ & $\hat{c}_{g_{5_{3}}}$ & $\hat{c}_{g_{5_{4}}}$ & $\hat{c}_{g_{55}}$ \\
\hline$o_{g 1_{1}}$ & $\hat{o}_{g_{1_{1}}}$ & $\hat{o}_{g_{1_{1}}}$ & $\hat{o}_{g_{1_{3}}}$ & $\hat{o}_{g_{1_{1}}}$ & $\hat{o}_{g_{1 !}}$ \\
\hline$o_{g 2_{2}}$ & $\hat{o}_{g_{2_{2}}}$ & $\hat{o}_{g_{2_{2}}}$ & $\hat{o}_{g_{2_{3}}}$ & $\hat{o}_{g_{24}}$ & $\hat{o}_{g_{2}}$ \\
\hline$o_{g 3_{t}}$ & $\hat{o}_{g_{3_{1}}}$ & $\hat{o}_{g_{3_{2}}}$ & $\hat{o}_{g_{3_{3}}}$ & $\hat{o}_{g_{3_{4}}}$ & $\hat{o}_{g_{3 \varepsilon}}$ \\
\hline$o_{g 4_{t}}$ & $\hat{o}_{g_{4_{1}}}$ & $\hat{o}_{g_{4_{2}}}$ & $\hat{o}_{g_{4_{3}}}$ & $\hat{o}_{g_{4_{4}}}$ & $\hat{o}_{g_{4 !}}$ \\
\hline$o_{g 5_{t}}$ & $\hat{o}_{g_{5_{1}}}$ & $\hat{o}_{g_{5_{2}}}$ & $\hat{o}_{g_{5_{3}}}$ & $\hat{o}_{g_{5_{4}}}$ & $\hat{o}_{g_{55}}$ \\
\hline
\end{tabular}

Note: ${ }^{*}$ For the purpose of simplicity, all the sustainability indicators representing challenge factors are equally weighted in the illustrative example.

By taking Eq. (8.11) and Eq. (8.12), these variables will jointly form capacity and challenge components of the supply chain under evaluation in 5 different years. If $\hat{v}_{s_{j_{1}}}, \hat{c}_{s_{j_{1}}}$ and $\hat{o}_{s_{j_{1}}}$ are the numerical values for the sustainability indicators representing environmental, economic, and social factors affecting the capacity of the supply chain in year " 1 ", respectively, then the value of the supply chain's capacity for the year "1", $s_{1}$, can be computed by applying Eq. (8.11). Similarly, if $\hat{v}_{g_{j_{1}}}, \hat{c}_{g_{j_{1}}}$ and $\hat{o}_{g_{j_{1}}}$ are the numerical values for the sustainability indicators representing environmental, economic, and social types of challenge factors imposed on the supply chain in year "1", respectively, then the value of the challenge imposed on the supply chain for the year "1", $g_{1}$, can be calculated by applying Eq. (8.12). By employing the same methodology, the capacity and challenge of the supply chain under evaluation can be calculated for each year, separately. Accordingly, $s_{1}, s_{2}, s_{3}, s_{4}$ and $s_{5}$ are the calculated values of the supply chain's capacity for the years " 1 " to "5", respectively. Similarly, $g_{1}, g_{2}, g_{3}, g_{4}$ and $g_{5}$ are the 
calculated values of the challenges imposed on the supply chain under consideration for the years "1" to "5", respectively. For the purposes of illustration, assume that $\mu_{s_{5}}=0.7114$ and $\mu_{g_{5}}=$ 0.4701 are mean values, and $\sigma_{S_{5}}=0.1579$ and $\sigma_{g_{5}}=0.1175$ are standard deviations for the related capacity and challenge components calculated for the years " 1 " to " 5 ", respectively. By applying these values in Eq. (8.14) and using the standard normal table, the sustainability of the supply chain under evaluation for the year " 5 " may be calculated as $\operatorname{Sus}_{S C_{5}}=0.8907$ or $89.07 \%$. This calculated value for sustainability shows that with the probability of $89.07 \%$, the supply chain under evaluation was successful in overcoming the imposed challenges, and hence progressed towards sustainability in the year " 5 ". In other words, this result shows that the probability that the supply chain under evaluation has improved (progressed) in positioning to be sustainable in the year "5" is equal to 89.07\%. Taking Eq. (8.14), it is clear that if the capacity of the supply chain is getting stronger while the challenge imposed on the supply chain is increasing at the same time, there might not be much progress observed towards sustainability. But if the supply chain's capacity is getting stronger while the imposed challenge is weakening, where the difference between the mean values of the involved capacity and challenge components is getting larger, better sustainability results (i.e., closer values to 1 or $100 \%$ ) will be expected.

The proposed sustainability model is particularly useful for evaluating changes in the sustainability of a supply chain over time. Accordingly, the process outlined above can be repeated to compute scores for subsequent years. For example, by plotting the numerical values of the sustainability indicators representing environmental, economic, and social factors affecting the capacity and challenge of the supply chain in the subsequent period (i.e., year "6"), the respective capacity (i.e., $s_{6}$ ) and challenge (i.e., $g_{6}$ ) components of the supply chain under evaluation can be calculated. Then, by employing all the calculated values of capacity and challenge components for the year " 1 " to "6" (i.e., $s_{1}, s_{2}, s_{3}, s_{4}, s_{5}, s_{6}$ and $g_{1}, g_{2}, g_{3}, g_{4}, g_{5}, g_{6}$ ), the relevant mean values (i.e., $\mu_{s_{6}}, \mu_{g_{6}}$ ) and standard deviations (i.e., $\sigma_{s_{6}}, \sigma_{g_{6}}$ ) for the year "6" can be determined. Ultimately, by applying the results of these computations in Eq. (8.14) and using the standard normal table, the sustainability of the supply chain under evaluation for the year "6" can be estimated. This methodology can be used to calculate the involved capacity and challenge components of the supply chain for any subsequent period (e.g., year 7, 8, ...), which 
ultimately will lead to the estimation of the sustainability of the supply chain under evaluation over the period of interest. This also highlights the fact that in order to estimate the sustainability of the supply chain at any designated period of interest, it is necessary to calculate and employ all the capacity and challenge components of all the previous periods involved.

As emphasized in the illustrative example above, fluctuations of values for the involved capacity and challenge factors will affect the supply chain's capacity and challenge components in each period, which will ultimately affect the sustainability of the supply chain under evaluation over time. Dealing with situations where the capacity and challenge factors affecting the sustainability of any supply chain under consideration are constantly changing is a major issue for policy prioritization and decision making. The supply chain's capacity might be deteriorating while at the same time the imposed challenges are intensifying, or vice versa. Consequently, it is necessary to monitor variations of the involved capacity and challenge factors, and to keep track of their changes over time. In order to do so, reliable and effective tools that are easy to use and able to provide fast feedback on the sustainability status of supply chain(s), are required. By applying Eq. (8.14) or Eq. (8.20) the progress status of the supply chain under evaluation towards or away from sustainability, can be assessed for each designated period, separately.

Furthermore, the cumulative impacts of factors involved in the supply chain's sustainability are implicitly addressed in the proposed SSCM models. As illustrated in the above example, all of the calculated capacity and challenge components for the years "1" to "5" (i.e., $s_{1}, s_{2}, s_{3}, s_{4}, s_{5}$ and $\left.g_{1}, g_{2}, g_{3}, g_{4}, g_{5}\right)$, were explicitly used in the computation of the sustainability for the year " 5 ". They were also included in the computation of the sustainability for year "6", alongside the respective calculated capacity (i.e., $s_{6}$ ) and challenge (i.e., $g_{6}$ ) components of the supply chain under evaluation in the same year. The sustainability of the supply chain in each designated period of interest therefore necessitates that the cumulative effects of all the involved factors in all the previous periods are considered.

\subsubsection{Implications of the SSCM Model}

The models presented in this study have a number of implications for academics and practitioners. From an academic perspective, this study presents one of the first probabilistic 
models for sustainability assessment of supply chains. This addresses an important gap in the literature given the ability of probabilistic models to accommodate the uncertainty associated with factors relevant to sustainability in supply chains (Brandenburg et al., 2014). The study also reinforces the notion of context-dependent capacity and challenge factors in sustainability assessments (Ahi and Searcy, 2013b). This underlines the importance of taking the unique local context of any particular supply chain into account. Several representative indictors were provided for these factors for all three areas of the TBL. However, the models also underscore the need for additional ratio-based indicators that comprehensively address the TBL (as a minimum) in a supply chain context. Although some attempts have been made to highlight the sustainability indicators used to address performance measurement in sustainable supply chains (e.g., Hassini et al., 2012), the literature also highlights that many of the indicators used were not designed to be applied in that context (Hassini et al., 2012). As a result, the indicators utilized often do not span all channels in the supply chain (Hassini et al., 2012). The models therefore also highlight the need to measure sustainability at the level of a supply chain, rather than that of a single firm. This, however, introduces a number of key research challenges. The effectiveness of any tool designed to measure sustainability on a supply chain basis is very much dependent on the availability of data across the entire chain under evaluation. However, as previously explained, such data is rarely available. In fact, the difficulties in obtaining the required data have formed a major barrier to the development of robust methods to measure the sustainability of supply chains (Veleva et al., 2003; Pagell and Wu, 2009; Bjorklund et al., 2012; Miemczyk et al., 2012; Hassini et al., 2012; Seuring and Gold, 2013; Seuring, 2013). Scientifically-sound methods of collecting data at the supply chain level are urgently needed. Moreover, this effort must be supported by improved methods of reporting on the sustainability performance of supply chains. Since few mandatory sustainability reporting requirements presently exist, the proposed SSCM models must rely on voluntarily reported information. This reliance on voluntarily shared information is particularly problematic given that the widely-used sustainability standards, including the GRI, were not designed to be primarily applied in a supply chain context. Although the GRI has recognized the importance of addressing issues related to the supply chain (GRI, 2013a), more specific guidance is necessary. Research on reporting at the supply chain level is therefore needed, particularly with respect to how the GRI could better accommodate that need. Finally, given that suppliers often play a role in multiple supply chains, there is a need to 
determine how their key sustainability impacts can be allocated to those chains. This is one of the fundamental challenges of measuring performance at the level of a supply chain. One of the reasons this is particularly important is that significant impacts could be generated at any point in the supply chain. For example, the greatest number of greenhouse gas emissions (a common factor used in sustainability performance measurement) in any particular supply chain may be generated in the extraction of raw materials by a supplier rather than in the production of the product by the focal firm. Failing to account for impacts throughout the entire supply chain could provide a distorted picture of the chain's overall sustainability performance. It is therefore essential that all key impacts for the factor in question are captured when the value for the factor is tabulated. Research on the allocation of environmental impacts is available in the literature on life cycle assessment. However, little work has been done on the allocation of a supplier's broader TBL impacts in the context of measuring sustainability performance at the supply chain level. The allocation of social impacts in supply chains is particularly challenging. Further research in this area is needed to support efforts to measure sustainability in the supply chain.

The proposed SSCM models also have a number of important practical implications. Many of these implications align with the academic implications noted above. For example, there is a clear need for practitioners to also work on devising better methods of collecting and reporting on data at the supply chain level. However, there are several other implications that are unique to practitioners. As pointed out earlier, policy and decision makers require timely information that reveals if a supply chain is generally becoming more or less sustainable (Foran et al., 2005). Accordingly, reliable measures that can be clearly interpreted and easily communicated and at the same time have the ability to provide timely information on sustainability assessment of supply chains are in demand.

By taking as many characteristics as may be involved in SSCM, the models developed in this study can be employed as integrative, multi-dimensional sustainability tools to analyze the tradeoffs among different characteristics of SSCM (e.g., environmental, economic, social, and potentially others). Moreover, given their probabilistic nature, the proposed SSCM models can encompass the involved uncertainty issues and behaviors (e.g., Sanchez Rodrigues et al., 2010), which have been relatively lacking in the various sustainability measures introduced in the literature (Searcy, 2012). Additionally, the cumulative impacts required for the explicit long-term 
focus of sustainability, which has rarely been addressed in the published studies on sustainability assessment measures (Lenzen et al., 2004; Searcy, 2012), can be embraced in the proposed SSCM models. Accordingly, in the proposed models, the sustainability of the supply chain under evaluation can be estimated for any designated period of interest while the cumulative effects of the involved factors in all the previous periods are taken into account. The SSCM models proposed in this study can be employed as practical and effective tools for the sustainability assessment of any supply chain under consideration. The increased understanding provided by the proposed SSCM models can assist practitioners as they improve the sustainability performance of their supply chains over time.

\subsection{Conclusion}

The integration of sustainability into the supply chain is an area of growing research interest. Accordingly, sustainability should be viewed as a holistic and interdisciplinary concept that encompasses environmental, economic, and social issues, as a minimum, at different stages in the supply chain(s). Therefore, it is becoming an essential requirement to assess sustainability in the supply chain context by developing appropriate tools to monitor a supply chain's performance towards sustainability.

This chapter presented two unique mathematical models for assessing sustainability in a supply chain. The models explicitly recognized that the involved supportive and hindering factors for sustainability in a supply chain are all fundamentally context dependent. Therefore, the probabilistic representations of sustainability presented in this study can offer realistic analytical modeling for sustainability assessment of supply chain(s). To demonstrate the application of the proposed SSCM models, an illustrative example focused on a TBL sustainability perspective was provided and discussed. By taking as many characteristics as may be involved in SSCM, the models developed in this study can be employed as assimilative, multi-dimensional sustainability frameworks to analyze the interactions and trade-offs among different characteristics of SSCM. Particularly, by focusing on the principles embedded in the TBL sustainability perspective, the

proposed SSCM models can be employed as integrative, three-dimensional sustainability tools to evaluate the effects of different environmental, economic, and social issues in the supply chain 
context. The developed models can be utilized as practical tools particularly for assessing sustainability performance of any supply chain under evaluation over time.

The study underlined in this chapter makes several contributions to the literature. First, it provided one of the first probabilistic models for assessing sustainability in the supply chain. The developed models explicitly recognized that the factors that enable and inhibit sustainability in a supply chain are all fundamentally context dependent. Both generic and weighted SSCM models developed in this study are unique in that they can encompass all three areas of the TBL sustainability concept (as a minimum) from a probabilistic perspective. The weighted SSCM model developed in this study incorporates a unique weighting component that has not been previously addressed in this context in the literature.

Moreover, this is one of the first studies that applies a multi-dimensional, probabilistic approach to assessing sustainability performance in supply chains. Second, this study provided a clear reference point for future work by both academics and practitioners. The study highlighted the need to systematically identify the key sustainability challenges and opportunities in a particular supply chain. Critically, it also highlighted the need for improved reporting and standardization of data collection procedures across the entire supply chain. The study identified and explained the key challenges in collecting sustainability data at the supply chain level. If data collection challenges can be overcome, the developed models provide a practical and straightforward way to assess the sustainability performance of any supply chain. The development of the proposed SSCM models was guided by the need for ease of use, simplicity, and the ability to quickly provide feedback on sustainability status of supply chains over time. 


\section{CHAPTER 9}

\section{CONCLUSION}

\subsection{Overall Summary}

This research has made several key contributions through developing a comprehensive definition of SSCM, a database of metrics used to measure GSCM and SSCM, a conceptual framework for measuring performance in SSCM, and probabilistic models for assessing and measuring progress towards sustainability at the company level and in the supply chain context. These contributions will open several directions and avenues for future research in the SSCM area. Detailed discussions of the research contributions followed by recommendations for future research are provided in the next sections, respectively.

\subsection{Research Contributions}

In Objective 1, a systematic research literature review was conducted to identify the published definitions of GSCM and SSCM. This provides a needed reference point on the great variety of definitions published in these areas. The results showed that 22 and 12 distinct definitions have been published to describe GSCM and SSCM, respectively. The analysis showed that there were many differences, both large and small, among the published definitions. The definitions varied in their coverage of business sustainability and SCM key characteristics. No comprehensive definition of GSCM or SSCM was identified, but there were several definitions that addressed at least half of the identified key characteristics. As a result, it is argued that the published definitions do not fully capture the meaning of SSCM. Therefore, to provide a reference point for future research in these areas, a new comprehensive definition of SSCM was suggested. The suggested definition captures all 13 of the key characteristics of SSCM (i.e., economic, environmental, social, volunteer, resilience, long-term, stakeholder, flow, coordination, relationship, value, efficiency, and performance focuses).

Overall, the contributions of the Objective 1 can be summarized as follows: 
- Introduced one of the most comprehensive sets of key characteristics for business sustainability and SCM offered in the literature to date.

- Developed the first comprehensive database of definitions for GSCM and SSCM through a systematic and structured content analysis of all the relevant identified literature.

- Highlighted the convergences and divergences as well as strengths and weaknesses of all the identified GSCM and SSCM definitions reported in the literature through detailed analyses of the definitions against each other and against the introduced key characteristics of business sustainability and SCM.

- Provided the much needed reference points on the great variety of definitions available to describe GSCM and SSCM by developing the most comprehensive definitions for GSCM and SSCM offered to date.

In Objective 2, a systematic research literature review was conducted to identify and analyze all the metrics published in the literature on GSCM and SSCM. The conducted analyses provide a needed reference point on the great variety of metrics highlighted in these areas. Since no systematic analysis of GSCM and SSCM metrics has been carried out and reported in the literature, the findings in Objective 2 will help to identify convergences and divergences as well as strengths and weaknesses of the published metrics. This provides a starting point for populating any other models and frameworks focusing on assessing sustainability of a supply chain. Building on the discussions provided earlier, policy and decision makers in the field of SSCM need metrics that can be unambiguously interpreted, easily communicated and at the same time, have the ability to provide timely information on sustainability assessment of supply chains. Considering the fundamentally multidimensional nature of sustainability, supply chains can concurrently become more sustainable in some dimensions and less sustainable in others, and it is still likely that they become unstable even if most related indicators are presenting improvements. A thorough analysis of the published metrics will enable more informed decisions related to their selection and use.

Objective 2 makes several contributions to the literature. First, it provides the first comprehensive database of metrics that have been reported in the literature on GSCM and SSCM. Second, the analysis of the published metrics enlightens the development of an original conceptual framework for measuring performance in GSCM and SSCM. Third, the analysis and 
framework provide a strong basis for future academic and practitioner work. The study highlights the need to develop a common understanding of what GSCM and SSCM entail, to develop metrics that address that common understanding, and to link metrics to the broader sustainability context in which supply chains operate. These requirements formed the foundation of the conceptual framework presented in the research.

As emphasized earlier in the study (i.e., Chapter 6), the great range of metrics utilized indicates that a general lack of agreement on what should be measured in GSCM and SSCM remains. Although an extensive array of metrics in these areas is available, this presents challenges in determining the metrics most appropriate to measuring green or sustainable performance in a particular supply chain. Nonetheless, the research presents an important starting point for managers interested in measuring sustainability performance in their supply chains. For academics, it further underlines the need to find common ground regarding the key areas to be measured in GSCM and SSCM. Objective 2 also highlighted that no context-based metric for GSCM or SSCM has been proposed in the literature. The overwhelming majority of the metrics published were classified as absolute metrics while a much smaller group of metrics were categorized as relative metrics. These forms of metrics are needed to measure progress over time within organizations and their associated supply chains. However, the lack of context-based metrics means that current measurement efforts are largely self-referential. There is little connection to the broader local, regional, and global context within which supply chains operate. This finding highlights the need for both academics and practitioners to develop context-based sustainability metrics for GSCM and SSCM.

Overall, the contributions of the Objective 2 can be summarized as follows:

- Developed the first comprehensive database of metrics that have been reported in the literature on GSCM and SSCM, through a systematic and structured content analysis of all the relevant identified literature. The database provides a strong basis for populating any other models and frameworks focusing on assessing sustainability of a supply chain.

- Highlighted the convergences and divergences as well as strengths and weaknesses of all the identified metrics used in the GSCM and SSCM areas through detailed analyses of 
the metrics against each other and against the key characteristics of business sustainability and SCM.

- Developed an original conceptual framework for measuring performance in GSCM and SSCM. Accordingly, by emphasizing the need to address all the key players in the supply chain, the broader sustainability context within which the supply chain operates, and all the key characteristics of GSCM and SSCM, the framework provides a strong basis for future academic and practitioner work.

In Objective 3, a probabilistic model was developed to assess sustainability performance of a company by explicitly adopting the strong sustainability concept. The developed sustainability model provides several contributions to the literature. The model provides a simple, straightforward approach to assessing sustainability performance. The model is one of the first to explicitly adopt a probabilistic approach to sustainability measurement. It is also explicitly applicable to the company level. By providing relatively simple and informative measurement, the proposed model can be employed as a practical tool, particularly for assessment of the sustainability performance of any given company over time, and also to guide the involved decision-making process more efficiently. It also provides a basis for improved reporting of sustainability performance at the company level. The proposed sustainability model may provide opportunities for making comparisons between companies operating in the same sector that use the same indicators, provided that they are measured in the same way. However, since few mandatory sustainability reporting requirements currently exist, the model must rely on the information that any respective entity is willing to report voluntarily. Although standards and guidelines (e.g., the GRI) have become more mainstream, the use of such frameworks is not currently mandatory and those applying such guidelines have considerable discretion in terms of what they choose to disclose. Therefore, while the proposed model in Objective 3 is a useful tool for assessing and evaluating sustainability of any respective company over time, dealing with such a lack of data comparability makes it difficult to perform comparisons between different companies.

Overall, the contributions of the Objective 3 can be summarized as follows: 
- Developed an original and straightforward mathematical model to assess the sustainability of a company from the strong sustainability perspective.

- The model is one of the first to explicitly adopt a probabilistic approach to sustainability measurement and assessment at the company level.

- The model exclusively recognizes the context-dependent status of factors that either enable or hinder progress towards sustainability.

- The model provides a basis for improved reporting and benchmarking in the field of sustainability performance measurement at the company level.

- The model may provide opportunities for making comparisons between companies, provided that the compared companies utilize the same indicators that are measured in the same way.

In Objective 4, two probabilistic models were developed to assess sustainability performance of a supply chain. By taking as many characteristics as may be involved in SSCM, the sustainability models developed in Objective 4 can be employed as integrative, multi-dimensional sustainability frameworks to analyze the interactions and trade-offs among the different characteristics of SSCM highlighted and discussed in Objective 1. Given their probabilistic nature, the proposed SSCM models can encompass the involved uncertainty behaviors and at the same time, they can embrace the cumulativeness of the entailed impacts required for the longterm focus of sustainability. In the proposed models, the sustainability of the supply chain in each designated period of interest can be estimated while the cumulative effects of the involved factors in all the previous periods are considered.

Objective 4 makes a number of important contributions to research and practice. From a research perspective, Objective 4 addresses an explicit call in the literature to develop probabilistic models for assessing sustainability in supply chains. This is important because probabilistic models are capable of accommodating the complexity and uncertainty inherent in modeling sustainability performance. From a practical perspective, the SSCM models developed in Objective 4 provide straightforward ways of assessing the sustainability performance of a supply chain over time. They therefore provide decision makers with needed reference points in identifying the challenges and opportunities for improving the sustainability of supply chains under their management. 
Finally, by providing relatively simple and informative measurement, both of the generic and weighted SSCM models proposed in Objective 4 can be used as effective and practical tools for assessing the sustainability performance of any given supply chain over time, and also to guide the entailed policy and decision-making processes more effectively.

Overall, the contributions of the Objective 4 can be summarized as follows:

- Developed original and straightforward mathematical models to assess the sustainability of a supply chain.

- The SSCM models are one of the first to explicitly adopt a probabilistic approach for sustainability measurement and assessment in the supply chain context.

- The SSCM models have an integrated and multidimensional nature, and thus, they can comprehensively accommodate as many characteristics as may be involved in SSCM.

- The SSCM models provide unique opportunities for evaluating sustainability of the supply chain at any designated period of interest while the cumulative effects of all the involved factors in all the previous periods are being considered.

- The SSCM models can be used as practical tools, particularly, for sustainability assessment of the supply chain over time.

- The SSCM models may provide opportunities for making comparisons between supply chains, provided that the required data are collected, allocated, and reported in the same way across all the supply chains under comparison scrutiny.

\subsection{Future Research Recommendations}

Given that research in both areas of GSCM and SSCM is still relatively new, a diversity of perspectives in terms of definitions is useful. However, as research on the integration of sustainability into SCM continues to expand, it will become increasingly important to address the inconsistencies in the various definitions of GSCM and SSCM. The lack of reasonably consistent definitions may lead to confusion regarding the appropriate scope in theory and practice of SSCM initiatives. This confusion can potentially be expanded if related terms, such as "green purchasing”, "closed-loop supply chain”, and "reverse logistics”, are considered. Consequently, 
exploring the implications of and potential resolutions to the many differences in the published definitions provides an avenue for future research.

There are several opportunities to extend the research presented in Objective 2. Fundamentally, there is a need to develop a common understanding of what exactly GSCM and SSCM entail (Ashby et al., 2012). Building on that point, there is also a need for research on how organizations can select metrics most appropriate to their circumstances. The conceptual framework proposed in Objective 2 underlines that focal firms need to consider all of the main players in the supply chain, must strive to address the 13 key characteristics of SSCM, and must be careful not to overlook the need for context-based metrics. The conceptual framework therefore provides a clear starting point for all organizations, though it is recognized that there are a multitude of potential metrics that may be used to fulfill these requirements. It is important to recognize that no one metric, or set of metrics, will apply equally well in all circumstances. While the conceptual framework provides a clear starting point for this process, it leaves the prioritization of specific metrics to the decision-makers in the focal firm. Moreover, the conceptual framework has not been tested in practice nor does it provide a set of specific metrics. A consolidated set of scientifically-sound metrics that have been tested in the real world would provide a useful reference point for organizations seeking to measure their GSCM or SSCM efforts. Given the fact that SSCM can be arguably considered as an extension of GSCM, metrics that address multiple key characteristics of SSCM are of particular interest. Although many examples of integrated metrics are available in the literature, the emphasis has overwhelmingly been on presenting metrics that address a single characteristic of SSCM. The development of scientifically-sound integrated metrics will help in promoting stronger linkages among various key characteristics of SSCM. Such linkages may help further drive the incorporation of green and sustainable practices into supply chain management. The study carried out in Objective 2 also underlined that additional effort is needed on the development of context-based metrics for GSCM and SSCM. It is acknowledged that there are many challenges in developing such metrics, particularly in determining the appropriate level of impact or contributions that individual organizations or supply chains must make in order to be deemed sustainable or not (McElroy and van Engelen, 2012). Nonetheless, such research is needed to underscore the connection that supply chains have to the broader context within which they operate. 
Furthermore, it should be explicitly noted that the research presented in this study focused on reviewing the metrics published in the peer-reviewed literature. One additional avenue of future research could be to analyze the metrics published and used by corporations engaged in the measurement of sustainability in their supply chains. A review of publicly available sustainability reports would provide insight into the metrics focused on this issue that corporations are choosing to share with their stakeholders. Interviews with managers at these corporations would provide an opportunity to explore questions related to how the metrics were developed, how they are used, and plans for developing new metrics going forward. The interviews could explicitly address questions related to the key challenges in developing metrics that address the 13 key characteristics of SSCM, metrics that link to the broader sustainability context in which the corporation and its supply chain operate, and metrics that address all key players in the supply chain. Moreover, in-depth case studies with a selected number of companies could permit a detailed, long-term exploration of these issues. Such research would provide greater insight into the metrics that are being applied in practice and the key challenges academics face in advancing research on the measurement of sustainability in supply chains. Finally, the conceptual framework developed in Objective 2 can also provide a strong basis for developing appropriate input-output analysis model(s) employed to assess performance in green and/or sustainable supply chains.

In Objective 3, the ecological economics, also known as strong sustainability, perspective was employed where the environmentally related factors were considered to be the primary and equally-weighted factors affecting the capacity and challenge to the company. However, as different decision-makers may wish to assign different priorities to different capacity and challenge factors involved, the inclusion of respective prominence weights to the model is recommended for the future research. This will provide an opportunity to evaluate sustainability of the company under the ecological economics paradigm more conclusively. Moreover, the capacity and challenge factors involved in the proposed sustainability model were considered as the variables acting independently. For the future research, development of a sustainability model that incorporates dependent capacity and challenge variables is recommended. Additionally, one of the assumptions made for the development of the proposed sustainability model was to use normal distributions for all the involved variables representing capacity and 
challenge factors. Further recommendation for the future research can be the consideration and employment of other meaningful probability distributions (e.g., log-normal, exponential, gamma, weibull) for the involved variables. In this light, employment of log-normal and gamma distributions are particularly useful when the uncertainties about the capacity, challenge, or both type of factors, are relatively large. Accordingly, to alleviate the effects and possibility of having any negative value for the involved variables (i.e., essentially considered as zero in the sustainability analyses and assessments conducted), utilizing log-normal and/or gamma distributions for the involved capacity and challenge factors, may provide more convincing results for the stochastic assessments of sustainability.

In Objective 4, the conducted study highlights the need for research on aligning data collection, indicator development, and reporting efforts across the entire supply chain. To date, the overwhelming majority of the research has focused on data collection, indicator development, and reporting for single entities in a supply chain, rather than the chain as a whole. It is acknowledged that measuring sustainability at the supply chain level is difficult. Collecting and reporting data across an entire supply chain is challenging even in supply chains with a small number of players. As the number of players increases these challenges are magnified. The fact that different suppliers play a role in different supply chains further complicates the matter. Objective 4 therefore highlights the need for further research on allocating the environmental, economic, and social impacts of suppliers to their (potentially many) customers. The measurement of sustainability at the level of a supply chain is not possible in the absence of such allocation mechanisms. Finally, the limited data that is available on supply chain sustainability is typically not reported in a manner that lends itself to a probabilistic approach to measurement. There is a need for further research on the development of probabilistic sustainability factors, including on how information may be translated into probability numbers that make sense. There is also a need for research on how this information could be reported so as to make measurement at the supply chain level possible on a wider scale than currently exists. All of these issues make the evaluation of sustainability performance at the supply chain level problematic in practice.

Drawing on the above, future research would need to focus on accommodating different enablers and inhibitors of sustainability that different companies in the supply chain may have. This challenge will become more complex as the number of players in the supply chain increases and 
it is recognized that detailed guidance on managing those challenges are needed. As a part of this effort, further research on the specific indicators that are applicable to measuring sustainability in supply chains is needed. Many of the indicators in the literature are either not intended to be applied in a supply chain context or do not lend themselves to being used in a probabilistic model. Although many example indicators were provided in this study, it is important to stress that they are intended as starting points. More detailed guidance on tailoring indicators to the unique needs of different supply chains is needed. Furthermore, the notion of context-dependent capacity and challenge factors for sustainability analysis and assessment may provide a basis for developing appropriate models, that specifically target the trade-offs between investment types and sustainability status of supply chains. 


\section{APPENDICES}

To provide illustrations of the great range of metrics used to measure similar core issues discussed in Chapter 6, analyses of the metrics that explicitly address energy- and water-related issues are provided in Appendices A and B, respectively. Furthermore, a representative sample calculation for sustainability assessment of the case company discussed in Chapter 7 is presented in Appendix C.

\section{APPENDIX A: Analysis of Metrics Addressing Energy Issues}

One prominent issue that addresses different characteristics of SSCM is energy use. Multiple authors have also emphasized the need to consider energy use in supply chains in order to address sustainability requirements (Cucchiella and D’Adamo, 2013; Halldorsson and Svanberg, 2013). Energy may be generated through a number of different technologies, such as combustion, wind, or solar systems. A variety of energy carriers (e.g., coal, crude oil, natural gas, wind, sunlight, waste and biomass) are used to provide different consumable forms of energy (e.g., electricity, heat and vehicle fuel) that are ultimately used by different industries and/or households. However, a number of fundamental energy-related issues have not been adequately considered in the design and implementation of modern supply chains (Rogers et al., 2007; Christopher, 2010; Halldorsson and Kovacs, 2010). Approaches to GSCM and SSCM must consider issues such as shortages of natural resources, variability in fuel prices, energy availability, energy sources used in manufacturing and/or transportation, and emissions (e.g., $\mathrm{CO}_{2}, \mathrm{SO}_{2}$ ), among others.

Building on the above, however, no systematic analysis of the use of energy-related metrics in GSCM and SSCM has been conducted. As noted earlier, this is an important oversight for two reasons. First, there are inconsistencies in the use of sustainability metrics (Roca and Searcy, 2012). Multiple metrics are often used to measure essentially the same sustainability issue and there is a need to explore how this has impacted the measurement of energy-related issues in GSCM and SSCM. Second, energy is one of the central sustainability issues in today's globally intense supply chains (Cucchiella and D’Adamo, 2013). There is therefore a need to direct particular attention to this important issue. Exploring the implications of the differences in the 
published energy-related metrics for green and sustainable SCM will provide much needed reference points in these areas (Cucchiella and D’Adamo, 2013).

A total of 113 unique metrics were identified that explicitly addressed energy-related issues. Approximately 65\% of these metrics appeared in the literature only once. Another 26\% appeared only twice. The results also highlight that approximately about $3 \%$ of the identified metrics appeared three times. Analysis of the results also shows that just eight metrics (7\%) appeared more than 4 times (i.e., "Energy use” (24 times), "Energy consumption” (21), "Energy efficiency” (11), “Energy used” (7), “Decrease of cost for energy consumption” (6), “Energy” (6), "Cumulative energy demand (primary energy used over the life cycle of a product or a process)” (5), and “Reduction of energy consumption” (4)).

Approximately, 64\% of the identified energy-related metrics focused explicitly on addressing environmental issues. “Energy use” (24 times), “Energy consumption” (21), “Energy efficiency” (11), and "Energy used” (7) were some of the high frequency metrics that explicitly addressed environmental issues. This is while "Energy return on investment” (1 time) and “Access to energy" (1) were the only metrics that exclusively addressing the economic and social issues, respectively. Flow, volunteer, resilience, and relationship focuses required for the explicit essence of GSCM or SSCM were not addressed by any of the energy-related metrics identified.

Approximately 35\% (i.e., 39 metrics) of the energy-related metrics addressed multiple characteristics of SSCM. The majority (i.e., 30 metrics) of these cross-cutting metrics addressed 2 characteristics of SSCM. The remaining of the cross-cutting metrics addressed 3 and 4 characteristics. A complete summary of the energy-related metrics that addressed multiple characteristics of SSCM is provided in Table A-1. No energy-related metric was identified that addressed 5 or more characteristics of SSCM. 
Table A-1: Overview of metrics that addressed multiple SSCM characteristics for Energy-related issues

\begin{tabular}{|c|c|c|c|}
\hline Categories & SSCM Characteristics & $\begin{array}{l}\text { No. of } \\
\text { Metrics }\end{array}$ & Examples of Cross-cutting Metrics (Frequency rates) \\
\hline \multirow{8}{*}{$\begin{array}{l}2 \\
\text { Characteristics }\end{array}$} & Environmental and Economic focuses & 14 & $\begin{array}{l}\text { Decrease of cost for energy consumption (6), Purchase of energy for own } \\
\text { consumption per enterprise (2), Design of products for reduced consumption of } \\
\text { energy (2) }\end{array}$ \\
\hline & Environmental and Performance focuses & 5 & $\begin{array}{l}\text { Operation energy saving (3), Energy units saved due to energy conservation } \\
\text { programmes (2), Performance in using energy (1) }\end{array}$ \\
\hline & Environmental and Efficiency focuses & 5 & $\begin{array}{l}\text { Energy efficiency (11), Energy efficiency per material (\%) (2), Possibilities of } \\
\text { using energy efficient and clean technologies are considered (1) }\end{array}$ \\
\hline & Environmental and Long-term focuses & 2 & $\begin{array}{l}\text { Cumulative energy demand (primary energy used over the life cycle of a product } \\
\text { or a process) (5), Reused energy (1) }\end{array}$ \\
\hline & Environmental and Stakeholder focuses & 1 & Energy used per customer (2) \\
\hline & Environmental and Value focuses & 1 & Energy requirement per unit of net value added (1) \\
\hline & Environmental and Social focuses & 1 & Organisational energy use (1) \\
\hline & Economic and Performance focuses & 1 & Production cost decreases as a result of energy and materials saving (1) \\
\hline \multirow{5}{*}{$\begin{array}{c}3 \\
\text { Characteristics }\end{array}$} & Environmental, Economic and Performance focuses & 3 & $\begin{array}{l}\text { Use of cleaner technology processes to make savings (energy) (2), Energy saving } \\
\text { (1), Energy cost savings (1) }\end{array}$ \\
\hline & Environmental, Economic and Efficiency focuses & 2 & $\begin{array}{l}\text { Development of energy-efficient products (1), Manufacturing processes energy } \\
\text { efficiency (1) }\end{array}$ \\
\hline & Environmental, Economic and Social focuses & 1 & Product design for lower energy consumption when using the product (1) \\
\hline & Environmental, Economic and Value focuses & 1 & Energy consumption per added industrial value (1) \\
\hline & Environmental, Efficiency and Performance focuses & 1 & Optimisation of efficiency through the use of energy efficient vehicles (1) \\
\hline $\begin{array}{c}\quad 4 \\
\text { Characteristics }\end{array}$ & $\begin{array}{l}\text { Environmental, Social, Stakeholder and Coordination } \\
\text { focuses }\end{array}$ & 1 & $\begin{array}{l}\text { Cooperation with customers for using less energy during product transportation } \\
\text { (1) }\end{array}$ \\
\hline
\end{tabular}


Analysis of metrics pertaining to the energy-related issues in GSCM and SSCM highlights that the majority of metrics are quantitative (i.e., 107 metrics, $94.7 \%$ of the total number of energyrelated metrics), and only a small percentage of them are qualitative (i.e., 6, 5.3\%) metrics. Examples of quantitative metrics include "Energy use” (24 times), "Energy consumption” (21), "Energy efficiency" (11), "Energy used” (7), and "Decrease of cost for energy consumption” (6). Examples of qualitative metrics include "Each type of energy used" (2 times), "Supporting the generation and distribution of renewable energy" (2),"Energy resources" (1), and "Access to energy" (1). Also, a relatively large number of these metrics were categorized as absolute metrics (i.e., 80 metrics or $70.8 \%$ of the total number of energy-related metrics) where only less than one third of them (i.e., 33 metrics or 29.2\%) fallen in the category of relative metrics. This is while no context-based metric was found to address energy-related issues. Examples of absolute metrics include "Energy use" (24 times), "Energy consumption” (21), "Energy used" (7), and "Decrease of cost for energy consumption" (6). Examples of relative metrics include "Energy efficiency” (11), “Energy intensity” (3), "Energy efficiency per material (\%)” (2), "Percentage of energy supplied by renewable sources" (1), and "Energy return on investment” (1). Overall, the results highlight that there are a variety of perspectives on how energy-related issues in GSCM and SSCM should be measured.

\section{A.1 Inductive Analysis of Energy-Related Metrics}

The metrics are also analyzed inductively to determine what distinct energy-related issues were covered. This analysis provides insight into the similarities and differences between the metrics reported. Although the specific name of the metric may vary, many metrics address similar core issues. The metrics are also analyzed to examine the extent to which they address environmental issues other than energy, such as emissions, material usage, waste, and transportation.

A number of distinct core issues were addressed by the energy-related metrics. "Use" and "consumption" of energy were by far the most frequently occurring core issues in the metrics. A total of 29 metrics (25.7\% of the total number of energy-related metrics) highlighted the "use" of energy followed by 28 metrics (24.8\%) that emphasized on the "consumption" of energy. Collectively, issues associated with the usage of energy therefore accounted for over $50 \%$ of the total energy-related metrics identified. The next most common core issue in the metrics focused 
on the "source" of the energy used. Fifteen (13.3\% of the total number of energy-related) metrics addressed this subject. This was followed by metrics that addressed core issues focused on "renewable" energy (10 metrics accounting for $8.9 \%$ of the total number of energy-related metrics), energy "efficiency" (8 metrics, 7\%), and energy "savings" (8 metrics, 7\%). A number of other core issues were addressed by a smaller number of metrics. In this group, "cost”, "intensity", and "conservation" of energy were each highlighted by 5 (4.4\% of the total) metrics. Energy "recovery" and "generation" were each addressed by 3 (2.7\%) of the metrics. Issues associated with "non-renewable” energy use and "demand" were each highlighted by 2 (1.8\%) metrics. Finally, a number of issues were addressed by only $1(0.9 \%)$ energy-related metric. Among this group, energy "type”, “revenues”, “reuse”, “return on investment”, “payback time”, "policy”, "atmosphere”, “footprint (ha)", and "productivity” were specific issues addressed by the metrics. However, "energy", as a very generic issue, along with a number of other broad issues like "net" and "total" energy, "reduction" and "requirement" of energy, and "access" to energy were also addressed by 1 metric each.

Over $98 \%$ of the energy-related metrics identified focused, at least in part, on environmental concerns. This is to be expected, given the close association of energy with environmental issues in the sustainability literature. For example, the GRI as world's most widely applied sustainability reporting guidelines classifies energy as an environmental aspect (GRI, 2013c). Accordingly, the metrics did incorporate some other key environmental aspects identified by the GRI, including materials, emissions, waste, transport, and product and services issues. Examples of such metrics for material issues include "Energy efficiency per material (\%)" (2 times), "Use of natural resources energy and raw materials (including: additives, auxiliaries and semimanufactured goods)" (1), and "Production cost decreases as a result of energy and materials saving" (1). "Renewable energy or energies without emission of $\mathrm{CO}_{2}$ (e.g. biomass energy, solar, wind, geothermal, nuclear power, hydrogen energy)" (1 time), "Reused energy" (1) and "Energy used per service" (2) are examples of metrics that address emissions, waste, and services issues, respectively. Similarly, transport issues are addressed by "Cooperation with customers for using less energy during product transportation” (2 times) and "Energy consumption transportation” (1). As a final example, product-related issues are addressed by a number of metrics. Examples include "Cumulative energy demand (primary energy used over the life cycle of a product or a 
process)" (5 times), "Energy used per unit of product” (2), "ECO-design requirements for energy using product" (2), "Energy consumption to produce products purchased externally" (1), "Energy intensity in $\mathrm{MJ} / \mathrm{m}^{3}$ of production (i.e., Annual total energy consumed by the firm in $\mathrm{MJ} /$ Annual production aggregated in $\mathrm{m}^{3}$ )" (1), "Quantity of energy used per year or per unit of product" (1), and "Improving production in relation to used energy and resource consumption" (1). No energy related metric was identified in the fields of GSCM and SSCM that explicitly addresses water, biodiversity, or compliance issues.

Considering the fact that renewable energy is one of the recent vital topics related to energy, which has not only environmental impacts but also creates economic opportunities for the societies, the metrics were also analyzed to determine, specifically, the extent to which they addressed renewable energy issues. Renewable energy is a resource that is regenerated naturally over a certain period of time and originated either directly from the sun (e.g., thermal, photoelectric and photochemical), or indirectly from the sun (e.g., wind, photosynthetic energy stored in biomass, and hydropower). It may also be derived from other sources of natural mechanisms in the environment (e.g., tidal and geothermal energy). Renewable energy, however, may not comprise energy resources that are originated from fossil fuels, and the waste products from fossil or inorganic sources (Johansson et al. 1993).

Given the fact that focusing on renewable energy sources may encourage health equity, reduce poverty, and build societies that live within environmental boundaries (Kilkis, 2012), renewable energy usage is potentially a critical component of supply chain sustainability (Cucchiella and D'Adamo, 2013). Accordingly, an analysis of the identified energy-related metrics used in GSCM and SSCM shows that only a total of 10 (8.9\%) metrics explicitly addressed renewable energy issues. These include 7 metrics that focused exclusively on the environmental characteristic of SSCM, namely "Supporting the generation and distribution of renewable energy" (2 times), "Renewable energy" (1), "Percentage of energy supplied by renewable sources" (1), "Renewable energy or energies without emission of $\mathrm{CO}_{2}$ (e.g., biomass energy, solar, wind, geothermal, nuclear power, hydrogen energy)" (1), "Possibilities of using renewable resources are considered when selecting energy" (1), "Fraction of facilities using renewable energy" (1), and "Percent of energy from renewable resources" (1). The other 2 metrics addressed both the economic and environmental characteristics of SSCM. These metrics are 
"Renewable energy purchased" and "Percentage of total annual consumption of energy (for electricity and heating) produced by the organization from renewable energy sources”. Both of these metrics appeared only once in the literature. The review highlights the need for a greater emphasis on metrics addressing renewable energy issues.

\section{APPENDIX B: Analysis of Metrics Addressing Water Issues}

Another underlying issue addressed by the identified metrics is water, and hence, an analysis of all metrics addressing water issues was conducted. Water was selected for the illustration because its use is generally recognized as a major sustainability issue and metrics pertaining to water issues are widely available. For example, water is one of the key environmental aspects addressed by the GRI, which has 5 metrics that directly contain the word "water" (i.e., "Total water withdrawal by source", "Water sources significantly affected by withdrawal of water", "Percentage and total volume of water recycled and reused", “Total water discharge by quality and destination", and "Identity, size, protected status, and biodiversity value of water bodies and related habitats significantly affected by the organization's discharges of water and runoff") (GRI, 2013a). Additionally, 3 other metrics that implicitly consider impacts on water based on the detailed description of the metric, have also been emphasized by the GRI (i.e., "Operational sites owned, leased, managed in, or adjacent to, protected areas and areas of high biodiversity value outside protected areas", "Description of significant impacts of activities, products, and services on biodiversity in protected areas and areas of high biodiversity value outside protected areas", and "Total number and volume of significant spills") (GRI, 2013a). Water was also the example used in the literature (i.e., McElroy and van Engelen, 2012) to demonstrate the difference between absolute, relative, and context-based metrics.

A total of 76 unique metrics focusing on water issues in GSCM and SSCM were identified. A broad range of issues related to water were addressed by the metrics, including consumption, efficiency, quality, usage, conservation, emissions, waste, contaminants, and pollution. A large number of metrics were devoted to any of these particular issues respectively, with an emphasis on absolute metrics (i.e., 56 metrics or $73.7 \%$ of the total number of water-related metrics) and relative metrics (i.e., 20 metrics or 26.3\%). Examples of absolute metrics include "Water consumption" (12), "Water waste” (10), "Water use” (9), and "Water emissions" (5). Examples 
of relative metrics include "Water efficiency" (4), "Optimization of process to reduce water use" (3), "Industrial water reuse ratio" (1), and "Wastewater rate" (1). No context-based metrics was developed to address water-related issues. Moreover, a majority of the metrics reported were quantitative (71 representing $93.4 \%$ of the total number of water-related metrics), though a small number of qualitative metrics were also developed (5 representing 6.6\%). While the examples of absolute metrics provided above can also be served as quantitative metrics, examples of qualitative metrics include "Water compliance" (1), "Plans for own waste water treatment plant" (1), "Clean transport modes (maritime and waterways)" (1), and "Housing quality (having electricity and potable water services)" (1). In any case, although a large number of metrics were utilized, they did tend to centre on a much smaller number of core issues. Subjects such as water consumption and water pollution were addressed by many different forms of metrics.

Analysis of the results shows that the most frequently used metrics were "Water consumption" (12 times), "Water waste” (10), "Water use” (9), “Reduction of waste water" (8), "Water emissions"(5), "Water efficiency" (4), "Optimization of process to reduce water use” (3), and "Water recovery" (2). Over 76\% (i.e., 58 metrics) of the metrics addressing water-related issues were appeared only once in the literature.

The majority (i.e., 54 metrics) of the water-related metrics focused exclusively on the environmental characteristic of SSCM. Among the many examples were "Water consumption" (12 times), "Water waste" (10), "Water emissions" (5), "Discharges to receiving streams and water bodies" (2), and "Waste water emissions" (2). There was only one metric identified that focused primarily on social issues, namely "Housing quality (having electricity and portable water service)", which was addressed only 1 time. There was no water-related metric identified that focused primarily on economic issues. However, it is important to note that the authors of the metrics analyzed may have considered economic issues to be implicit in some of those published. For example, a metric such as "Water waste" could implicitly encompass economic motivations, particularly in literature published in the management realm. In fact, in their extensive review of peer-reviewed literature on SSCM, Seuring and Muller (2008) assumed that the economic dimension was covered since all of the papers in their analysis were drawn from management-related journals. 
Multiple characteristics of SSCM were addressed by 21 water-related metrics. A total of 14 cross-cutting metrics addressed 2 characteristics, 5 metrics highlighted 3, and 2 metrics covered 4 characteristics. A summary of the water-related metrics that addressed multiple characteristics of SSCM is provided in Table B-1. No water-related metric was identified that addressed 5 or more characteristics of SSCM. 
Table B-1: Overview of metrics that addressed multiple SSCM characteristics for Water-related issues

\begin{tabular}{|c|c|c|c|}
\hline Categories & SSCM Characteristics & $\begin{array}{l}\text { No. of } \\
\text { Metrics }\end{array}$ & Examples of Cross-cutting Metrics (Frequency rates) \\
\hline \multirow{6}{*}{$\begin{array}{c}2 \\
\text { Characteristics }\end{array}$} & Environmental and Long-term focuses & 5 & $\begin{array}{l}\text { Industrial water reuse ratio (1), Water sources (recycled and reused) affected by } \\
\text { the organization (1), Middle water reuse ratio (i.e., Chinese term for the } \\
\text { recyclable treated wastewater from wastewater treatment plants) (1), Net water } \\
\text { consumed (total used- recycled) (1), Total volume of water recycled/reused } \\
\left(\mathrm{m}^{3} / \mathrm{yr}\right)(1)\end{array}$ \\
\hline & Environmental and Economic focuses & 2 & $\begin{array}{l}\text { Purchase of water for own consumption per enterprise (2), Water used in } \\
\text { process (1) }\end{array}$ \\
\hline & Environmental and Social focuses & 2 & Drinking water (1), Water consumption and quality (1) \\
\hline & Environmental and Efficiency focuses & 2 & Water efficiency (4), Improvement of efficiency of waste water collection (1) \\
\hline & Environmental and Performance focuses & 2 & Optimization of process to reduce water use (3), Water saving (1) \\
\hline & Environmental and Stakeholder focuses & 1 & $\begin{array}{l}\text { [Suppliers] help us during the transition phase toward more environmental } \\
\text { friendly material (e.g., ink change, water-based adhesive) (1) }\end{array}$ \\
\hline \multirow{3}{*}{$\begin{array}{c}3 \\
\text { Characteristics }\end{array}$} & Environmental, Economic and Value focuses & 3 & $\begin{array}{l}\text { Industrial wastewater generation per added industrial value (1), Fresh water } \\
\text { consumption per added industrial value (1), Water consumption per net value } \\
\text { added (1) }\end{array}$ \\
\hline & Environmental, Economic and Social focuses & 1 & Water (2) \\
\hline & Environmental, Economic and Performance focuses & 1 & Use of cleaner technology processes to make savings (water) (1) \\
\hline \multirow{2}{*}{$\begin{array}{c}4 \\
\text { Characteristics }\end{array}$} & $\begin{array}{l}\text { Environmental, Economic, Social and Stakeholder } \\
\text { focuses }\end{array}$ & 1 & $\begin{array}{l}\text { Arranging for funds to help suppliers to purchase equipment for pollution } \\
\text { prevention, waste water recycling, etc. (1) }\end{array}$ \\
\hline & $\begin{array}{l}\text { Environmental, Economic, Value and Performance } \\
\text { focuses }\end{array}$ & 1 & Output value of products utilization of waste gas, water \& solid wastes (1) \\
\hline
\end{tabular}




\section{APPENDIX C: Representative Sample Calculation for Sustainability Assessment of the Case Company}

Taking the data presented in Tables (7-1) and (7-2), relevant values for the challenge and capacity factors in the year 2011 are summarized in Table (C-1):

Table C-1: Challenge and Capacity Factors in Year 2011

\begin{tabular}{|c|c|c|c|c|c|}
\hline $\boldsymbol{\alpha}$ & $\mathbf{1}$ & $\mathbf{2}$ & $\mathbf{3}$ & $\mathbf{4}$ & $\mathbf{5}$ \\
\hline $\boldsymbol{h}_{\boldsymbol{\alpha}}$ & 0.2205 & 0.3448 & 0.7935 & 0.0081 & 0.5150 \\
\hline $\boldsymbol{c}_{\boldsymbol{\alpha}}$ & 0.9791 & 0.4026 & 0.4000 & 0.9400 & 0.8880 \\
\hline
\end{tabular}

Where:

$$
\begin{aligned}
& h_{\alpha}=\text { Challenge factor } \\
& c_{\alpha}=\text { Capacity factor } \\
& \alpha=\text { Index of sustainability indicators representing challenge and capacity factors }
\end{aligned}
$$

Taking the data summarized in Table (C-1) and using the "AVERAGE" and "STDEV" functions in the MS Excel, the respective mean values and standard deviations for the related challenge and capacity factors are calculated as follows:

$$
\begin{array}{ll}
\mu_{h}=0.3844, & \sigma_{h}=0.2970 \\
\mu_{c}=0.7219 &
\end{array}
$$

By plotting these values in Eq. (7.6), the respective sustainability $S u s_{k}$ can be estimated as:

$$
\text { Sus }_{k}=1-\varphi\left(-\frac{0.7219-0.3844}{\left(0.2945^{2}+0.2970^{2}\right)^{1 / 2}}\right)=1-\varphi(-0.8071)
$$

Using the standard normal table $\varphi(-0.8071)$ is approximated at 0.2090 , and therefore, sustainability of the case company for the year 2011 will be estimated as:

$$
\text { Sus }_{k}=1-0.2090=0.7910 \text { or } 79.10 \%
$$




\section{REFERENCES}

Abbasi, M., Nilsson, F., 2012. Themes and challenges in making supply chains environmentally Sustainable. Supply Chain Management: An International Journal 17(5), 517-530.

Abdallah, T., Farhat, A., Diabat, A., Kennedy, S., 2012. Green supply chains with carbon trading and environmental sourcing: Formulation and life cycle assessment. Applied Mathematical Modelling 36(9), 4271-4285.

Ahi, P., Searcy, C., 2013a. A comparative literature analysis of definitions for green and sustainable supply chain management, Journal of Cleaner Production 52(1), 329-341, DOI: 10.1016/j.jclepro.2013.02.018.

http://www.sciencedirect.com/science/article/pii/S095965261300067X

Ahi, P., Searcy, C., 2013b. A stochastic approach for sustainability analysis under the green economics paradigm. Stochastic Environmental Research and Risk Assessment, Article in Press, DOI: $10.1007 / \mathrm{s} 00477-013-0836-5$.

http://ink.springer.com/article/10.1007/s00477-013-0836-5

Akyuz, G.R., Erkan, T.E., 2010. Supply chain performance measurement: a literature review. International Journal of Production Research 48(17), 5137-5155.

Albino, V., Balice, A.,Dangelico, R.M., 2009. Environmental strategies and green product development: An overview on sustainability-driven companies. Business Strategy and the Environment 18(2), 83-96.

Andic, E., Yurt, O., Baltacioglu, T., 2012. Green supply chains: Efforts and potential applications for the Turkish market. Resources, Conservation and Recycling 58, 50-68.

Aras, G., Crowther, D., 2009. Making sustainable development sustainable. Management Decision 47(6), 975-88.

Ashby, A., Leat, M., Hudson-Smith, M., 2012. Making connections: a review of supply chain management and sustainability literature. Supply Chain Management: An International Journal 17(5), 497-516.

Asif, M., Searcy, C., Zutshi, A., Ahmad, N., 2011. An integrated management systems approach to corporate sustainability. European Business Review 23(4), 353-367.

Ayres, R.U., 2007. On the practical limits to substitution. Ecological Economics 61(1), 115-128.

Ayres, R.U., 2008. Sustainability economics: where do we stand? Ecological Economics 67(2), 281-310.

Azapagic, A., 2004. Developing a framework for sustainable development indicators for the mining and minerals industry. Journal of Cleaner Production 12(6), 639-662. 
Azapagic, A., Perdan, S., 2000. Indicators of Sustainable Development for Industry: A General Framework. Process Safety and Environmental Protection 78(4), 243-261.

Azevedo, S.G., Carvalho, H., Duarte, S., Cruz-Machado, V., 2012. Influence of green and lean upstream supply chain management practices on business sustainability. IEEE Transactions on Engineering Management 59(4), 753-765.

Badurdeen, F., Iyengar, D., Goldsby, T.J., Metta, H., Gupta, S., Jawahir, I.S., 2009. Extending total life-cycle thinking to sustainable supply chain design. International Journal of Product Lifecycle Management 4(1/2/3), 49-67.

Bai, C., Sarkis, J., Wei, X., Koh, L., 2012. Evaluating ecological sustainable performance measures for supply chain management. Supply Chain Management: An International Journal 17(1), 78-92.

Bansal, T., 2010. Network for Business Sustainability. http://nbs.net/wp-content/uploads/Primer_Business_Sustainability.pdf, Accessed on April 05, 2012.

Barrett, J., Scott, A., 2001a. An Ecological Footprint of Liverpool: developing sustainable scenarios. Stockholm Environment Institute, York.

Barrett, J., Scott, A., 2001b. The Ecological Footprint: A Metric for Corporate Sustainability. Corporate Environmental Strategy 8(4), 316-325.

Baumgartner, S., Quaas, M.F., 2009. Ecological-economic viability as a criterion of strong sustainability under uncertainty. Ecological Economics 68(7), 2008-2020.

Beamon, B.M., 1999a. Measuring supply chain performance. International Journal of Operations \& Production Management 19(3), 275-292.

Beamon, B.M., 1999b. Designing the green supply chain. Logistics Information Management 12(4), 332-342.

Bjorklund, M., Martinsen, U., Abrahamsson, M., 2012. Performance measurements in the greening of supply chains. Supply Chain Management: An International Journal 17(1), 29-39.

Bodini, A., 2012. Building a systemic environmental monitoring and indicators for sustainability: What has the ecological network approach to offer? Ecological Indicators 15(1), 140-148.

Bohringer, C., Jochem, P.E.P., 2007. Measuring the immeasurable - a survey of sustainability indices. Ecological Economics 63(1), 1-8. 
Bonney, M., Jaber, M.Y., 2013. Developing an input-output activity matrix (IOAM) for environmental and economic analysis of manufacturing systems and logistics chains. International Journal of Production Economics 143(2), 589-597.

Bonney, M., Jaber, M.Y., 2013. Deriving research agendas for manufacturing and logistics systems: A methodology. International Journal of Production Economics, Article in Press.

Booysen, F., 2002. An overview and evaluation of composite indices of development. Social Indicators Research 59(2), 115-151.

Bowen, F., Cousins, P., Lamming, R., Faruk, A., 2001a. Horses for courses: explaining the gap between the theory and practice of green supply. Greener Management International 35, 41-60.

Bowen, F., Cousins, P., Lamming, R., Faruk, A., 2001b. The role of supply management capabilities in green supply. Production and Operations Management 10(2), 174-189.

Brandenburg, M., Govindan, K., Sarkis, J., Seuring, S., 2014. Quantitative models for sustainable supply chain management: Developments and directions. European Journal of Operational Research 233(2), 299-312.

Brent, A., 2005. Integrating LCIA and LCM: evaluating environmental performances for supply chain management in South Africa. Management of Environmental Quality: An International Journal 16(2), 130-142.

Burgess, K., Singh, P., Koroglu, R., 2006. Supply chain management: a structured literature review and implications for future research. International Journal of Operations \& Production Management 26(7), 703-729.

Buyukozkan, G., Cifci, G., 2011. A novel fuzzy multi-criteria decision framework for sustainable supplier selection with incomplete information. Computers in Industry 62(2), 164174.

Buyukozkan, G., Cidci, G., 2012. A novel hybrid MCDM approach based on fuzzy DEMATEL, fuzzy ANP and fuzzy TOPSIS to evaluate green suppliers. Expert Systems with Applications 39(3), 3000-3011.

Caldelli, A., Parmigiani, M.L., 2004. Management information system - A tool for corporate sustainability. Journal of Business Ethics 55(2), 159 -171.

Caniato, F., Caridi, M., Crippa, L., Moretto, A., 2012. Environmental sustainability in fashion supply chains: An exploratory case based research. International Journal of Production Economics 135(2), 659-670.

Carter, C.R., 2011. Call for theory: the maturation of the supply chain management discipline. Journal of Supply Chain Management 47(2), 3-7. 
Carter, C.R., Ellram, L.M., 1998. Reverse logistics: a review of the literature and framework for future investigation. Journal of Business Logistics 19(1), 85-102.

Carter, C.R., Kale, R., Grimm, C.M., 2000. Environmental purchasing and firm performance: an empirical investigation. Transportation Research Part E: Logistics and Transportation Review 36(3), 219-228.

Carter, C.R., Dresner, M., 2001. Purchasing's role in environmental management: cross functional development of grounded theory. Journal of Supply Chain Management 37(2), 12-26.

Carter, R.C., Rogers, D.S., 2008. A framework of sustainable supply chain management: moving toward new theory. International Journal of Physical Distribution \& Logistics Management 38(5), 360-387.

Carter, R.C., Easton, P.L., 2011. Sustainable supply chain management: evolution and future directions. International Journal of Physical Distribution \& Logistics Management 41(1), 46-62.

Cato, M.S., 2009. Green Economics: an introduction to theory, policy and practice. Earthscan, London, Sterling, VA.

Charvet, F.F., Cooper, M.C., Gardner, J.T., 2008. The intellectual structure of supply chain management: a bibliographic approach. Journal of Business Logistics 29(1), 47-74.

Chavas, J.P., 2000. Ecosystem valuation under uncertainty and irreversibility. Ecosystems 3(1), 11-15.

Chen, I.J., Paulraj, A., 2004. Towards a theory of supply chain management: the constructs and measurements. Journal of Operations Management 22(2), 119-150.

Chen, C.C., 2005. Incorporating green purchasing into the frame of ISO 14000. Journal of Cleaner Production 13(9), 927-933.

Cholette, S., Venkat, K., 2009. The energy and carbon intensity of wine distribution: Astudy of logistical options for delivering wine to consumers. Journal of Cleaner Production 17(16), 14011413.

Christopher, M., 2010. Logistics and Supply Chain Management: Creating Value-Added Networks. Financial Times, Prentice Hall, Harlow.

Ciliberti, F., Pontrandolfo, P., Scozzi, B., 2008. Investigating corporate social responsibility in supply chains: a SME perspective. Journal of Cleaner Production 16(15), 1579-1588.

Clift, R., 2003. Metrics for supply chain sustainability. Clean Technologies and Environmental Policy 5(3), 240-247. 
Closs, D.J., Speier, C., Meacham, N., 2011. Sustainability to support end-to-end value chains: the role of supply chain management. Journal of the Academy of Marking Science 39(1), 101116.

Cobb, C., Halstead, T., Rowe, J., 1995. The Genuine Progress Indicator: Summary of Data and Methodology. Redefining Progress, Washington DC.

Colicchia, C., Strozzi, F., 2012. Supply chain risk management: a new methodology for a systematic literature review. Supply Chain Management: An International Journal 17(4), 403418.

Cook, D. J., Mulrow, C. D., Haynes, R. B., 1997. Systematic Reviews: Synthesis of Best Evidence for Clinical Decisions. Annals of Internal Medicine 126(5), 376-380.

Cooper, M.C., Lambert, D.M., Pagh, J.D., 1997. Supply chain management: more than a new name for logistics. International Journal of Logistics Management 8(1), 1-13.

Corbett, C.J., De Croix, G.A., 2001. Shared-savings contracts for indirect materials in supply chains: channel profits and environmental impacts. Management Science 47(7), 881-893.

Cucchiella, F., D’Adamo, I., 2013. Issue on supply chain of renewable energy. Energy Conversion and Management 76, 774-780.

Cuthbertson, R., Piotrowicz, W., 2008. Supply chain best practices-identification and categorisation of measures and benefits. International Journal of Productivity \& Performance Management 57(5), 389-404.

Cuthbertson, R., Piotrowicz, W., 2011. Performance measurement systems in supply chains: A framework for contextual analysis. The International Journal of Productivity and Performance Management 60(6), 583-602.

Dahlsrud, A., 2008. How corporate social responsibility is defined: An analysis of 37 definitions. Corporate Social Responsibility and Environmental Management 15(1), 1-13.

Daly, H.E., Cobb, J.B., 1989. For the common good: Redirecting the economy toward community, the environment and sustainable future. Beacon Press, Boston.

Dantsis, T., Douma, C., Giourga, C., Loumou, A., Polychronaki, E.A., 2010. A methodological approach to assess and compare the sustainability level of agricultural plant production systems. Ecological Indicators 10(2), 256-263.

De Brito, M.P., Van der Laan, E.A., 2010. Supply Chain Management and Sustainability: Procrastinating Integration in Mainstream Research. Sustainability 2(4), 859-870. 
De Giovanni, P., Esposito Vinzi, V., 2012. Covariance versus component-based estimations of performance in green supply chain management. International Journal of Production Economics 135(2), 907-916.

Delbufalo, E., 2012. Outcomes of inter-organizational trust in supply chain relationships: a systematic literature review and a meta-analysis of the empirical evidence. Supply Chain Management: An International Journal 17(4), 377-402.

Dietz, S., Neumayer, E., 2007. Weak and strong sustainability in the SEEA: concepts and measurement. Ecological Economics 61(4), 617-626.

Dyllick ,T., Hockerts, K., 2002. Beyond the business case for corporate sustainability. Business Strategy and the Environment 11(2), 130-141.

Dzemydiene, D., 2008. Preface to sustainable development problems in the issue. Technological and Economic Development of Economy 14(1), 8-10.

Ebert, U., Welsch, H., 2004. Meaningful environmental indices: a social choice approach. Journal of Environmental Economics and Management 47(2), 270-283.

Eckelman, M.J., 2010. Facility-level energy and greenhouse gas life-cycle assessment of the global nickel industry. Resources, Conservation and Recycling 54(4), 256-266.

Edwards, J.B., McKinnon, A.C., Cullinane, S.L., 2010. Comparative analysis of the carbon footprints of conventional and online retailing: a "last mile" perspective. International Journal of Physical Distribution \& Logistics Management 40(1/2), 103-123.

Ekins, P., Simon, S., Deutsch, L., Folke, C., De Groot, R., 2003. A framework for the practical application of the concepts of critical natural capital and strong sustainability. Ecological Economics 44(2-3), 165-185.

El Saadany, A.M.A., Jaber, M.Y., Bonney, M., 2011. Environmental performance measures for supply chains. Management Research Review 34(11), 1202-1221.

Elkington, J., 1997. Cannibals with forks: the triple bottom line of 21st century business. Capstone, Oxford.

Elmuti, D., 2002. The perceived impact of supply chain management on organizational effectiveness. Journal of Supply Chain Management 38(3), 49-57.

Eng, T.Y., 2005. The influence of a firm's cross-functional orientation on supply chain performance. Journal of Supply Chain Management 41(4), 4-16.

Erb, K.H., 2004. Actual land demand of Austria 1926-2000: a variation on ecological footprint assessments. Land Use Policy 21(3), 247-259. 
Fabbe-Costes, N., Jahre, M., 2007. Supply chain integration improves performance: the Emperor's new suit? International Journal of Physical Distribution \& Logistics Management 37(10), 835-855.

Fabbe-Costes, N., Roussat, C., Colin, J., 2011. Future sustainable supply chains: what should companies scan? International Journal of Physical Distribution \& Logistics Management 41(3), 228-252.

Faisal, M.N., 2010. Sustainable supply chains: a study of interaction among the enablers. Business Process Management Journal 16(3), 508-529.

Ferguson, M.E., Toktay, L.B., 2006. The effect of competition on recovery strategies. Production and Operations Management 15(3), 351-368.

Ferretti, I., Zavanella Zanoni, S., Diana, A.L., 2007. Greening the aluminium supply chain. International Journal of Production Economics 108(1-2), 236-245.

Fichtner, W., Frank, M., Rentz, O., 2004. Inter-firm energy supply concepts: an option for cleaner energy production. Journal of Cleaner Production 12(8-10), 891-899.

Fisher, M.L., 1997. What is the right supply chain for your product? Harvard Business Review 75(2), 105-116.

Fleischmann, M., Van Wassenhove, L.N., van Nunen, J.A.E.E., van der Laan, E.A., Dekker, R. and Bloemhof-Ruwaard, J.M., 1997. Quantitative models for reverse logistics: a review. European Journal of Operational Research 103(1), 1-17.

Font, X., Tapper, R., Schwartz, K., Kornilaki, M., 2008. Sustainable supply chain management in tourism. Business Strategy and the Environment 17(4), 260-271.

Foran, B., Lenzen, M., Dey, C., Bilek, M., 2005. Integrating sustainable chain management with triple bottom line accounting. Ecological Economics 52(2), 143-157.

Frankel, R., Bolumole, Y. A., Eltantawy, R. A., Paulraj, A. and Gundlach, G. T., 2008. The domain and scope of SCM's foundational disciplines - insights and issues to advance research. Journal of Business Logistics 29(1), 1-30.

Gavronski, I., Klassen, R.D., Vachon, S., do Nascimento, L.F.M., 2011. A resource-based view of green supply management. Transportation Research Part E 47(6), 872-885.

Geldermann, J., Treitz, M., Rentz, O., 2007. Towards sustainable production networks. International Journal of Production Research 45(18-19), 4207-4424.

Georgiadis, P., Besiou, M., 2009. Environmental strategies for electrical and electronic equipment supply chains: which to choose? Sustainability 1(3), 722-733. 
Giannetti, B.E., Almeida C.M.V.B., Bonilla, S.H., 2010. Comparing emergy accounting with well-known sustainability metrics: The case of Southern Cone Common Market, Mercosur. Energy Policy 38(7), 3518-3526.

Gibson, B.J., Mentzer, J.T., Cook, R.L., 2005. Supply chain management: the pursuit of a consensus definition. Journal of Business Logistics 26(2), 17-25.

Gimenez, C., Tachizawa, E.M., 2012. Extending sustainability to suppliers: a systematic literature review. Supply Chain Management: An International Journal 17(5), 531-543.

Glock, C.H., Jaber, M.Y., Searcy, C. 2012. Sustainability strategies in an EPQ model with priceand quality-sensitive demand. International Journal of Logistics Management 23(3), 340-359.

Gnoni, M.G., Elia, V., Lettera, G., 2011. A strategic quantitative approach for sustainable energy production from biomass. International Journal of Sustainable Engineering 4(2), 127-135.

Gold, S., Seuring, S., Beske, P., 2010. The constructs of sustainable supply chain management A content analysis based on published case studies. Progress in Industrial Ecology 7(2), 114-137.

Gold, S., Seuring, S., 2011. Supply chain and logistics issues of bio-energy production. Journal of Cleaner Production 19(1), 32-42.

Gonzalez-Benito, J., Gonzalez-Benito, O., 2005. Environmental proactivity and business performance: an empirical analysis. Omega International Journal of Management Science 33(1), $1-15$.

Goodland, R., Ledec, G., 1987. Neoclassical economics and principles of sustainable development. Ecological Modelling 38(1-2), 19-46.

Gopal, P.R.C., Thakkar, J., 2012. A review on supply chain performance measures and metrics: 2000-2011. International Journal of Productivity and Performance Management 61(5), 518-547.

Gowdy, J., 2005. Toward a new welfare economics for sustainability. Ecological Economics 53(2), 211-222.

GRI (Global Reporting Initiative), 2013a.

https://www.globalreporting.org/resourcelibrary/GRIG4-Part1-Reporting-Principles-andStandard-Disclosures.pdf, Accessed on January 20, 2014.

GRI (Global Reporting Initiative), 2013b.G4 Sustainability Reporting Guidelines, Implementation Manual. https://www.globalreporting.org/resourcelibrary/GRIG4-Part2Implementation-Manual.pdf, Accessed on January 20, 2014.

GRI (Global Reporting Initiative), 2013c. https://www.globalreporting.org/reporting/G3andG3-1/Pages/default.aspx. Accessed on October 22, 2013. 
Graham, T.S., Dougherty, P.J., Dudley, W.N., 1994. The long term strategic impact of purchasing partnerships. International Journal of Purchasing and Material Management 30(4), 13-18.

Green, K., Morton, B., New, S., 1996. Purchasing and environmental management: interactions, policies and opportunities. Business Strategy and the Environment 5(3), 188-197.

Guiffrida, A.L., Jaber, M.Y., 2008. Managerial and economic impacts of reducing delivery variance in the supply chain. Applied Mathematical Modelling 32(10), 2149-2161.

Gunasekaran, A., Patel, C., McCaughey, R.E., 2004. A Framework for supply chain performance measurement. International Journal of Production Economics 87(3), 333-347.

Gunasekaran, A., Kobu, B., 2007. Performance measures and metrics in logistics and supply chain management: a review of recent literature (1995-2004) for research and applications. International Journal of Production Research 45(12), 2819-2840.

Gungor, A., Gupta, S.M., 1999. Issues in environmentally conscious manufacturing and product recovery: a survey. Computers \& Industrial Engineering 36(4), 811-853.

Gurtu, A., Searcy, C., Jaber, M.Y., 2012. An Analysis of Keywords Used in the Literature on Green Supply Chains. 10th Supply Chain Management Symposium, Toronto, ON. September 30 - October 2, 2012.

Gutés, M.C., 1996. The concept of weak sustainability. Ecological Economics 17(3), 147-156.

Haake, H., Seuring, S., 2009. Sustainable procurement of minor items -Exploring limits to sustainability. Sustainable Development 17(5), 284-294.

Hahn, T., Figge, F., Pinkse, J., Preuss, L., 2010. Trade-offs in corporate sustainability: you can't have your cake and eat it. Business Strategy and the Environment 19(4), 217-229.

Hall, J., 2001. Environmental supply chain innovation. Greener Management International 35(15), 105-119.

Halldorsson, A., Kovacs, G., 2010. The sustainable agenda and energy efficiency: Logistics solutions and supply chains in times of climate change. International Journal of Physical Distribution \& Logistics Management 40(1-2), 5-13.

Halldorsson, A., Svanberg, M., 2013. Energy resources: trajectories for supply chain management. Supply Chain Management: An International Journal 18 (1), 66-73.

Hamdouch, A., Zuindeau, B., 2010. Sustainable development, 20 years on: methodological innovations, practices and open issues. Journal of Environmental Planning and Management 53(4), 427-438. 
Handfield, R.B., Walton, S.V., Seegers, L.K., Melnyk, S.A., 1997. 'Green’ value chain practices in the furniture industry. Journal of Operations Management 15(4), 293-315.

Handfield, R.B., Nichols, E.L., 1999. Introduction to supply chain management. Prentice-Hall, New Jersey.

Hanna, M.D., Newman, W.R., Johnson, P., 2000. Linking operational and environmental improvement through employee involvement. International Journal of Operations \& Production Management 20(2), 148-165.

Hart, S.L., Ahuja, G., 1996. Does it pay to be green? An empirical examination of the relationship between emission reduction and firm performance. Business Strategy and the Environment 5(1), 30-37.

Hartwick, J.M., 1977. Intergenerational equity and the investing of rents from exhaustible resources. The American Economic Review 67(5), 972-974.

Hasle, P., Jensen, P.L., 2012. Ergonomics and sustainability - challenges from global supply chains. Work 41(1), 3906-3913.

Hassini, E., Surti, C., Searcy, C., 2012. A literature review and a case study of sustainable supply chains with a focus on metrics. International Journal of Production Economics 140(1), 69-82.

Hediger, W., 2010. Welfare and capital-theoretic foundations of corporate social responsibility and corporate sustainability. The Journal of socio-economics 39(4), 518-526.

Heikkila, J., 2002. From supply to demand chain management: efficiency and customer satisfaction. Journal of Operations Management 20(6), 747-767.

Herva, M., Franco, A., Ferreiro, S., Alvarez, A., Roca, E., 2008. An approach for the application of the Ecological Footprint as environmental indicator in the textile sector. Journal of Hazardous Materials 156(1-3), 478-487.

Hervani, A.A., Helms, M.M., Sarkis, J., 2005. Performance measurement for green supply chain management. Benchmarking: An International Journal 12(4), 330-353.

Heuting, R., Reijnders, L., 2004. Broad sustainability contra sustainability: the proper construction of sustainability indicators. Ecological Economics 50(3-4), 249-260.

H’Mida, S., Lakhal, S.Y., 2007. A model for assessing the greenness effort in a product supply chain. International Journal of Global Environmental Issues 7(1), 4-24.

Ho, W., 2008. Integrated analytic hierarchy process and its applications: a literature review. European Journal of Operational Research 186(1), 211-228. 
Holdgate, M.W., 1993. The sustainable use of tropical coastal resources: A key conservation issue. AMBIO 22(7), 481-482.

Holland, L., 2003. Can the Principle of the Ecological Footprint be Applied to Measure the Environmental Sustainability of Business? Corporate Social Responsibility and Environmental Management 10(4), 224-232.

Holliday, C., 2001. Sustainable growth, the DuPont way. Harvard Business Review 79(8), 129134.

Hsu, C.W., Hu, A.H., 2008. Green supply chain management in the electronic industry. International journal of Environmental Science and Technology 5(2), 205-216.

Hugo, A., Pistikopoulos, E.N., 2005. Environmentally conscious long-range planning and design of supply chain networks. Journal of Cleaner Production 13(15), 1471-1491.

Hutchins, M.J., Sutherland, J.W., 2008. An exploration of measures of social sustainability and their application to supply chain decisions. Journal of Cleaner Production 16(15), 1688-1698.

Hydro-Quebec, 2012.

http://www.hydroquebec.com/profile/index.html. Accessed on December 30, 2012.

Hydro-Quebec, 2011a. Annual Report 2011. Montreal. ISBN 978-2-550-63872-8, ISSN 07026706.

Hydro-Quebec, 2011b. Corporate Profile and Publications, Sustainability Reports. http://www.hydroquebec.com/publications/en/enviro_performance/index.html. Accessed on March 10, 2013.

Hydro-Quebec, 2011c. Sustainable Development, GRI, Environmental Performance Indicators. http://www.hydroquebec.com/sustainable-development/gri/performance_environ.html. Accessed on March 10, 2013.

IISD (International Institute for Sustainable Development), 1992. Business Strategies for Sustainable Development. IISD, Winnipeg, Canada.

Jaber, M.Y., El Saadany, A.M.A., Rosen, M.A., 2011. Simple price-driven Reverse Logistics system with entropy and exergy costs. International Journal of Exergy 9(4), 486-502.

Jaber, M.Y., Glock, C.H., El Saadany, A.M.A., 2013. Supply chain coordination with emission reduction incentives. International Journal of Production Research 51(1), 69-82.

Jain, V., Wadhwa, S., Deshmukh, S.G., 2009. Select supplier-related issues in modeling a dynamic supply chain: Potential, challenges and direction for future research. International Journal of Production Research 47(11), 3013-3039. 
Johansson, T.B., Kelly, H., Reddy, A.K.N., Williams, R.H., 1993. Renewable energy: sources for fuels and electricity. Island Press, Washington (DC).

Jorgensen, A.L., Knudsen, J.S., 2006. Sustainable competitiveness in global value chains how do small Danish firms behave? Corporate Governance 6(4), 449-462.

Kainuma, Y., Tawara, N., 2006. A multiple attribute utility theory approach to lean and green supply chain management. International Journal of Production Economics 101(1), 99-108.

Kapur, K.C., Lamberson, L.R., 1977. Reliability in Engineering Design. John Wiley \& Sons, New York, pp. 124-128.

Khoo, H.H., Spedding, T.A., Bainbridge, I., Taplin, D.M.R., 2001. Creating a green supply chain. Greener Management International 35(19), 70-88.

Kilkis, S. A., 2012. A net-zero building application and its role in exergy-aware local energy strategies for sustainability. Energy Conversion and Management 63, 208-217.

Kim, J.H., Youn, S., Roh, J.J., 2011. Green supply chain management orientation and firm performance: Evidence from South Korea. International Journal of Services and Operations Management 8(3), 283-304.

Klassen, R.D., McLaughlin, C.P., 1996. The impact of environmental management on firm performance. Management Science 42(8), 1199-214.

Klassen, R.D., Vachon, S., 2003. Collaboration and evaluation in the supply chain: the impact on plant-level environmental investment. Production and Operations Management 12(3), 336-352.

Klassen, R.D., Vereecke, A., 2012. Social issues in supply chains: Capabilities link responsibility, risk (opportunity), and performance. International Journal of Production Economics 140(1), 103-115.

Krajnc, D., Glavic, P., 2005a. A model for integrated assessment of sustainable development. Resources, Conservation and Recycling 43(2), 189-208.

Krajnc, D., Glavic, P., 2005b. How to compare companies on relevant dimensions of sustainability. Ecological Economics 55(4), 551-563.

Kratena, K., 2008. From ecological footprint to ecological rent: an economic indicator for resource constraints. Ecological Economics 64(3), 507-516.

Krippendorf, K., 2004. Content Analysis: An Introduction to Its Methodology, 2nd ed. Sage, Thousand Oaks, California. 
Kuan, F.Y., Ho, Y.P., Wang, R.Y., Chen, C.W., 2013. Using RPC Block Adjustment models for the accuracy of environmental research, cartography and geomarketing: a new concept of cartography. Stochastic Environmental Research and Risk Assessment 27(6), 1315-1331.

Kuo, R.J., Wang, Y.C., Tien, F.C., 2010. Integration of artificial neural network and MADA methods for green supplier selection. Journal of Cleaner Production 18(12), 1161-1170.

Lakhal, S.Y., H’Mida, S., Islam, M.R., 2007. Green supply chain parameters for a Canadian petroleum refinery company. International Journal of Environmental Technology and Management 7(1-2), 56-67.

Lambert, D.M., Cooper, M.C., Pagh, J.D., 1998. Supply chain management: implementation issues and research opportunities. International Journal of Logistics Management 9(2), 1-19.

Lamming, R., Hampson, J., 1996. The environment as a supply chain management issue. British Journal of Management (Special issue) 7(S1), S45-S62.

Larson, P.D., Rogers, D., 1998. Supply chain management: definition growth and approaches. Journal of Marketing Theory and Practice 6(3), 1-5.

Lau, K.H., 2011. Benchmarking green logistics performance with a composite index. Benchmarking 18(6), 873-896.

Lee, S.Y., Klassen, R.D., 2008. Drivers and enablers that foster environmental management capabilities in small- and medium-sized suppliers in supply chains. Production and Operations Management 17(6), 573-586.

Lenzen, M., Dey, C.J., Murray, S.A., 2004. Historical accountability and cumulative impacts: The treatment of time in corporate sustainability reporting. Ecological Economics 51(3-4), 237250.

Lindholm, O., Greatorex, J.M., Paruch, A.M., 2007. Comparison of methods for calculation of sustainability indices for alternative sewerage systems -Theoretical and practical considerations. Ecological Indicators 7(1), 71-78.

Linton, J.D., Klassen, R., Jayaraman, V., 2007. Sustainable supply chains: an introduction. Journal of Operations Management 25(6), 1075-1082.

Liu, S., Leat, M., Hudson Smith, M., 2011. State-of-the-art sustainability analysis methodologies for efficient decision support in green production operations. International Journal of Sustainable Engineering 4(3), 236-250.

Lockyer, K.G., Wynne, R.M., 1989. The life profile of stock as a control. International Journal of Operations \& Production Management 9(1), 57-66. 
Lummus, R., Krumwiede, D., Vokurka, R., 2001. The relationship of logistics to supply chain management: developing a common industry definition. Industrial Management \& Data Systems 101(8), 426-432.

Marchini, A., Facchinetti, T., Mistri, M., 2009. F-IND: A framework to design fuzzy indices of environmental conditions. Ecological Indicators 9(3), 485-496.

Marvuglia, A., Benetto, E., Rios, G., Rugani, B., 2013. SCALE: Software for CALculating Emergy based on life cycle inventories. Ecological Modelling 248, 80-91.

Mayer, A.L., 2008. Strengths and weaknesses of common sustainability indices for multidimensional systems. Environment International 34(2), 277-291.

McElroy, M.W., Jorna, R.J., van Engelen, J., 2008. Social quotients and the social footprint. Corporate Social Responsibility and Environmental Management 15(4), 223-234.

McElroy, M.W., van Engelen, J.M.L., 2012. Corporate sustainability management: the art and science of managing non-financial performance. Earthscan, London, U.K.

Meixell, M.J., Gargeya, V.B., 2005. Global supply chain design: a literature review and critique. Transportation Research Part E: Logistics and Transportation Review 41(6), 531-550.

Melnyk, S.A., Sroufe, R.P., Calantone, R., 2003. Assessing the impact of environmental management systems on corporate and environmental performance. Journal of Operations Management 21(3), 329-351.

Mentzer, J.T., DeWitt, W., Keebler, J.S., Min, S., Nix, N.W., Smith, C.D., Zacharia, Z.G., 2001. Defining Supply Chain Management. Journal of Business Logistics 22(2), 1-25.

Mentzer, J. T., Stank, T. P. and Esper, T. L., 2008. Supply chain management and its relationship to logistics, marketing, production, and operations management. Journal of Business Logistics 29(1), 31-46.

Merriam-Webster, 2012. Merriam-Webster Online Dictionary. http://www.merriam-webster.com/dictionary/definition, Accessed on May 30, 2012

Merriam-Webster, 2014a. Merriam-Webster Online Dictionary. http://www.merriam-webster.com/dictionary/metric, Accessed on January 20, 2014.

Merriam-Webster, 2014b. Merriam-Webster Online Dictionary. http://www.merriam-webster.com/dictionary/indicator, Accessed on January 20, 2014.

Miemczyk, J., Johnsen, T.E., Macquet, M., 2012. Sustainable purchasing and supply management: a structured literature review of definitions and measures at the dyad, chain and network levels. Supply Chain Management: An International Journal 17(5), 478-496. 
Min, H., Galle, W.P., 2001. Green purchasing practices of US firms. International Journal of Operations \& Production Management 21(9), 1222-1238.

Mirshojaeian Hosseini, H., Kaneko, S., 2011. Dynamic sustainability assessment of countries at the macro level: A principal component analysis. Ecological Indicators 11(3), 811-823.

Montabon, F., Meinyk, S.A., Stroofe, R., Calantone, R.J., 2000. ISO 14000: assessing its perceived impact on corporate performance. Journal of Supply Chain Management 36(1), 4-16.

Moore, S.B., Manring, S.L., 2009. Strategy development in small and medium sized enterprises for sustainability and increased value creation. Journal of Cleaner Production 17(2), 276-282.

Morali, O., Searcy, C., 2013. A Review of Sustainable Supply Chain Management Practices in Canada. Journal of Business Ethics 117(3), 635-658.

Nagurney, A., Dong, J., Zhang, D., 2002. A supply chain network equilibrium model. Transportation Research Part E: Logistics and Transportation Review 38(5), 281-303.

Nagurney, A., Toyasaki, F., 2003. Supply chain supernetworks and environmental criteria. Transportation Research Part D: Transport and Environment 8(3), 185-213.

Nardo, M. Saisana, M., Saltelli, A., Tarantola, S., 2005. Tools for Composite Indicators Building. European Commission, Joint Research Centre, Institute for the Protection and the Security of the Citizen, Econometrics and Statistical Support to Antifraud Unit, I-21020 Ispra (VA) Italy, Report number: EUR 21682 EN.

New, S., Green, K., Morton, B., 2000. Buying the environment: the multiple meanings of green supply. In: Fineman, S. (Ed.), The Business of Greening. Routledge, London.

Ngai, E.W.T., Chau, D.C.K., Lo, C.W.H., Lei, C.F., 2013. Design and development of a corporate sustainability index platform for corporate sustainability performance analysis. Journal of Engineering and Technology Management, Article in Press.

Nijkamp, P., Rossi, E., Vindigni, G., 2004. Ecological Footprints in Plural: A Meta-analytic Comparison of Empirical Results. Regional Studies 38(7), 747-765.

Noci, G., 1997. Designing 'green’ vendor rating systems for the assessment of a supplier’s environmental performance. European Journal of Purchasing \& Supply Management 3(2), 103114.

Noori, H., Chen, C., 2003. Applying scenario-driven strategy to integrate environmental management and product design. Production and Operations Management 12, 353-368.

Ozkul, A., Barut, M., 2009. Measuring supply chain relationships: a social network approach. International Journal of Integrated Supply Management 5(1), 38-61. 
Pagell, M., Wu, Z., 2009. Building a more complete theory of sustainable supply chain management using case studies of 10 exemplars. Journal of Supply Chain Management 45(2), 37-56.

Parmigiani, A., Klassen, R.D., Russo, M.V., 2011. Efficiency meets accountability: Performance implications of supply chain configuration, control, and capabilities. Journal of Operations Management 29(3), 212-223.

Pazirandeh, A., Jafari, H., 2013. Making Sense of Green Logistics. International Journal of Productivity and Performance Management 62(8), 889-904.

Pearce, D., 1988. Economics, Equity and Sustainable Development. Futures 20(6), 598-605.

Pearce, D.W., Atkinson, G.D., 1993. Capital theory and the measurement of sustainable development: an indicator of "weak” sustainability. Ecological Economics 8(2), 103-108.

Pesonen, H.L., 2001. Environmental management of value chains. Greener Management International 33(14), 45-58.

Pil, F.K., Rothenberg, S., 2003. Environmental performance as a driver of superior quality. Production and Operations Management 12(3), 404-415.

Pilbeam, C., Alvarez, G., Wilson, H., 2012. The governance of supply networks: a systematic literature review. Supply Chain Management: An International Journal 17(4), 358-376.

Pishvaee, M.S., Razmi, J., 2012. Environmental supply chain network design using multiobjective fuzzy mathematical programming. Applied Mathematical Modelling 36(8), 3433-3446.

Pojasek, R.B., 2007. A framework for business sustainability. Environmental Quality Management 17(2), 81-88.

Porter, M.E., Van de Linde, C., 1995. Green and competitive. Harvard Business Review, September-October 1995, 120-134.

Prescott-Allen, R., 2001. The Wellbeing of Nations. Island Press, Washington, DC.

Preuss, L., 2009. Addressing sustainable development through public procurement: the case of local government. Supply Chain Management: An International Journal 14(3), 213-223.

Putzhuber, F., Hasenauer, H, 2010. Deriving sustainability measures using statistical data: A case study from the Eisenwurzen, Austria. Ecological Indicators 10(1), 32-38.

Quariguasi Frota Neto, J., Walther, G., Bloemhof, J., van Nunen, J.A.E.E., Spengler, T., 2009. A methodology for assessing eco-efficiency in logistics networks. European Journal of Operational Research 193(3), 670-682. 
Radermacher, W., 1999. Indicators, Green Accounting and Environment Statistics-Information Requirements for Sustainable Development. International Statistical Review 67(3), 339-354.

Ramani, K., Ramanujan, D., Bernstein, W.Z., Zhao, F., Sutherland, J., Handwerker, C., Choi, J.K., Kim, H., Thurston, D., 2010. Integrated Sustainable Life Cycle Design: A Review. Journal of Mechanical Design, Transactions of the ASME 132(9), 10041-15.

Ramos, T.B., Caeiro, S., 2010. Meta-performance evaluation of sustainability indicators. Ecological Indicators 10(2), 157-166.

Rao, P., Holt, D., 2005. Do green supply chains lead to competitiveness and economic performance? International Journal of Operations \& Production Management 25(9), 898-916.

Reefke, H., Trocchi, M., 2013. Balanced Scorecard for Sustainable Supply Chains: Design and Development Guidelines. International Journal of Productivity and Performance Management 62(8), 805-826.

Rees, W.E., 2006. Ecological Footprints and Bio-Capacity: Essential Elements in Sustainability Assessment. Chapter 9 in: Dewulf J, Van Langenhove H (Eds.) Renewables-Based Technology: Sustainability Assessment, John Wiley and Sons, Chichester UK, pp. 143-157.

Rio Declaration on Environment and Development, 1992. http://www.c-fam.org/docLib/20080625_Rio_Declaration_on_Environment.pdf. Accessed on July 15, 2013.

Roca, L.C., Searcy, C., 2012. An analysis of indicators disclosed in corporate sustainability reports. Journal of Cleaner Production 20(1), 103-118.

Rockstrom, J., Steffen, W., Noone, K., Persson, A., Chapin III F.S., et al., 2009. A safe operating space for humanity. Nature 461(24), 472-475.

Rogers, Z., Kelly, T.G., Rogers, D.S., Carter, C.R., 2007. Alternative fuels: are they achievable? International Journal of Logistics: Research \& Application 10(3), 269-282.

Ronchi, E., Federico, A., Musmeci, F., 2002. A system oriented integrated indicator for sustainable development in Italy. Ecological Indicators 2(1-2), 197-210.

Saaty, T.L., 1990. How to make a decision: the analytic hierarchy process. European Journal of Operational Research 48(1), 9-26.

Saint Jean, M., 2008. Polluting emissions standards and clean technology trajectories under competitive selection and supply chain pressure. Journal of Cleaner Production 16(S1), S113S123. 
Saisana, M., Tarantola, S., 2002. State-of-the-art Report on Current Methodologies and Practices for Composite Indicator Development. European Commission, Joint Research Centre, Institute for the Protection and the Security of the Citizen, Technological and Economic Risk Management Unit, Report number: EUR 20408 EN.

Salzmann, O., Ionescu-Somers, A., Steger, U., 2005. The business case for sustainability: literature review and research options. European Management Journal 23(1), 27-36.

Sanchez Rodrigues, V.A., Stantchev, D., Potter, A.T., Naim, M.M., 2010. The impact of logistics uncertainty on sustainable transport operations. International Journal of Physical Distribution \& Logistics Management 40(1/2), 61-83.

Sarkis, J., 1998. Evaluating environmentally conscious business practices. European Journal of Operational Research 107(1), 159-174.

Sarkis, J., 2003. A strategic decision framework for green supply chain management. Journal of Cleaner Production 11(4), 397-409.

Sarkis, J., Helms, M.M., Hervani, A.A., 2010. Reverse logistics and social sustainability. Corporate Social Responsibility and Environmental Management 17(6), 337-354.

Sarkis, J., Zhu, Q., Lai, K.-H., 2011. An organizational theoretic review of green supply chain management literature. International Journal of Production Economics 130(1), 1-15.

Schaefer, F., Luksch, U., Steinbach, N., Cabeça, J., Hanauer, J., 2006. Ecological Footprint and Biocapacity -The world's ability to regenerate resources and absorb waste in a limited time period. European Communities, Luxembourg.

Schaubroeck, T., Staelens, J., Verheyen, K., Muys, B., Dewulf, J., 2012. Improved ecological network analysis for environmental sustainability assessment: a case study on a forest ecosystem. Ecological Modelling 247, 144-156.

Searcy, C., McCartney, D., Karapetrovic, S., 2007. Sustainable development indicators for the transmission system of an electric utility. Corporate Social Responsibility and Environmental Management 14(3), 135-151.

Searcy, C., McCartney, D., Karapetrovic, S., 2008. Identifying priorities for action in corporate sustainable development indicator programs. Business Strategy and the Environment 17(2), 137148.

Searcy, C., 2012. Corporate sustainability performance measurement systems: a review and research agenda. Journal of Business Ethics 107(3), 239-253.

Seuring, S., 2008. Assessing the rigor of case study research in supply chain management. Supply Chain Management 13(2), 128-137. 
Seuring, S., 2011. Supply Chain Management for Sustainable Products - Insights From Research Applying Mixed Methodologies. Business Strategy and the Environment 20(7), 471-484.

Seuring, S., 2013. A review of modeling approaches for sustainable supply chain management. Decision Support Systems 54(4), 1513-1520.

Seuring, S., Muller, M., 2008. From a literature review to a conceptual framework for sustainable supply chain management. Journal of Cleaner Production 16(15), 1699-1710.

Seuring, S., Sarkis, J., Muller, M., Rao, P., 2008. Sustainability and Supply Chain ManagementAn Introduction to the Special Issue. Journal of Cleaner Production 16(14), 1545-1551.

Seuring, S., Gold, S., 2012. Conducting content-analysis based literature reviews in supply chain management. Supply Chain Management: An International Journal 17(5), 544-555.

Seuring, S., Gold, S., 2013. Sustainability management beyond corporate boundaries: from stakeholders to performance. Journal of Cleaner Production 56(1), 1-6.

Shang, K.C., Lu, C.S., Li, S., 2010. A taxonomy of green supply chain management capability among electronics-related manufacturing firms in Taiwan. Journal of Environmental Management 91(5), 1218-1226.

Sharma, S., Vredenburg, H., 1998. Proactive corporate environmental strategy and the development of competitively valuable organizational capabilities. Strategic Management Journal 19, 729-753.

Sheu, J.B., Chou, Y.H., Hu, C.C., 2005. An integrated logistics operational model for greensupply chain management. Transportation Research Part E: Logistics and Transportation Review 41(4), 287-313.

Shrivastava, P., 1995. The role of corporations in achieving ecological sustainability. Academy of Management Review 20(4), 936-960.

Shuaib, M., Metta, H., Lu, T., Badurdeen, F., Jawahir, I.S., Goldsby, T., 2011. Design and performance evaluation of sustainable supply chains: approach and methodologies. Advances in Sustainable Manufacturing 8, 347-352.

Singh, R.K., Murty, H.R., Gupta, S.K., Dikshit, A.K., 2007. Development of composite sustainability performance index for steel industry. Ecological Indicators 7(3), 565-588.

Singh, R.K., Murty, H.R., Gupta, S.K., Dikshit, A.K., 2009. An overview of sustainability assessment methodologies (Review). Ecological Indicators 9(2), 189-212.

Singh, R.K., Murty, H.R., Gupta, S.K., Dikshit, A.K., 2012. An overview of sustainability assessment methodologies. Ecological Indicators 15(1), 281-299. 
Singhal, K., Singhal, J., 2012. Imperatives of the science of operations and supply-chain management. Journal of Operations Management 30(3), 237-244.

Slawinski, N., Bansal, P., 2010. Short on time: Managing the time paradox in business sustainability. Academy of Management Best Papers Proceedings.

Solow, R.M., 1974. Intergenerational equity and exhaustible resources. Review of Economic Studies 41(5), 29-45.

Solow, R.M., 1986. On the intergenerational allocation of natural resources. Scandinavian Journal of Economics 88(1), 141-149.

Solow, R., 1993. An almost practical step towards sustainability. Resources Policy 19, 162-172.

Sonesson, U., Berlin, J., 2003. Environmental impact of future milk supply chains in Sweden: a scenario study. Journal of Cleaner Production 11(3), 253-266.

Spangenberg, J.H., 2005. Economic sustainability of the economy: concepts and indicators. International Journal of Sustainable Development 8(1-2), 47-64.

Srivastava, S.K., 2007. Green supply-chain management: a state-of-the-art literature review. International Journal of Management Reviews 9(1), 53-80.

Srivastava, S.K., 2008. Network design for reverse logistics. Omega: The International Journal of Management Science 36(4), 535-548.

Steurer, R., Langer, M.E., Konrad, A., Martinuzzi, A., 2005. Corporations, stakeholders and sustainable development I: a theoretical exploration of business-society relations. Journal of Business Ethics 61(3), 263-281.

Stewart, G., 1995. Supply chain performance benchmarking study reveals keys to supply chain excellence. Logistics Information Management 8(2), 38-44.

Stock, J.R., Boyer, S.L., 2009. Developing a consensus definition of supply chain management: A qualitative study. International Journal of Physical Distribution \& Logistics Management 39(8), 690-711.

Stock, J.R., Boyer, S.L., Harmon, T., 2010. Research opportunities in supply chain management. Journal of the Academy of Marketing Science 38(1), 32-41.

Su, Y.F., Yang, C., 2010. Why are enterprise resource planning systems indispensable to supply chain management? European Journal of Operational Research 203(1), 81-94.

Subramoniam, R., Huisingh, D., Chinnam, R.B., 2010. Aftermarket remanufacturing strategic planning decision-making framework: Theory \& practice. Journal of Cleaner Production 18(1617), 1575-1586. 
Svensson, G., 2002. The theoretical foundation of supply chain management: a functionalist theory of marketing. International Journal of Physical Distribution \& Logistics Management 32(9), 734-754.

Tan., R.B.H., Khoo, H.H., 2005. An LCA study of a primary aluminum supply chain. Journal of Cleaner Production 13(6), 607-618.

Tang, C.S., 2006. Perspectives in supply chain risk management. International Journal of Production Economics 103(2), 451-488.

Tang, C.S., Zhou, S., 2012. Research advances in environmentally and socially sustainable operations. European Journal of Operational Research 223(3), 585-594.

Tanguay, G.A., Rajaonson, J., Lefebvre, J.F., Lanoie, P., 2010. Measuring the sustainability of cities: An analysis of the use of local indicators. Ecological Indicators 10(2), 407-418.

Tanzil, D., Beloff, B.R., 2006. Assessing Impacts: Overview on Sustainability Indicators and Metrics. Environmental Quality Management 15(4), 41-56.

Tatari, O., Nazzal, M., Kucukvar, M., 2012. Comparative sustainability assessment of warm-mix asphalts: A thermodynamic based hybrid life cycle analysis. Resources, Conservation and Recycling 58, 18-24.

Taticchi, P., Tonelli, F., Pasqualino, R., 2013. Performance Measurement of Sustainable Supply Chains A literature Review and a Research Agenda. International Journal of Productivity and Performance Management 62(8), 782-804.

Tranfield, D., Denyer, D., Smart, P., 2003. Towards a Methodology for Developing EvidenceInformed Management Knowledge by Means of Systematic Review. British Journal of Management 14(3), 207-222.

Trent, R., 2004. What everyone needs to know about SCM. Supply Chain Management Review 8(2), 52-60.

Trowbridge, P., 2001. A case study of green supply chain management at advanced micro devices. Greener Management International 35(15), 121-135.

Turnhout, E., Hisschemoller, M., Eijsackers, H., 2007. Ecological indicators: between the two fires of science and policy. Ecological Indicators 7(2), 215-228.

Ukidwe, N.U., Bakshi, B.R., 2005. Flow of natural versus economic capital in industrial supply networks and its implications to sustainability. Environmental Science and Technology 39(24), 9759-9769.

United Nations Development Programme, 2005. Human Development Report 2005. Oxford University Press, Oxford. 
Vachon, S., Klassen, R., 2006. Extending green practices across the supply chain: the impact of upstream and downstream integration. International Journal of Operations \& Production Management 26(7), 795-821.

Van den Bergh, J.C.J.M., 2010. Externality or sustainability economics? Ecological Economics 69(11), 2047-2052.

Van Marrewijk, M., 2003. Concepts and definitions of CSR and corporate sustainability: between agency and communion. Journal of Business Ethics 44(2), 95-105.

Veleva, V., Ellenbecker, M., 2001. Indicators of sustainable production: framework and methodology. Journal of Cleaner Production 9(6), 519-549.

Veleva, V., Hart, M., Greiner, T., Crumbley, C., 2003. Indicators for measuring environmental sustainability: a case study of the pharmaceutical industry. Benchmarking: An International Journal 10(2), 107-119.

Wackernagel, M., Rees, W.E., 1996. Our Ecological Footprint - Reducing human impact on the Earth. New Society Publishers, Gabriola Island, BC.

Wackernagel, M., 1998. The Ecological Footprint of Santiago de Chile. Local Environment 3(1), 7-25.

Walker, H., Di Sisto, L., McBain, D., 2008. Drivers and barriers to environmental supply chain management practices: Lessons from the public and private sectors. Journal of Purchasing and Supply Management 14(1), 69-85.

Walters, D., Lancaster, G., 2000. Implementing value strategy through the value chain. Management Decision 38(3), 160-179.

Walton, S., Handfield, R., Melnyk, S., 1998. The green supply chain: integrating suppliers into environmental management processes. International Journal of Purchasing and Materials Management 34(1), 2-11.

Wang, Z., Sarkis, J., 2013. Investigating the Relationship of Sustainable Supply Chain Management with Corporate Financial Performance. International Journal of Productivity and Performance Management 62(8), 871-888.

WCED (World Commission on Environment and Development), 1987. Our common future. Oxford University Press, Oxford, UK.

Weber, M., 2008. The business case for corporate social responsibility: a company-level measurement approach for CSR. European Management Journal 26(4), 247-261. 
Wee, H.M., Lee, M.C., Yu, J.C.P., Wang, C.E., 2011. Optimal replenishment policy for a deteriorating green product: Life cycle costing analysis. International Journal of Production Economics 133(2), 608-611.

Wiedmann, T.O., Lenzen, M., Barrett, J.R., 2009. Companies on the Scale - Comparing and Benchmarking the Sustainability Performance of Businesses. Journal of Industrial Ecology 13(3), 361-383.

Wilkinson, A., Hill, M., Gollan, P., 2001. The sustainability debate. International Journal of Operations \& Production Management 21(12), 1492-1502.

Wilson, J., Tyedmers, P., Pelot, R., 2007. Contrasting and comparing sustainable development indicator metrics. Ecological Indicators 7(2), 299-314.

Wittstruck, D., Teuteberg, F., 2011. Understanding the Success Factors of Sustainable Supply Chain Management: Empirical Evidence from the Electrics and Electronics Industry. Corporate Social Responsibility and Environmental Management 19(3), 141-158.

Wolf, J., 2011. Sustainable Supply Chain Management Integration: A Qualitative Analysis of the German Manufacturing Industry. Journal of Business Ethics 102(2), 221-235.

Wolf, C., Seuring, S. 2010. Environmental impacts as buying criteria for third party logistical services. International Journal of Physical Distribution \& Logistics Management 40(1-2), 84102.

Wong, C., Skipworth, H., Godsell, J., Achimugu, N., 2012. Towards a theory of supply chain alignment enablers: a systematic literature review. Supply Chain Management: An International Journal 17(4), 419-437.

Wu, Z., Pagell, M., 2011. Balancing priorities: Decision-making in sustainable supply chain management. Journal of Operations Management 29(6), 577-590.

Wycherley, I., 1999. Greening supply chains: the case of the Body Shop International. Business Strategy and the Environment 8(2), 120-127.

Xu, L.D., 2011. Information architecture for supply chain quality management. International Journal of Production Research 49(1), 183-198.

Yakovleva, N., Sarkis, J., Sloan, T., 2012. Sustainable benchmarking of supply chains: The case of the food industry. International Journal of Production Research 50(2), 1297-1317.

Yang, C.L., Lin, S.P., Chan, Y.H., Sheu, C., 2010. Mediated effect of environmental management on manufacturing competitiveness: an empirical study. International Journal of Production Economics123(1), 210-220. 
Yeh, W.C., Chuang, M.C., 2011. Using multi-objective genetic algorithm for partner selection in green supply chain problems. Expert Systems with Applications 38(4), 4244-4253.

Zhang, C. T., Liu, L. P., 2013. Research on coordination mechanism in three-level green supply chain under non-cooperative game. Applied Mathematical Modelling 37(5), 3369-3379.

Zhou, L., Tokos, H., Krajnc, D., Yang, Y., 2012. Sustainability performance evaluation in industry by composite sustainability index. Clean Technologies and Environmental Performance 14(5), 789-803.

Zhu, Q., Sarkis, J., Geng, Y., 2005. Green supply chain management in China: pressures, practices and performance. International Journal of Operations \& Production Management 25 (5), 449-468.

Zhu, Q.H., Sarkis, J., 2006. An inter-sectoral comparison of green supply chain management in China: drivers and practices. Journal of Cleaner Production 14(5), 472-486.

Zhu, Q., Sarkis, J., Lai, K., 2008. Confirmation of a measurement model for green supply chain management practices implementation. International Journal of Production Economics 111(2), 261-273.

Zhu, Q., Dou, Y., Sarkis, J., 2010. A portfolio-based analysis for green supplier management using the analytical network process. Supply Chain Management: An International Journal 15(4), 306-319.

Zsidisin, G., Jun, M., Adams, L., 2000. The relationship between information technology and service quality in the dual-direction supply chain. International Journal of Service Industry Management 11(4), 312-328. 